Facet Joint Interventions Guidelines

\title{
@ Comprehensive Evidence-Based Guidelines for Facet Joint Interventions in the Management of Chronic Spinal Pain: American Society of Interventional Pain Physicians (ASIPP) Guidelines
}

\begin{abstract}
Laxmaiah Manchikanti, MD, Alan D. Kaye, MD, PhD, Amol Soin, MD, Sheri L. Albers, DO, Douglas Beall, MD, Richard E. Latchaw, MD, Mahendra R. Sanapati, MD, Shalini Shah, MD, Sairam Atluri, MD, Alaa Abd-Elsayed, MD, MPH, Salahadin Abdi, MD, PhD, Steve Aydin, DO, Sanjay Bakshi, MD, Mark Boswell, MD, PhD, Ricardo Buenaventura, MD, Joseph Cabaret, MD, Aaron K. Calodney, MD, Kenneth D. Candido, MD, Paul J. Christo, MD, Lynn Cintron, MD, Sudhir Diwan, MD, Christopher Gharibo, MD, Jay Grider, DO, PhD, Myank Gupta, MD, Bill Haney, MD, Michael E. Harned, MD, Standiford Helm II, MD, Jessica Jameson MD, Sunny Jha, MD, Adam M. Kaye, Pharm D, FASCP, FCPhA, Nebojsa Nick Knezevic, MD, PhD, Radomir Kosanovic, MD, Maanasa V. Manchikanti, Annu Navani, MD, Gabor Racz, MD, Vidyasagar Pampati, MSc, Ramarao Pasupuleti, MD, Cyril Philip, MD, Kartic Rajput, MD, Nalini Sehgal, MD, Gururau Sudarshan, MD, Rachana Vanaparthy, MBBS, Bradley W. Wargo, DO, and Joshua A. Hirsch, MD
\end{abstract}

From: The American Society of Interventional Pain Physicians

Author Affiliations on pp. S103-S105.

Address Correspondence: Laxmaiah Manchikanti, M.D. 67 Lakeview Drive

Paducah, Kentucky 42001 E-mail: drlm@thepainmd.com

Disclaimer: There was no external funding in the preparation of this manuscript.

Conflict of interest: Each author certifies that he or she, or a member of his or her immediate

family, has no commercial association (i.e., consultancies, stock ownership, equity interest, patent/licensing arrangements, etc.) that might pose a conflict of

interest in connection with the submitted manuscript.

Manuscript received: 04-15-2020 Revised manuscript received: 05-25-2020 Accepted for publication: 05-26-2020

Free full manuscript: www.painphysicianjournal.com
Background: Chronic axial spinal pain is one of the major causes of significant disability and health care costs, with facet joints as one of the proven causes of pain.

Objective: To provide evidence-based guidance in performing diagnostic and therapeutic facet joint interventions.

Methods: The methodology utilized included the development of objectives and key questions with utilization of trustworthy standards. The literature pertaining to all aspects of facet joint interventions, was reviewed, with a best evidence synthesis of available literature and utilizing grading for recommendations.

\section{Summary of Evidence and Recommendations:}

Non-interventional diagnosis:

- The level of evidence is II in selecting patients for facet joint nerve blocks at least 3 months after onset and failure of conservative management, with strong strength of recommendation for physical examination and clinical assessment.

- The level of evidence is IV for accurate diagnosis of facet joint pain with physical examination based on symptoms and signs, with weak strength of recommendation.

Imaging:

- The level of evidence is I with strong strength of recommendation, for mandatory fluoroscopic or computed tomography (CT) guidance for all facet joint interventions.

- The level of evidence is III with weak strength of recommendation for single photon emission computed tomography (SPECT).

- The level of evidence is $\mathbf{V}$ with weak strength of recommendation for scintography, magnetic resonance imaging (MRI), and computed tomography (CT) .

\section{Interventional Diagnosis:}

Lumbar Spine:

- The level of evidence is I to II with moderate to strong strength of recommendation for lumbar diagnostic facet joint nerve blocks.

- Ten relevant diagnostic accuracy studies with 4 of 10 studies utilizing controlled comparative local anesthetics with concordant pain relief criterion standard of $\geq 80 \%$ were included.

- The prevalence rates ranged from $27 \%$ to $40 \%$ with false-positive rates of $27 \%$ to $47 \%$, with $\geq 80 \%$ pain relief. 
Cervical Spine:

- The level of evidence is II with moderate strength of recommendation.

- Ten relevant diagnostic accuracy studies, 9 of the 10 studies with either controlled comparative local anesthetic blocks or placebo controls with concordant pain relief with a criterion standard of $\geq 80 \%$ were included.

- The prevalence and false-positive rates ranged from $29 \%$ to $60 \%$ and of $27 \%$ to $63 \%$, with high variability.

Thoracic Spine:

- The level of evidence is II with moderate strength of recommendation.

- Three relevant diagnostic accuracy studies, with controlled comparative local anesthetic blocks, with concordant pain relief, with a criterion standard of $\geq 80 \%$ were included.

- $\quad$ The prevalence varied from $34 \%$ to $48 \%$, whereas false-positive rates varied from $42 \%$ to $58 \%$.

\section{Therapeutic Facet Joint Interventions:}

Lumbar Spine:

- The level of evidence is II with moderate strength of recommendation for lumbar radiofrequency ablation with inclusion of 11 relevant randomized controlled trials (RCTs) with 2 negative studies and 4 studies with long-term improvement.

- The level of evidence is II with moderate strength of recommendation for therapeutic lumbar facet joint nerve blocks with inclusion of 3 relevant randomized controlled trials, with long-term improvement.

- The level of evidence is IV with weak strength of recommendation for lumbar facet joint intraarticular injections with inclusion of 9 relevant randomized controlled trials, with majority of them showing lack of effectiveness without the use of local anesthetic.

Cervical Spine:

- The level of evidence is II with moderate strength of recommendation for cervical radiofrequency ablation with inclusion of one randomized controlled trial with positive results and 2 observational studies with long-term improvement.

- The level of evidence is II with moderate strength of recommendation for therapeutic cervical facet joint nerve blocks with inclusion of one relevant randomized controlled trial and 3 observational studies, with long-term improvement.

- The level of evidence is $\mathbf{V}$ with weak strength of recommendation for cervical intraarticular facet joint injections with inclusion of 3 relevant randomized controlled trials, with 2 observational studies, the majority showing lack of effectiveness, whereas one study with 6-month follow-up, showed lack of long-term improvement.

Thoracic Spine:

- The level of evidence is III with weak to moderate strength of recommendation with emerging evidence for thoracic radiofrequency ablation with inclusion of one relevant randomized controlled trial and 3 observational studies.

- The level of evidence is II with moderate strength of recommendation for thoracic therapeutic facet joint nerve blocks with inclusion of 2 randomized controlled trials and 2 observational studies with long-term improvement.

- The level of evidence is III with weak to moderate strength of recommendation for thoracic intraarticular facet joint injections with inclusion of one randomized controlled trial with 6 month follow-up, with emerging evidence.

Antithrombotic Therapy:

- $\quad$ Facet joint interventions are considered as moderate to low risk procedures; consequently, antithrombotic therapy may be continued based on overall general status.

Sedation:

- The level of evidence is II with moderate strength of recommendation to avoid opioid analgesics during the diagnosis with interventional techniques.

- The level of evidence is II with moderate strength of recommendation that moderate sedation may be utilized for patient comfort and to control anxiety for therapeutic facet joint interventions.

Limitations: The limitations of these guidelines include a paucity of high-quality studies in the majority of aspects of diagnosis and therapy.

Conclusions: These facet joint interventions guidelines were prepared with a comprehensive review of the literature with methodologic quality assessment with determination of level of evidence and strength of recommendations

Key words: Chronic spinal pain, interventional techniques, diagnostic blocks, therapeutic interventions, facet joint nerve blocks, intraarticular injections, radiofrequency neurolysis

Disclaimer: These guidelines are based on the best available evidence and do not constitute inflexible treatment recommendations. Due to the changing body of evidence, this document is not intended to be a "standard of care." 


\subsection{INTRODUCTION}

Chronic axial spinal pain with or without extremity pain, chest wall pain, or headaches is one of the major causes of disability and healthcare costs. The State of the US Health 1990-2010, a publication describing the burden of diseases, injuries, and risk factors (1), showed that morbidity and chronic disability now account for nearly half of the US health burden, with increasing life expectancy, despite substantial progress and improvement in overall health. This assessment also showed that among the 30 leading diseases and injuries contributing to years lived with disability in 2010 in the United States, low back pain ranked number 1, whereas neck pain ranked number 3, with musculoskeletal disorders ranking number 2 , and depression and anxiety ranking number 4 and 5 (1-8). Further, Dieleman et al $(7,8)$ showed an estimated spending of $\$ 87.6$ billion in managing low back and neck pain in 2013, increasing to $\$ 134.5$ billion in 2016, accounting for the highest amount of the various disease categories. Chronic persistent spinal pain is reported in $25 \%$ to $60 \%$ of patients for at least one year, and even longer following an initial episode (2-6,9-17).

Based on the literature, utilizing controlled diagnostic blocks, the intervertebral discs, facet joints, nerve root dura, and sacroiliac joints have been shown as potential sources of spinal pain and extremity pain (18-25). Multiple modalities, both diagnostic and therapeutic, have emerged in managing spinal pain over the years $(4-6,18-74)$. Despite exponential growth of treatments, the indications and medical necessity of multiple interventions, specifically those directed at facet joint pain, are debated $(6,14,15,18-39,75-82)$. Interventional modalities for the diagnosis and treatment of facet joint pain continue to elicit significant debate despite advances in understanding and with recent publications relating to declining utilization (83-93). The studies focusing on diagnosis and effectiveness $(6,18-39,75-$ $82,94,95)$ and cost utility analysis have shown favorable clinical and cost utility (96-102).

Accurate selection of patients for diagnostic and therapeutic modalities with facet joint pain, meeting appropriate medical necessity and indications, is crucial. Recent evaluation of utilization of interventional techniques (83) and facet joint interventions in particular $(84,85)$ have shown significant changes in utilization patterns before and after 2009, after the enactment of the Affordable Care Act (ACA) (103-108).

The literature has shown that utilizing controlled diagnostic blocks, the prevalence of facet joint pain is
$27 \%$ to $41 \%$ in the low back, with a false-positive rate of $25 \%$ to $44 \%$; a prevalence of $36 \%$ to $67 \%$ and falsepositive rate of $27 \%$ to $63 \%$ in the cervical spine; and a prevalence rate of $34 \%$ to $48 \%$ with false-positive rates of $42 \%$ to $48 \%$ in the thoracic spine (18).

Multiple guidelines have been published about managing spinal pain dealing with various interventional techniques, including regenerative medicine $(4-6,40)$. The American Society of Interventional Pain Physicians (ASIPP) guidelines in managing spinal interventional techniques were published in 2013 (6). ASIPP has been at the forefront of guideline development for the use of both interventional techniques and opioids (4-6) and other aspects of interventional pain management $(40,109,110)$. The present guidelines have been developed specifically for interventional techniques to manage facet joint pain. These guidelines include an overview of the current literature regarding the use of interventional techniques in the diagnosis and treatment of spinal facet joint pain.

\subsection{Methods}

\subsection{Rationale}

The National Uniform Claims Committee (NUCC) defines interventional pain management as the discipline of medicine devoted to the diagnosis and treatment of pain related disorders principally with the application of interventional techniques in managing subacute, chronic, persistent, and intractable pain, independently or in conjunction with other modalities of treatment (111). In addition, the Medicare Payment Advisory Commission (MedPAC) defines interventional pain management techniques as minimally invasive procedures including percutaneous precision needle placement of drugs in targeted areas or ablation of targeted nerves; surgical techniques such as laser and endoscopic discectomy; and the placement of intrathecal infusion pumps and spinal cord stimulators for the diagnosis and management of chronic, persistent, or intractable pain (112).

Chronic spinal pain is a complex and multifactorial disease process with numerous treatment modalities applied in the management of the problem, and the growing social and economic costs continue to influence medical decision-making. Intervertebral discs, facet joints, sacroiliac joints, ligaments, fascia, muscles, and nerve root dura are proven pain generators in the spine $(6,18-25)$. Interventional pain physicians are familiar with various image-guided interventional techniques for the management of spinal pain. 


\subsection{Objectives}

The objective of these guidelines is to provide a rational and systematic approach to the application of diagnostic and therapeutic interventional techniques in managing facet joint pain. The guidelines are based upon the available evidence concerning the effectiveness and safety in the treatment of spinal pain. The literature clearly shows the value of evidence-based guidelines and need for appropriate updating of the guidelines to update clinical practices (113-117).

\subsubsection{Key Questions}

These guidelines focus on the following key questions regarding spinal pain secondary to spinal pain of facet joint origin:

1. What is the impact of chronic spinal pain on health care resources?

2. What are the statistics regarding the trends in utilization of treatment modalities in managing spinal pain?

3. What is the pathophysiologic and structural basis of spinal facet joint pain?

4. What is the evidence of diagnostic accuracy and value of non-interventional methods in the diagnosis of facet joint pain?

5. What is the evidence of diagnostic accuracy of interventional procedures in the diagnosis of facet joint pain?

6. Are the available therapeutic facet joint interventional therapies in managing chronic spinal pain effective?

7. What is the evidence for cost-effectiveness of interventional techniques in managing spinal facet joint pain?

8. What are the adverse consequences and harms and related precautions in providing facet joint interventions?

9. What are the guidelines for diagnostic and therapeutic interventions in managing spinal facet joint pain?

10. What are the guidelines for type and frequency of diagnostic and therapeutic facet joint interventions in managing chronic spinal pain?

\subsection{Adherence to Trustworthy Standards}

In preparation of these guidelines for facet joint interventions, the standards from the Institute of Medicine (IOM) and the National Guideline Clearinghouse Extent Adherence to Trustworthy Standards (NEATS) were followed (118-120). The NEATS instrument was developed and tested as a tool to be used by the trained staff at the Agency for Healthcare Research and Quality (AHRQ) National Guideline Clearinghouse to provide assessment focused on adherence.

\subsubsection{Disclosure of Guideline Funding Source}

Comprehensive evidence-based guidelines for facet joint interventions in managing chronic spinal pain of facet joint origin were commissioned, prepared, edited, and endorsed by ASIPP without external funding.

\subsubsection{Disclosure and Management of Financial Conflicts of Interests}

Potential conflicts of interest for all panel members within the last 5 years were evaluated prior to the finalizing of these guidelines. Conflicts of interests extended beyond financial relationships, including personal experience, practice patterns, academic interests, and promotions. The panel members with potential conflicts were recused from discussion or preparation of the guidelines in which they had conflicts of interest, and these members agreed not to discuss any aspect of a given guideline with the related industry before data publication.

\subsubsection{Composition of Guideline Development Group}

A panel of experts in managing spinal pain and interventional techniques from various medical fields, convened by ASIPP, reviewed the evidence and formulated recommendations for interventional techniques in managing facet joint pain. Overall, the panel provided a broad representation of academic and non-academic clinical practitioners with interest and expertise in interventional techniques as applicable to facet joint pain.

\subsection{Evidence Review}

These guidelines were developed utilizing consensus among the panel members after they had reviewed all published literature concerning the use and safety of facet joint interventions in patients with chronic spinal pain. The recommendations have been developed using principles of best evidence synthesis developed by the Cochrane Review, incorporating multiple guidelines modified by ASIPP (121).

\subsubsection{Grading or Rating the Quality or Strength of Evidence}

The grading of evidence is based on randomized controlled trials (RCTs), observational studies, and other 
Table 1. Qualitative modified approach to grading of evidence of diagnostic accuracy and therapeutic effectiveness studies.

\begin{tabular}{|c|l|l||}
\hline Level I & Strong & $\begin{array}{l}\text { Evidence obtained from multiple relevant high quality randomized controlled trials } \\
\text { or } \\
\text { Evidence obtained from multiple high quality diagnostic accuracy studies }\end{array}$ \\
\hline Level II & Moderate & $\begin{array}{l}\text { Evidence obtained from at least one relevant high quality randomized controlled trial or multiple relevant } \\
\text { moderate or low quality randomized controlled trials } \\
\text { or } \\
\text { Evidence obtained from at least one high quality diagnostic accuracy study or multiple moderate or low } \\
\text { quality diagnostic accuracy studies }\end{array}$ \\
\hline Level III & Fair & $\begin{array}{l}\text { Evidence obtained from at least one relevant moderate or low quality randomized controlled trial study } \\
\text { or } \\
\text { Evidence obtained from at least one relevant high quality non-randomized trial or observational study with } \\
\text { multiple moderate or low quality observational studies } \\
\text { or } \\
\text { Evidence obtained from at least one moderate quality diagnostic accuracy study in addition to low quality } \\
\text { studies }\end{array}$ \\
\hline Level V & $\begin{array}{l}\text { Limited } \\
\text { based }\end{array}$ & $\begin{array}{l}\text { Evidence obtained from multiple moderate or low quality relevant observational studies } \\
\text { or } \\
\text { Evidence obtained from multiple relevant low quality diagnostic accuracy studies }\end{array}$ \\
\hline
\end{tabular}

Modified from: Manchikanti et al. A modified approach to grading of evidence. Pain Physician 2014; 17:E319-E325 (121).

Table 2. Guide for strength of recommendations.

\begin{tabular}{|l|l||}
\hline Rating for Strength of recommendation \\
\hline Strong & $\begin{array}{l}\text { There is high confidence that the recommendation reflects best practice. This is based on: a) strong evidence for a true net } \\
\text { effect (e.g., benefits exceed harms); b) consistent results, with no or minor exceptions; c) minor or no concerns about study } \\
\text { quality; and/or d) the extent the panelists' agreement. Other compelling considerations (discussed in the guideline's literature } \\
\text { review and analyses) may also warrant a strong recommendation. }\end{array}$ \\
\hline Moderate & $\begin{array}{l}\text { There is moderate confidence that the recommendation reflects best practice. This is based on: a) good evidence for a true } \\
\text { net effect (e.g. benefits exceed harms); b) consistent results, with minor and/or few exceptions; c) minor and/or few concerns } \\
\text { about study quality; and/or d) the extent of panelists' agreement. Other compelling considerations (discussed in the guideline's } \\
\text { literature review and analyses) may also warrant a moderate recommendation. }\end{array}$ \\
\hline Weak & $\begin{array}{l}\text { There is some confidence that the recommendation offers the best current guidance for practice. This is based on: a) limited } \\
\text { evidence for a true net effect (e.g., benefits exceed harms); b) consistent results, but with important exceptions; c) concerns } \\
\text { about study quality; and/or d) the extent of panelists' agreement. Other considerations (discussed in the guideline's literature } \\
\text { review and analyses) may also warrant a weak recommendation. }\end{array}$ \\
\hline
\end{tabular}

Source: National Guideline Clearinghouse Extent Adherence to Trustworthy Standards (NEATS) instrument (119).

clinical reports. In addition, systematic reviews and meta-analyses were utilized. The grading of evidence based on ASIPP guidelines is shown in Table 1 (121).

This grading system specifies levels of scientific evidence and offers an approach to grading the quality of evidence and secondarily the strength of recommendations. AHRQ has recommended a similar approach to the strength of a recommendation $(119,120)$.

\section{4 .2 Assessment and Recommendations of Benefits and Harms}

These guidelines describe the potential benefits and harms for the interventions and explicitly link the information to specific recommendations.

\subsubsection{Evidence Summary of Recommendations}

Guideline-supporting documents summarize the relevant supporting evidence and link this information to the recommendations.

\subsubsection{Rating or Grading the Strength of recommendations}

IOM standards demand that for each recommendation, a rating of the strength of the recommendation related to benefits and harms, available evidence, and the confidence in the underlying evidence should be provided. To meet appropriate standards, the rating schemes recommended by NEATS were utilized as shown in Table 2 (119). 


\section{4 .5 Specificity of Recommendations}

Evidence and best practices were utilized in forming recommendations for facet joint intervention recommendations.

\subsection{External Review}

Guidelines have been subjected to external peer review as per the policies of the publishing journal, Pain Physician.

\subsection{Updating Guidelines}

The interventional techniques for facet joint pain guidelines will be updated within 5 years or less, based on significant changes in scientific evidence, public policy, or adverse events occurring before January 2025.

\subsection{Impact Of Chronic Spinal Pain on Health Care}

Key Question 1: What is the impact of chronic spinal pain on health care resources?

Health care expenditures have been escalating over the years with estimates of the US health care spending reaching $\$ 3.66$ trillion in $2018(122,123)$. Further, health care expenditures are expected to continue to grow at a rate of $5.5 \%$ from 2018 to $2027(123,124)$. Overall, in 2018, cost of health care was $\$ 11,212$ per person, with an annual expenditure of $\$ 3.65$ trillion, the cost per person in 2027 will rise to $\$ 12,119.04$. US spending on person and public health care from 1996 to $2013(7,125)$ showed an estimated spending of a total of $\$ 183$ billion, with $\$ 87.6$ billion on low back and neck pain and on musculoskeletal disorders of $\$ 95.5$ billion. However, more recent estimates from the same group (8) from 1996 to 2016 showed more ominous data in reference to the expenditures increasing health care spending from an estimated $\$ 1.4$ trillion in 1996 or $\$ 5,259$ per person with $13.3 \%$ of gross domestic product (GDP) to an estimated $\$ 3.1$ trillion in 2016 with an estimated GDP of $17.9 \%$ and per person cost of $\$ 9,655$. Approximately $43 \%$ of these expenses were paid by public insurance. In 2016, low back and neck pain had the highest amount of health care spending with an estimated $\$ 134.5$ billion with $33.7 \%$ of that spending by public insurance and other musculoskeletal disorders accounted for the second highest amount of health care spending of $\$ 129.8$ billion, totaling $\$ 264.3$ billion with a $44.4 \%$ increase compared to 2013. In this assessment, diabetes accounted for the third highest amount of the health care spending (8). However, in the previous assessment by Dieleman et al
$(7,125)$, diabetes had the highest health care spending in 2013, with ischemic heart disease as the second highest amount of health care spending, followed by low back and neck pain for the third highest. It appears that expenditures have increased disproportionately with low back and neck pain with the highest health care spending, whereas diabetes and ischemic heart disease ranked lower in spending. However, the calculus of health care spending drastically changed in 2020 due to the coronavirus, leading to COVID-19 (126-137). The coronavirus epidemic not only increased overall health care expenditures due to COVID-19, but also affected the entire health care system with significant increases of costs and reduced access to health care (126-137).

Overall, the impact of chronic pain continues to be disproportionate and enormous (1-17,70-73,138-150). Figure 1 shows musculoskeletal pain and years lived with disability. Even prior to the Corona pandemic, the annual US expenditures alone, including direct medical cost and lost wages due to chronic pain have been estimated to be higher than those for cancer, heart disease, and diabetes combined $(1-8,40,103-108,138-143)$. As shown above by Dieleman et al (8), low back and neck pain constitute the number one category of expense in medical expenditures in the United States. However, in spite of extensive expenditures and numerous measures undertaken to control the expenditures (103-108), with ever increasing treatment options, disability continues to escalate (1-8,138-152). As shown in Fig. 2, Dieleman et al (8) illustrated the expenses related to musculoskeletal conditions, including back and neck pain, as determined in 2016 based on spending on health care in the US.

Chronic persistent spinal pain lasting longer than one year is reported in $25 \%$ to $60 \%$ of the patients $(2-19,40,73,143-152)$. The prevalence of pain in various spinal regions, is variable, with the highest prevalence in the low back pain of $43 \%$, followed by the neck at $32 \%$, with the lowest in thoracic spine (149). Overall prevalence of low back pain and neck pain over a period of one-year time frame ranged from $22 \%$ to $65 \%$ with an estimated lifetime occurrence of $11 \%$ to $84 \%$ for low back $(2,153-156)$ and neck pain from $20 \%$ to $40 \%$ with a lifetime prevalence of $67 \%(3,148,157)$. Freburger et al (158) in assessment of rising prevalence of chronic low back pain from 1992 to 2006 showed that prevalence of chronic, impairing low back pain rose significantly over the 14-year interval, from 3.9\% in 1992 to $10.2 \%$ in 2006 . They reported increases for all adult age strata, in males and females, and in white and black 

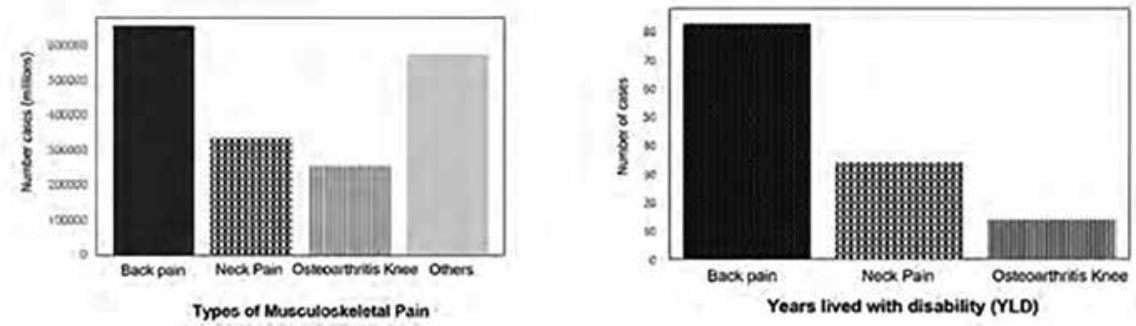

A: Number of persons affected by musculoskeletal pain (millions); B: Global number of years lived with disability (YLD; millions); Data are as of 2010, updated from the Source Global Burden of Disease 2010 Study

Fig. 1. Prevalence of musculoskeletal pain and years lived with disability.

Source: Hoy D, March L, Brooks P, et al. The global burden of low back pain: Estimates from the Global Burden of Disease 2010 study. Ann Rheum Dis 2014; 73:968-974 (144).

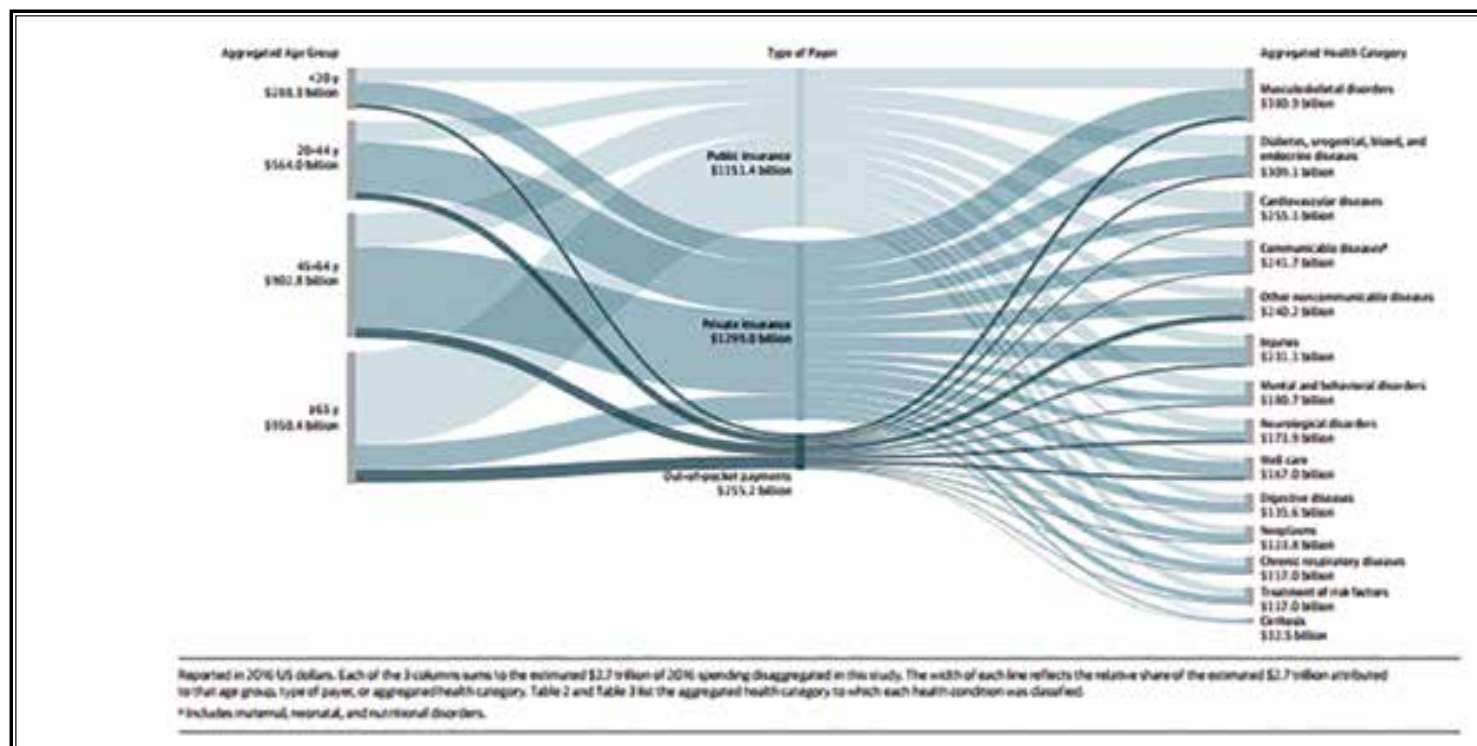

Fig. 2. Estimated health care spending by aggregated age group, type of payer, and aggregated health category in 2016. Source: Dieleman JL, Cao J, Chapin A, et al. US health care spending by payer and health condition, 1996-2016. JAMA 2020; 323:863-884 (8).

races. However, symptom, severity and general health were similar for both years, with some increase in individuals seeking care from a health care provider in the past year, increasing from $73.1 \%$ to $84 \%$, while the mean number of visits in all providers were similar. They concluded that the prevalence of chronic, impairing low back pain has risen significantly in North Carolina, with continuing high levels of disability and care utilization. They also concluded that a substantial portion of the rise in low back pain care costs over the past 2 decades may be related to the rising prevalence. These studies have not been repeated since then. However, based on the other studies of disability and health care costs, the prevalence, as well as disability, continue to escalate $(1,7,8,138,144,159-161)$.

Further, Blyth et al (162), in assessing the global burden of musculoskeletal pain, summarized the current understanding of the global burden of musculoskeletal related conditions, applying evidence-based principles generated the prevalence and identified key gaps in the understanding of musculoskeletal pain, with proposals to address these gaps. They identified 2 key 
long-term drivers of contemporary burden of disease estimates, including age, structure of populations, and their longevity. Most painful musculoskeletal conditions increase with age and because there is an increase in multi-morbidity, non-communicable diseases, and reduced physical activity associated with musculoskeletal pain, the global burden related to pain will rise substantially, with increasing global population of 65 years and older, which also applies to the United States $(160,162)$. They also identified escalating growth of treatments, along with harms associated with treatment, including medication-based interventions, notably long-term opioids, non-steroidal, and steroidal immunosuppressive therapies, and surgical interventions. However, these were not included in their estimated burden. Further, it has been shown that in both developed and developing countries, there are consistent trends of population aging over time (142). The rate at which aging is occurring is faster in developing countries than in developed countries. It has been predicted that by 2050, there will be 5 times more people aged 40 and over in developing countries than in developed countries (160). Given the importance of musculoskeletal pain with regard to functional status in older age group, these findings have profound implications for future disability burden and treatments provided to reduce it (142).

A systematic review of the prevalence of musculoskeletal symptoms in the construction industry (161), including back and neck pain, one-year prevalence of low back pain was $51.1 \%$ whereas for neck pain, it was $24.4 \%$, and $19.8 \%$ for upper back pain. Thus, some prominent authors have indicated that guidelines must be different for developing countries and developed countries in reference to invasive and non-invasive treatments $(37,161)$. Chou et al $(37)$ and Acaroğlu et al (161) with inclusion of prominent authors such as Côté and Haldeman, synthesized recommendations on the use of common elective surgical and interventional procedures for individuals with recommendation of epidural injections, as well as augmentation procedures with formation of clinical care pathways on patient presentation in low and middle income communities, contrary to their descriptions of earlier presentations of opposition to these interventions in the US $(42,43,163-$ 167). In these guidelines, they theorized that epidural steroid injections and augmentation procedures are less expensive than most surgeries with fewer harms and vertebroplasty should be considered over kyphoplasty as an option for patients with severe pain and disability due to osteoporotic vertebral compression fractures.

\subsection{Trends in Utilization of Usage of Health Care Modalities in Managing Facet Joint Pain}

Key Question 2: What are the statistics regarding the trends in utilization of treatment modalities in managing spinal pain?

Exploding health care costs are major U.S. and world issues which have led to the implementation of various health care reform measures, regulations, and to the imposition of guidelines which have often been based on public policy priorities to reduce health care costs. These governmental actions have often resulted from feigned evidence-based medicine and comparative effectiveness research muddled with conflicts and controversies $\quad(4-6,40,83-87,103-108,122-124,138-$ $146,168-170)$. There has been escalating growth of various modalities for the treatment of musculoskeletal/ spinal pain, including physical therapy, drug therapy, interventional techniques, and surgical interventions (4-6,40-72,83-87, 103-108, 168-175).

While the utilization of interventional techniques and surgical interventions are the focus of current debate, other conservative modalities have also been utilized extensively $(58,70-72,170-175)$. Unfortunately, despite diagnostic and therapeutic advances, the increasing prevalence of low back pain, secondary disability, and their adverse economic impact, continue to escalate.

\subsection{Surgery}

National trends in surgical interventions have been well described (44-60,166-169,176-178). Best et al (46) assessed the national surgical trends for intervertebral disc disorders and spinal stenosis between 1994 and 2006. The number of procedures increased from 6.1 to 34.2 for intervertebral disc disorders, and from 0.38 to 3.46 for spinal stenosis per 100,000 population. Yoshihara and Yoneoka (169) in an assessment of national surgical trends for lumbar degenerative disc disease in the U.S. from 2000 to 2009 showed a 2.4 -fold population-adjusted increase. Bae et al (60) showed that from 2004 to 2009 there was an increase of spinal fusions for lumbar spinal stenosis from $21.5 \%$ to $31.2 \%$, even though the rate of decompressions decreased from 58.5 $\%$ to $49.2 \%$.

Reoperation rates for disc herniation and spinal stenosis have been shown to vary from 10 to $23 \%$ (54). Overall, $40 \%$ of postoperative patients develop postsurgery syndrome or failed back surgery syndrome, requiring further treatment. Unfortunately, the numbers of pre- and post-operative patients with disabilities 
requiring surgical interventions including complex fusions, those patients being treated for failed back surgery syndrome, and patients with refractory chronic low back pain continue to increase (27-30,176-192).

Overall results of surgical interventions have been lackluster, consequently, post-surgery syndrome, or pain after operative procedures of the spine is observed in a significant proportion of patients (176-192). Fritsch et al (181) reported that epidural fibrosis, recurrent disc herniation, instability, and facet joints were responsible for recurring symptomatology. While it has been reported that a specific etiology of back pain can be diagnosed in only about $15 \%$ of patients with certainty based on clinical examination alone $(6,18-25,186-195)$, it is even more difficult in post lumbar surgery syndrome to identify the origins of pain, either from the facet joints, discs, sacroiliac joint, or other structures or combination of structures. Manchikanti et al (177) have shown the prevalence of facet joint pain in chronic low back pain in post-surgical patients of $16 \%$ with a $95 \%$ confidence interval $(\mathrm{Cl})$ of $9 \%$ to $23 \%$, with a false positive rate with a single block with lidocaine of $49 \%$, and in the neck with post-surgical chronic neck pain related to facet joints (178) of $36 \%$ with $50 \%$ false positive rates, with controlled comparative local anesthetic blocks with $80 \%$ relief as the criterion standard. In addition, DePalma et al (189), in a small number of patients, assessed the etiology of chronic low back pain in patients having undergone lumbar fusion and identified 5 patients of the 28 fusion cases with facet joint pain. They also identified among these patients, 7 with internal disc disruption, 12 with sacroiliac joint pain, and 4 due to soft tissue irritation from fusion hardware. DePalma et al (190) also studied the prevalence of facet joint pain and showed the prevalence of facet joint pain was not significantly different from patients without surgical discectomy. Manchikanti et al (192), in another study, assessed contribution of facet joints to chronic low back pain in post laminectomy syndrome with a prevalence of $44 \%$ in patients who never underwent surgery compared to $32 \%$ in the patients who underwent surgical intervention. Klessinger (191) described the effectiveness of medial branch blocks and radiofrequency neurotomy in facet joint pain in patients with post lumbar surgery syndrome. Consequently, many of these patients undergo facet joint interventions after surgical interventions.

\subsection{Interventional Techniques}

The use of interventional techniques for the treat- ment of spinal pain and musculoskeletal disorders increased until 2009, at which point utilization began to decrease. (83-91). Recent analysis of growth of utilization of interventional techniques in managing chronic pain in the Medicare population (83) showed an overall decline in utilization of interventional techniques from 2009 to 2018 of $6.7 \%$, with an annual decline of $0.8 \%$ per 100,000 fee-for-service (FFS) Medicare population, despite an increase of $0.7 \%$ per year of population growth (3.2\% of those 65 years or older), and a $3 \%$ annual increase in Medicare participation from 2009 to 2018. Further, analysis of utilization patterns of epidural procedures (87) showed epidural procedures have declined at a rate of $20.7 \%$ per 100,000 Medicare enrollees from 2009 to 2018, with an annual decline of $2.5 \%$. This analysis (87) also showed a decline in all categories, with an annual decrease of $4.7 \%$ for lumbar interlaminar and caudal epidural injections, $4.7 \%$ decline for cervical/thoracic transforaminal epidural injections, $1.1 \%$ decline for lumbar/sacral transforaminal injections, and $0.4 \%$ decline for cervical/thoracic interlaminar epidural injections. Overall declines were higher for lumbar interlaminar epidural injections of $34.9 \%$, compared to lumbar/sacral transforaminal epidural injections of $9.4 \%$ (Fig. 3).

Manchikanti et al $(84,85)$ also analyzed utilization patterns of facet joint interventions. A recent manuscript of updated utilization patterns (85) showed an increase of facet joint interventions of $1.9 \%$ annually and $18.8 \%$ total from 2009 to 2018 per 100,000 FFS Medicare population compared with an annual increase of $17 \%$ and overall increase of 309.9\% from 2000 to 2009. Further analysis showed lumbosacral facet joint nerve block sessions decreased at an annual rate of $0.2 \%$ from 2009 to 2018, compared with an increase of $15.2 \%$ from 2000 to 2009. In contrast, lumbosacral facet joint neurolysis sessions increased at an annual rate of $7.4 \%$ from 2009 to 2018 , compared to an annual increase of $23 \%$ from 2000 to 2009 . Neurolysis grew more rapidly than facet joint blocks during the same period. In 2000, there were 6.7 lumbar facet block sessions for each lumbar neurolysis session. By 2018, lumbar facet block sessions were 1.9 for each neurolysis. Cervical and thoracic facet joint injections increased at an annual rate of 0.5 $\%$ compared with cervicothoracic facet joint neurolysis sessions of $8.7 \%$ from 2009 to 2018 . Cervical facet joint injections increased $4.9 \%$ from 2009 to 2018 compared with neurolysis procedures of $112 \%$. The proportion of cervical facet joint sessions to neurolysis sessions changed from 8.9:1 in 2000 to $2.4: 1$ in 2018. This data is 

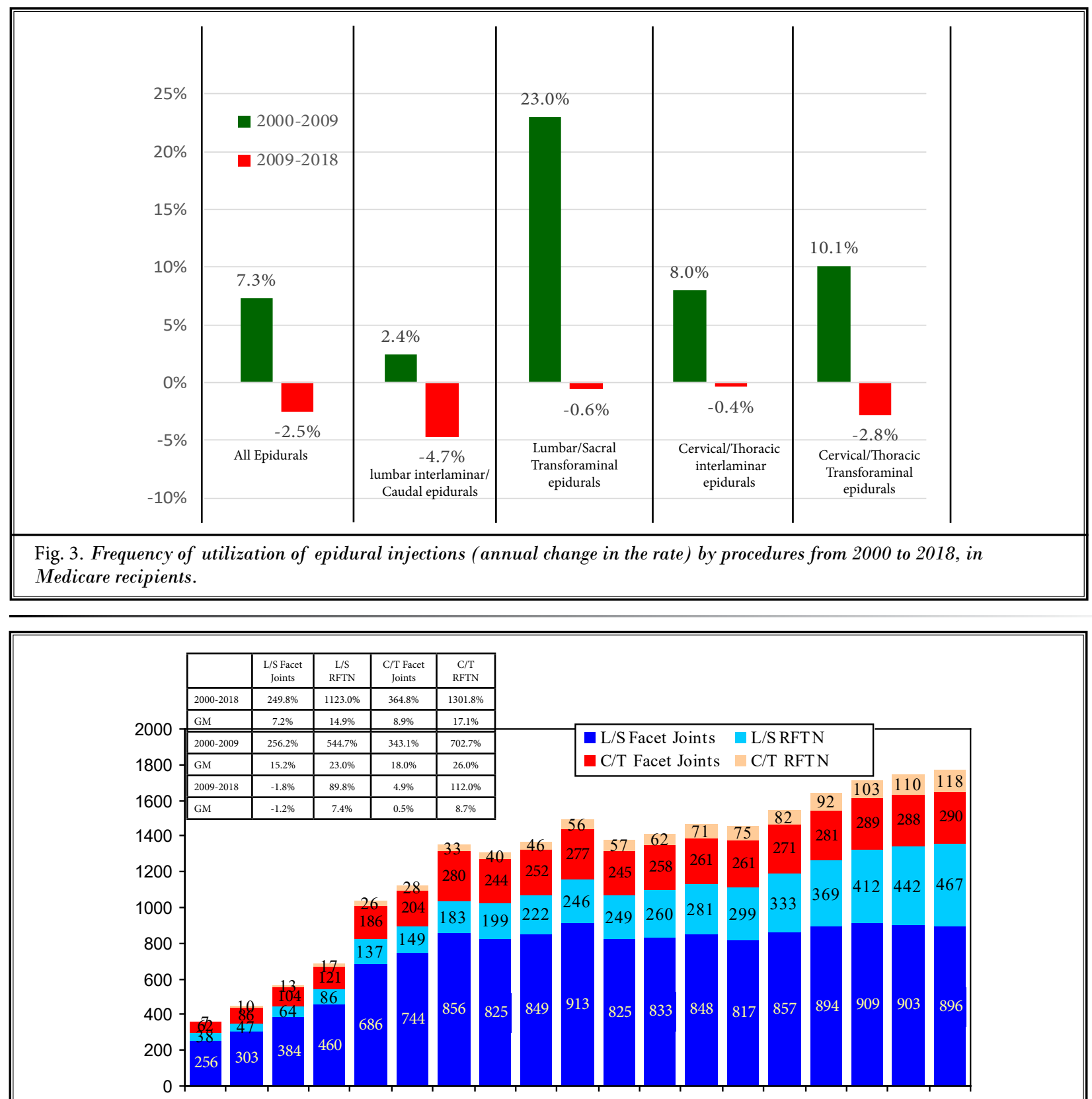

2000200120022003200420052006200720082009201020112012201320142015201620172018

Fig. 4. Proportional frequency of utilizations of facet joint intervention sessions for primary codes (per 100,000 Medicare beneficiaries) from 2000-2018.

L/S - Lumbosacral; C/T = Cervicothoracic; RFTN = Radiofrequency thermoneurolysis; GM - Geometric Average Annual Change

illustrated in Fig. 4, which shows the proportion of various types of facet joint intervention from 2000 to 2018. Figure 5 also shows comparative utilization patterns based on an annual rate from 2000 to 2009 and 2009 to 2018. Significant differences are noted in growth pat- terns with increases in facet neurolysis and decline of lumbar facet joint blocks with a mild increase in cervical/ thoracic facet joint blocks. This data is in contrast to the data of all interventional techniques and also epidural procedures, which consistently showed reductions from 


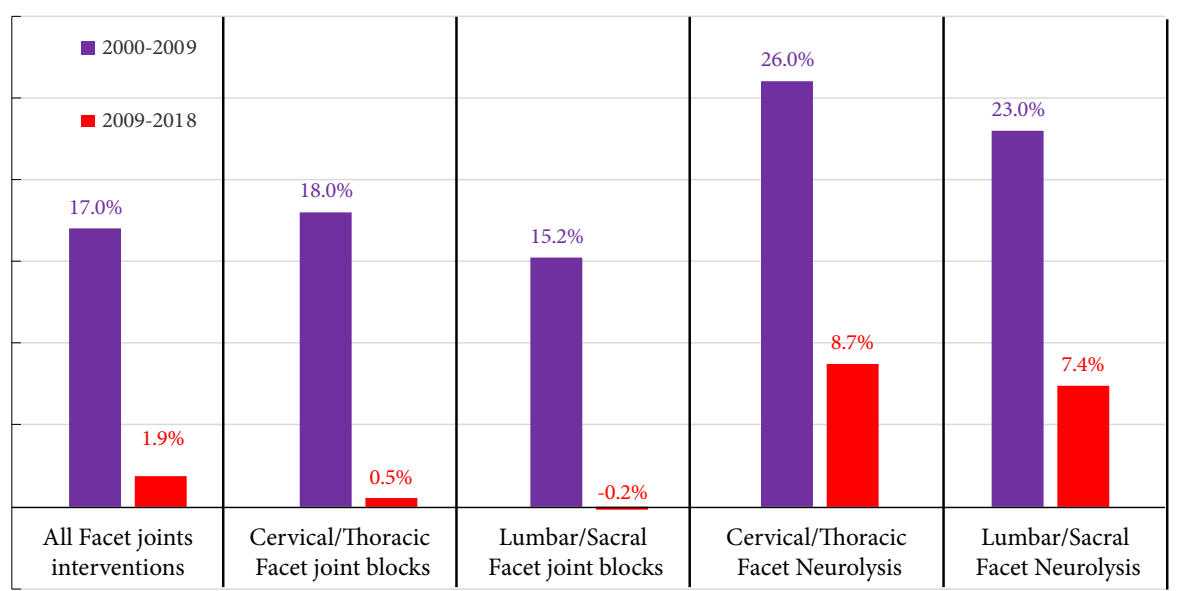

Fig. 5. Comparative utilization patterns based on an annual rate from 2000-2009 and 2009-2018.

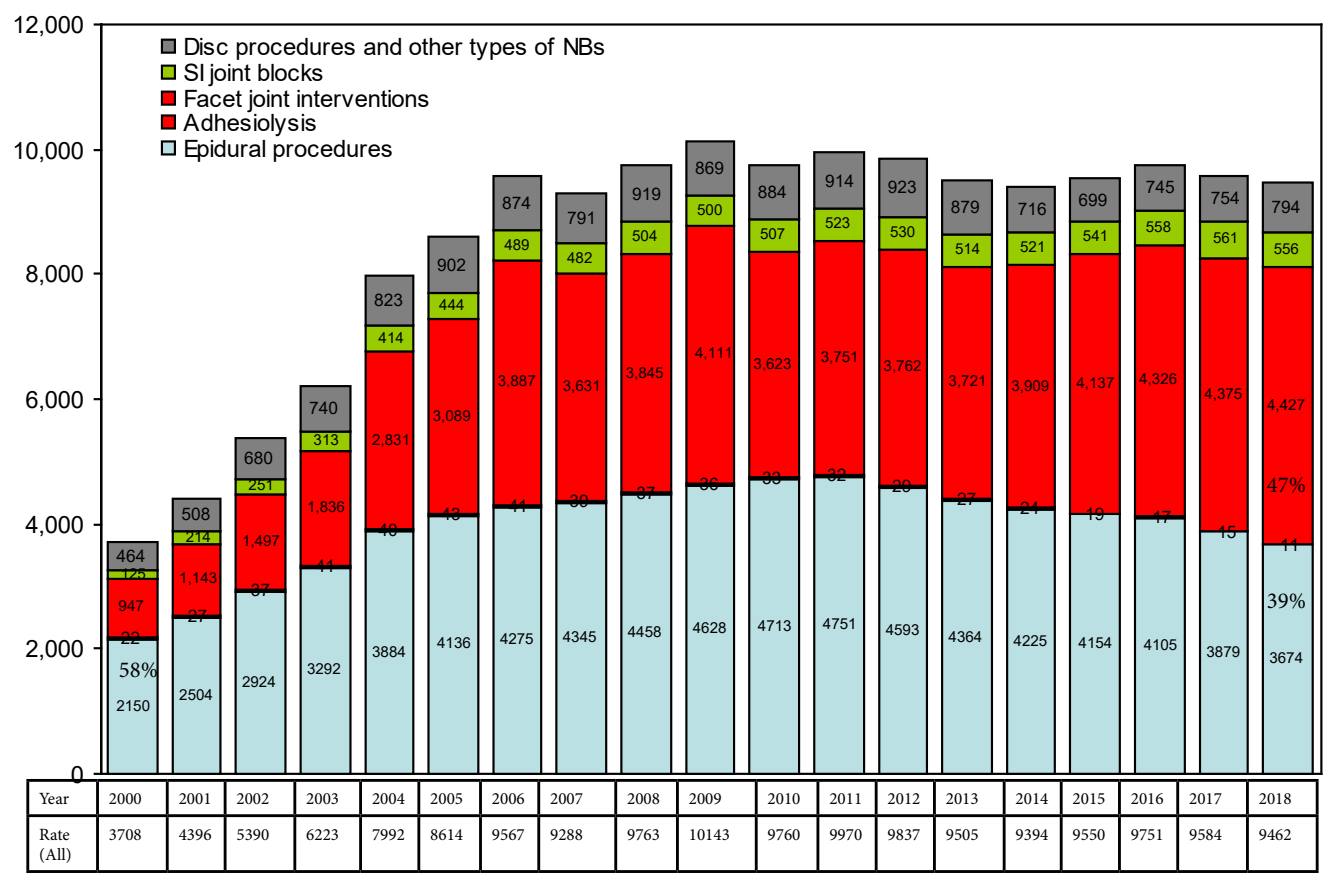

Fig. 6. Distribution of procedural characteristics (rates) by type of procedures from 2000 to 2018.

2009 to 2018. Changes in the ratio is also important in that neurolysis is more expensive than facet injections. Facet joint interventions constituted $26 \%$ of the total interventional techniques in 2000 compared to $47 \%$ of total procedures in 2018, as shown in Fig. 6.
Starr et al (88) assessed trends in lumbar radiofrequency ablation utilization from 2007 to 2016. The results showed that, from 2007 to 2016, lumbar radiofrequency sessions per 100,000 enrollees per year increased at an annual rate of $9.7 \%$. They also showed 
that lumbar facet joint injection use increased from 201 to 251 sessions per 100,000 enrollees, a $24.9 \%$ overall increase or $2.5 \%$ annual increase. These results show significantly fewer number of procedures performed in younger population as the data was derived from MarketScan Commercial Claims and Encounters Databases. In contrast, the data in FFS Medicare population (85), facet joint nerve block sessions were 825 compared to 909 in 2016. However, since then, they declined to 896 in 2018. For radiofrequency neurotomy, there were 199 lumbar facet neurolysis sessions in 2007 compared to 412 in 2016, which increased to 467 in 2018 in FFS Medicare population. The trends seem to be similar with increase in frequency of radiofrequency neurolysis compared to lumbar facet joint nerve blocks. Starr et al (88) also showed the number of patients receiving 2 lumbar facet joint injection procedures prior to lumbar radiofrequency ablation group increased from $51.1 \%$ in 2010 to $58.8 \%$ in 2016 . The cost estimations for lumbar radiofrequency ablation cost per 100,000 enrollees went from $\$ 94,570$ in 2007 to $\$ 266,680$ in 2016 , a $12.2 \%$ annual increase. For lumbar facet joint injections, the cost per 100,000 enrollees went from \$257,280 in 2007 to $\$ 396,580$ in 2016 , a $4.9 \%$ annual increase. The costs were not adjusted to inflation.

Manchikanti et al (196) published in 2013 an analysis of utilization trends and Medicare expenditures of spinal interventional techniques from 2000 to 2008. The data showed that Medicare recipients receiving spinal interventional techniques increased $107.8 \%$ from 2000 to 2008, with an annual average increase of $9.6 \%$, whereas spinal interventional techniques increased $186.8 \%$, at an annual rate of increase of $14.1 \%$ per 100,000 FFS Medicare beneficiaries. They showed overall per patient costs were $\$ 1,054.33$ in 2000 , which increased to $\$ 1,104.57$ in 2008. Overall approved amounts throughout the country in FFS population were $\$ 362,347,025$ in 2000 compared to $\$ 1,231,180,420$ in 2008 , a $240 \%$ increase for all spinal interventional techniques.

Manchikanti et al (197) in a recent manuscript assessed the cost utility of facet joint interventions from 2009 to 2018 in FFS Medicare population. The data utilized for both these assessments $(196,197)$ was with $5 \%$ Medicare data, whereas for other studies (83-91) it was $100 \%$ Medicare data. Utilization patterns were similar with $5 \%$ or $100 \%$ data.

This analysis showed expenditures increased by $79 \%$ from 2009 to 2018 in the form of total cost for facet joint interventions (197). Cervical and lumbar facet joint injections increased $35 \%$ and $37 \%$, whereas cervical and lumbar radiofrequency neurotomy increased $185 \%$ and $169 \%$ with a total increase of costs of $79 \%$ at an annual rate of $6.7 \%$ (Table 3). However, inflation-adjusted expenditures with 2018 US dollars showed an overall increase of $53 \%$ with an annual increase of $4.9 \%$. In addition, inflation-adjusted costs, overall increase was $6 \%$ with an annual increase of $0.7 \%$ per procedure. Overall per patient costs, with inflation adjustment, decreased from $\$ 1,925$ to $\$ 1,785$ with an overall decline of $7 \%$ and an annual decline of $0.8 \%$. Allowed charges per visit also declined after inflation adjustment from $\$ 951.76$ to $\$ 849.86$ with an overall decline of $11 \%$ and annual decline of $1.3 \%$. This analysis also showed staged episodes of radiofrequency neurotomy were performed in $23.9 \%$ of the patients and more than 2 visits for radiofrequency neurotomy in $6.9 \%$ in lumbar spine and $9.6 \%$ staged and $5.1 \%$ more than 2 episodes in cervical spine.

Overall, from 2009 to 2018, the Medicare population increased by $30.1 \%$ with an annual increase of $3.3 \%$. In contrast, the total number of patients undergoing facet joint interventions increased by $65.1 \%$ with an annual increase rate of $5.7 \%$. Total visits also increased $71.5 \%$ with an annual rate of $6.2 \%$. Total episodes of the procedures increased $58.3 \%$ with an annual increase of $5.2 \%$. Adjusted to 100,000 Medicare population, patients increased $26.8 \%$ with an annual increase of $2.7 \%$, visits increased $31.8 \%$ with an annual increase of $3.1 \%$, episodes increased $21.5 \%$ with an annual increase of $2.2 \%$ and, finally, procedures increased $43.9 \%$ with an annual increase of $4.1 \%$ (Table 4 ).

\subsection{Opioids in Spinal Pain}

Multiple reviews have been performed in reference to opioid use, overuse, abuse, and a multitude of adverse consequences including opioid-related deaths $(5,40,70-72,140,198-215)$. The US drug overdose data of drug-related deaths from 2018 shows an arrest of the escalation and a dip in the curve towards reductions. In 2017, US drug overdosage data of drugrelated deaths showed escalating statistics with over 70,000 drug overdoses, of which 47,600 were related to opioid overdoses, as shown in Fig. 7 (211,214-219). It has been shown that the majority of the increases were related to synthetic opioids, as well as heroin. This data also showed a drop of a $14.5 \%$ in prescription drug opioid deaths, including methadone, to over 17,000 . However, heroin deaths continued to increase, and in 2017, there were over 15,000 deaths due to 
Facet Joint Interventions Guidelines 2020

\begin{tabular}{|c|c|c|c|c|c|c|c|c|c|c|c|c|c|c|c|c|c|c|c|c|c|c|c|c|c|c|c|}
\hline & \begin{tabular}{|c|c}
\multirow{2}{*}{} \\
in
\end{tabular} & 官 & $\begin{array}{l}\stackrel{\circ}{i n} \\
\stackrel{i n}{+}\end{array}$ & 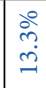 & $\begin{array}{l}0 \\
\infty \\
\infty \\
\infty\end{array}$ & & $\begin{array}{l}\text { 今े } \\
\text { iे }\end{array}$ & 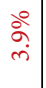 & \begin{tabular}{l|} 
\\
\\
$:$ \\
$\stackrel{\circ}{\circ}$
\end{tabular} & \begin{tabular}{|c|}
$\circ$ \\
$\stackrel{\circ}{\circ}$ \\
$\stackrel{0}{0}$
\end{tabular} & | & लें & $\stackrel{8}{3}$ & 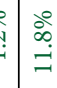 & $\stackrel{\mathrm{m}}{\stackrel{0}{2}}$ & $\begin{array}{l}\stackrel{\circ}{\circ} \\
\stackrel{\circ}{+} \\
+\end{array}$ & & \begin{tabular}{|c|}
0 \\
$i n$ \\
ñ
\end{tabular} & \begin{tabular}{|c|}
$\stackrel{\circ}{\circ}$ \\
$\stackrel{m}{\circ}$
\end{tabular} & \begin{tabular}{|c|}
$\stackrel{\circ}{\circ}$ \\
$\stackrel{\text { Ij }}{\mathrm{j}}$
\end{tabular} & & $\begin{array}{l}0 \\
\stackrel{2}{\circ} \\
6 \\
6\end{array}$ & \begin{tabular}{l|}
\multirow{+}{*}{} \\
के
\end{tabular} & 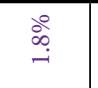 & 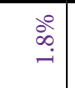 & $\begin{array}{cc}0 \\
\text { oे } \\
\vdots \\
\vdots\end{array}$ & 号 \\
\hline & $\frac{\circ}{b}$ & 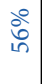 & 웅 & & $\stackrel{\circ}{\stackrel{\circ}{=}}$ & & ڤั̀ & $\stackrel{\circ}{\stackrel{2}{7}}$ & 亏ें & \begin{tabular}{|l|}
$\stackrel{\circ}{\circ}$ \\
$\stackrel{-}{-}$
\end{tabular} & $\stackrel{\circ}{\infty}$ & ळे & $\stackrel{\circ}{\circ}$ & $\stackrel{\circ}{\stackrel{2}{c}}$ & 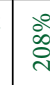 & 今ે & & $\begin{array}{l}\circ \\
\stackrel{\circ}{m}\end{array}$ & iñ & $\mid \begin{array}{c}0 \\
0 \\
\infty \\
\infty \\
-1\end{array}$ & فِ & হั & iे & 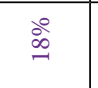 & $\begin{array}{l}\infty \\
\infty \\
-1\end{array}$ & 2 & $\breve{\Xi}_{\mathscr{J}}$ \\
\hline 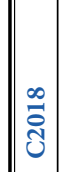 & 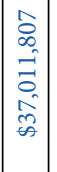 & 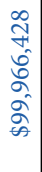 & $\begin{array}{l}0 \\
\infty \\
\infty \\
0 \\
0 \\
\infty \\
\infty \\
\infty \\
0 \\
0\end{array}$ & 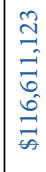 & 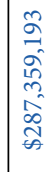 & & 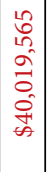 & 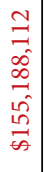 & 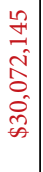 & $\mid$\begin{tabular}{c|}
8 \\
0 \\
0 \\
0 \\
0 \\
0 \\
0 \\
0 \\
$\infty$ \\
$\infty$
\end{tabular} & 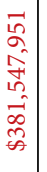 & 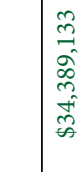 & 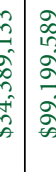 & 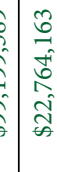 & 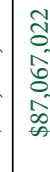 & 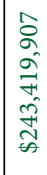 & $\infty$ & 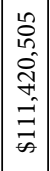 & 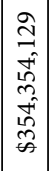 & 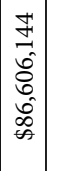 & 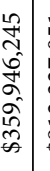 & 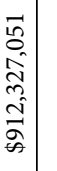 & 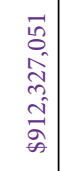 & 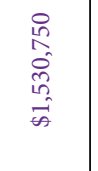 & $\begin{array}{l}n \\
\infty\end{array}$ & $\begin{array}{l}\infty \\
\infty \\
\rightarrow= \\
\rightarrow\end{array}$ & 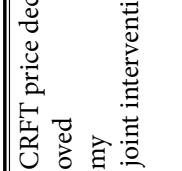 \\
\hline 突 & 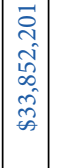 & 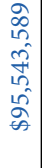 & 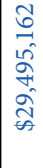 & 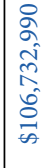 & 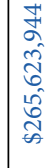 & & 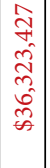 & 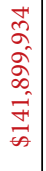 & 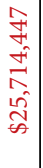 & 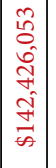 & 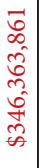 & 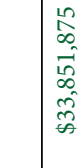 & 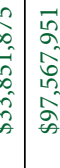 & 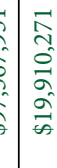 & $\begin{array}{l}0 \\
2 \\
2 \\
10 \\
0 \\
0 \\
0 \\
0 \\
0\end{array}$ & $\begin{array}{l}10 \\
0 \\
0 \\
0 \\
0 \\
0 \\
0 \\
\cdots \\
0 \\
0 \\
0\end{array}$ & 공 & 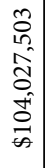 & 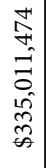 & 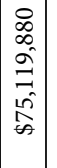 & 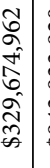 & 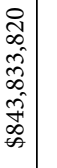 & 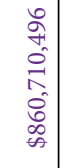 & 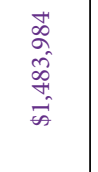 & $\stackrel{20}{\infty}$ & $\begin{array}{l}\hat{2} \\
\rightarrow \\
\omega\end{array}$ & 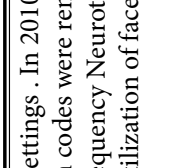 \\
\hline | & $\begin{array}{c}\hat{n} \\
\hat{n} \\
\hat{2} \\
0 \\
\infty \\
\infty \\
\hat{n}\end{array}$ & $\begin{array}{l}\text { Dे } \\
\hat{i} \\
\hat{N} \\
\hat{I} \\
\vec{\sigma}\end{array}$ & 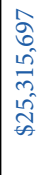 & 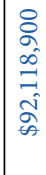 & 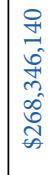 & & 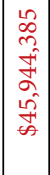 & 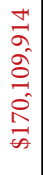 & 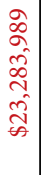 & 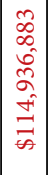 & 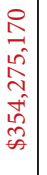 & 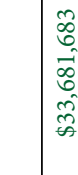 & 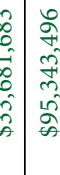 & 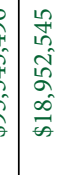 & 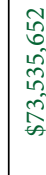 & 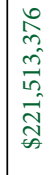 & 号 & 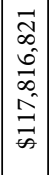 & 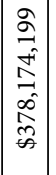 & $\left|\begin{array}{c}\overrightarrow{3} \\
\hat{\sim} \\
\hat{1} \\
\hat{n} \\
0 \\
0 \\
\infty\end{array}\right|$ & 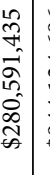 & 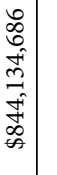 & 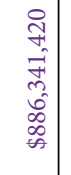 & 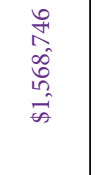 & $\begin{array}{l}0 \\
\Leftrightarrow\end{array}$ & $\begin{array}{l}\vec{\sigma} \\
\vec{\omega}\end{array}$ & 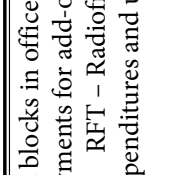 \\
\hline 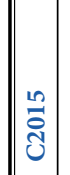 & 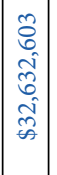 & $\begin{array}{l}0 \\
\text { W } \\
\cdots \\
\infty \\
\infty \\
\infty \\
\infty \\
\infty \\
\infty\end{array}$ & 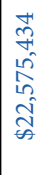 & 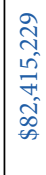 & 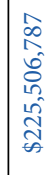 & & 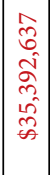 & 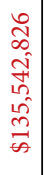 & 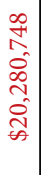 & 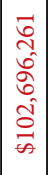 & 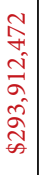 & & 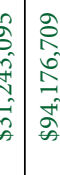 & 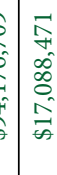 & 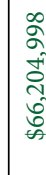 & 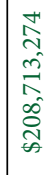 & 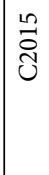 & 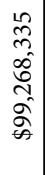 & 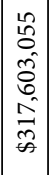 & 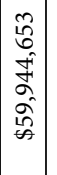 & 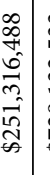 & 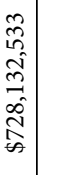 & 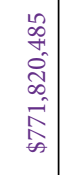 & 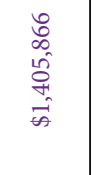 & $\vec{*}$ & & 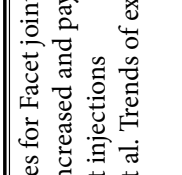 \\
\hline 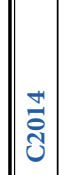 & 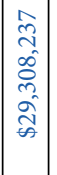 & 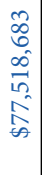 & 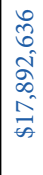 & 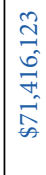 & $\begin{array}{l}0 \\
0 \\
0 \\
10 \\
0 \\
0 \\
0 \\
0 \\
0 \\
0\end{array}$ & & 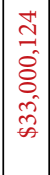 & 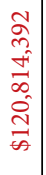 & 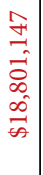 & 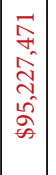 & 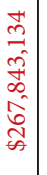 & $\begin{array}{l}\infty \\
\infty \\
\hat{1} \\
\text { m } \\
0 \\
0 \\
\infty \\
\infty \\
0\end{array}$ & 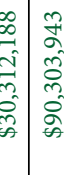 & 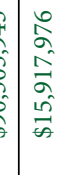 & 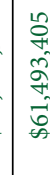 & 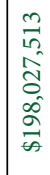 & 范 & 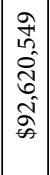 & 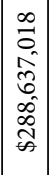 & 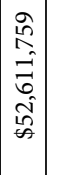 & 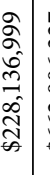 & 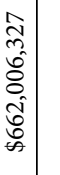 & 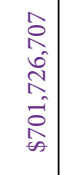 & 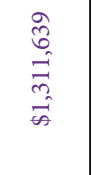 & $\stackrel{m}{\infty}$ & $\begin{array}{c}\mathbb{A} \\
\stackrel{\rightarrow}{A}\end{array}$ & 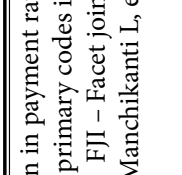 \\
\hline 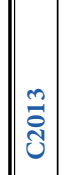 & 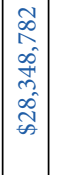 & 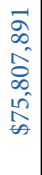 & $\mid \begin{array}{l}0 \\
\infty \\
\infty \\
0 \\
0 \\
\hat{N} \\
0 \\
0 \\
0 \\
0\end{array}$ & $\mid \begin{array}{l}\infty \\
o \\
o \\
0 \\
\infty \\
\infty \\
b \\
b\end{array}$ & 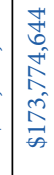 & & 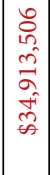 & 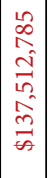 & 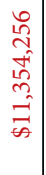 & 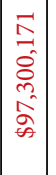 & 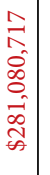 & & 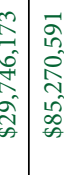 & 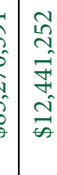 & 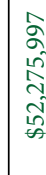 & $\begin{array}{l}m \\
0 \\
\hat{d} \\
\hat{N} \\
\hat{\hat{n}} \\
\hat{\omega}\end{array}$ & 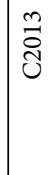 & $\mid$\begin{tabular}{c|}
$\vec{b}$ \\
+ \\
0 \\
0 \\
0 \\
0 \\
0 \\
0 \\
0
\end{tabular} & 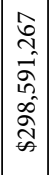 & 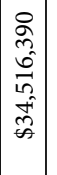 & 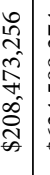 & 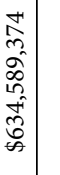 & $\begin{array}{ll}\overrightarrow{1} \\
0 \\
0 \\
0 \\
0 \\
0 \\
0 \\
0 \\
0 \\
0 \\
0\end{array}$ & 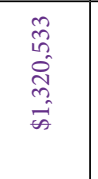 & $\frac{m}{m}$ & $\begin{array}{l}\infty \\
\infty \\
\infty \\
\Leftrightarrow \\
\Leftrightarrow\end{array}$ & 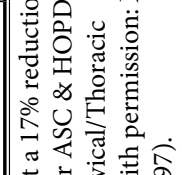 \\
\hline స్తి & 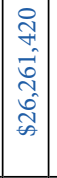 & 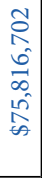 & $\begin{array}{l}0 \\
\infty \\
0 \\
0 \\
0 \\
0 \\
0 \\
0 \\
\infty \\
\infty\end{array}$ & 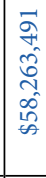 & $\begin{array}{l}2 \\
0 \\
o \\
y \\
y \\
0 \\
0 \\
0\end{array}$ & & 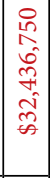 & 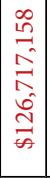 & 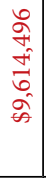 & $\begin{array}{c}\infty \\
\infty \\
\infty \\
+ \\
0 \\
+ \\
0 \\
0 \\
\infty\end{array}$ & 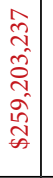 & & 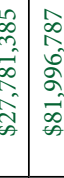 & 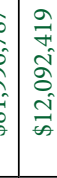 & 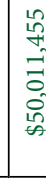 & 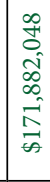 & 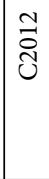 & 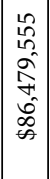 & 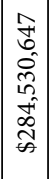 & 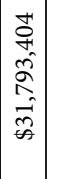 & 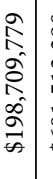 & 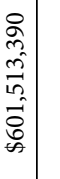 & $\begin{array}{l}n \\
2 \\
0 \\
2 \\
0 \\
0 \\
1 \\
0 \\
0 \\
0 \\
\infty\end{array}$ & 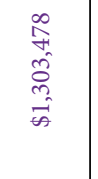 & $m$ & $\begin{array}{l}7 \\
\Rightarrow \\
0 \\
\Leftrightarrow\end{array}$ & 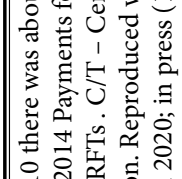 \\
\hline चี & 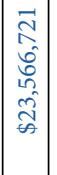 & 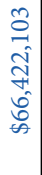 & $\mid \begin{array}{l}2 \\
\hat{\alpha} \\
\hat{d} \\
\alpha \\
\alpha \\
\infty \\
\infty\end{array}$ & 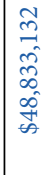 & 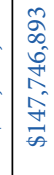 & & 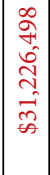 & 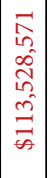 & 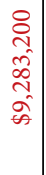 & $\mid \begin{array}{l}\overrightarrow{1} \\
2 \\
2 \\
\overrightarrow{0} \\
0 \\
0 \\
0 \\
0 \\
0\end{array}$ & 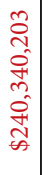 & 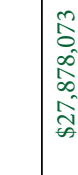 & 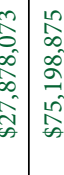 & 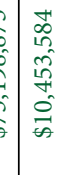 & 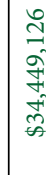 & $\begin{array}{l}\hat{\sigma} \\
\text { ô } \\
\hat{\alpha} \\
\text { के } \\
\text { के }\end{array}$ & $\overrightarrow{\text { ปิ }}$ & 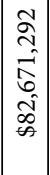 & 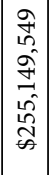 & 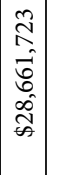 & 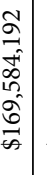 & 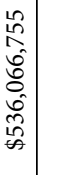 & 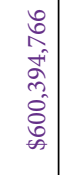 & 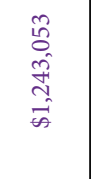 & $\frac{7}{\infty}$ & $\begin{array}{l}0 \\
\infty \\
\Rightarrow \\
\Leftrightarrow\end{array}$ & 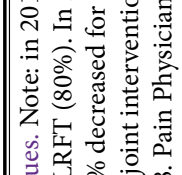 \\
\hline 离 & 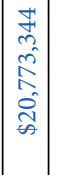 & 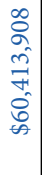 & 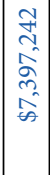 & 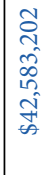 & 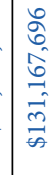 & & $\left|\begin{array}{l}n \\
\hat{\sigma} \\
+ \\
0 \\
0 \\
\hat{i} \\
\hat{n}\end{array}\right|$ & 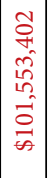 & 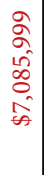 & 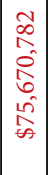 & 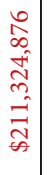 & 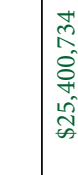 & 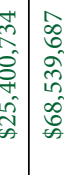 & 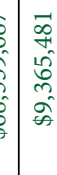 & $\begin{array}{l}0 \\
\infty \\
\infty \\
\infty \\
\infty \\
\infty \\
0 \\
\infty \\
\infty \\
\infty\end{array}$ & 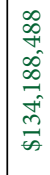 & $\begin{array}{l}\stackrel{0}{1} \\
\text { ปें }\end{array}$ & 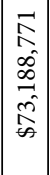 & 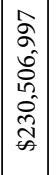 & 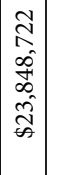 & 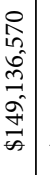 & 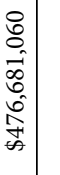 & 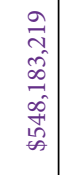 & $\begin{array}{l}\infty \\
\infty \\
+\infty \\
\infty \\
0 \\
=-1 \\
=\infty\end{array}$ & $\underset{\infty}{*}$ & $\begin{array}{l}\sqrt{2} \\
\rightarrow= \\
\Leftrightarrow\end{array}$ & 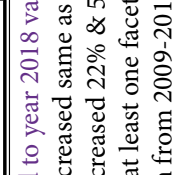 \\
\hline डે & 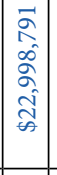 & 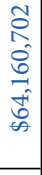 & $\mid \begin{array}{l}0 \\
0 \\
10 \\
\hat{2} \\
0 \\
0 \\
0 \\
0 \\
0 \\
0\end{array}$ & $\begin{array}{l}0 \\
\sigma \\
\sigma \\
\alpha \\
\hat{\alpha} \\
\hat{\alpha} \\
\hat{n}\end{array}$ & 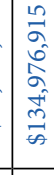 & & 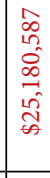 & 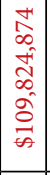 & $\begin{array}{l}n \\
0 \\
0 \\
\delta \\
0 \\
0\end{array}$ & $\mid \begin{array}{c}0 \\
0 \\
0 \\
0 \\
0 \\
0 \\
0 \\
0 \\
0\end{array}$ & 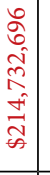 & 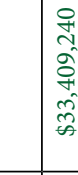 & 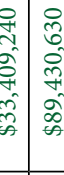 & 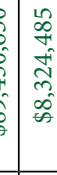 & 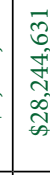 & 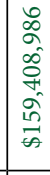 & 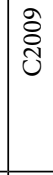 & $\mid$\begin{tabular}{c|}
$\infty$ \\
0 \\
0 \\
$\infty$ \\
$\infty$ \\
$i n$ \\
$\infty$ \\
$\infty$ \\
$\infty$ \\
$\infty$
\end{tabular} & 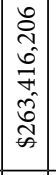 & $\left|\begin{array}{c}0 \\
0 \\
0 \\
\infty \\
0 \\
0 \\
0 \\
0 \\
0 \\
\infty \\
\infty\end{array}\right|$ & 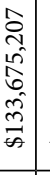 & 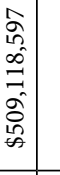 & 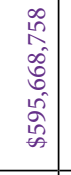 & 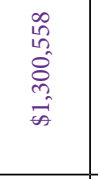 & $m$ & $\begin{array}{l}\stackrel{2}{a} \\
\widehat{a} \\
\vec{\omega}\end{array}$ & 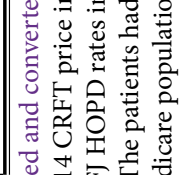 \\
\hline $\begin{array}{l}0 \\
\text { 足 } \\
\end{array}$ & 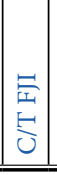 & 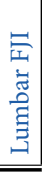 & $E$ & 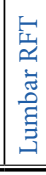 & 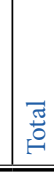 & & \begin{tabular}{|l}
$\mathbf{9}$ \\
$\mathbf{4}$ \\
$\mathbf{3}$ \\
\end{tabular} & 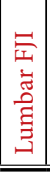 & 臣 & 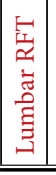 & 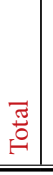 & 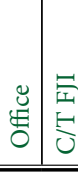 & 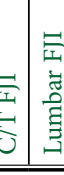 & 宏 & 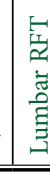 & $=$ & ثِ & \begin{tabular}{|l|} 
\\
\\
\\
\\
\end{tabular} & 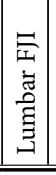 & 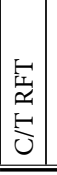 & 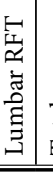 & 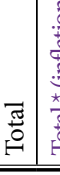 & 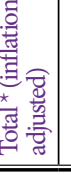 & 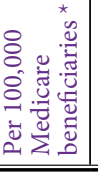 & 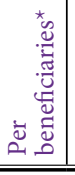 & 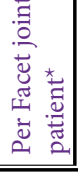 & 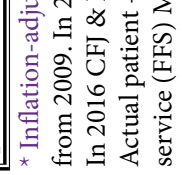 \\
\hline
\end{tabular}


Pain Physician: May/June 2020 23:S1-S127

Table 4. Characteristics of Medicare beneficiaries and utilization pattern of facet joint interventions.

\begin{tabular}{|c|c|c|c|c|c|c|c|c|c|c|c|c|}
\hline Year & Y2009 & Y2010 & Y2011 & Y2012 & Y2013 & Y2014 & Y2015 & Y2016 & Y2017 & Y2018 & Change & $\overline{~ G M}$ \\
\hline $\begin{array}{l}\text { U.S. } \\
\text { Population }\end{array}$ & 307,006 & 308,746 & 311,583 & 313,874 & 316,129 & 318,892 & 320,897 & 323,127 & 326,625 & 327,167 & $6.6 \%$ & $0.7 \%$ \\
\hline$\geq 65$ years & 39,570 & 40,268 & 41,370 & 43,144 & 44,704 & 46,179 & 47,734 & 49,244 & 51,055 & 52,347 & $32.3 \%$ & $3.2 \%$ \\
\hline $\begin{array}{l}\text { Medicare } \\
\text { Beneficiaries }\end{array}$ & 45,801 & 46,914 & 48,300 & 50,300 & 51,900 & 53,500 & 54,900 & 56,500 & 58,000 & 59,600 & $30.1 \%$ & $3.0 \%$ \\
\hline$\geq 65$ years & 38,177 & 38,991 & 40,000 & 41,900 & 43,100 & 44,600 & 46,000 & 47,500 & 49,200 & 50,800 & $33.1 \%$ & $3.2 \%$ \\
\hline $\begin{array}{l}(\%>=65 \\
\text { years })\end{array}$ & $83.4 \%$ & $83.1 \%$ & $82.8 \%$ & $83.3 \%$ & $83.0 \%$ & $83.4 \%$ & $83.8 \%$ & $84.1 \%$ & $84.8 \%$ & $85.2 \%$ & & \\
\hline$<65$ years & 7,624 & 7,923 & 8,300 & 8,500 & 8,800 & 8,900 & 9,000 & 9,000 & 8,900 & 8,800 & $15.4 \%$ & $1.6 \%$ \\
\hline \multicolumn{13}{|c|}{ Facet joint Interventions } \\
\hline \begin{tabular}{|l} 
Allowed \\
Services \\
(Procedures) \\
\end{tabular} & $1,860,600$ & $1,716,860$ & $1,800,300$ & $1,911,020$ & $1,946,180$ & $2,074,980$ & $2,283,980$ & $2,441,560$ & $2,565,900$ & $2,677,540$ & $43.9 \%$ & $4.1 \%$ \\
\hline Rate & 4,062 & 3,660 & 3,727 & 3,799 & 3,750 & 3,878 & 4,160 & 4,321 & 4,424 & 4,493 & $10.6 \%$ & $1.1 \%$ \\
\hline Visits & 625,860 & 635,440 & 661,440 & 723,420 & 758,640 & 821,020 & 906,720 & 973,700 & $1,027,720$ & $1,073,500$ & $71.5 \%$ & $6.2 \%$ \\
\hline Rate & 1,366 & 1,354 & 1,369 & 1,438 & 1,462 & 1,535 & 1,652 & 1,723 & 1,772 & 1,801 & $31.8 \%$ & $3.1 \%$ \\
\hline \multicolumn{13}{|l|}{ Patients } \\
\hline$>=65$ years & 223,700 & 223,220 & 231,160 & 245,640 & 253,600 & 276,960 & 308,020 & 336,000 & 360,780 & 387,040 & $73.0 \%$ & $6.3 \%$ \\
\hline $\begin{array}{l}(\%>=65 \\
\text { years })\end{array}$ & $72.3 \%$ & $71.3 \%$ & $69.9 \%$ & $69.0 \%$ & $69.1 \%$ & $69.9 \%$ & $71.1 \%$ & $72.4 \%$ & $73.7 \%$ & $75.7 \%$ & & \\
\hline Rate & 488 & 476 & 479 & 488 & 489 & 518 & 561 & 595 & 622 & 649 & $33.0 \%$ & $3.2 \%$ \\
\hline$<65$ years & 85,740 & 89,720 & 99,500 & 110,580 & 113,260 & 119,080 & 125,500 & 127,900 & 128,540 & 123,980 & $44.6 \%$ & $4.2 \%$ \\
\hline Rate & 187 & 191 & 206 & 220 & 218 & 223 & 229 & 226 & 222 & 208 & $11.1 \%$ & $1.2 \%$ \\
\hline $\begin{array}{l}\text { Total } \\
\text { Patients }\end{array}$ & 309,440 & 312,940 & 330,660 & 356,220 & 366,860 & 396,040 & 433,520 & 463,900 & 489,320 & 511,020 & $65.1 \%$ & $5.7 \%$ \\
\hline Rate & 676 & 667 & 685 & 708 & 707 & 740 & 790 & 821 & 844 & 857 & $26.8 \%$ & $2.7 \%$ \\
\hline \multicolumn{13}{|c|}{ Episodes (primary codes only) } \\
\hline $\begin{array}{l}\text { Facet Joints } \\
\text { Interventions }\end{array}$ & 675,860 & 651,720 & 679,380 & 742,540 & 762,420 & 821,720 & 905,400 & 968,660 & $1,022,900$ & $1,069,800$ & $58.3 \%$ & $5.2 \%$ \\
\hline Rate & 1,476 & 1,389 & 1,407 & 1,476 & 1,469 & 1,536 & 1,649 & 1,714 & 1,764 & 1,795 & $21.6 \%$ & $2.2 \%$ \\
\hline \multicolumn{13}{|c|}{ Episodes based Age groups } \\
\hline$>=65$ & 463,500 & 443,700 & 453,280 & 488,860 & 502,200 & 548,920 & 620,400 & 679,400 & 735,340 & 797,460 & $72.1 \%$ & $6.2 \%$ \\
\hline Rate & 1,214 & 1,138 & 1,133 & 1,167 & 1,165 & 1,231 & 1,349 & 1,430 & 1,495 & 1,570 & $29.3 \%$ & $2.9 \%$ \\
\hline$<65$ & 212,360 & 208,020 & 226,100 & 253,680 & 260,220 & 272,800 & 285,000 & 289,260 & 287,560 & 272,340 & $28.2 \%$ & $2.8 \%$ \\
\hline Rate & 2,785 & 2,626 & 2,724 & 2,984 & 2,957 & 3,065 & 3,167 & 3,214 & 3,231 & 3,095 & $11.1 \%$ & $1.2 \%$ \\
\hline \multicolumn{13}{|c|}{ Episodes based on Place of Service } \\
\hline ASC & 160,560 & 166,400 & 180,020 & 208,340 & 205,000 & 225,340 & 257,180 & 283,980 & 305,060 & 326,120 & $103.1 \%$ & $8.2 \%$ \\
\hline Rate & 351 & 355 & 373 & 414 & 395 & 421 & 468 & 503 & 526 & 547 & $56.1 \%$ & $5.1 \%$ \\
\hline HOPD & 144,320 & 153,660 & 164,460 & 179,220 & 188,220 & 197,340 & 220,500 & 238,860 & 248,920 & 261,980 & $81.5 \%$ & $6.8 \%$ \\
\hline Rate & 315 & 328 & 340 & 356 & 363 & 369 & 402 & 423 & 429 & 440 & $39.5 \%$ & $3.8 \%$ \\
\hline Office & 370,980 & 331,660 & 334,900 & 354,980 & 369,200 & 399,040 & 427,720 & 445,820 & 468,920 & 481,700 & $29.8 \%$ & $2.9 \%$ \\
\hline Rate & 810 & 707 & 693 & 706 & 711 & 746 & 779 & 789 & 808 & 808 & $-0.2 \%$ & $0.0 \%$ \\
\hline
\end{tabular}

Reproduced with permission: Manchikanti L, et al. Trends of expenditures and utilization of facet joint interventions in fee-for-service (FFS) Medicare population from 2009-2018. Pain Physician 2020; in press (197). 


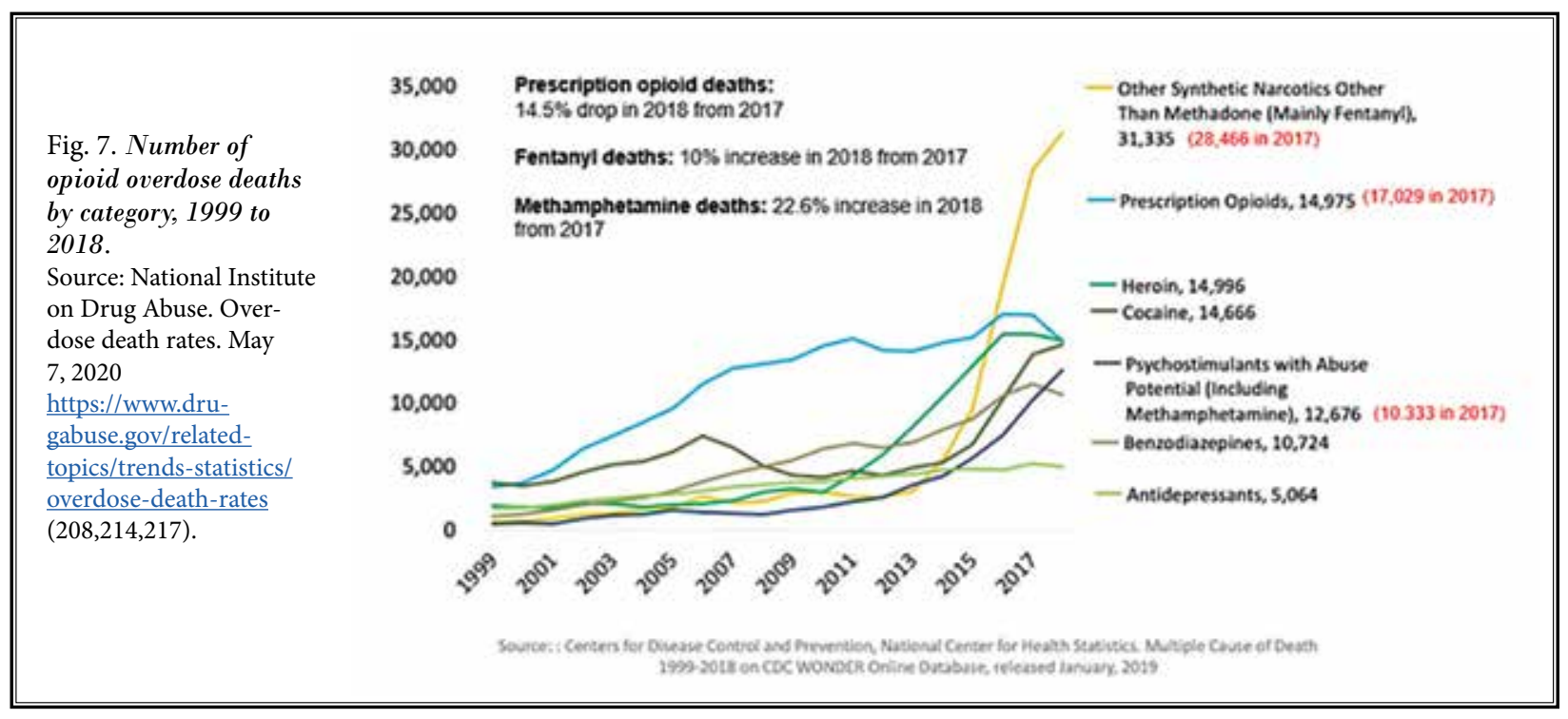

Fig. 8. Total opioid prescriptions in the United States in millions, 2013-2018.

Source: https://www.end-opioid-epidemic. org/wp-content/uploads/2019/06/AMAOpioid-Task-Force-2019-Progress-Report-web.pdf

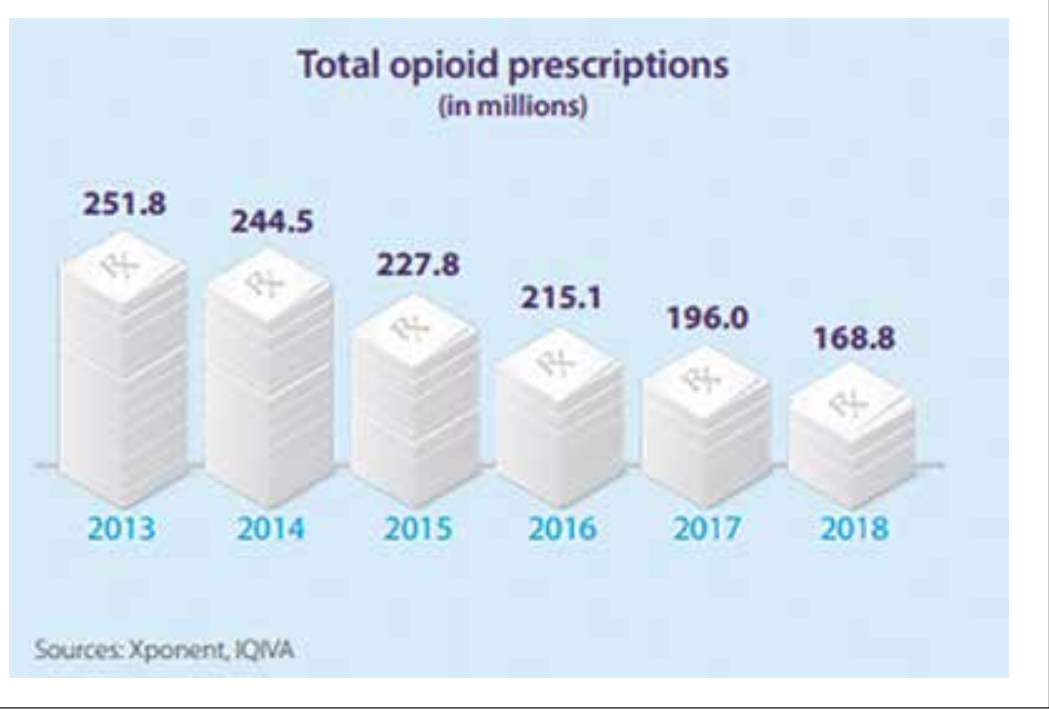

heroin. Fentanyl deaths are the category largely responsible for the escalating opioid epidemic (207). Reversing the trend, 2018 drug and opioid-involved overdose deaths in the United States from Centers for Disease Control and Prevention (CDC) showed not only the flattening of the curve, but also a dip in the curve for overall opioid deaths and more significantly for prescription opioids (214). The data showed that opioids were involved in approximately $70 \%(n=46,802)$ in contrast to 47,600 in 2017 of drug overdose deaths during 2018 , representing a $2 \%$ decline in overall opioid death rates. The report also showed a decline of overdose death rates of $14.5 \%$ for prescription opi- oids, and $3 \%$ for heroin from 2017. However, unfortunately, rates involving synthetic opioids increased $10 \%$ even though lower than previous years, but the trend continued. If we can control overdose deaths related to heroin and synthetic opioids, the opioid epidemic will be resolved.

In addition, recent data from 2018 (214) shows that overall prescriptions provided have shown a downward trend with 168.8 million prescriptions in 2018 compared to 251.8 million in 2013 Fig. 8 (213). More recently, potentially increased morbidity and mortality has been reported in patients with high dose opioids or those suffering with opioid use disorder (215). 


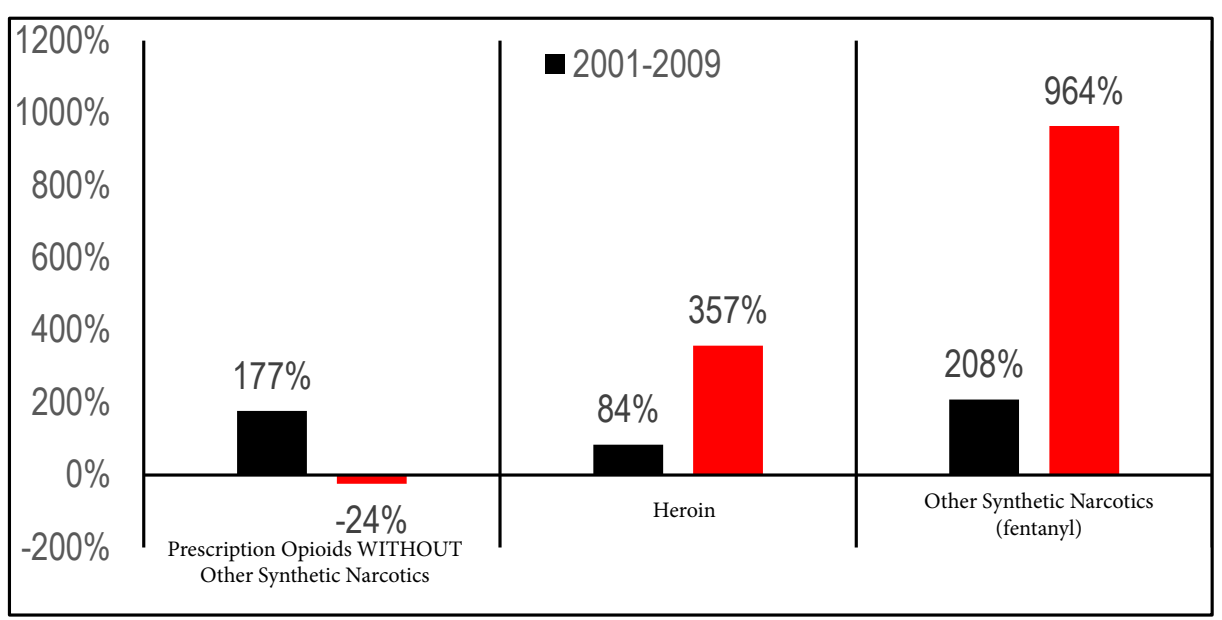

Fig. 9. Quantification of opioid deaths.

Source: NIDA. Overdose Death Rates. National Institute on Drug Abuse website. May 7, 2020. https://www.drugabuse. gov/related-topics/ trends-statistics/overdose-death-rates (217).

Manchikanti et al (198) described various issues related to the opioid epidemic and pointed out the tragic failures of the current systems to control opioid misuse. Thus, multiple factors propagated the epidemic, starting with the fifth vital sign pain movement together with a confluence of interest and a failure of oversight from the opioid industry, which was largely responsible for the epidemic. Multiple confluences of interests were reported, including promotion of opioids based on inadequate evidence with advocacy from Portenoy and Foley (220). Further fuel was added with the establishment of pain as the fifth vital sign, which was embraced by multiple organizations and it was essentially forced on hospitals and other health care professionals in assessing pain relief and quality improvement $(5,198)$. Further contributing issues were the medical boards themselves. The majority of the guidelines although allegedly written for appropriate opioid use, were essentially promoting excessive use and abuse patterns, as they were developed by the opioid industry with confluence of interest. Further, multiple failures in the oversight of opioid manufacturing, distribution, diversion and import, in addition to medical necessity and appropriate monitoring of opioid prescriptions fueled the epidemic (198).

It is difficult to point out the reasons for the explosion of the fentanyl epidemic, along with increases in the usage of heroin, as well as cocaine, as shown in Figs. 7 and 9 (217). The significant movement to control the opioid epidemic in the United States was initiated with prescription drug monitoring programs, state regulations curbing opioid prescriptions, and increasing the focus on education. Overall federal spending increased
$128 \%$ from 2017 to 2018 with the major increases in federal spending due to treatment and recovery programs with costs ranging from approximately $\$ 599$ million to 2.1 billion (218-230). Overall, total opioid spending increased from $\$ 3.3$ billion in 2007 to $\$ 7.4$ billion in 2018 in the United States (218). The numerous regulations and enhanced prescription drug monitoring programs have also contributed to the decrease in opioid prescriptions from a high of 255 million in 2012 to 168.8 million in 2018 , a decrease of $34 \%$. In fact, overall decline in the number of prescriptions with reduced dosages, faces a multitude of criticisms against the CDC guidelines and other measures (228-235).

Following a multitude of complaints, the US Department of Health and Human Services, as well as the CDC, have clarified and also are encouraging the providing of opioids for patients with appropriate medical necessity, even though they continue to focus on reduced utilization $(233,234)$. Some also have postulated that the reduction in opioid dosages is propelling patients into the streets to illicitly use, initially, prescription drugs and then leading to heroin which may be contaminated with fentanyl, and/or using fentanyl itself.

However, with the Corona pandemic and the inability to monitor the patients appropriately and with increased relaxations and an increase from the Drug Enforcement Administration (DEA) of opioid production, it is not known what the recent future will hold for reductions in consumption and death rates. Further, mandated reductions by the DEA of $25 \%$ in $2017,20 \%$ in 2018 , and $10 \%$ in 2019 , and proposed reductions in 2020 has been reversed by this increased production. 


\subsection{Pathophysiology and Structural Basis of Spinal Facet Joint Pain}

\section{Key Question 3: What is the pathophysiologic and structural basis of spinal facet joint pain?}

It is well known that chronic spinal pain is a multifactorial disorder with multiple potential etiologies. In the 1980s and 1990s, the biopsychosocial approach dominated chronic spinal pain management. Further, medically unexplained pain was the subject of controversy with numerous publications in the medical literature (236-243). This issue is now rarely discussed. With the development of modern technology, including magnetic resonance imaging (MRI), computed tomography (CT), axial scanning $\mathrm{CT}$, neurophysiologic testing, and comprehensive physiological examination and psychological assessment, we continue to be able to objectively identify the cause of spinal pain in only $15 \%$ of patients, in the absence of disc herniation and neurological deficits $(6,18-25,186,188,193,194,236-260)$.

The majority of painful conditions originate from the spine, with pain in the neck, upper back, mid back, low back, and upper or lower extremities. Bogduk postulated that for any structure to be deemed a cause of back pain (252):

- $\quad$ The structure should have a nerve supply.

- The structure should be capable of causing pain similar to that seen clinically, ideally demonstrated in normal volunteers.

- The structure should be susceptible to diseases or injuries that are known to be painful.

- The structure should have been shown to be a source of pain in patients, using diagnostic techniques of known reliability and validity.

Kuslich et al (25) identified intervertebral discs, facet joints, ligaments, fascia, muscles, and nerve root dura as tissues capable of transmitting pain in the low back. Based on the available evidence with multiple diagnostic interventions, specifically with controlled diagnostic blocks, intervertebral discs, facet joints, sacroiliac joints, and nerve roots have been proven to be common sources of pain in volunteers and patients with spinal pain $(6,18-21,244,258-281)$. In contrast to the structures which are amenable to controlled diagnostic blocks, vertebrae, muscles, and ligaments have not been identified by proven diagnostic techniques. Multiple prospective evaluations identified patients with different structures as causation with chronic neck or low back pain after failure of conservative therapy of undetermined etiology by medical history, physical examination, X-ray, CT, MRI, and EMG/NCG. Earliest of the studies in lumbar spine in a prospective evaluation, Pang et al (282), with a pain mapping strategy in patients with intractable low back pain after failing conservative therapy without disc herniation or radiculitis, showed pain from facet joints in $24 \%$, combined lumbar nerve root and facet disease in $24 \%$, combined facet and sacroiliac joints in $4 \%$, lumbar nerve root irritation in $20 \%$, internal disc disorder in $7 \%$, sacroiliac joint in $6 \%$, and sympathetic dystrophy in $2 \%$. In a second study, Manchikanti et al (283), assessed the relative contributions of various structures in patients with chronic low back pain after failure of conservative modalities of treatment, with lack of radiological evidence to indicate disc protrusion or radiculopathy, utilizing controlled comparative double diagnostic blocks, showed $40 \%$ of the patients with facet joint pain, $26 \%$ with discogenic pain, $2 \%$ with sacroiliac joint pain, and possibly $13 \%$ with segmental dural/nerve root pain. In these studies, no cause was identified in 13\% (282) and $19 \%$ of the patients (283). Schwarzer et al (284-290) in separate studies showed facet joint pain from $15 \%$ to $40 \%$ of the patients, internal disc disruption in $39 \%$ of the patients, and sacroiliac joint pain in $30 \%$ of the patients. DePalma et al (291) in a retrospective evaluation of 156 patients with chronic low back pain assessed the source of pain to be discogenic pain, facet joint pain, and sacroiliac joint pain, using controlled comparative local anesthetic blocks. Their study showed a prevalence of facet joint pain in $31 \%$, prevalence of disc disruption in $42 \%$, and sacroiliac joint pain in $18 \%$ of the patients. Bokov et al (292) utilizing multiple diagnostic strategies in chronic low back identified facet joint pain in $50.6 \%$ of the cases utilizing $50 \%$ pain relief as the criterion standard, discogenic pain in $16.9 \%$ of the cases, and sacroiliac joint pain in $7.2 \%$ of cases. They were unable to identify a source of pain in $25.3 \%$ of cases.

In the cervical spine, Bogduk and Aprill (293) assessed the prevalence of discogenic pain and zygapophysial facet joint pain. They showed that discs alone were symptomatic in only $20 \%$ of the sample. However, in $41 \%$ of the patients, both a symptomatic disc and symptomatic zygapophysial joints were identified. Yin and Bogduk (294) in a study of 143 patients with chronic neck pain of various origins identified discogenic pain in $16 \%$ of the patients and zygapophysial joint pain in $55 \%$ of the patients with lack of diagnosis in $32 \%$ of those patients who completed investigation, and only $46 \%$ of the sample completed the investigations. 
Pathophysiologic phases of facet joint pain, degeneration of the spine, and the relationship to osteoarthritis has been described in multiple manuscripts $(6,18-21,255-257,295-309)$. The facet or zygapophysial joints are paired diarthrodial joints in the posterior aspect of the vertebral column and are the only true synovial joints between adjacent spinal levels in humans $(249,256,257)$. Facet joint arthritis is intimately linked to the distinct but functionally related condition of degenerative disc disease, which affects structures in the anterior aspect of the vertebral column. At every spinal level except C1/C2, the so-called "3-joint complex", or motion segment, is formed by the 3 articulations between adjacent vertebrae: one disc and 2 facet joints $(295,302,305,306)$. Thus, the spine may be considered as a structure composed of multiple motion segments connected in series, with a composite of motion in the individual segments. Since, 3 joints in each motion segment are highly interdependent, any changes in one segment can affect the other 2 , and vice versa $(295,302,305,306)$. Thus, lesions that affect the disc tend to eventually have an effect on the facet joints, and trauma or instability of the posterior structures may in turn affect the disc $(257,299,300,307-309)$. Multiple studies have shown that pathology begins in the disc and is followed by changes in the facet joints in the majority of individuals (299,307-309).

Facet joint osteoarthritis is a clinical and pathological construct that involves the functional failure of the synovial facet joints. Even though facet joint arthritis is often viewed as a disease of articular cartilage loss and bony hypertrophy, the process of failure actually involves the whole joint, including the subchondral bone, cartilage, ligament, synovium, and periarticular paraspinal muscles and soft tissues.

Facet joints have been shown to be well innervated, including the subchondral bone, synovium, synovial folds, and joint capsule (310-331). However, articular cartilage of the facet joint is aneural. The nerve endings, which form the part of the medial branch emanating from the dorsal ramus, are involved in pain sensation and proprioception (311). The medial branch is particularly crucial because it is responsible for sensory input from the midline of the spine to the facet joint line (311). Consequently, many facet joint diagnostics and interventions rely on pain patterns and relief by blocking medial branch nervous signals (310). Overall, innervation of the facet joints has been demonstrated from medial branches of the dorsal rami in multiple studies (311-331). In addition, neuroanatomic studies have demonstrated free and encapsulated nerve endings in facet joints, as well as nerves containing substance $P$ and calcitonin gene-related peptides (332-346). Further, neurophysiologic studies also have shown that facet joint capsules contain low threshold mechanoreceptors, mechanically sensitive and silent nociceptors (321-350). Inflammation leads to decreased thresholds of nerve endings in facet capsules as well as elevated baseline discharge rates (301,321,343-353). Biomechanical studies also have shown that lumbar and cervical facet joint capsule can undergo high strains during spine-loading (321,354-357). Further, basic science as well as clinical studies have shown multiple factors including mechanical injury, inflammation, and degeneration of the facet joints to produce persistent pain $(244,259,260,303,307,358-382)$. In the cervical spine, differences have been demonstrated in pressure and thermal pain hypersensitivity between patients with acute and chronic neck pain in healthy subjects (370). In addition, cold hypersensitivity was also demonstrated. Javanshir et al (370) concluded that the results supported the existence of different sensitization mechanisms between patients with acute and chronic mechanical and insidious neck pain.

Thus, based on the neurophysiologic and pathophysiologic evidence, spinal facet joints have been shown to be a source of pain in the neck and referred pain in the head and upper extremities, upper back, mid back, and referred pain in chest wall, and low back and referred pain in the lower extremity.

\subsection{Non-Interventional Diagnosis of Facet Joint Pain}

Key Question 4: What is the evidence of diagnostic accuracy and value of non-interventional methods in the diagnosis of facet joint pain?

Accurate diagnosis of underlying causes is a prerequisite for successful therapy of low back pain. Assessment of a patient with spinal pain starts with patient self-report questionnaire items and history taking, followed by physical examination to help clinicians generate a probable hypothesis which may help differentiate those patients with pain of musculoskeletal origin from those with non-spinal or serious spinal pathology (383). In other areas of medicine, this paradigm has been shown to be valid, or is assumed to be so (384). However, in spinal pain, the reliability of history and physical examination in detecting sources of spinal pain is less certain. Petersen et al (385) developed a clinical classification in low back pain based 
on best evidence diagnostic rules. They described that diagnostic reasoning with a structural/pathoanatomical focus is common among clinicians (386), and it is regarded as an essential component of the biopsychosocial model $(237,244,259,260,386-394)$. In the modern era of advanced diagnostics with supplementation of advanced imaging added to physical examination and history, and a multitude of diagnostic interventions, clinicians are focusing more so on the "bio" part of the biopsychosocial model. It is crucial that appropriate diagnosis is available to provide the most effective treatment for the individual patient. Multiple studies have been published along with systematic reviews evaluating the value and validity of non-invasive assessment including history, physical examination, and imaging $(6,23,383,385,390-397)$. While imaging is not very useful in identifying facet pain; however, imaging is necessary and useful in identifying red flags, disc herniation, and discogenic pain. Consequently, once appropriate diagnosis is made, the terminology relating to nonspecific low back pain may be removed. The term "nonspecific low back pain" does not refer to any primary studies to support the diagnosis or the position of the authors. The term "nonspecific low back pain", often advanced by those without involvement with interventional diagnosis, has been questioned $(255,398)$. The validity and reliability of history taking and physical examination in clinical practice continue to be debated (390). However, physicians use the information gained from history taking and physical examination to decide on the use of further diagnostic tests, including imaging. Many researchers have attempted to develop a series of diagnostic clinical criteria to establish the diagnosis of facet joint pain as cause of axial spinal pain. Consequently, multiple publications included patient history and physical examination of multiple criteria as indicators of pain that may be facet joint related as shown in Table 5. These included unilateral or bilateral axial spinal pain associated with shoulder, buttock, hip or back of thigh, or paravertebral thoracic pain (399), pseudoradicular pain (400), morning stiffness (401), pain on extension and rotation (392,393,401-403), negative neurological examination $(401,404,405)$, and normal gait (406). However, the sensitivity and specificity of these criteria are very low. Even then, history and physical examination continue to be the fundamental for screening patients with low back pain (407), even though they cannot establish facet joint diagnosis as the specific cause of the pain, but provide suspicion of the diagnosis $(392,393,407)$.

In a manuscript of systematic review of the literature and pilot study assessing clinical diagnosis scale for pain of lumbar facet origin (393), the authors incorporated 6 phases, utilizing a total of 36 signs and symptoms for the diagnosis of lumbar facet joint pain that were submitted to the group of experts, where a total of 12 , with 8 symptoms and 4 signs were included in the final survey. They also performed diagnostic facet blockade

Table 5. Positive signs and symptoms in patients with positive blocks.

\begin{tabular}{|l|c|c|c|}
\hline \multirow{2}{*}{\multicolumn{1}{|c|}{ Symptoms }} & \multicolumn{2}{c|}{ General Population (n = 28) } & Diagnostic (n = 22) \\
\cline { 2 - 4 } & Positive \% (n) & Negative \% (n) & Positive \% (n) \\
\hline Unilateral/bilateral lumbar paraspinal pain & $96.4(27)$ & $3.6(1)$ & $95.5(21)$ \\
\hline Axial pain & $100(28)$ & 0 & $100(22)$ \\
\hline Pain irradiating to above the knee & $46.4(13)$ & $53.6(13)$ & $36.4(8)$ \\
\hline More lumbar pain than leg pain & $64.3(18)$ & $35.7(10)$ & $59.1(13)$ \\
\hline Pain worsens with extension & $46.4(13)$ & $53.6(15)$ & $50(11)$ \\
\hline Pain worsens with axial rotation & $46.4(13)$ & $53.6(15)$ & $45.5(10)$ \\
\hline Absence of radicular pattern & $71.4(20)$ & $28.6(8)$ & $68.2(15)$ \\
\hline Alleviated or improved at rest & $71.4(20)$ & $28.6(8)$ & $77.3(17)$ \\
\hline New lumbar facet sign & $46.4(13) \mathrm{SD}=3$ & $42.9(12)$ & $40.9(9) \mathrm{SD}=2$ \\
\hline $\begin{array}{l}\text { Pain induced by pressure on the facet joint or transverse } \\
\text { process }\end{array}$ & $57.1(16)$ & $42.9(12)$ & $68.2(15)$ \\
\hline Range of motion & $67.9(19)$ & $82.1(23)$ & $63.6(14)$ \\
\hline Kemp's sign & $82.1(23)$ & $17.9(5)$ & $81.8(18)$ \\
\hline
\end{tabular}

Source: Gómez Vega JC, Acevedo-González JC. Clinical diagnosis scale for pain lumbar of facet origin: systematic review of literature and pilot study. Neurocirugia (Astur) 2019; 30:133-143 (393). 
in 31 patients, mostly women, with an average age of $60 \pm 11.5$ years, with a preoperative pain of $8 / 10$ and post-operative of $1.7 / 10$. The signs and symptoms most frequently found included in a diagnostic scale were 3 symptoms (1 - axial or bilateral axial lumbar pain, 2 improvement with rest, and 3 - absence of nerve root pattern), and may have pseudoradicular pain, however, the pain is greater in lumbar area than pain in the leg. They provided 3 clinical signs: Kemp sign, also referred to as Kemp's test $(395,408)$, Quadrant Test $(395,409)$, Extension-Rotation test $(393,410)$, and Facet Stress Sign or Acevedo Sign (393), named after the author describing this sign $(393,396)$. All of the descriptors are very well known except for the Facet Stress Sign which describes the patient in supine position, raises the one lower extremity as if in a straight leg raising test and brings it down against the pressure applied by the examiner at the foot level. The examiner lets the pressure go suddenly before it touches the examination table and the examiner also quickly holds it again stopping the patient's leg from abruptly hitting the surface of the table. The sign is considered positive if pain is reproduced on the same side as the symptom from the suspected facet joints. The authors of the manuscript showed that the diagnostic sensitivity of this was $70.3 \%$, whereas, specificity was $50 \%$ with a positive predictive value of 90.47 and a negative predictive value of $20 \%$ and accuracy of 67.7. Proposed diagnostic scale for lumbar pain of facet origin, as shown in Table 6, shows positive signs and symptoms in the general population $(n=28)$ and patients with positive blocks.

Prior to these publications, earlier publications starting with Revel's publication in 1972, with a proposed general criteria of 7 clinical signs, with the presence of 5 out of 7 during the assessment of the patient, predicting an adequate response to lumbar facet joint block with a sensitivity of $92 \%$ and specificity of $80 \%$ $(402,411)$. Laslett et al (412) utilized Revel's criteria as a screening test. Their results showed that Revel's results were not replicated. Sensitivity of Revel's criteria was low (less than 17\%) and specificity was high (approximately 90\%). Absence of pain with cough or sneeze just reached significance in one model. They concluded that Revel's criteria were unsuitable as a clinical screening test to select chronic low back pain patients for initial facet joint blocks (412). Laslett et al (413) subsequently attempted to refine clinical prediction rules. Utilizing a double block paradigm with various intervals of pain relief and a cutoff value of less than $90 \%$, no clinical findings predicted positive response to facet joint injections. However, they noted that a cutoff value of $95 \%$, showed that a negative Extension Rotation test, absence of pain centralization, age over 50 years, pain relief with walking, pain relief with sitting, paraspinal onset, and a score on the Modified Somatic Perceptions Questionnaire suggesting somatization were predictors of facet joint pain. In another study, Young, Aprill and Laslett (414) were unable to find clinical characteristics associated with positive intraarticular facet joint injection except for lack of pain provocation when rising from sitting, and absence of pain centralization, even though they identified several predictive factors for sacroiliac joint and lumbar discogenic pain (414). Manchikanti et al (415) assessed the inability of the clinical picture to characterize pain from facet joints in 200 patients with the conclusion that history, clinical features, and radiological features were of no significance or assistance in making the diagnosis of facet joint pain with certainty. They specifically assessed Revel's criteria (402). They were unable to identify any groups of tests with a significance.

Table 6. Proposed diagnostic scale for lumbar pain of facet origin.

\begin{tabular}{|l||}
\hline Symptoms \\
\hline 1. Unilateral/bilateral axial lumbar pain \\
\hline 2. Improves or is alleviated with rest \\
\hline 3. Absence of a radicular pattern, although a pseudoradicular pattern may be present, but with more lumbar pain than leg pain \\
\hline Signs \\
\hline 1. Kemp's sign \\
\hline 2. Induced pain in the articular or transverse apophysis \\
\hline 3. Sign of facet stress or new lumbar facet sign \\
\hline
\end{tabular}

Source: Gómez Vega JC, Acevedo-González JC. Clinical diagnosis scale for pain lumbar of facet origin: systematic review of literature and pilot study. Neurocirugia (Astur) 2019; 30:133-143 (393). 
Manchikanti et al (416) also evaluated correlates of nonphysiological behavior in patients with chronic low back pain. Based on the historical reliance on Waddell's symptoms and signs, patients with positive signs and symptoms were considered as exaggerating the pain and were utilized to describe the patients as malingerers $(26,27,416-418)$. Manchikanti et al showed that among the 120 patients with chronic low back pain, $22 \%$ of the patients presented with nonphysiological symptoms, $28 \%$ of the patients with nonphysiological signs and $16 \%$ with combined presence of nonphysiological signs and symptoms. Overall, they showed a significant correlation of nonphysiological signs with depression, anxiety, and somatization, both by diagnosis of depression, anxiety, and somatization. However, the correlation was present for nonphysiological symptoms only with elevated scores of anxiety and somatization.

Multiple authors have conducted studies of individual signs and symptoms for the diagnosis of facet joint pain such as the new clinical sign, Kemp's Sign (395,408-410), spinal percussion test (395), spring test, segmental rotation test, and Acevedo Test among others $(393,395,419)$; however, none of them has proposed a clear diagnostic scale. In a systematic review, Maas et al (397) concluded that there was no diagnostic scale available with adequate performance, and finally the patients' history and physical examination could only give a cautious direction for diagnosis. Schwarzer et al (284) in a prospective study attempted to identify presumptive clinical features in 176 patients with chronic low back pain using double, comparative local anesthetic injections or medial branch blocks, were unable to identify none of the 16 physical signs or symptoms evaluated for association with a positive response. In another study, Schwarzer et al (290) showed that none of the historical features or clinical tests discriminated between patients diagnosed with facet joint pain and those who had negative blocks. DePalma et al (420) in a retrospective assessment of axial pain, identified that presence of paramedian pain significantly increased the likelihood of sacroiliac joint pain and facet joint pain confirmed with diagnostic blocks. In another study, DePalma et al (421) showed that older age and higher body mass index (BMI) were more likely to be associated with a diagnosis of facet joint pain compared with internal disc disruption and sacroiliac joint pain.

Similar to low back, though much less frequently, clinical diagnostic tests have been described in the diagnosis of cervical facet joint pain $(269,272,384,422-428)$. However, no such descriptions are available in the tho- racic spine. Usunier et al (422) in a systematic review and meta-analysis compared clinical diagnostic tests with medial branch blocks for adults with persistent cervical zygapophysial joint pain. In this systematic review, they identified 4 clinical tests in the 7 studies they used in the review and meta-analysis $(269,272,384,423)$. Two of the tests had sufficient data and at least 2 independent cohorts allowing statistical pooling (384,423-425). The 4 tests were passive intersegmental motion testing $(384,423,425)$, mechanical sensitivity $(424,425)$, cervical zygapophysial joint pain patterns $(269,272,425)$ and extension-rotation test (425). Aprill et al (272) and Dywer et al (269) evaluated the diagnostic utility of cervical facet joint referral patterns or pain maps. They reported strong agreement between pain maps and localization of cervical facet joints with 9 of 10 participants having medial branch blocks confirmed cervical zygapophysial joint pain at predicted segments (272). Speldewinde et al (425) in their retrospective audit found that $36 \%$ of the patients confirmed to have cervical facet joint pain, $83 \%$ were predicted at the correct segment by following the pain maps described by Dwyer and colleagues (269). However, neither of them provided sufficient evidence in reference to the false-positives, false-negatives, true-negatives, etc., to allow statistical pooling and were unable to obtain these from the primary authors (422). Schneider and colleagues (426) in 125 patients described an extension-rotation test that was not described in other primary evidence in the systematic review. They reported a sensitivity to be 0.83 and specificity to be 0.59 . In addition, local tenderness was also investigated in cervical zygapophysial joint pain. In this assessment, 33 patients with chronic unilateral neck pain were assessed. Pressure pain thresholds (PPTs) were assessed at all cervical zygapophysial joints. The diagnosis of zygapophysial joint pain was made by diagnostic facet joint nerve blocks. The results showed that zygapophysial joint pain was present in 14 patients. In these cases, the differences in mean PPT between affected side and contralateral side were not significant. The authors concluded that assessing mechanical pain sensitivity is not diagnostic for cervical facet joint pain.

Multiple guidelines by ASIPP $(6,18,19,236-238,240$ 243), International Spine Intervention Society (ISIS) standards (258), and consensus guidelines of multiple societies (23) were unable to provide definitive answers.

Thus, conventional clinical features are unreliable in diagnosing zygapophysial (facet) joint pain. The distinguishing features of somatic or referred pain secondary to facet joints and radicular pain secondary to 
Table 7. Features of somatic and radicular pain.

\begin{tabular}{|c|c|c|}
\hline & Axial (Somatic) or Referred Pain & Radicular Pain \\
\hline \multirow{5}{*}{ Segment Causes } & Posterior segment or element & Anterior segment \\
\hline & Facet joint pain & Disc herniation \\
\hline & Sacroiliac joint pain & Annular tear, discogenic pain \\
\hline & Myofascial syndrome & Spinal stenosis \\
\hline & $\begin{array}{l}\text { Internal disc disruption/discogenic pain/central } \\
\text { foraminal stenosis }\end{array}$ & \\
\hline \multicolumn{3}{|l|}{ Symptoms } \\
\hline \multirow{7}{*}{ Quality } & Dull, aching, deep & Sharp, shooting, superficial, lancinating \\
\hline & Like an expanding pressure & Like an electric shock \\
\hline & Poorly localized & Well localized \\
\hline & Covers a wide area & Extremity pain worse than axial pain \\
\hline & Axial pain or headache worse than extremity pain & Paraesthesia present \\
\hline & No paraesthesia & Well defined \\
\hline & No radicular pain or shooting pain & Radicular distribution \\
\hline \multirow{3}{*}{ Modification } & Worse with extension & Worse with flexion \\
\hline & $\begin{array}{l}\text { Better with flexion } \\
\text { Better with rest } \\
\end{array}$ & $\begin{array}{l}\text { Better with extension } \\
\text { May or may not improve with rest }\end{array}$ \\
\hline & No radicular pattern & Radicular pattern \\
\hline \multirow{3}{*}{ Radiation } & Low back to hip, thigh, groin & Follows nerve distribution \\
\hline & Radiation below elbow or knee unusual & Radiation below elbow or knee common \\
\hline & Quasi segmental & Radicular pattern \\
\hline \multicolumn{3}{|l|}{ Signs } \\
\hline Tenderness to Deep Palpation & $\begin{array}{l}\text { Moderate to severe paravertebral or midline and } \\
\text { paravertebral }\end{array}$ & $\begin{array}{l}\text { Moderate to severe midline and mild paravertebral } \\
\text { or midline only }\end{array}$ \\
\hline Sensory Alteration & Uncommon - only subjective & Probable - common \\
\hline \multirow{2}{*}{ Motor Changes } & Only subjective weakness & Objective weakness \\
\hline & Atrophy rare & Atrophy possibly present \\
\hline Reflex Changes & None & Commonly described, but seen only occasionally \\
\hline \multirow{2}{*}{ Straight Leg Raises } & Only low back pain & Reproduction of leg pain \\
\hline & No lumbar root tension signs & Positive root tension signs \\
\hline \multirow{2}{*}{ Spurling Test } & Neck pain only & Reproduction of radicular pain \\
\hline & No cervical root signs & Positive Spurling test \\
\hline
\end{tabular}

disc pathology are described in Table 7. Figure 10 shows pain diagrams of facet joint pain which may be similar to discogenic pain and/or disc herniation. Consequently, there are no definitive physical examination or historical signs that can reliably diagnose facet joint pain or predict response to facet joint blocks in individuals with chronic low back pain. However, pain that is not predominantly in the midline and possibly tenderness overlying the facet joints, appear to be weakly associated with a positive response to facet joint interventions. Overall, based on numerous publications, somatic/ axial pain with paravertebral tenderness, worse with exten- sion, associated with negative neurological symptoms and signs appear to be the features which support proceeding to diagnostic facet joint nerve blocks.

Arthritis or facet degeneration is usually found on multiple imaging tests, and is only a potential cause of low back pain without certainty (429-438). It has been shown that plain oblique radiography has a sensitivity of $55 \%$ and specificity of $69 \%$ in distinguishing between the presence and absence of degenerative disease confirmed with facet joint nerve blocks in 50 consecutive patients with low back pain (429). However, it also has been shown that oblique radiography was more specific 


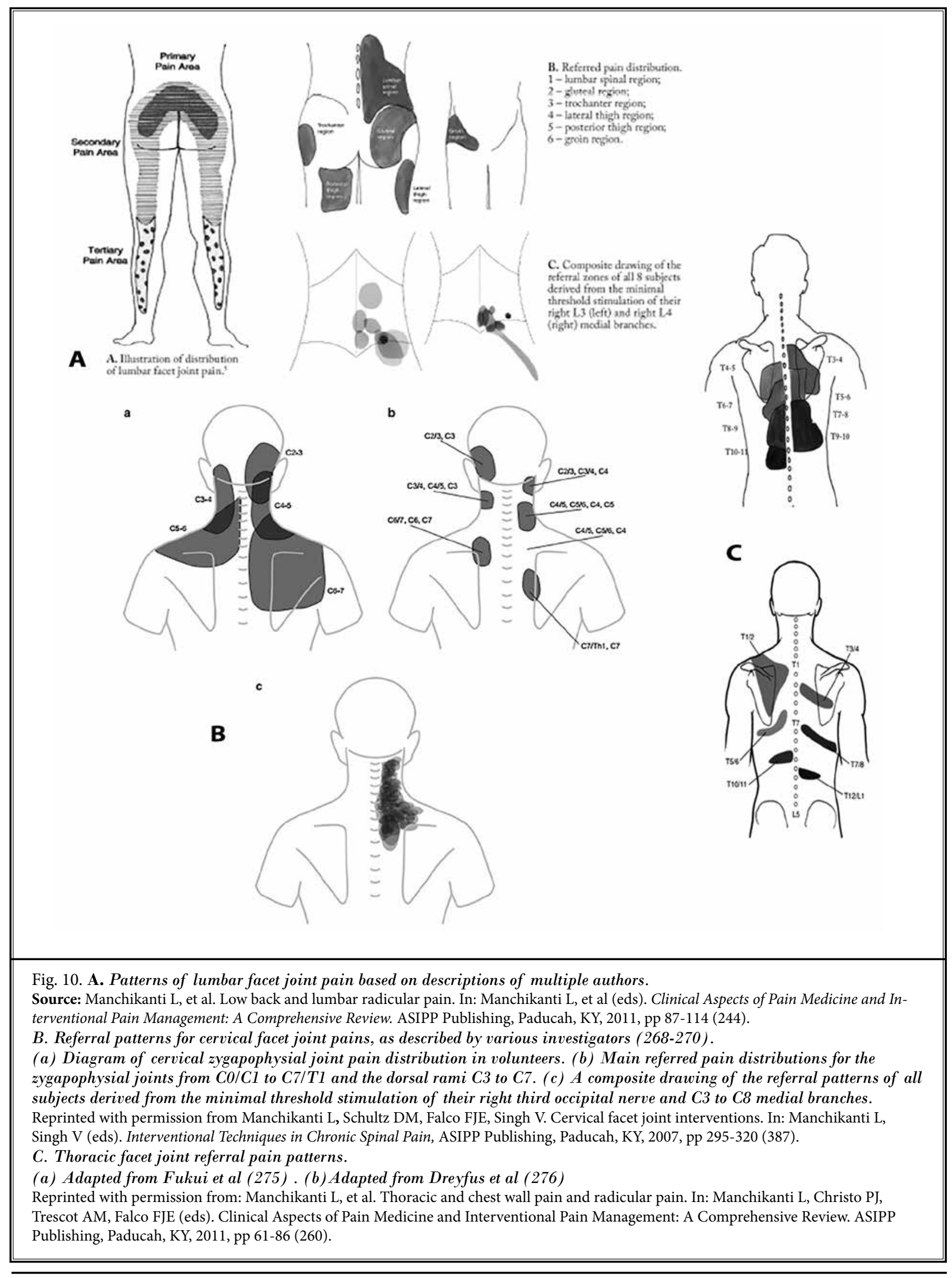


Table 8. Grading of facet joint arthritis based on the imaging tests.

\begin{tabular}{|l|l||}
\hline Grade 0 & Normal \\
\hline Grade 1 & $\begin{array}{l}\text { Mild degenerative disease: joint space narrowing less than } 2 \mathrm{~mm} \text { and/or small osteophytes and/or mild hypertrophy } \\
\text { of the articular process. }\end{array}$ \\
\hline Grade 2 & $\begin{array}{l}\text { Moderate degenerative disease: joint space narrowing }(<1 \mathrm{~mm}) \text { and/or moderate osteophytes and/or moderate } \\
\text { hypertrophy of the articular process and/or mild subarticular bone erosions. }\end{array}$ \\
\hline Grade 3 & $\begin{array}{l}\text { Severe degenerative disease: narrowing of the facet joint space and/or large osteophytes and/or severe hypertrophy } \\
\text { of the articular process and/or severe subarticular bone erosions and/or subchondral cysts and/or vacuum } \\
\text { phenomenon }\end{array}$ \\
\hline
\end{tabular}

Source: de Andrés Ares J, Gilsanz F. Diagnostic nerve blocks in the management of low back pain secondary to facet joint syndrome. Rev Esp Anestesiol Reanim 2019; 66:213-221 (392).

in distinguishing absent or mild disease from moderate or severe disease with $94 \%$, even though its sensitivity was far lower, at $23 \%$. Further interobserver agreement among the radiologists performing the plain radiology study was $57 \%$, but the discrepancy rate was $43 \%$ (429). The CT scan of patients with facet arthritis showed a kappa value of 0.46 , which represented perfect agreement in $63 \%$ of cases, and discrepancy in $27 \%$ (430). Further, both CT and MRI have been shown to be valid tools for detecting facet degeneration (430). Facet joint arthritis has been classified into 4 grades, according to the imaging tests $(429,430)$ as shown in Table 8 . However, Grade 2 and 3 degeneration patients may not have low back pain, and patients with Grade 0 and 1 arthritis may present with facet joint pain. Consequently, there is no correlation between specific imaging tests, CT and MRI or plain radiographs and the presence or absence of facet joint pain (431). However, Schwarzer et al (286) assessed the ability of CT to identify a painful zygapophysial joint in patients with chronic low back pain. Evaluation in 63 patients, CT and blocks of zygapophysial joints at 3 levels showed no correlation in patients with and without pain originating from the zygapophysial joint. They concluded that CT has no place in the diagnosis of lumbar zygapophysial joint pain.

Investigators were prompted to look at more complex imaging tests, such as scintography, however presenting contradictory results for the diagnosis of low back pain $(431,432,437)$. The most widely investigated imaging modality used to detect potentially painful facet joints is single photon emission computed tomography (SPECT), a nuclear medicine imaging technique performed with intravenous administration of a gamma-emitting radioisotope and involving considerable radiation exposure compared with conventional radiography. In fact, SPECT may be one of the most reliable tests for facet joint pathology as the quantity of emissions detected from the radionuclide provides a measure of biological activity, identifying active inflammation involving facet and other joints. In addition, scintigraphy is a similar technique that also requires administration of gamma-emitting radioisotope and uses external detectors. However, it generates only 2-dimensional images instead of 3-dimensional images as in SPECT. Multiple studies in the past have been conducted with SPECT, scintography, or CT utilizing controlled diagnostic blocks reporting mixed results regarding their correlation and predictive value (286,431-440).

SPECT was assessed with confirmatory medial branch blocks in at least 4 studies $(431,435,436,439)$. Freiermuth et al (431) in a randomized, double blind, placebo-controlled trial with inclusion of 29 patients with low back pain performed SPECT scans on all patients, following which patients were examined by a pain clinician. Based on the results of the clinical examination, the patients received a series of 3 fluoroscopically guided medial branch blocks with $0.5 \mathrm{~mL}$ of lidocaine $2 \%, 0.5 \%$ bupivacaine, or a placebo injection of sodium chloride solution. Three substances were injected randomly and the clinician was blinded to the injectate. They utilized a $70 \%$ pain relief or a numeric pain rating less than 3 as a criterion standard. The entire series of 3 blocks were considered to be negative if $\geq 50 \%$ pain reduction was reported following a placebo injection. Following completion of the first series of blocks, $24 \%$ (7 of 29) of patients had a positive response and $76 \%$ (22 of 29) had a negative response. Among individuals who had positive blocks, 4 of 7 had positive SPECT scans, with a sensitivity of $57 \%$, and 17 of 22 had negative SPECT scans with a specificity of $77 \%$. A second series of blocks was also performed in 6 patients, 2 of whom had a positive response. The authors concluded that SPECT should not be recommended as a first line diagnostic tool prior to facet joint interventions.

The second RCT was by Jain et al (435) involving 80 patients. Forty patients were randomized to receive 
SPECT scan prior to diagnostic block. The group not receiving SPECT were solely based on clinical assessment. Facet joint blocks were performed utilizing $0.6 \mathrm{~mL}$ of a local anesthetic, with a positive block defined as $\geq 50 \%$ pain reduction 4 hours after the block was completed. In the SPECT scan group, 7 of 40 patients were diagnosed with facet arthropathy, while 14 of 40 patients in the control group had a similar diagnosis. In the SPECT scan group, $71 \%$ (5 of 7) had a positive facet joint nerve block compared to $43 \%$ (6 of 14) in the control group. Between the groups, response rate to facet joint blocks was statistically significant. Thus, this study is in favor of SPECT prior to performing diagnostic facet joint blocks.

However, in another observational study (436), the authors performed facet joint nerve blocks in 30 patients with chronic low back pain with and without facet joint positive SPECT cases. The primary outcome measure of pain relief was $\geq 50 \%$ pain reduction on VAS at weeks 2 and 4 following the facet joint nerve blocks. All facet joint nerve blocks were performed using ultrasound guidance and the injectate consisted of $2 \mathrm{~mL}$ of lidocaine $1 \%$ and triamcinolone $30 \mathrm{mg}$. At week 2 follow-up, $85.7 \%$ (24 of 28) of patients in the SPECT scan positive group reported $\geq 50 \%$ pain reduction compared with $20 \%$ in the SPECT negative group. At 4-week follow-up, $78.6 \%$ in the SPECT-positive group reported $\geq 50 \%$ pain reduction compared with none in the SPECT-negative group. Overall, these results also appear to be positive. However, these were not performed for diagnostic purposes.

Facet joint intraarticular injections were also performed in 2 prospective, open-label studies. In the first study by Pneumaticos et al (437), 47 patients were randomized in 2:1 ratio to receive a SPECT scan prior to fluoroscopically-guided intraarticular facet joint injection or no scan prior to intraarticular injection. Patients randomized to SPECT scan who had a positive SPECT scan were further categorized into positive and negative scans. The primary outcome measure was changed in pain scores at 1, 3, and 6 months following the injections. Fluoroscopically guided facet joint injections were performed with an injection of 2.5 $\mathrm{mL}$ of bupivacaine $0.5 \%, 0.5 \mathrm{~mL}$ of betamethasone, total dose of $3 \mathrm{mg}$. Change in pain scores was significantly greater in SPECT-positive group compared with SPECT-negative group and the group which has not had SPECT. The results were statistically significant at 3 months also. They speculated that SPECT was helpful in diagnosing facet joint pain and also was cost effective. However, follow-up cost effectiveness studies have not been conducted. Medicare reimbursement was reduced from $\$ 2,191$ to $\$ 1,865$, inclusive of imaging costs as per the cost per patient. In another study (436), 58 patients with a clinical diagnosis of facet joint pain received SPECT scans with 22 showing facet joint positive scans and 36 with negative scans. Outcome measures were at 1, 3, and 6 months included VAS pain scores, present pain intensity score, and the modified McGill Pain Questionnaire. Fluoroscopically guided intraarticular injections consisted of $1 \mathrm{~mL}$ of lidocaine $1 \%$ and methylprednisolone $40 \mathrm{mg}$. At 1 month and 3 months follow-ups, the patients who were positive on SPECT showed significantly greater reductions of pain. This was also considered as a positive study even though no diagnostic blocks were performed in these patients. Further, a group of authors (433) also have compared intraarticular facet joint injections and facet joint nerve blocks with a 12-week follow-up in patients with chronic low back pain who had lumbar facet joint positive SPECT scans. The results of this study showed at 12-week follow-up, $61 \%$ of the patients experienced $\geq 50 \%$ pain reduction in the intraarticular group compared with $26 \%$ (6 of 23) in the facet joint nerve blocks group. They calculated the sensitivity and specificity of facet joint SPECT scan in the intraarticular group as $79 \%$ and $70 \%$, respectively. In a prospective assessment, SPECT was assessed for sensitivity and specificity comparing with plain or scintigraphy for identifying patients likely to respond to intraarticular facet joint injections (434). In a study assessing facet joint pain in 43 patients, the sensitivity and specificity of planar scintigraphy for identifying intraarticular injection confirmed facet joint pain was $71 \%$ and $76 \%$, respectively. The sensitivity and specificity for SPECT was $100 \%$ and $71 \%$.

Perez-Roman et al (439) also assessed the use of SPECT for hypermetabolic facet identification in diagnosis of cervical and axial low back pain. In this retrospective review of adult patients, 190 patients underwent high resolution SPECT/CT imaging. A total of 85 patients (48\%) demonstrated zygapophysial joint hypermetabolism on SPECT imaging. A total of 202 hypermetabolic facets were identified, indicating the average number of facets with facet joint pain was $2.38 \pm 1.91$. Of the patients with a positive scan, lumbar facets were most commonly affected $(69 \%)$, followed by cervical ( $24 \%)$ and thoracic region $(6 \%)$.

The level of evidence is II in selecting patients for facet joint nerve blocks at least 3 months after onset and failure of conservative management who are with 
axial pain, tenderness over the facet joints, reduced range of motion, pain reduction with rest, and absence of radicular pattern, with strong strength of recommendation for physical examination and assessment.

The level of evidence is $\mathrm{I}$, with strong strength of recommendation, for mandatory fluoroscopic or CT guidance for all facet joint interventions.

The level of evidence is IV for accurate diagnosis of facet joint pain with physical examination based on symptoms and signs, with weak strength of recommendation.

The level of evidence is III supporting the use of SPECT for identifying painful lumbar facet joints prior to diagnostic facet joint nerve blocks. However, the cost effectiveness of SPECT is not established; strength of recommendation is weak.

The level of evidence is $\mathbf{V}$ with weak strength of recommendation for scintography, MRI and $\mathrm{CT}$, for identifying painful facet joints.

\subsection{Diagnostic Facet Joint Interventions}

Key Question 5: What is the evidence of diagnostic accuracy and value of interventional procedures in the diagnosis of facet joint pain?

It has been postulated that facet joint degeneration can result from abnormal motion associated with spondylolisthesis, vertical loading from disc degeneration as well as arthritis, similar to that seen in other synovial joints $(249,367,368,370,441)$. The following have been put forth to be the basis for pain: an osteophyte impinging on a nerve, a capsule being stretched, synovial villi being trapped within articular surfaces, and chemicals that cause an inflammatory reaction $(249,351,367,369,370,372-374,441)$. Facet joints also have been shown to be richly innervated by the medial branches of the dorsal rami (311-327). In addition to this innervation, neuroanatomic, neurophysiologic, and biomechanical studies have shown that facet joints have both free and encapsulated nerve endings and that they also have nerves that contain substance $P$ as well as calcitonin gene-related peptide (CGRP) (328-359).

Based on the postulates of Bogduk (252), spinal facet joints have been shown to have an abundant nerve supply (311-327); to be capable of causing persistent pain $(6,18,19,22,24,244,258-276,279-281,328$ $359,387)$; to be affected by osteoarthritis, rheumatoid arthritis, spondylitis, degeneration, inflammation, and injury which in turn leads to a restriction of motion and pain upon motion $(6,18,249,279-281,351,367,369,372$ -
374,429-439); and using reliable and valid diagnostic techniques have been determined to be a source of pain $(6,18,19,22,24,244,259,260,279-294,415)$. Consequently, controlled local anesthetic blocks of spinal facet joints or medial branch blocks are employed to diagnose facet joint pain.

The reasoning behind this is that a painful joint will cease being painful for the local anesthetic's duration of action, whereas anesthetic blockade of a nonpainful joint will not alter the pain report. By repeating the block with an anesthetic agent that has a different duration of action reproducing the analgesic response, it increases the probability that the blocked joint is the actual source of pain. Thus, to ensure accuracy and validity, these blocks must be controlled and verified for delivery of a local anesthetic agents and eliminate placebo response $(6,18,19,22,244,259,260,279$ 294,415,421,441-454). A single facet joint injection is not recommended, since it cannot control for a false-positive response, even though some have advocated therapeutic interventions without any diagnostic blocks $(95,455-459)$. The diagnostic accuracy of facet joint nerve blocks has been demonstrated with longterm follow-up $(6,18,19,22,24,34,35,446,448)$. However, multiple manuscripts have been published opposing the accuracy of diagnostic facet joint nerve blocks $(23,165,411,414,455-459)$.

Multiple systematic reviews have supported the value and validity of diagnostic facet joint nerve blocks. Apart from systematic reviews performed by interventional pain physicians (18), Rubenstein and van Tulder (445) wrote a systematic review in 2008 concluding that there was strong evidence for the diagnostic accuracy of facet joint blocks in evaluating spinal pain. Since then, multiple other studies have been published only improving the diagnostic value and validity.

A true placebo control for nerve blocks has been extremely difficult to achieve and thus far, true placebo control trials have not been performed. Further objections have arisen from those who oppose diagnostic interventions in general $(6,18,22,24,163-165)$. The emotions of those in favor of diagnostic injections also run high, describing these opponents as embracing diagnostic nihilism towards spinal pain (391).

\subsection{Methods}

The methodology utilized in this guideline preparation followed the systematic review process derived from Standards for Reporting of Diagnostic Accuracy Studies (STARD) initiative (460), evidence based systematic re- 
views and diagnostic accuracy studies $(6,16-22,390,461$ 467). All systematic reviews and diagnostic accuracy studies evaluating spinal facet joint pain of cervical, thoracic, and lumbar facet joints were considered.

\subsubsection{Literature Search}

All available literature in all languages from all countries providing appropriate management with outcome evaluations were considered for inclusion. Searches were performed from the following sources without language restrictions:

1. PubMed from 1966 www.ncbi.nlm.nih.gov/sites/ entrez?db=pubmed

2. Cochrane Library www.thecochranelibrary.com/ view/0/index.html

3. Google Scholar https://scholar.google.com/

4. US National Guideline Clearinghouse (NGC) www. guideline.gov/

5. Previous systematic reviews and cross references

6. Clinical Trials clinicaltrials.gov/

7. All other sources including non-indexed journals and abstracts

The search period was from 1966 through March 2020.

\subsubsection{Search Strategy}

The search strategy emphasized chronic cervical, mid back, and low back pain, facet or zygapophysial joint pain, cervical, thoracic, and lumbar facet joint interventions, and diagnostic cervical, thoracic, and lumbar facet joint nerve blocks.

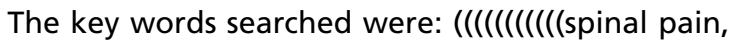
chronic low back pain) OR chronic back pain) OR chronic neck pain) OR facet joint pain) OR lumbosciatic pain) OR postlaminectomy) OR lumbar surgery syndrome) OR cervical post surgery syndrome OR spinal stenosis) OR zygapophysial)) AND ((((((facet joint) OR zygapophyseal) OR zygapophysial) OR medial branch block) OR diagnostic block) OR intraarticular))

This systematic review of the diagnostic accuracy of facet joint injections focused on the studies of prevalence and false-positive rates. All other studies were reviewed for their influence on diagnostic accuracy. Only cervical, thoracic, and lumbar facet joint nerve blocks performed under fluoroscopy or CT imaging techniques were evaluated. If the blocks were performed with any other imaging method, or if performed blindly, the study was excluded. All studies using controlled diagnostic blocks in all languages from all sources describing appropriate outcome evaluations with proper statistical evaluations were reviewed. Reports without an appropriate diagnosis, nonsystematic reviews, book chapters, and case reports were excluded.

\subsubsection{Data Collection and Analysis}

The methodology and process of this systematic review were based on STARD initiative (460), previous systematic reviews (18,20-22), and quality assessment tools (465-467). The quality of each individual article used in this assessment was based on the Quality Appraisal of Reliability Studies (QAREL) checklist (Appendix Table 1) $(18,20-22,460-464)$. This checklist has been validated and utilized in multiple systematic reviews (18,20-22,460-464). The final selected studies had their quality and applicability assessed with a 12-item checklist. Expert methodologists signed off on the checklist's face validity (465-467). This checklist was also developed in accordance to STARD (460) and the Quality Assessment of Diagnostic Accuracy Studies (QUADAS) (465) appraisal tool. Each checklist item was assessed independently and given a grade of "yes," "no," "unclear," or "not applicable."

\subsubsection{Inclusion and Exclusion Criteria}

Only studies utilizing controlled diagnostic blocks either with placebo, comparative local anesthetic blocks or single blocks, with appropriate assessment and statistical evaluation were utilized. Further, studies scoring at least 4 on a scale of 12 on the Quality Appraisal Tool for Studies of Diagnostic Reliability (QAREL) were utilized for diagnostic accuracy analysis (465-467).

\subsubsection{Data Extraction and Management}

Two review authors working independently, in an unblinded standardized manner, developed search criteria, searched for relevant literature, selected the manuscripts and extracted the data from the included studies. Disagreements were resolved by discussion between the 2 reviewers; if needed, another author would resolve the dispute.

\subsection{Methodological Quality Assessment}

Methodological quality assessment was performed by multiple review authors with groups of 2 authors reviewing 4 to 6 manuscripts apiece. The assessment was carried out independently in an unblinded standardized manner to assess the methodological quality and internal validity of all the studies considered for inclusion. The methodological quality assessment was 
performed in a manner to avoid any discrepancies, but if any occurred, they were evaluated by a third reviewer and settled by consensus. Continued issues were also discussed with the entire group and resolved.

If any conflict of interest arose, including a reviewer assigned to review a manuscript he had written, that reviewer was not allowed to assess the manuscript's methodological quality.

The minimum acceptable relief was considered to be $\geq 50 \%$ as the cutoff threshold for a positive block during the performance of previously painful movements.

\subsection{Analysis of Evidence}

The analysis of the evidence was performed based on grading of evidence utilizing best evidence synthesis, developed with modification of multiple available criteria including those of the United States Preventive Services Task Force (USPSTF) criteria as illustrated in Table 1 (121).

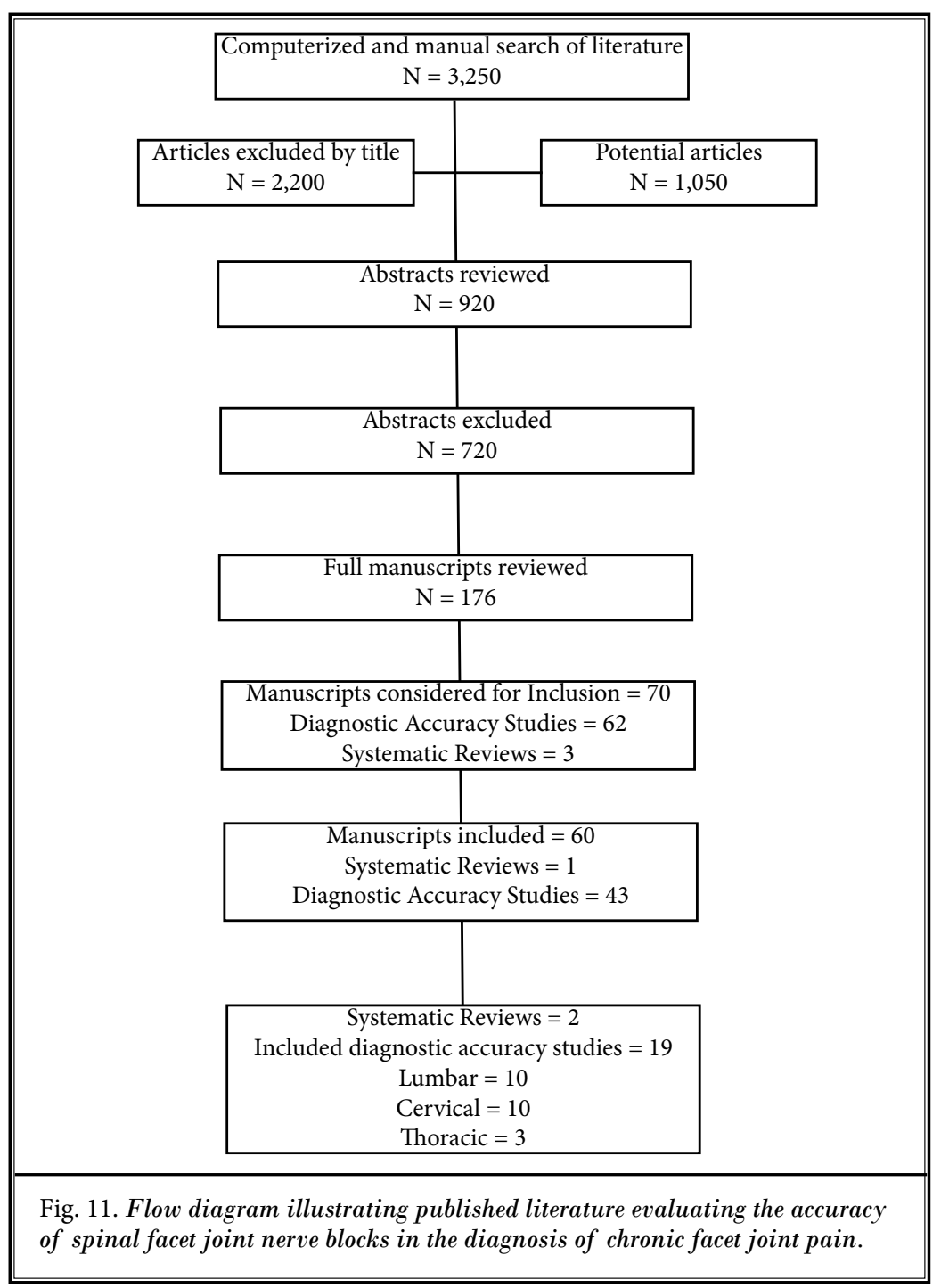

The basis for diagnostic facet joint nerve blocks lies in the fact that a painful joint will cease being painful upon the injection of a local anesthetic at least during the duration of pharmacological action of local anesthetic. However, anesthetic blockade of a nonpainful joint will not alter the pain report. In addition, by repeating the block with an anesthetic agent that has a different duration of action, most likely the one longer than the first one with short acting local anesthetic during the first block, followed by a longer acting local anesthetic during the second block, not only that analgesic response is reproduced, but it increases the probability that the blocked joint is the actual source of pain. Consequently, to ensure accuracy and validity, controlled comparative local anesthetic blocks and verification of the needle placement and delivery of local anesthetic agents to eliminate or significantly reduce placebo responses is mandatory $(6,18,19,22-24,165,411,414,441-$ $459,461,462)$. Consequently, a single facet joint injection or a nerve block may produce high false-positive responses and is not recommended for clinical utility.

\subsection{Results}

Figure 11 shows the study selection flow diagram. There were multiple studies considered for inclusion $(177,178,180,189$ $192,283-286,291,294,402,411-$ $415,420,421,426,446$ 448,452,453,455,468-499). Among these, 2 systematic reviews $(18,22)$ and 19 diagnostic accuracy studies (283-285,289,291,294,415,425,446,468$473,475-478,480)$ met the inclusion criteria for diagnostic accuracy with prevalence and/or false-positive rates. There were 10 studies in lumbar region (283-285,289,291,415,446,468471), 10 studies in cervical region 
(294,425,470-473,475-478), and 3 studies in thoracic region $(470,471,480)$.

Relevant studies assessing factors influencing the diagnostic accuracy were included with descriptions $\quad(177,178,189-192,286,402,411-415,421,446-$ $448,452,453,455,474,483,484,487-493)$.

\subsubsection{Methodological Quality Assessment}

Appendix Table 1 lists the QAREL criteria for carrying out the methodological quality assessment of included studies. Studies achieving at least 4 of 12 or higher scores were included. Scores of 8 of 12 or higher were considered to be high quality, while 4 to 7 were considered to be moderate quality.

The methodological quality assessment performed is detailed in Tables 9 and 10. A total of 19 studies meeting inclusion criteria were assessed (283$285,289,291,294,415,425,446,468-473,475,476-478,480)$.

\section{4 .2 Characteristics of Diagnostic Studies}

Characteristics of diagnostic accuracy studies are described in Table 11. Table 12 shows characteristics of studies that were not of diagnostic accuracy, but describing factors influencing diagnostic blocks and accuracy of diagnosis.

\section{4 .3 Lumbar Facet Joint Pain}

Table 13 shows the data of prevalence and false-positive rate of facet joint pain in the lumbar spine. There was a total of 10 studies (283-285,289,2 $91,415,448,468-471$ ) assessing the prevalence of lumbar facet joint pain. Only primary studies with assessment of prevalence and false-positive rates with $80 \%$ relief criterion standard were included.

Controlled diagnostic blocks were performed utilizing multiple criterion standards with $\geq 50 \%$, $\geq 75 \%$, and $\geq 80$. The criterion standards of $\geq 75 \%$ or $\geq 80 \%$ showed similar results. The 3 studies $(284,285,289)$ of prevalence and false-positive rate assessment in U.S. in younger population with post traumatic onset utilizing $50 \%$ pain relief as the criterion standard were of high quality, including over 230 patients and showing variable results. The first 2 studies performed by Schwarzer et al (284) showed variable prevalence rates based on the country and the population studied with $15 \%$ (284) and $40 \%$ with Australian study performed with intraarticular injection of saline (289) in older population, with a false-positive rate of $38 \%$ (285) in a third study in the population in the United States. Consequently, the evidence for $50 \%$ pain relief as the crite- rion standard when performed in certain populations appears to be good; however, another study following these pioneering studies with a large number of heterogenous patients in U.S. showed a high prevalence of $61 \%$ with a false-positive rate of $17 \%$ (448). In addition, authors of these studies utilized an acute pain model with duration of pharmacological action of local anesthetic rather than chronic pain model where it exceeds the pharmacological action of the local anesthetic. Thus, the evidence for $50 \%$ pain relief with controlled diagnostic blocks was not considered due to variable evidence despite 2 high quality studies due to internal inconsistency.

Four studies were performed utilizing $\geq 75 \%$ pain relief (presumably the majority with $\geq 80 \%$ relief) as the criterion standard $(291,415,468,469)$ with 656 patients in a heterogenous population with prevalence ranging from $30 \%$ to $45 \%$, and a false-positive rate of $31 \%$ to $45 \%$. All the 4 studies were performed in the United States in heterogenous population. Manchikanti et al $(415,468,469)$ utilized chronic pain approach with relief lasting beyond pharmacological duration of the action, whereas, DePalma et al (291) utilized $\leq 2$ hours for lidocaine and $\leq 8$ hours duration which is much shorter than in chronic pain patients.

The criterion standard of $80 \%$ pain relief was utilized in 4 studies $(283,446,470,471)$ in 1,802 patients that showed a prevalence ranging from $27 \%$ to $40 \%$ in a heterogenous population. All the patients assessed with $80 \%$ pain relief criterion standard were by Manchikanti and colleagues $(283,446,470,471)$. They utilized the standard of chronic pain with relief lasting beyond pharmacological duration of action of the local anesthetic for both lidocaine and bupivacaine. Further, Manchikanti et al also utilized lidocaine the shortacting local anesthetic initially followed by bupivacaine the longer-acting anesthetic in all the studies.

The evidence for accuracy of lumbar facet joint nerve blocks is Level I to II based on 10 diagnostic accuracy studies with 4 studies utilizing $\geq 80 \%$ criterion standard of pain relief with a prevalence rate of $27 \%$ to $40 \%$ with false-positive rates of $27 \%$ to $47 \%$, with moderate to strong strength of recommendation.

\subsubsection{Cervical Facet Joint Pain}

Table 14 shows the prevalence and false-positive rates of cervical facet joint nerve blocks in the assessment of facet joint pain in the neck with a total of 10 studies $(294,425,470-473,475-478)$, assessing the prevalence and/or false-positive rates of facet joint nerve 
Pain Physician: May/June 2020 23:S1-S127

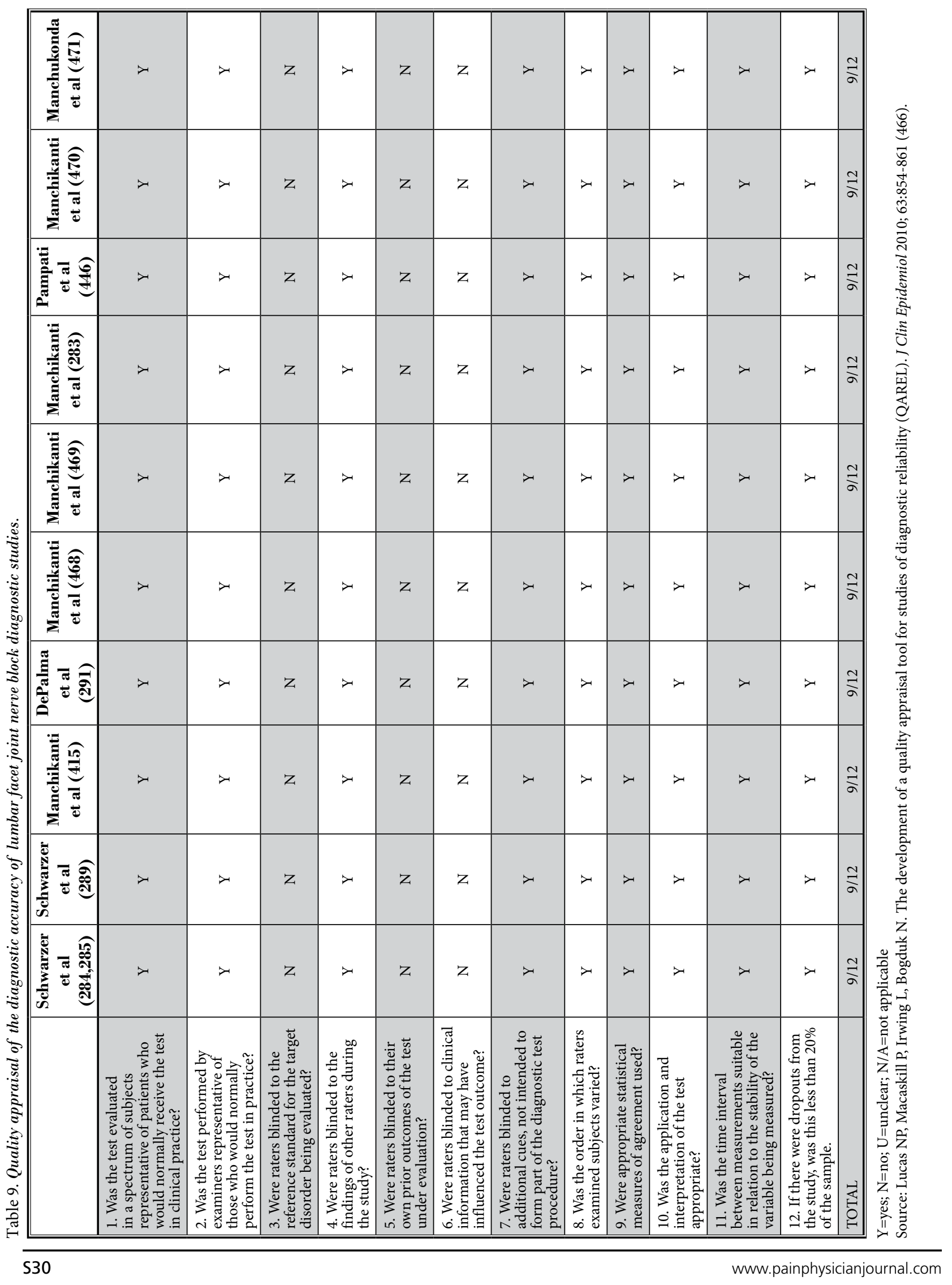


Facet Joint Interventions Guidelines 2020

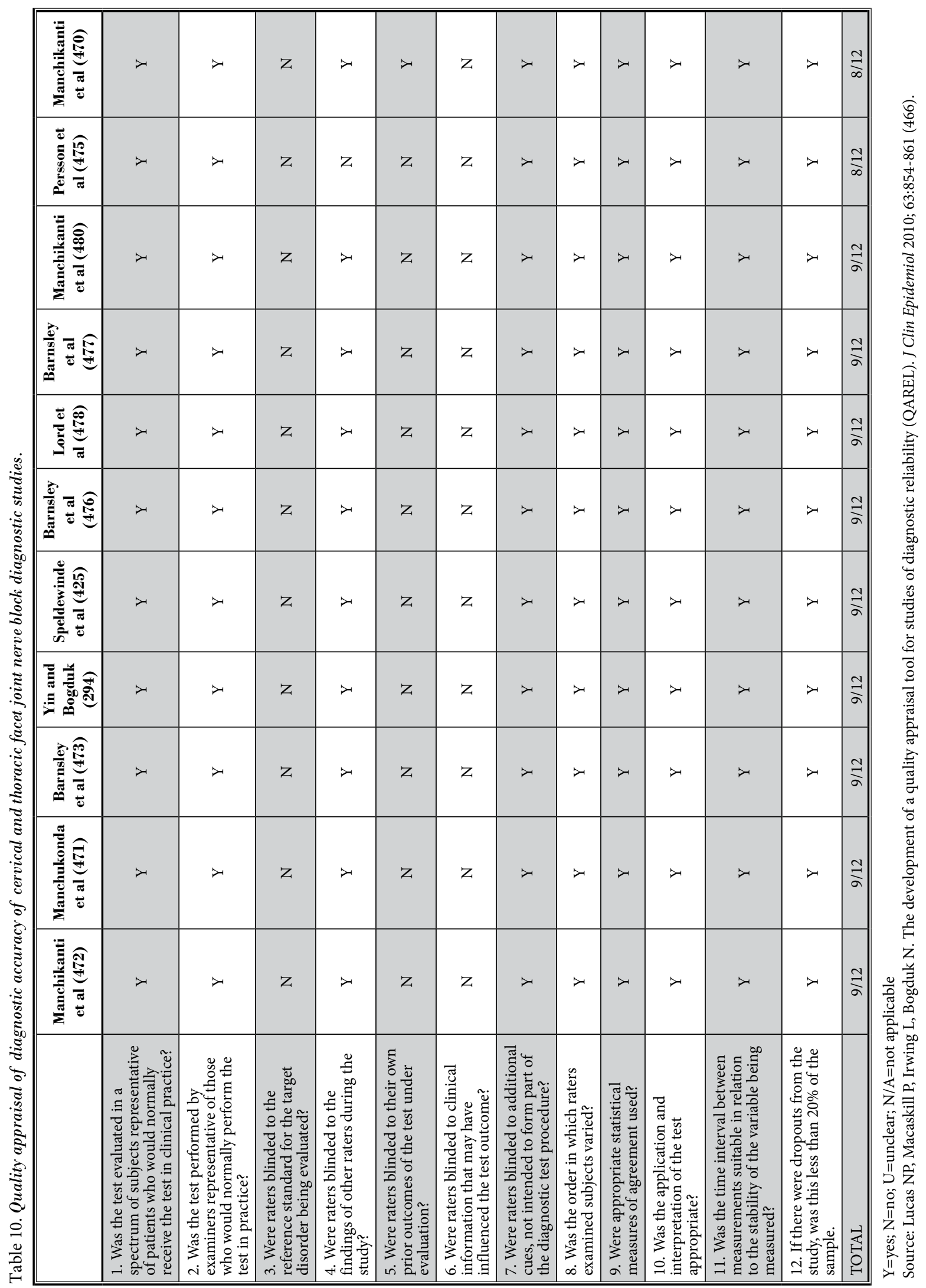




\begin{tabular}{|c|c|c|c|c|c|c|}
\hline 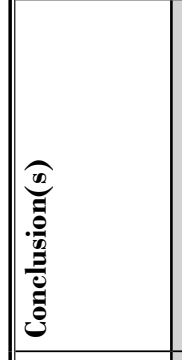 & 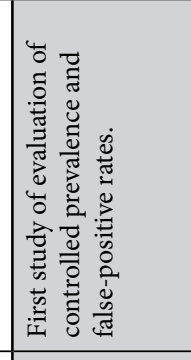 & 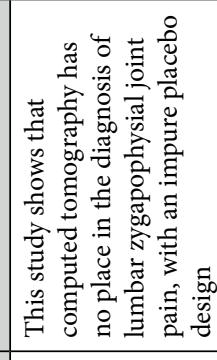 & 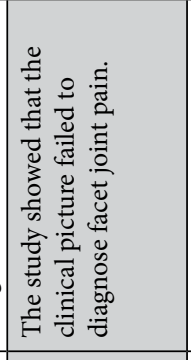 & 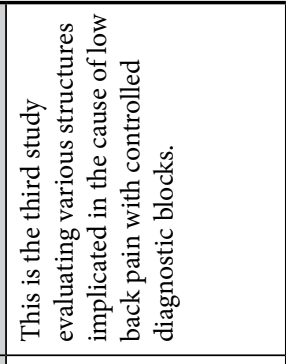 & 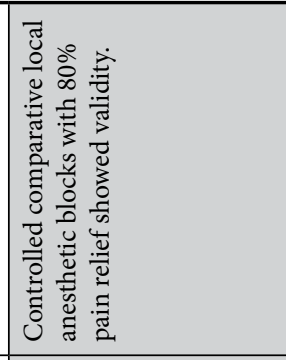 & 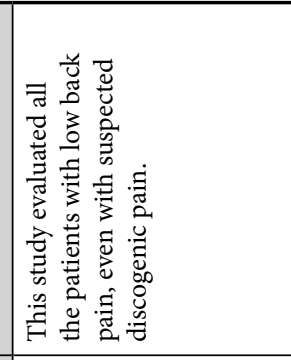 \\
\hline 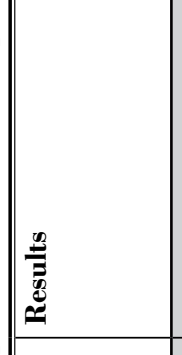 & 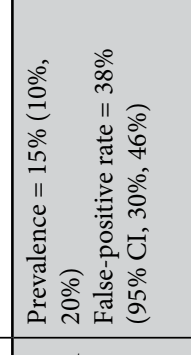 & 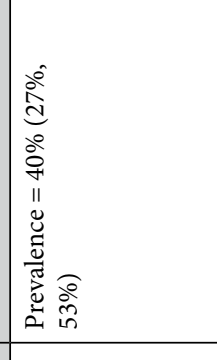 & 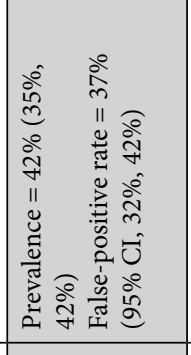 & 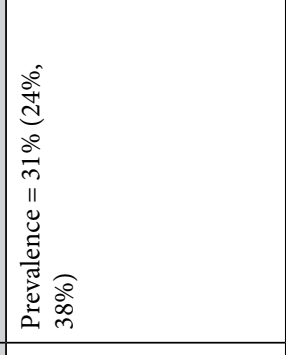 & 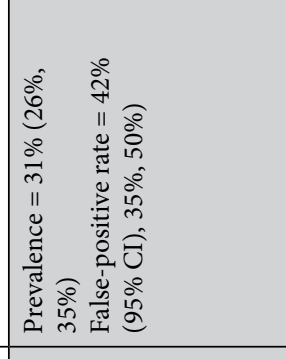 & 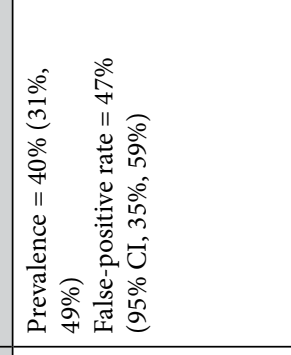 \\
\hline 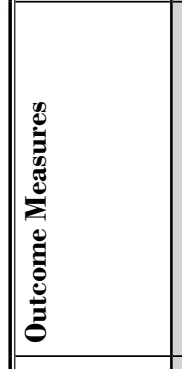 & 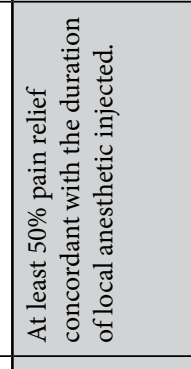 & 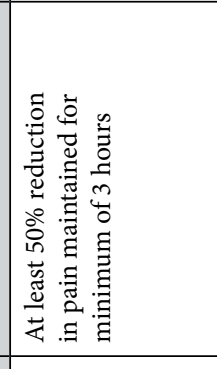 & 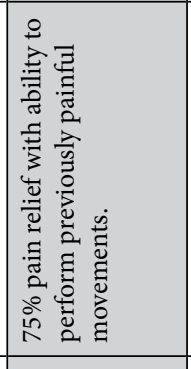 & 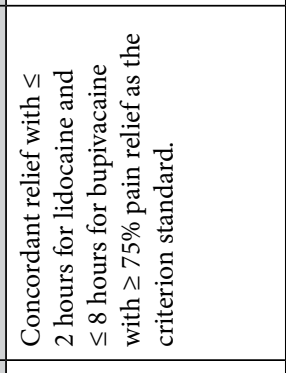 & 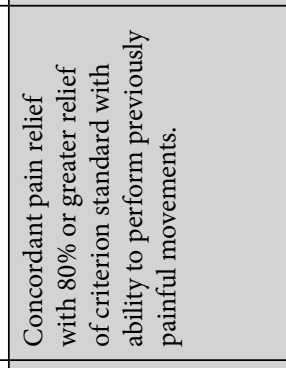 & 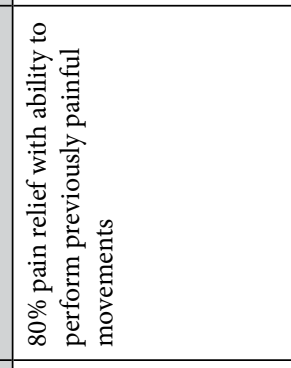 \\
\hline 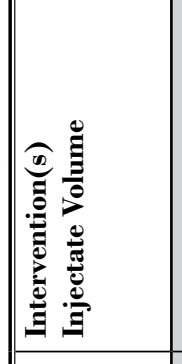 & 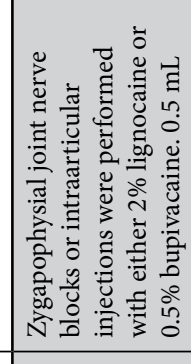 & 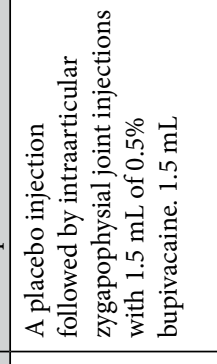 & 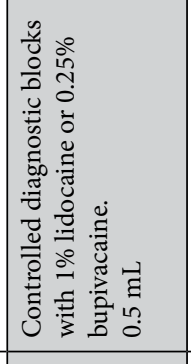 & 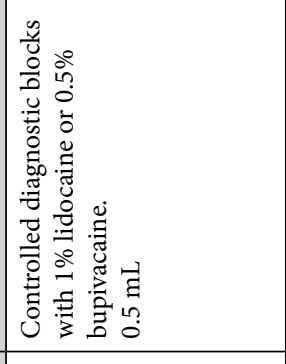 & 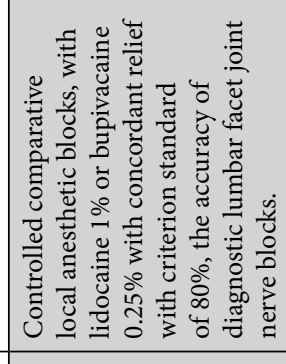 & 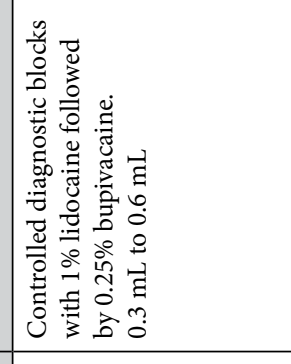 \\
\hline 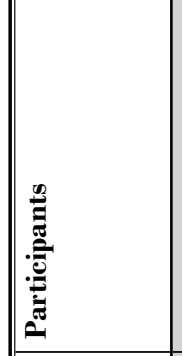 & 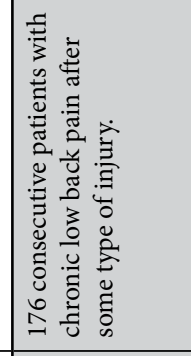 & 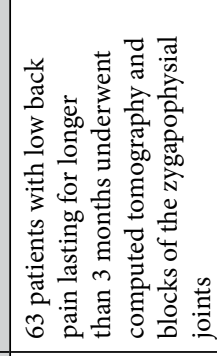 & 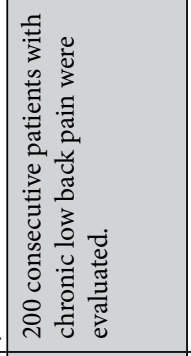 & 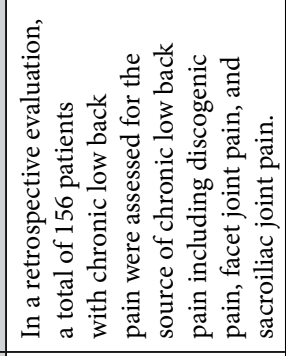 & 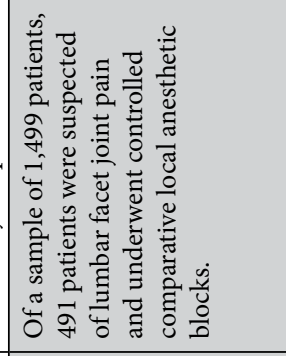 & 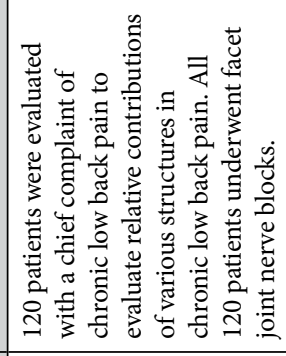 \\
\hline 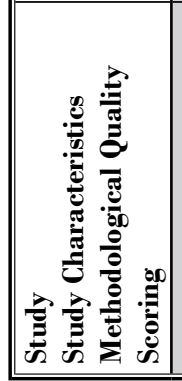 & 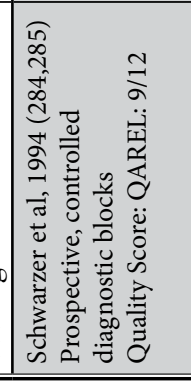 & 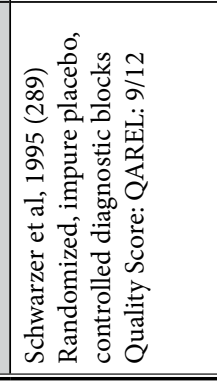 & 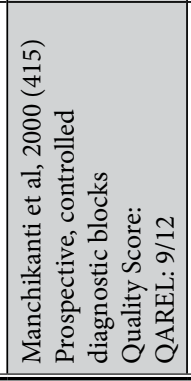 & 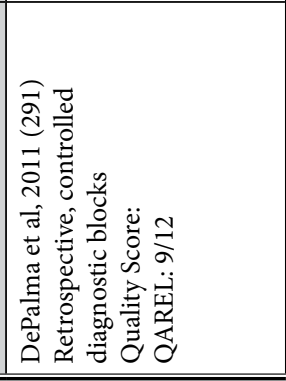 & 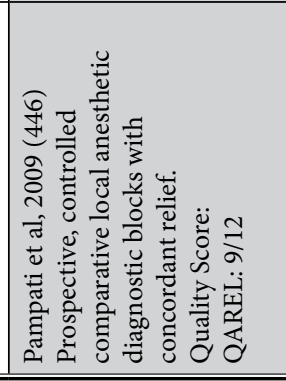 & 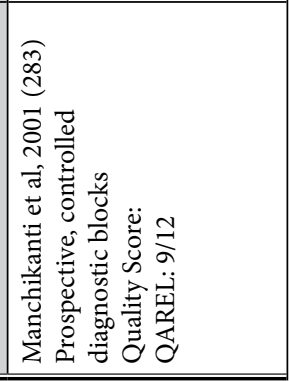 \\
\hline
\end{tabular}




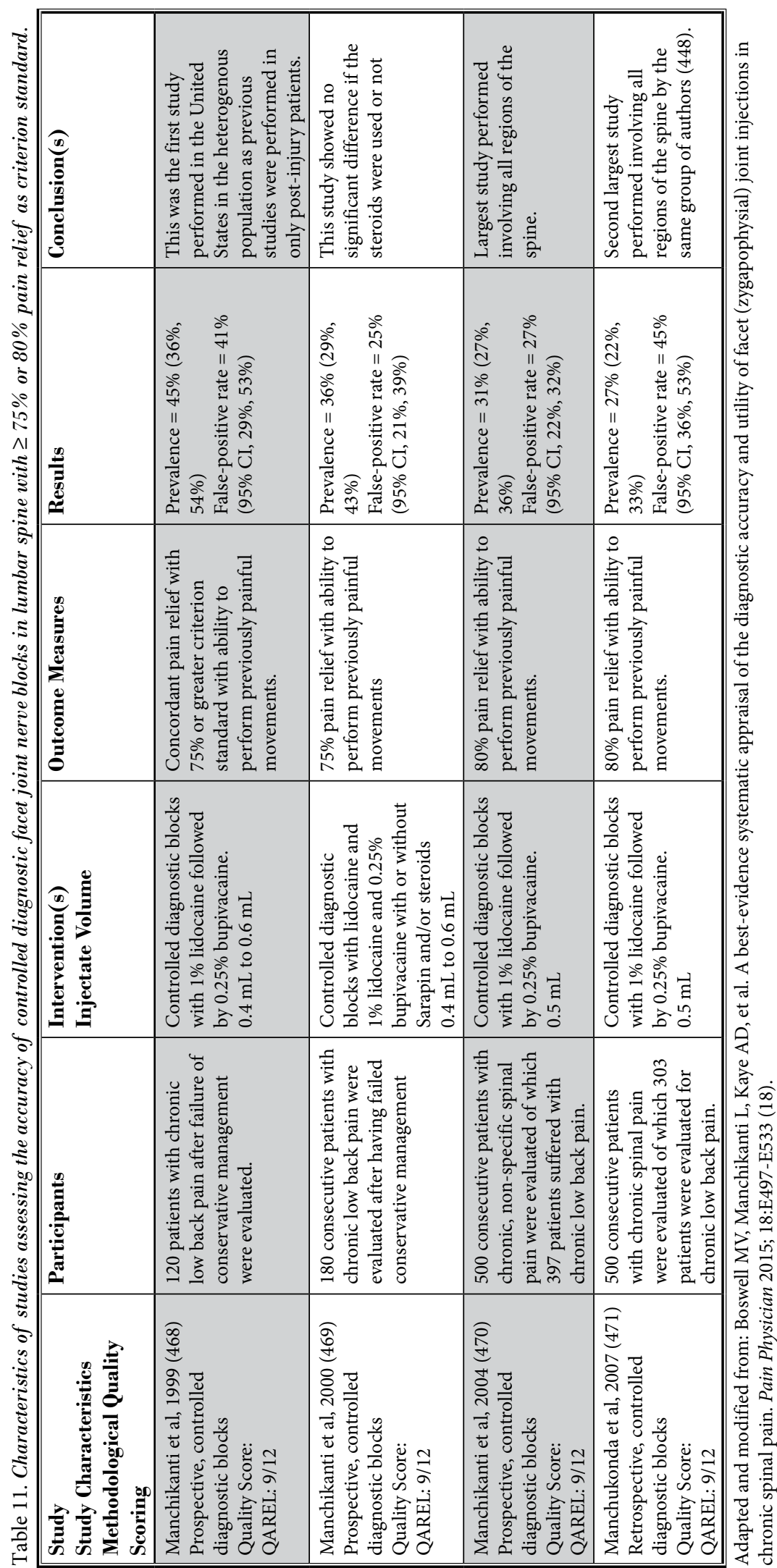

blocks with controlled diagnostic blocks in 1,117 patients. Six of 10 studies meeting inclusion criteria utilized criterion standard of $100 \%$ pain relief $(294,425,473,476-478), 3$ of the studies utilized $\geq 80 \%$ pain relief as the criterion standard $(470,471,475)$, whereas one study utilized $75 \%$ pain relief as the criterion standard (472). A total of 460 patients were included with $100 \%$ criterion standard and all of them utilized acute pain standard with a duration of pharmacological action of local anesthetic. Three studies utilizing $80 \%$ pain relief as the criterion standard included 551 patients $(470,471,475)$, whereas a single study which included $75 \%$ as the criterion standard included 106 patients (472). All the studies conducted by Manchikanti and colleagues (470-472) used chronic pain model with relief patterns lasting much longer than the duration of pharmacological activity. A single study by Persson et al (475) with $80 \%$ pain relief criterion also utilized acute pain relief model with duration of pharmacological action of local anesthetics.

Two studies by Manchikanti and colleagues $(470,471)$ with 251 and 255 patients assessed with $\geq$ $80 \%$ pain relief as the criterion standard showed variable results with prevalence of $39 \%$ or $55 \%$ and false positive rates of $45 \%$ or $63 \%$. These are the 2 studies performed with a chronic pain model. Manchikanti et al (472) also utilized $75 \%$ as the criterion standard with prevalence of $60 \%$ and false positive rate of $40 \%$. However, utilizing $100 \%$ pain relief in 6 studies, 5 of them determined the prevalence rate ranging from $36 \%$ to $60 \%$ $(294,425,473,476,478)$ and one study with false-positive rate of $27 \%$ (477). One study performed by 


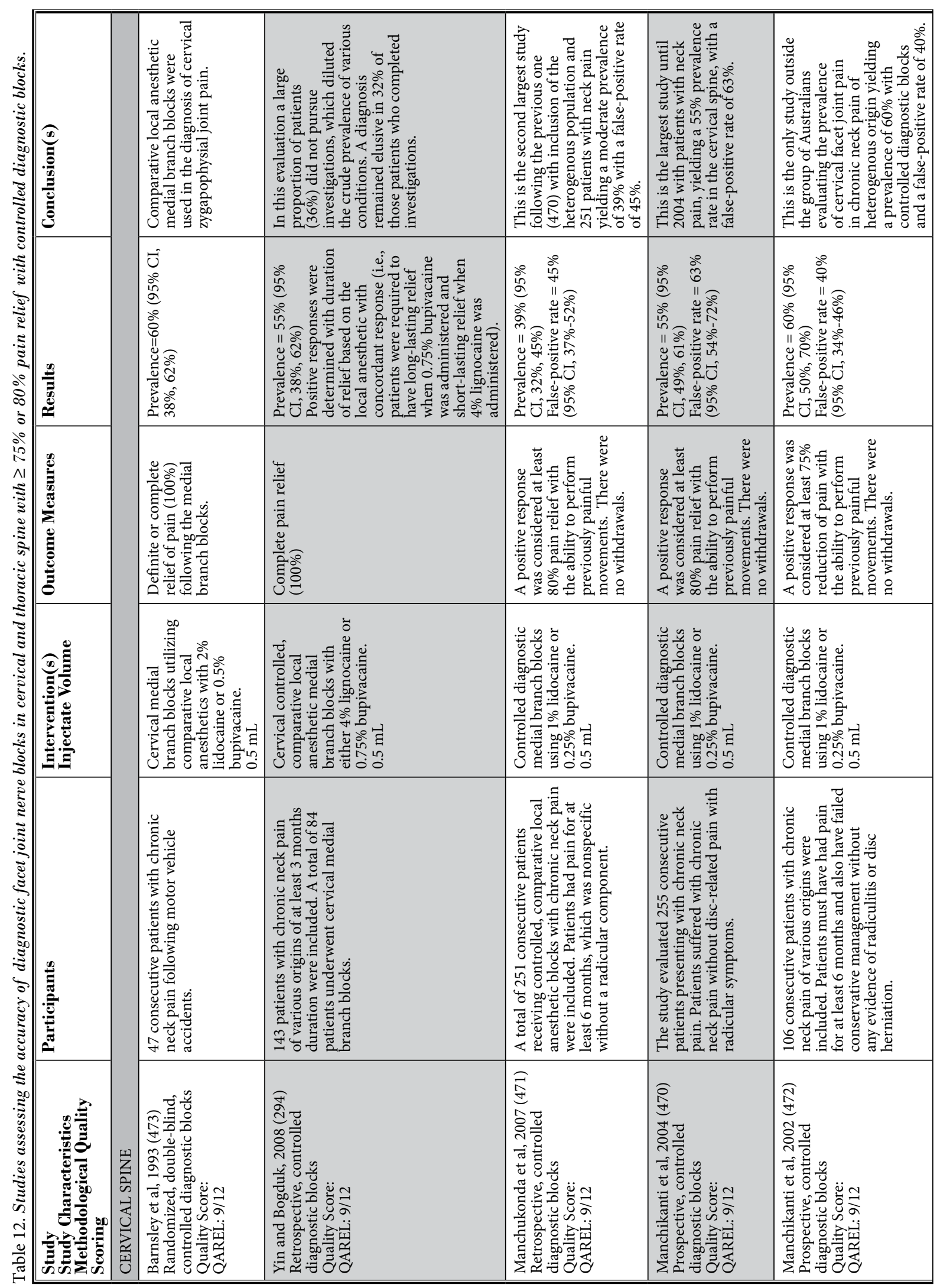


Facet Joint Interventions Guidelines 2020

\begin{tabular}{|c|c|c|c|c|c|}
\hline 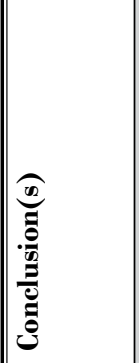 & 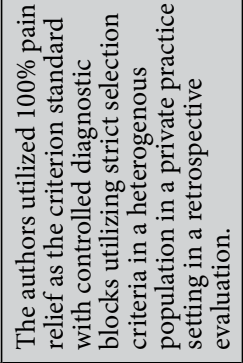 & 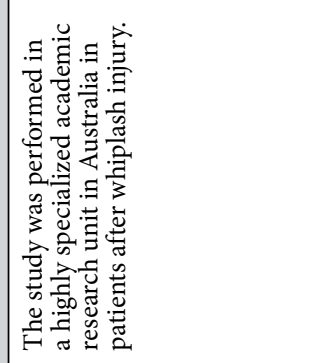 & 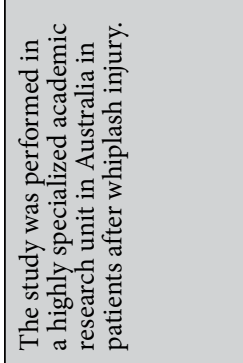 & 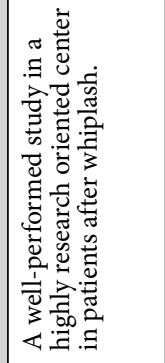 & 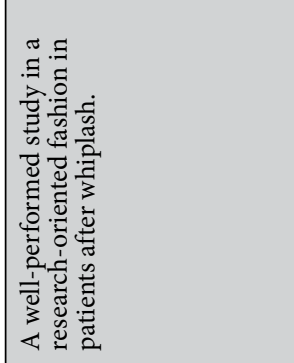 \\
\hline 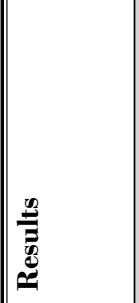 & 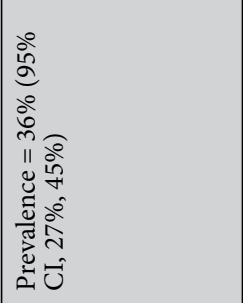 & 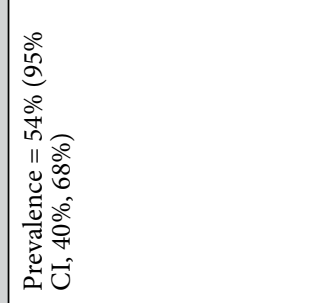 & 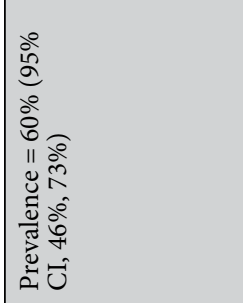 & 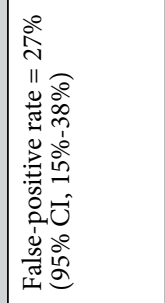 & 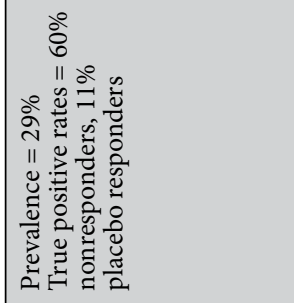 \\
\hline | & 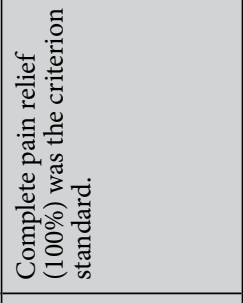 & 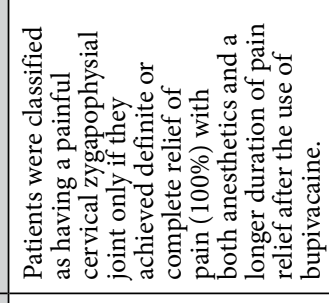 & 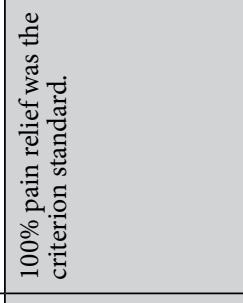 & 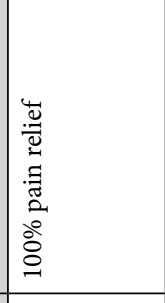 & 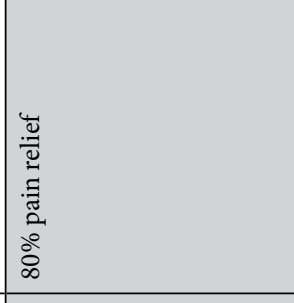 \\
\hline 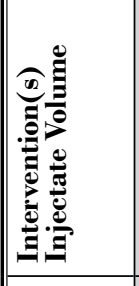 & 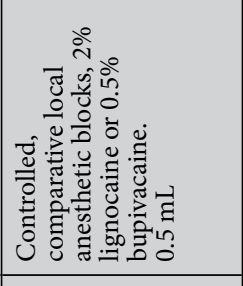 & 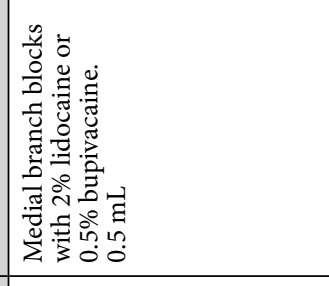 & 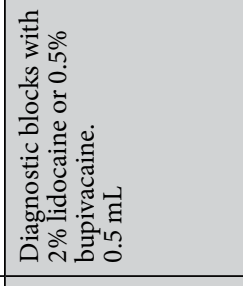 & 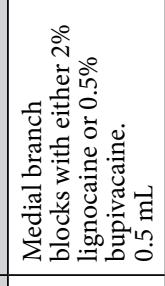 & 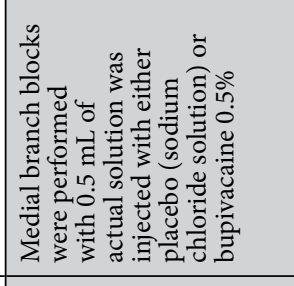 \\
\hline & 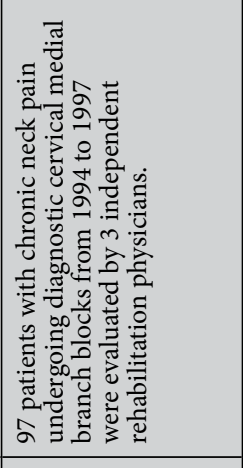 & 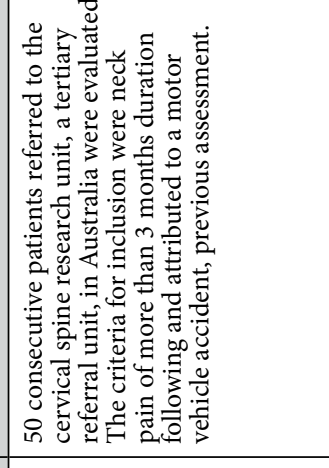 & 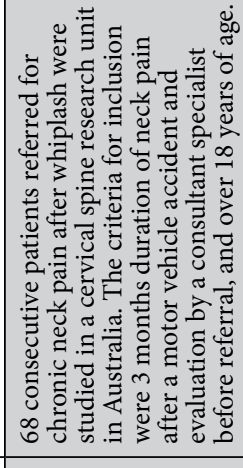 & 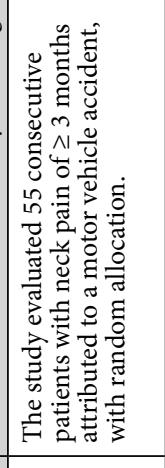 & 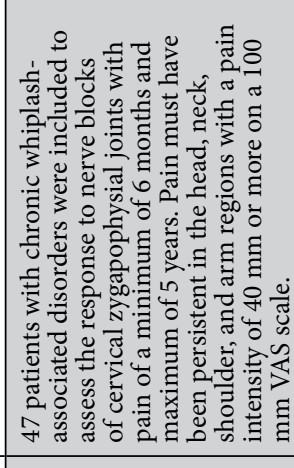 \\
\hline 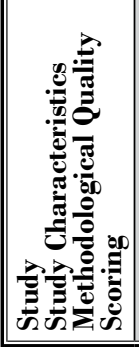 & 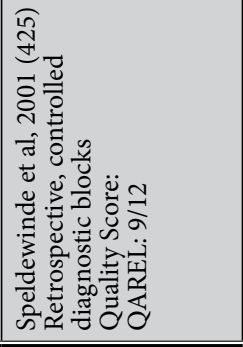 & 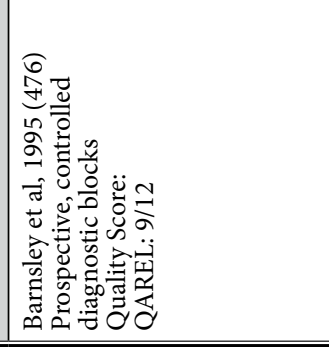 & 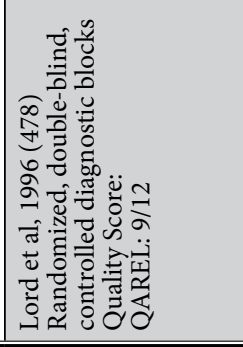 & 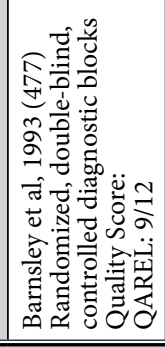 & 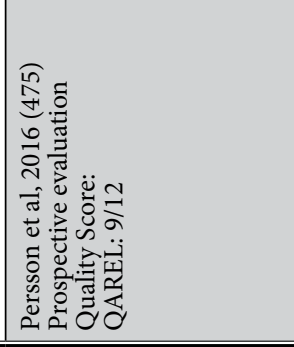 \\
\hline
\end{tabular}

www.painphysicianjournal.com 


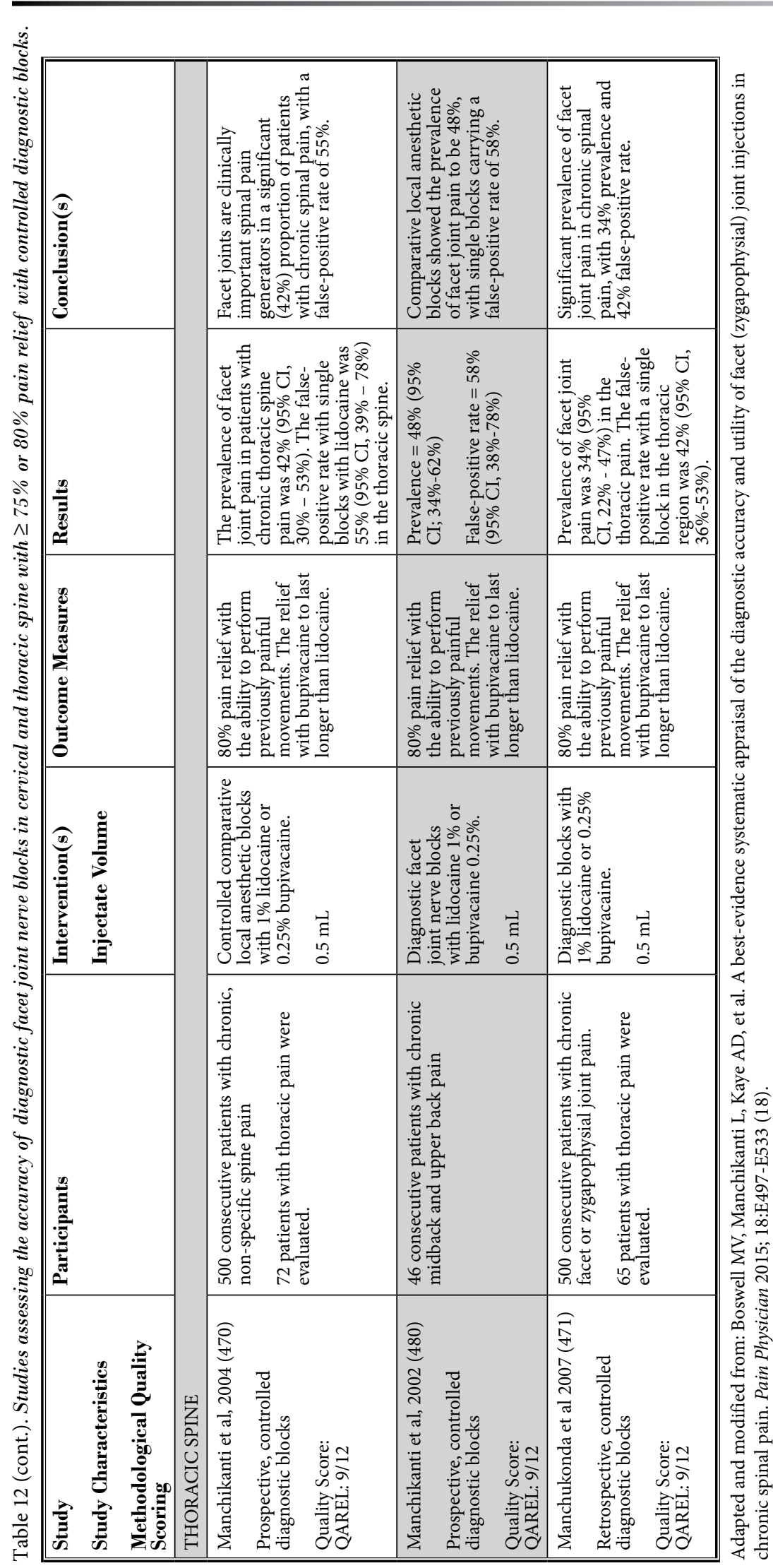

authors other than Bogduk's group or Manchikanti and colleagues with $80 \%$ criterion standard showed a prevalence of $29 \%$. Other authors, without involvement of Bogduk or Manchikanti, Speldewinde et al (425) also showed $36 \%$ prevalence.

Consequently, the evidence for dual blocks with controlled diagnostic blocks $\geq 80 \%$ or $100 \%$ criterion standard of cervical facet joint pain is Level II with multiple studies showing variable prevalence with internal inconsistency ranging from $36 \%$ to $60 \%$ and false-positive rates ranging from $27 \%$ to $63 \%$. The strength of recommendation for cervical facet joint nerve blocks in accurately diagnosing facet joint pain is moderate utilizing a controlled comparative local anesthetic block regimen in chronic pain with $\geq 80 \%$ relief criterion standard and relief lasting significantly longer than the pharmacological duration.

\subsubsection{Thoracic Facet Joint Pain}

Table 15 shows the data of prevalence and false-positive rates of thoracic facet joint pain by diagnostic blocks from 3 studies by the same group of clinicians $(470,471,480)$ in high quality studies with inclusion of 183 patients with $80 \%$ pain relief as the criterion standard with prevalence ranging from $34 \%$ to $48 \%$ and a falsepositive rate of $42 \%$ to $58 \%$.

The evidence for the accuracy of thoracic facet joint nerve blocks is Level II based on 3 high quality studies $(470,471,480)$ utilizing controlled comparative local anesthetic blocks and a chronic pain approach with relief lasting longer than pharmacological duration of action of local anesthetics used with a prevalence of $34 \%$ to $48 \%$ and a false-positive rate of $42 \%$ to $48 \%$. The strength of recommendation 
Facet Joint Interventions Guidelines 2020

Table 13. Data of prevalence and false-positive rate of facet joint pain by diagnostic blocks in the lumbar spine.

\begin{tabular}{||l|c|c|c|c|c|}
\hline \multicolumn{1}{|c|}{ Study } & $\begin{array}{c}\text { Methodological } \\
\text { Criteria Score }\end{array}$ & $\begin{array}{c}\text { Number of } \\
\text { Patients }\end{array}$ & $\begin{array}{c}\text { Criterion } \\
\text { Standard of } \\
\text { Percent Relief }\end{array}$ & $\begin{array}{c}\text { Prevalence Estimates } \\
\text { with 95\% Confidence } \\
\text { Intervals }\end{array}$ & $\begin{array}{c}\text { False-Positive Rate } \\
\text { with 95\% Confidence } \\
\text { Intervals }\end{array}$ \\
\hline Manchikanti et al (283) & $9 / 12$ & 120 & $\geq 80 \%$ & $40 \%(31 \%, 49 \%)$ & $47 \%(95 \% \mathrm{CI}, 35 \%, 59 \%)$ \\
\hline Pampati et al (446) & $9 / 12$ & 491 & $\geq 80 \%$ & $31 \%(26 \%, 35 \%)$ & $42 \%(95 \% \mathrm{CI}, 35 \%, 50 \%)$ \\
\hline Manchikanti et al (470) & $9 / 12$ & 397 & $\geq 80 \%$ & $31 \%(27 \%, 36 \%)$ & $27 \%(95 \% \mathrm{CI}, 22 \%, 32 \%)$ \\
\hline Manchukonda et al (471) & $9 / 12$ & 303 & $\geq 80 \%$ & $27 \%(22 \%, 33 \%)$ & $45 \%(95 \% \mathrm{CI}, 36 \%, 53 \%)$ \\
\hline Manchikanti et al (415) & $9 / 12$ & 200 & $\geq 75 \%$ & $42 \%(35 \%, 42 \%)$ & $37 \%(95 \% \mathrm{CI}, 32 \%, 42 \%)$ \\
\hline DePalma et al (291) & $9 / 12$ & 156 & $\geq 75 \%$ & $31 \%(24 \%, 38 \%)$ & $\mathrm{NA}$ \\
\hline Manchikanti et al (468) & $9 / 12$ & 120 & $\geq 75 \%$ & $45 \%(36 \%, 54 \%)$ & $41 \%(95 \% \mathrm{CI}, 29 \%, 53 \%)$ \\
\hline Manchikanti et al (469) & $9 / 12$ & 180 & $\geq 75 \%$ & $36 \%(29 \%, 43 \%)$ & $25 \%(95 \% \mathrm{CI}, 21 \%, 39 \%)$ \\
\hline Schwarzer et al (284,285) & $9 / 12$ & 176 & $\geq 50 \%$ & $15 \%(10 \%, 20 \%)$ & $38 \%(95 \% \mathrm{CI}, 30 \%, 46 \%)$ \\
\hline Schwarzer et al (289) & $9 / 12$ & 57 of 63 & $\geq 50 \%$ & $40 \%(27 \%, 53 \%)$ & $\mathrm{NA}$ \\
\hline
\end{tabular}

$\mathrm{NA}=$ not applicable; $\mathrm{CI}=$ confidence interval

Adapted and modified from: Boswell MV, Manchikanti L, Kaye AD, et al. A best-evidence systematic appraisal of the diagnostic accuracy and utility of facet (zygapophysial) joint injections in chronic spinal pain. Pain Physician 2015; 18:E497-E533 (18).

Table 14. Data of prevalence and false-positive rate of facet joint pain by diagnostic blocks in the cervical spine.

\begin{tabular}{||l|c|c|c|c|c||}
\hline \multicolumn{1}{|c|}{ Study } & $\begin{array}{c}\text { Methodological } \\
\text { Criteria Score }\end{array}$ & $\begin{array}{c}\text { Number of } \\
\text { Patients }\end{array}$ & $\begin{array}{c}\text { Criterion } \\
\text { Standard of } \\
\text { Percent Relief }\end{array}$ & $\begin{array}{c}\text { Prevalence Estimates } \\
\text { with 95\% Confidence } \\
\text { Intervals }\end{array}$ & $\begin{array}{c}\text { False-Positive Rate } \\
\text { with 95\% Confidence } \\
\text { Intervals }\end{array}$ \\
\hline Barnsley et al (473) & $9 / 12$ & 47 & $100 \%$ & $60 \%$ & NA \\
\hline Yin and Bogduk (294) & $9 / 12$ & 143 & $100 \%$ & $55 \%(95 \%$ CI, 38\%, 62\%) & NA \\
\hline Speldewinde et al (425) & $9 / 12$ & 97 & $100 \%$ & $36 \%(95 \%$ CI, 27\%, 45\%) & NA \\
\hline Barnsley et al (476) & $9 / 12$ & 50 & $100 \%$ & $54 \%(95 \%$ CI, $40 \%, 68 \%)$ & NA \\
\hline Lord et al (478) & $9 / 12$ & 68 & $100 \%$ & $60 \%(95 \%$ CI, $46 \%, 73 \%)$ & NA \\
\hline Barnsley et al (477) & $9 / 12$ & 55 & $100 \%$ & NA & $27 \%(95 \%$ CI, $15 \%-38 \%)$ \\
\hline Persson et al (475) & $9 / 12$ & 45 & $\geq 80 \%$ & $29 \%$ & NA \\
\hline Manchukonda et al (471) & $9 / 12$ & 251 of 500 & $\geq 80 \%$ & $39 \%(95 \% \mathrm{CI}, 32 \%, 45 \%)$ & $45 \%(95 \% \mathrm{CI}, 37 \%-52 \%)$ \\
\hline Manchikanti et al (470) & $9 / 12$ & 255 of 500 & $\geq 80 \%$ & $55 \%(95 \% \mathrm{CI}, 49 \%, 61 \%)$ & $63 \%(95 \% \mathrm{CI}, 54 \%-72 \%)$ \\
\hline Manchikanti et al (472) & $9 / 12$ & 106 & $\geq 75 \%$ & $60 \%(95 \% \mathrm{CI}, 50 \%, 70 \%)$ & $40 \%(95 \% \mathrm{CI}, 34 \%-46 \%)$ \\
\hline
\end{tabular}

$\mathrm{NA}=$ not applicable; $\mathrm{CI}=$ confidence interval

Adapted and modified from: Boswell MV, Manchikanti L, Kaye AD, et al. A best-evidence systematic appraisal of the diagnostic accuracy and utility of facet (zygapophysial) joint injections in chronic spinal pain. Pain Physician 2015; 18:E497-E533 (18).

for thoracic facet joint nerve blocks in diagnosing thoracic facet joint pain is moderate.

\subsection{A Philosophical Approach - Paradigm Shift from Acute Pain to Chronic Pain}

The philosophical approach with mathematical validation by Bogduk et al of controlled diagnostic blocks was extensively studied. However, this was based on an acute pain model $(441-444,473,477,494,499)$. The philosophy of Bogduk is based on the literature derived from investigations and advocacy of comparative local anesthetic blocks as a substitute for placebo controls (441$444,473,477,494,499)$. The principle is that a patient with genuine pain would obtain short-lived pain relief when a short-acting local anesthetic was used, but longer lasting relief when a long-acting local anesthetic was used. This paradigm is based on double blind, randomized, controlled studies that have conclusively demonstrated that bupivacaine is a substantially and significantly longer acting anesthetic than lidocaine (500-507). Thus, the controlled comparative local anesthetic blocks have been validated extensively $(6,18,441-444)$. However, this does not 
Pain Physician: May/June 2020 23:S1-S127

Table 15. Data of prevalence and false-positive rate of facet joint pain by diagnostic blocks in the thoracic spine.

\begin{tabular}{||l|c|c|c|c|c||}
\hline \multicolumn{1}{||}{ Study } & $\begin{array}{c}\text { Methodological } \\
\text { Criteria Score }\end{array}$ & $\begin{array}{c}\text { Number } \\
\text { of } \\
\text { Patients }\end{array}$ & $\begin{array}{c}\text { Criterion } \\
\text { Standard of } \\
\text { Percent Relief }\end{array}$ & $\begin{array}{c}\text { Prevalence Estimates } \\
\text { with 95\% Confidence } \\
\text { Intervals }\end{array}$ & $\begin{array}{c}\text { False-Positive Rate with } \\
\text { 95\% Confidence Intervals }\end{array}$ \\
\hline Controlled Blocks & $9 / 12$ & 46 & $\geq 80 \%$ & $48 \%(95 \%$ CI; 34\%-62\%) & $58 \%(95 \%$ CI, 38\%-78\%) \\
\hline Manchikanti et al (480) & $9 / 12$ & 72 & $\geq 80 \%$ & $42 \%(95 \%$ CI; 30\%-53\%) & $55 \%(95 \%$ CI, 38\%-78\%) \\
\hline Manchikanti et al (470) & $9 / 12$ & 65 & $\geq 80 \%$ & $34 \%(95 \%$ CI; 22\%-47\%) & $42 \%(95 \%$ CI, 36\%-53\%) \\
\hline Manchukonda et al (471) &
\end{tabular}

$\mathrm{NA}=$ Not Available; $\mathrm{CI}=$ Confidence Interval

Adapted and modified from: Boswell MV, Manchikanti L, Kaye AD, et al. A best-evidence systematic appraisal of the diagnostic accuracy and utility of facet (zygapophysial) joint injections in chronic spinal pain. Pain Physician 2015; 18:E497-E533 (18).

take into consideration the differences between acute and chronic pain. Further, in this modality, Bogduk et al (441-444) postulated that any relief more than proposed, i.e., short-acting $\leq 2$ hours and long-acting $\leq 8$ hours, is considered as false-positive or long placebo response. For practical purposes, the pharmacological duration of local anesthetic has been used, which is 45 minutes for short-acting lidocaine and 90 minutes for long-acting bupivacaine

In contrast, chronic pain is a complex biopsychosocial phenomenon compared to acute pain. The manuscript on diagnostic blocks for chronic spinal pain failed to explore these aspects. Manchikanti and colleagues $(197,446-448,469,508-513)$ have explored the duration of relief in chronic pain patients with a paradigm shift from acute pain to chronic pain. Thus, local anesthetics provide different types of relief in chronic pain than in acute pain. They have been used extensively in interventional pain management, specifically in epidural injections since 1901, until epidural steroids were advocated in 1952, and even earlier for various types of nerve blocks $(514,515)$. In chronic pain, local anesthetics provide long-term relief based on various principles, in addition to traditional duration of pharmacological activity. The effectiveness of local anesthetics on duration of relief in chronic pain is based on alteration of multiple pathophysiologic mechanisms, including noxious peripheral stimulation, excess nociception, sensitization of pain pathways and excess release of neurotransmitters, causing complex central responses including hyperalgesia windup, nociceptive sensitization and phenotype changes, which are also considered as part of neural plasticity (514516). In fact, Tables 16 and 17 show the relief patterns with $\geq 80 \%$ criterion standard. One assessment in the cervical spine, as shown in Table 16, demonstrated that patients with double block positive injections, with lidocaine, $\geq 80 \%$ relief was 6 days with total relief of 30.91 days. With bupivacaine, $\geq 80 \%$ relief was 11.86 days, with total relief of 55.29 days in double-block positive patients in the chronic pain model. In the assessment of lumbar spine, as shown in Table 17, a lidocaine block showed duration of relief $\geq 80 \%$ for 6 days, whereas, bupivacaine block showed $\geq 80 \%$ relief for 11.86 days with total relief of 55.44 days.

Based on these findings, criticism has been advanced against multiple descriptions in the past of the appropriateness of criteria for controlled comparative local anesthetic blocks, $50 \%, 75 \%, 80 \%$, or $100 \%$ pain relief criterion standard, along with duration of the relief with diagnostic blocks, appropriateness of therapeutic facet joint nerve blocks, and multiple procedural aspects of radiofrequency neurotomy $(18,19,22,24,197,446,448,468,469,508-513)$. Bogduk (444) has categorized philosophical approaches into 3 categories. He described (444) a purist approach by him and his colleagues (441-444), a second approach by Manchikanti et al without a particular name $(446,448,469,508-513)$, and a pragmatic approach by Cohen et al $(455,458,459)$. However, there are stark contrasts and differences between these approaches. It is also important to note that Bogduk believes lumbar facet joint pain is not that common, consequently, the only way it can diagnosed is performing placebo controlled blocks, and he believes they are cost effective. Bogduk and colleagues and Cohen and colleagues continue to utilize acute pain model with one recommending placebo controlled blocks with $100 \%$ pain relief despite the fact that they utilized in the lumbar spine, $50 \%$ or more relief as the criterion standard in their publications $(284,285,289)$. In contrast, Manchikanti et al utilized a chronic pain model. Further, Cohen et al's 
Facet Joint Interventions Guidelines 2020

Table 16. Duration of relief with controlled comparative local anesthetic blocks in the diagnosis of cervical facet joint pain.

\begin{tabular}{|l|c|c|c|c|c|c|c||}
\hline \multicolumn{9}{|c|}{ Duration of Relief in days (average) } \\
\hline & & \multicolumn{3}{|c|}{$1 \%$ Lidocaine Block } & \multicolumn{4}{c|}{$0.25 \%$ Bupivacaine Block } \\
\hline Outcome & $\mathrm{N}$ & $50-79 \%$ & $>=80 \%$ & Total Relief & $50-79 \%$ & $>=80 \%$ & Total Relief \\
\hline False positive & 50 & 24.54 & 6.64 & 31.18 & 26.25 & 0.18 & 26.43 \\
\hline Negative & 99 & 8.11 & 0.04 & 8.15 & 0.00 & 0.00 & 0.00 \\
\hline Positive & 145 & 24.81 & 6.10 & 30.91 & 43.28 & 11.86 & 55.29 \\
\hline Total & 294 & 19.14 & 4.15 & 23.29 & 38.71 & 8.82 & 47.64 \\
\hline
\end{tabular}

Table 17. Duration of relief with controlled comparative local anesthetic blocks in the diagnosis of lumbar facet joint pain.

\begin{tabular}{|l|c|c|c|c|c|c|c||}
\hline \multicolumn{9}{|c|}{ Duration of Relief in days (average) } \\
\hline & & \multicolumn{3}{c|}{ 1\% Lidocaine Block } & \multicolumn{3}{c||}{ 0.25\% Bupivacaine Block } \\
\hline Outcome & $\mathrm{N}$ & $50-79 \%$ & $>=80 \%$ & Total Relief & $50-79 \%$ & $>=80 \%$ & Total Relief \\
\hline False positive & 101 & 24.89 & 5.95 & 30.83 & 23.58 & 3.02 & 26.60 \\
\hline Negative & 96 & 9.63 & 0.02 & 9.65 & 0.00 & 0.00 & 0.00 \\
\hline Positive & 102 & 26.04 & 6.07 & 32.11 & 42.47 & 12.96 & 55.44 \\
\hline Total & 299 & 20.38 & 4.09 & 24.47 & 33.07 & 8.02 & 41.09 \\
\hline
\end{tabular}

patients are recruited from military personnel, whereas Bogduk and colleagues' patients are from Australia, with some patients from the United States, mostly with a younger age group and also motor vehicle injuries.

Derby et al following principles developed by Bogduk et al and also ISIS standards $(517,518)$ described the role of diagnostic medial branch blocks, their cutoff values, and effectiveness of influence on outcomes. Derby et al $(517,518)$ in correlating lumbar medial branch neurotomy results with diagnostic medial branch block cutoff values to optimize therapeutic outcomes concluded that double medial branch block protocol better correlated with favorable medial branch neurotomy outcomes compared with a single medial branch protocol. Using a double medial branch block protocol, a 70\% cutoff value for reported subjective pain relief post medial branch block best predicted overall outcome following medial branch neurotomy. Without a confirmatory medial branch block, an $80 \%$ cutoff value was the optimal value. Multiple systematic reviews in the past $(19,35,519)$ also showed significantly better improvement in duration and with quality and quantity in patients undergoing dual medial branch blocks with $80 \%$ pain relief as the criterion standard.

Multiple other authors also have shown the longterm improvement following medial branch blocks $(19,22,24,508-513)$.

In contrast, over the years, Cohen and colleagues $(95,455,458)$ argued that $50 \%$ relief with a single block was appropriate and there was no therapeutic activity with facet joint nerve blocks. However, the studies were not designed to test if therapeutic facet joint nerve blocks were effective or not. Despite the arguments, these studies did show that diagnostic facet joint nerve blocks provided relief up to one month (458).

\subsection{Factors Influencing Diagnostic Accuracy}

Multiple factors affecting the diagnostic accuracy and subsequent outcomes have been published as shown in Table 18.

\subsubsection{Age}

The influence of age was assessed in 3 studies $(421,483,490)$; however only one study assessed patients suffering from cervical facet joint pain. Manchikanti et al (490) in assessing 424 patients suffering from either low back or neck pain reported overall prevalence of neck pain in $39 \%$ of the patients with $45 \%$ false-positive rate. They also showed that in the cervical spine, the lowest prevalence was in younger patients with $33 \%$ and highest in the older patients aged 61 to 70 years with $42 \%$. In low back, they showed the lowest prevalence in the younger age with $18 \%$ with highest prevalence in those aged 51 to 60 years. However, in contrast to other evaluations, they showed lower prevalence in those aged 41 to 50 years of age.

Three other studies also described age-related influence $(291,421,483)$. In 2 studies, DePalma et al 
Table 18. Assessment of factors influencing prevalence and false-positive rates of facet joint pain in lumbar, cervical, and thoracic regions.

\begin{tabular}{|c|c|c|c|}
\hline Study & Methods and Assessment Criteria & Results & Comments \\
\hline \multicolumn{4}{|l|}{ Influence of Age } \\
\hline $\begin{array}{l}\text { Manchikanti et al, } 2008 \\
(490) \\
\text { Lumbar and cervical } \\
\text { Age-related prevalence of } \\
\text { facet joint involvement in } \\
\text { chronic low back and neck } \\
\text { pain was evaluated in a } \\
\text { retrospective assessment }\end{array}$ & $\begin{array}{l}\text { A total of } 424 \text { patients were divided into } \\
6 \text { groups based upon age with Group } \\
\text { I aged } 18 \text { - } 30 \text { years, Group II aged } 31 \text { - } \\
40 \text { years, Group III aged } 41-50 \text { years, } \\
\text { Group IV aged } 51-60 \text { years, Group V } \\
\text { aged } 61-70 \text { years, and Group VI } \geq 70 \\
\text { years of age. }\end{array}$ & $\begin{array}{l}\text { The prevalence of cervical facet joint- } \\
\text { related pain was the lowest (33\%) in } \\
\text { Group VI and highest ( } 42 \% \text { ) in Group } \\
\text { I with overall prevalence of } 39 \% \text {. False- } \\
\text { positive rates for cervical facet joint blocks } \\
\text { ranged from } 39 \% \text { (Group III) to } 58 \% \\
\text { (Group V) with an overall false-positive } \\
\text { rate of } 45 \% \text {. } \\
\text { The prevalence of facet joint involvement } \\
\text { in lumbar spinal pain ranged from } 18 \% \\
\text { (in Group II) to } 44 \% \text { (in Group IV), with } \\
\text { significant differences noted when Group } \\
\text { II and Group III were compared to other } \\
\text { groups and with higher rates in Group } \\
\text { V with overall prevalence of } 27 \% \text {. False- } \\
\text { positive rates were highest in patients aged } \\
61 \text { to } 70 \text { years ( } 64 \% \text { ) and lowest in patients } \\
\text { aged } 51 \text { to } 60 \text { years (30\%) with overall } \\
\text { false-positive rate of } 45 \% \text {. }\end{array}$ & $\begin{array}{l}\text { The first age-related prevalence } \\
\text { study with controlled comparative } \\
\text { local anesthetic blocks in a } \\
\text { heterogenous population in a } \\
\text { private practice setting assessing } \\
\text { in a large proportion of patients, } \\
\text { both cervical and lumbar spine } \\
\text { facet joint pain. }\end{array}$ \\
\hline $\begin{array}{l}\text { DePalma et al, } 2012 \text { (421) } \\
\text { Lumbar } \\
\text { Assessment of } \\
\text { relationships between } \\
\text { age, gender, and body } \\
\text { mass index and source of } \\
\text { chronic low back pain }\end{array}$ & $\begin{array}{l}153 \text { patients with chronic low back } \\
\text { pain were evaluated in a retrospective } \\
\text { evaluation with dual diagnostic } \\
\text { blocks with } 1 \% \text { lidocaine and } 0.5 \% \\
\text { bupivacaine with concordant relief of } \\
75 \% \text { of the criterion standard. }\end{array}$ & $\begin{array}{l}\text { Age, gender, and body mass index were } \\
\text { each significantly associated with the } \\
\text { source of chronic low back pain. Facet } \\
\text { joint pain was the most likely source of } \\
\text { chronic low back pain for male patients } \\
\text { who were approximately } 54 \text { years of age } \\
\text { (30\% - 54\%) whereas, for female patients } \\
\text { who were } 65 \text { years facet joint pain was } \\
\text { most likely }(46 \%-57 \%) \text {. }\end{array}$ & $\begin{array}{l}\text { This multivariate analysis of the } \\
\text { relationships between age, gender, } \\
\text { and body mass index and the } \\
\text { source of chronic low back pain } \\
\text { shows all factors are significantly } \\
\text { associated with the source of } \\
\text { chronic low back pain with findings } \\
\text { suggesting a significant relationship } \\
\text { among these factors. However, facet } \\
\text { joint pain was more prevalent in } \\
\text { females with increased BMI. }\end{array}$ \\
\hline $\begin{array}{l}\text { Manchikanti et al, } 2001 \\
(483) \\
\text { Lumbar } \\
\text { Assessment of the role of } \\
\text { facet joints in chronic low } \\
\text { back pain in the elderly }\end{array}$ & $\begin{array}{l}\text { Controlled comparative prevalence } \\
\text { study in } 100 \text { patients, in which } 50 \\
\text { patients below age of } 65 \text { and } 50 \\
\text { patients aged } 65 \text { or over were assessed. } \\
\text { Controlled diagnostic blocks were } \\
\text { performed with } 75 \% \text { pain relief with } \\
\text { ability to perform previously painful } \\
\text { movements utilized as the criterion } \\
\text { standard. }\end{array}$ & $\begin{array}{l}\text { The prevalence of facet joint pain was } \\
\text { determined as } 30 \% \text { in the adults below } \\
\text { the age of } 65 \text { and } 52 \% \text { in the elderly above } \\
\text { the age of } 65 \text { with false-positive rates of } \\
26 \% \text { and } 33 \% \text {, respectively. }\end{array}$ & $\begin{array}{l}\text { This study showed higher } \\
\text { prevalence of facet joint pain } \\
\text { in the elderly compared to the } \\
\text { younger age group in contrast to } \\
\text { the latest study by Manchikanti et } \\
\text { al which showed no differences } \\
\text { (468). }\end{array}$ \\
\hline \multicolumn{4}{|c|}{ Influence of Clinical Assessment } \\
\hline $\begin{array}{l}\text { Revel et al, } 1992,1998 \\
(402,411) \\
\text { Lumbar } \\
\text { Randomized controlled } \\
\text { trials to identify facet } \\
\text { joint blocks for low back } \\
\text { pain to identify predictors } \\
\text { of a good response for } \\
\text { facet joint pain for low } \\
\text { back pain and capacity } \\
\text { of the clinical picture to } \\
\text { characterize low back } \\
\text { pain relieved by facet joint } \\
\text { anesthesia. }\end{array}$ & $\begin{array}{l}\text { In the preliminary study, they included } \\
51 \text { patients with identification of } \\
\text { multiple variables such as older age, } \\
\text { absence of exacerbation by coughing, } \\
\text { relief when recumbent, absence of } \\
\text { exacerbation by forward flexion, and } \\
\text { when raising from this flexion, absence } \\
\text { of worsening by hyperextension, and } \\
\text { extension-rotation. In the second study, } \\
\text { they tested these criteria to identify } \\
\text { patients with painful facet joints in } 80 \\
\text { patients utilizing diagnostic facet joint } \\
\text { injections with injection of either } 2 \% \\
\text { lidocaine or } 1 \mathrm{~mL} \text { of sodium chloride } \\
\text { solution with intraarticular of } 1 \mathrm{~mL} \\
\text { of } 2 \% \text { lidocaine or } 1 \text { mL of sodium } \\
\text { chloride solution in a randomized } \\
\text { fashion with } 75 \% \text { pain relief as the } \\
\text { criterion standard. }\end{array}$ & $\begin{array}{l}\text { Following the first study, they identified } \\
\text { what they called Revel et al's ( } 402,411 \text { ) } \\
\text { criteria. In the second study, they tested these } \\
\text { results. They showed that a set of } 5 \text { clinical } \\
\text { characteristics may be utilized to select low } \\
\text { back pain patients based on the response to } \\
\text { local anesthetic injections. They showed that } \\
\text { there was a significant interaction between } \\
\text { clinical group and injection effect in patients } \\
\text { with back pain. The presence of } 5 \text { among } 7 \\
\text { variables, namely, age } \geq 65 \text { years and pain } \\
\text { that was not exacerbated by coughing, } \\
\text { not worsened by hyperextension, not } \\
\text { worsened by forward flexion, not worsened } \\
\text { when rising from flexion, not worsened } \\
\text { by extension-rotation, and well relieved by } \\
\text { recumbency with inclusion of the last item } \\
\text { always, distinguished } 92 \% \text { of the patients } \\
\text { responding to local anesthetic injections with } \\
\text { a positive diagnosis, whereas } 80 \% \text { of those } \\
\text { not responding when they had no such signs. }\end{array}$ & $\begin{array}{l}\text { This study attempted to identify } \\
\text { certain clinical features as } \\
\text { predictors of facet joint pain } \\
\text { which can be confirmed by } \\
\text { local anesthetic blocks. While } \\
\text { they show the importance of } \\
\text { local anesthetic blocks, there is } \\
\text { only a single study discussing } \\
\text { Revel et al's }(402,411) \text { criteria. } \\
\text { These criteria have been shown } \\
\text { to be unreliable in other studies } \\
(412,415) \text {. }\end{array}$ \\
\hline
\end{tabular}


Facet Joint Interventions Guidelines 2020

Table 18. (cont.) Assessment of factors influencing prevalence and false-positive rates of facet joint pain in lumbar, cervical, and thoracic regions.

\begin{tabular}{|c|c|c|c|}
\hline Study & Methods and Assessment Criteria & Results & Comments \\
\hline $\begin{array}{l}\text { Laslett et al, } 2004 \text { (412) } \\
\text { Lumbar } \\
\text { Lumbar facet joint nerve } \\
\text { blocks to test Revel et } \\
\text { al's }(402,411) \text { model } \\
\text { as a screening test in a } \\
\text { prospective, blinded, } \\
\text { concurrent reference } \\
\text { standard related validity } \\
\text { design. }\end{array}$ & $\begin{array}{l}\text { In this study, the authors utilized } \\
\text { controlled diagnostic blocks with a } \\
75 \% \text { or more reduction in pain as the } \\
\text { criterion standard utilizing either } 2 \% \\
\text { lidocaine or } 0.75 \% \text { bupivacaine, either } \\
\text { into the target joint or the facet joint } \\
\text { nerves. Patients were selected based on } \\
\text { the clinical criteria described by Revel e } \\
\text { tal }(402,411) .151 \text { chronic low back pain } \\
\text { patients were evaluated. }\end{array}$ & $\begin{array}{l}\text { The results of this study were in stark } \\
\text { contrast to those of Revel et al ( } 402,411) \\
\text { with low sensitivity and high specificity. } \\
\text { The authors showed that } 2 \text { items, no } \\
\text { pain with cough and sneezing and no } \\
\text { exacerbation of pain rising from flexion } \\
\text { approached statistical significance in a } \\
\text { relation to reduction in pain after facet } \\
\text { joint blocks. The authors concluded that } \\
\text { neither strategy utilizing Revel et al's } \\
\text { ( } 402,411) \text { criteria is suitable as a clinical } \\
\text { device for screening of facet joint pain. The } \\
\text { authors also concluded that these criteria } \\
\text { cannot be considered diagnostic of painful } \\
\text { lumbar facet joints. They also concluded } \\
\text { that only placebo-controlled or dual } \\
\text { controlled diagnostic blocks will be able to } \\
\text { diagnose the source of low back pain from } \\
\text { facet joints. }\end{array}$ & $\begin{array}{l}\text { This study disproved the } \\
\text { hypothesis by Revel et al's } \\
(402,411) \text { criteria of } 5 \text { salient } \\
\text { identifying predictors. Further, } \\
\text { this study also emphasized the } \\
\text { value of dual diagnostic blocks } \\
\text { utilizing either placebo or } 2 \\
\text { separate local anesthetics. }\end{array}$ \\
\hline $\begin{array}{l}\text { Manchikanti et al , } 2000 \\
\text { (415) } \\
\text { Lumbar, cervical and } \\
\text { thoracic } \\
\text { A prospective evaluation } \\
\text { of the ability of clinical } \\
\text { picture to characterize pain } \\
\text { from facet joints. }\end{array}$ & $\begin{array}{l}\text { In this study, the authors evaluated } 200 \\
\text { patients with chronic low back pain } \\
\text { utilizing controlled comparative local } \\
\text { anesthetic blocks with } 1 \% \text { lidocaine or } \\
0.25 \% \text { bupivacaine. They compared the } \\
\text { results of the blocks with Revel et al's } \\
\text { ( } 402,411 \text { ) criteria with age, pain well } \\
\text { relieved in supine position, absence of } \\
\text { pain exacerbation by coughing, absence } \\
\text { of pain exacerbation by forward } \\
\text { flexion, absence of pain exacerbation by } \\
\text { deflexion, absence of pain exacerbation } \\
\text { by hyperextension, and absence of pain } \\
\text { exacerbation by extension-rotation, and } \\
\text { traumatic onset of pain. }\end{array}$ & $\begin{array}{l}\text { In assessment of } 200 \text { patients, this study } \\
\text { showed lack of correlation between Revel } \\
\text { et al's }(402,411) \text { criteria and positive } \\
\text { diagnosis by controlled diagnostic blocks. } \\
\text { The authors concluded that the history, } \\
\text { clinical features, and radiological features } \\
\text { are of no significance or assistance in } \\
\text { making the diagnosis of facet joint pain } \\
\text { with certainty. }\end{array}$ & $\begin{array}{l}\text { This study shows the value of } \\
\text { controlled diagnostic blocks and } \\
\text { lack of correlation with Revel et } \\
\text { al's }(402,411) \text { criteria with similar } \\
\text { results presented in the study by } \\
\text { Laslett et al (412). }\end{array}$ \\
\hline $\begin{array}{l}\text { Schwarzer et al, } 1995 \text { (286) } \\
\text { Lumbar } \\
\text { A prospective cross- } \\
\text { sectional analytic study } \\
\text { to assess whether the } \\
\text { presence or absence of pain } \\
\text { originating from the lumbar } \\
\text { facet joint correlates with } \\
\text { changes seen on computed } \\
\text { tomography. }\end{array}$ & $\begin{array}{l}\text { The authors evaluated } 57 \text { patients with } \\
\text { placebo injections or intraarticular } \\
\text { injections. The patients also underwent } \\
\text { computed tomography. The facet joints } \\
\text { of all images were scored by multiple } \\
\text { independent masked radiologists. }\end{array}$ & $\begin{array}{l}\text { The results of this study showed there } \\
\text { was poor interobserver agreement using } \\
\text { total joint scores for all } 3 \text { assessments. } \\
\text { There was no correlation between the } \\
\text { positive diagnostic blocks and computed } \\
\text { tomographic findings. The authors } \\
\text { concluded that computed tomography } \\
\text { has no place in the diagnosis of lumbar } \\
\text { facet joint pain. }\end{array}$ & $\begin{array}{l}\text { This study clearly shows lack of } \\
\text { correlation between radiologic } \\
\text { assessment and facet joint pain. }\end{array}$ \\
\hline $\begin{array}{l}\text { Young et al, 2003 (414) } \\
\text { Lumbar } \\
\text { In a prospective, criterion- } \\
\text { related concurrent } \\
\text { validity study performed } \\
\text { at a private radiology } \\
\text { practice specializing in } \\
\text { spinal diagnostics in the } \\
\text { United States, the authors } \\
\text { attempted to identify } \\
\text { significant components } \\
\text { of a clinical examination } \\
\text { that are associated with } \\
\text { symptomatic facet joints, } \\
\text { along with discs and } \\
\text { sacroiliac joints. }\end{array}$ & $\begin{array}{l}\text { The authors studied } 120 \text { patients with } \\
\text { chronic lumbar or lumbopelvic pain } \\
\text { in a private radiology practice with } \\
\text { clinical examination by a physical } \\
\text { therapist and injection procedures } \\
\text { including lumbar discography, lumbar } \\
\text { facet joint injections, or sacroiliac joint } \\
\text { injections as requested by the referring } \\
\text { physician or if deemed indicated by the } \\
\text { radiologist. A single diagnostic block } \\
\text { was performed with } 80 \% \text { pain relief as } \\
\text { the criterion standard. }\end{array}$ & $\begin{array}{l}\text { They failed to identify a significant } \\
\text { relationship with clinical characteristics } \\
\text { for lumbar facet joint pain, even though } \\
\text { they were able to identify centralization } \\
\text { for discogenic pain and } 3 \text { or more positive } \\
\text { pain provocation tests for sacroiliac joint } \\
\text { pain. The authors identified that absence } \\
\text { of pain when rising from sitting as an } \\
\text { indicator for lumbar facet joint pain. }\end{array}$ & $\begin{array}{l}\text { The authors identified absence } \\
\text { of pain when rising from sitting } \\
\text { as indicator of lumbar facet joint } \\
\text { pain. }\end{array}$ \\
\hline
\end{tabular}


Table 18. (cont.) Assessment of factors influencing prevalence and false-positive rates of facet joint pain in lumbar, cervical, and thoracic regions.

\begin{tabular}{|c|c|c|c|}
\hline Study & Methods and Assessment Criteria & Results & Comments \\
\hline $\begin{array}{l}\text { Laslett et al , } 2006 \text { (413) } \\
\text { Lumbar } \\
\text { A prospective blinded } \\
\text { study with a secondary } \\
\text { analysis to seek evidence } \\
\text { of variables potentially } \\
\text { valuable as predictors } \\
\text { of screening for } \\
\text { zygapophysial joint block } \\
\text { outcomes. }\end{array}$ & $\begin{array}{l}\text { In this subgroup analysis, } 151 \text { chronic } \\
\text { low back pain patients were assessed } \\
\text { with controlled diagnostic blocks } \\
\text { utilizing either lidocaine } 2 \% \text { or } \\
\text { bupivacaine } 0.75 \% \text { with } 75 \% \text { to } 95 \% \\
\text { or more pain reduction as the criterion } \\
\text { standard. The authors correlated } \\
\text { various factors including pain } \\
\text { drawings, questionnaires, and a clinical } \\
\text { examination before screening lumbar } \\
\text { facet joint nerve blocks. }\end{array}$ & $\begin{array}{l}\text { The results showed that at the } 75 \% \text { pain } \\
\text { reduction standard, } 24.5 \% \text { responded to } \\
\text { screening facet joint nerve blocks and } \\
10.8 \% \text { responded at the } 95 \% \text { standard. } \\
\text { They also showed that there were no } \\
\text { variables which were useful predictors of } \\
\text { facet joint pain with } 90 \% \text { pain reduction } \\
\text { of less than } 90 \% \text {. They also showed that } 7 \\
\text { clinical findings were associated with } 95 \% \\
\text { pain reduction after blocks. They showed } 5 \\
\text { useful clinical predictor rules for ruling out } \\
\text { a } 95 \% \text { pain reduction with } 100 \% \text { sensitivity } \\
\text { and one clinical prediction rule had a } \\
\text { likelihood ratio of } 9.7 \text {, which produced } \\
\text { a 5-fold improvement in post test } \\
\text { probability. They concluded that a negative } \\
\text { extension rotation test, the centralization } \\
\text { phenomenon, and } 4 \text { clinical predictor } \\
\text { rules effectively rule out pain ablation after } \\
\text { screening zygapophysial joint block. }\end{array}$ & $\begin{array}{l}\text { The results are inapplicable } \\
\text { clinically as it demands } 95 \% \text { pain } \\
\text { reduction after diagnostic blocks. } \\
\text { However, for those utilizing } 95 \% \\
\text { or higher pain relief for diagnostic } \\
\text { purposes, the results are useful. }\end{array}$ \\
\hline \multicolumn{4}{|c|}{ Influence of Psychological Factors } \\
\hline $\begin{array}{l}\text { Manchikanti et al, } 2008 \\
(488) \\
\text { Cervical, thoracic, and } \\
\text { lumbar } \\
\text { Assessment of influence of } \\
\text { psychological variables on } \\
\text { the diagnosis of facet joint } \\
\text { involvement in spinal pain } \\
\text { of chronic neck, low back, } \\
\text { and thoracic pain. }\end{array}$ & $\begin{array}{l}\text { A total of } 438 \text { patients undergoing } \\
\text { controlled comparative local anesthetic } \\
\text { blocks were included in the study. } \\
\text { Patients were allocated based on } \\
\text { the psychological profile. Primary } \\
\text { groups consisted of patients with } \\
\text { major depression, generalized anxiety } \\
\text { disorder, and somatization disorder. }\end{array}$ & $\begin{array}{l}\text { The prevalence of facet joint pain in } \\
\text { chronic spinal pain ranged from } 25 \% \text { to } \\
40 \% \text { in patients without psychopathology, } \\
\text { whereas it ranged from } 28 \% \text { to } 43 \% \text { in } \\
\text { patients with a positive diagnosis of major } \\
\text { depression, generalized anxiety disorder, } \\
\text { and somatization disorder, compared to } \\
23 \% \text { to } 39 \% \text { in patients with a negative } \\
\text { diagnosis. Regional facet joint pain } \\
\text { prevalence and false-positive rates were } \\
\text { higher in the cervical region in patients } \\
\text { with major depression. In the lumbar } \\
\text { and thoracic regions, no significant } \\
\text { differences were noted. }\end{array}$ & $\begin{array}{l}\text { The study included a large } \\
\text { proportion of patients with } \\
\text { controlled comparative local } \\
\text { anesthetic blocks in a private } \\
\text { practice setting. A significant } \\
\text { proportion of patients suffered } \\
\text { with either a single or multiple } \\
\text { psychological disorders. } \\
\text { Surprisingly, the only differences } \\
\text { observed were in the cervical region } \\
\text { with no significant differences } \\
\text { observed in thoracic and lumbar } \\
\text { regions based on the psychological } \\
\text { diagnosis or multiple diagnoses, } \\
\text { or a combination of multiple } \\
\text { diagnoses. }\end{array}$ \\
\hline $\begin{array}{l}\text { Wasan et al, } 2009 \text { (493) } \\
\text { Lumbar and cervical } \\
\text { Evaluation of influence } \\
\text { of psychopathology to } \\
\text { predict the outcome of } \\
\text { medial branch blocks with } \\
\text { corticosteroid injection for } \\
\text { chronic axial low back or } \\
\text { neck pain }\end{array}$ & $\begin{array}{l}86 \text { patients for chronic axial low } \\
\text { back or cervical pain in a prospective } \\
\text { cohort study were classified into } \\
\text { low psychopathology group, } \\
\text { moderate psychopathology group, } \\
\text { or high psychopathology group. } \\
\text { Diagnostic blocks were performed } \\
\text { utilizing facet joint nerve blocks with } \\
\text { methylprednisolone } 20 \text { to } 30 \mathrm{mg} \text { and } \\
0.25 \% \text { bupivacaine with a total volume } \\
\text { of } 1 \text { to } 1.25 \mathrm{~mL} \text { injection per level. }\end{array}$ & $\begin{array}{l}\text { The low psychopathology group reported } \\
\text { a mean } 23 \% \text { improvement in pain at one } \\
\text { month while the high psychopathology } \\
\text { group reported a mean worsening of } \\
-5.8 \% \text { of pain. } 45 \% \text { of low group had a } \\
\text { least } 30 \% \text { improvement in pain versus } \\
10 \% \text { in the high group. }\end{array}$ & $\begin{array}{l}\text { This is a poorly performed flawed } \\
\text { evaluation with inappropriate } \\
\text { methodology. }\end{array}$ \\
\hline \multicolumn{4}{|l|}{ Influence of Body Mass Index } \\
\hline $\begin{array}{l}\text { Manchikanti et al, } 2001 \\
(484) \\
\text { Lumbar } \\
\text { Assessment of the role } \\
\text { of obesity in chronic low } \\
\text { back pain. }\end{array}$ & $\begin{array}{l}\text { Authors evaluated } 100 \text { patients with } \\
\text { low back pain. Patients were divided } \\
\text { into } 2 \text { groups, Group I was normal } \\
\text { weight and Group II was obese. Facet } \\
\text { joints were investigated with diagnostic } \\
\text { blocks using lidocaine } 1 \% \text { initially } \\
\text { followed by bupivacaine } 0.25 \% \text {, at least } \\
2 \text { weeks apart. A definite response was } \\
\text { defined as relief of at least } 75 \% \text { in the } \\
\text { symptomatic area. }\end{array}$ & $\begin{array}{l}\text { The results showed that the prevalence } \\
\text { rate of facet joint pain in chronic low back } \\
\text { pain in Group I or non-obese patients } \\
\text { was 36\%, in contrast to } 40 \% \text { in Group } \\
\text { II, or the obese patient group, with no } \\
\text { significant differences among the } 2 \\
\text { groups. The study also showed a false- } \\
\text { positive rate of } 39 \% \text { in the total sample, or } \\
44 \% \text { in Group I non-obese patients and } \\
33 \% \text { in Group II, or obese patients. }\end{array}$ & $\begin{array}{l}\text { This study showed the prevalence } \\
\text { of lumbar facet joint pain of } 40 \% \\
\text { in obese patients and } 36 \% \text { in } \\
\text { patients of normal weight with a } \\
\text { false-positive rate of } 33 \% \text { in obese } \\
\text { patients and } 44 \% \text { in non-obese } \\
\text { patients is similar to the results } \\
\text { of multiple previous studies } \\
\text { concluding that facet joint pain is } \\
\text { a common occurrence in obese } \\
\text { patients; however, the incidence of } \\
\text { facet joint mediated pain is similar } \\
\text { in obese patients and non-obese } \\
\text { patients. }\end{array}$ \\
\hline
\end{tabular}


Table 18. (cont.) Assessment of factors influencing prevalence and false-positive rates of facet joint pain in lumbar, cervical, and thoracic regions.

\begin{tabular}{|c|c|c|c|}
\hline Study & Methods and Assessment Criteria & Results & Comments \\
\hline $\begin{array}{l}\text { DePalma et al, } 2012 \text { (421) } \\
\text { Lumbar } \\
\text { Assessment of } \\
\text { relationships between } \\
\text { age, gender, and body } \\
\text { mass index and source of } \\
\text { chronic low back pain }\end{array}$ & $\begin{array}{l}153 \text { patients with chronic low back } \\
\text { pain were evaluated in a retrospective } \\
\text { evaluation with dual diagnostic } \\
\text { blocks with } 1 \% \text { lidocaine and } 0.5 \% \\
\text { bupivacaine with concordant relief of } \\
75 \% \text { of the criterion standard. }\end{array}$ & $\begin{array}{l}\text { Body mass index was associated with } \\
\text { significant increases in the prevalence of } \\
\text { facet joint pain in female patients. Facet } \\
\text { joint pain was the most likely source } \\
\text { of chronic low back pain for men who } \\
\text { were approximately } 54 \text { years of age ( } 30 \% \\
-54 \% \text { ), regardless of BMI, whereas, for } \\
\text { women patients who were } 65 \text { years old, } \\
\text { facet joint pain was most likely } 46 \% \text { - } \\
57 \% \text {. }\end{array}$ & $\begin{array}{l}\text { Based on this study it appears that } \\
\text { obese women may have a higher } \\
\text { prevalence of facet joint pain. }\end{array}$ \\
\hline \multicolumn{4}{|l|}{ Influence of Surgery } \\
\hline \begin{tabular}{|l} 
Manchikanti et al, 2007 \\
(177) \\
Lumbar \\
Assessment of facet joint \\
pain in post lumbar \\
surgery syndrome \\
\end{tabular} & $\begin{array}{l}\text { A total of } 117 \text { consecutive patients with } \\
\text { chronic, nonspecific low back pain, } \\
\text { after lumbar surgical intervention(s) } \\
\text { were evaluated with controlled, } \\
\text { comparative local anesthetic blocks. }\end{array}$ & $\begin{array}{l}\text { The prevalence of lumbar facet joint } \\
\text { pain in patients with recurrent pain after } \\
\text { various surgical intervention(s) was } 16 \% \\
\text { ( } 95 \% \text { confidence interval, } 9 \% \text { - } 23 \% \text { ). The } \\
\text { false-positive rate with a single block with } \\
\text { lidocaine was } 49 \% \text {. }\end{array}$ & $\begin{array}{l}\text { This study showed prevalence of } \\
\text { lumbar facet joint pain in patients } \\
\text { after surgical interventions of } \\
16 \% \text { with a false-positive rate of } \\
49 \% \text { with a single block. }\end{array}$ \\
\hline $\begin{array}{l}\text { DePalma et al, } 2011 \text { (189) } \\
\text { Lumbar } \\
\text { Evaluation of etiology of } \\
\text { chronic low back pain in } \\
\text { patients having undergone } \\
\text { lumbar fusion }\end{array}$ & $\begin{array}{l}\text { A total of } 28 \text { fusion cases identified } \\
\text { from } 170 \text { low back pain patients } \\
\text { undergoing diagnostic procedures were } \\
\text { assessed. Controlled diagnostic blocks } \\
\text { were performed. }\end{array}$ & $\begin{array}{l}\text { After } 28 \text { fusion cases, } 5 \text { patients were } \\
\text { identified with zygapophysial pain } \\
\text { with a prevalence of facet joint pain of } \\
\text { approximately } 18 \% \text {. }\end{array}$ & $\begin{array}{l}\text { The results showed that } \\
\text { patients even after lumbar } \\
\text { fusion have persistent low back } \\
\text { pain secondary to facet joint } \\
\text { involvement in approximately } \\
18 \% \text { of the patients. This is } \\
\text { similar to other reports (59). }\end{array}$ \\
\hline $\begin{array}{l}\text { DePalma et al, } 2012 \text { (190) } \\
\text { Lumbar } \\
\text { Evaluation of the source } \\
\text { of chronic low back pain } \\
\text { based on the history of } \\
\text { surgical discectomy. }\end{array}$ & $\begin{array}{l}158 \text { patients underwent dual diagnostic } \\
\text { blocks with } 1 \% \text { lidocaine and } 0.5 \% \\
\text { bupivacaine with concordant relief of } \\
75 \% \text { of the criterion standard. A total of } \\
158 \text { patients were evaluated. }\end{array}$ & $\begin{array}{l}\text { The study showed facet joint pain in } \\
18.2 \% \text { of the patients whereas it was } \\
32.6 \% \text { of the patients in patients without } \\
\text { surgical intervention. However, there } \\
\text { were only } 2 \text { patients positive in patients } \\
\text { with surgical discectomy. }\end{array}$ & $\begin{array}{l}\text { Results show lower prevalence in } \\
\text { patients with surgical discectomy; } \\
\text { however, the sample size was } \\
\text { extremely small. }\end{array}$ \\
\hline $\begin{array}{l}\text { Manchikanti et al, } 2001 \\
\text { (192) } \\
\text { Lumbar } \\
\text { Assessment of the role of } \\
\text { facet joint pain in post- } \\
\text { surgery syndrome }\end{array}$ & $\begin{array}{l}\text { This prospective, randomized, } \\
\text { controlled comparative evaluation was } \\
\text { performed to determine the prevalence } \\
\text { of facet joint pain in persistent low } \\
\text { back pain in postlumbar laminectomy } \\
\text { patients with a comparative non- } \\
\text { surgical group. } 100 \text { patients with } 50 \\
\text { patients in each group were randomly } \\
\text { assigned with group I consisting of } 50 \\
\text { patients without history of previous } \\
\text { surgery and group II consisting of } \\
50 \text { patients with history of previous } \\
\text { surgery. }\end{array}$ & $\begin{array}{l}\text { Results showed that the prevalence of } \\
\text { facet joint mediated pain in non-surgical } \\
\text { patients was } 44 \% \text { compared to } 32 \% \\
\text { in post-surgical patients determined } \\
\text { by comparative controlled local } \\
\text { anesthetic blocks utilizing lidocaine } \\
\text { and bupivacaine. This study also } \\
\text { showed a false-positive rate of } 36 \% \text { in } \\
\text { the non-surgical group and } 24 \% \text { in the } \\
\text { post-surgical group. In conclusion, this } \\
\text { study shows that facet joint mediated } \\
\text { symptomatology in chronic low back pain } \\
\text { is prevalent, both in non-surgical as well } \\
\text { as post-surgical patients even though the } \\
\text { prevalence was somewhat higher in the } \\
\text { non-surgical group compared to post- } \\
\text { surgical group. }\end{array}$ & $\begin{array}{l}\text { There was a lower prevalence of } \\
\text { facet joint pain in patients after } \\
\text { surgical interventions. }\end{array}$ \\
\hline $\begin{array}{l}\text { Manchikanti et al, } 2008 \\
(178) \\
\text { Cervical } \\
\text { Retrospective evaluation } \\
\text { in post cervical surgery } \\
\text { syndrome }\end{array}$ & $\begin{array}{l}251 \text { consecutive patients with persistent } \\
\text { neck pain requiring diagnostic facet } \\
\text { joint nerve blocks were evaluated. } \\
\text { There were } 45 \text { patients post surgery } \\
\text { and } 206 \text { patients without surgery with } \\
\text { chronic persistent neck pain of at least } \\
3 \text { months duration after failure of } \\
\text { conservative management }\end{array}$ & $\begin{array}{l}\text { Without surgery: } \\
\text { Prevalence }=39 \% \\
\text { False-positive rate }=43 \% \\
\text { Postsurgery: } \\
\text { Prevalence }=36 \% \\
\text { False-positive rate }=50 \%\end{array}$ & $\begin{array}{l}\text { This is the only study evaluating } \\
\text { the differences in prevalence } \\
\text { following surgical intervention. } \\
\text { Even though this is a retrospective } \\
\text { evaluation, it utilized controlled, } \\
\text { comparative local anesthetic } \\
\text { blocks in a practical setting. }\end{array}$ \\
\hline
\end{tabular}


Pain Physician: May/June 2020 23:S1-S127

Table 18. (cont.) Assessment of factors influencing prevalence and false-positive rates of facet joint pain in lumbar, cervical, and thoracic regions.

\begin{tabular}{|c|c|c|c|}
\hline Study & Methods and Assessment Criteria & Results & Comments \\
\hline $\begin{array}{l}\text { Klessinger, } 2013 \text { (191) } \\
\text { Lumbar } \\
\text { Retrospective practice } \\
\text { audit }\end{array}$ & $\begin{array}{l}\text { Medial branch blocks were performed } \\
\text { using local anesthetic and bupivacaine } \\
\text { for the first injection in } 120 \text { patients. } \\
\text { They also tested in patients with } \\
\text { positive response, but recurrence of } \\
\text { pain with second diagnostic block } \\
\text { utilizing bupivacaine } 0.25 \% \text {. } \\
\text { Patients with persistent back pain } \\
\text { after surgery were tested with repeated } \\
\text { medial branch blocks. Those patients } \\
\text { who consistently report at least } 80 \% \\
\text { pain relief underwent radiofrequency } \\
\text { neurotomy. A successful outcome was } \\
\text { defined as at least } 50 \% \text { pain reduction } \\
\text { enduring for } 6 \text { months. }\end{array}$ & $\begin{array}{l}479 \text { patients who underwent } \\
\text { microsurgical lumbar disc operations, } \\
\text { persistent axial back pain occurred in } \\
120 \text {, of whom } 34 \text { had positive responses } \\
\text { to diagnostic blocks and were treated } \\
\text { with radiofrequency neurotomy. Twenty } \\
\text { patients ( } 58.8 \% \text { ) achieved at least } 50 \% \\
\text { reduction in pain for a minimum of } 6 \\
\text { months. }\end{array}$ & $\begin{array}{l}\text { This study shows prevalence } \\
\text { of zygapophysial joint pain in } \\
\text { post-lumbar surgery syndrome } \\
\text { as 7\%. They also treated the } \\
\text { procedure with approximately } \\
60 \% \text { improvement with } \\
\text { radiofrequency neurotomy which } \\
\text { also confirms the diagnosis. The } \\
\text { disadvantages include this is a } \\
\text { retrospective assessment. } \\
\text { Demographic features did not } \\
\text { show the type of surgery these } \\
\text { patients have had, including the } \\
\text { type of fusion and the issues } \\
\text { related to the access to the medial } \\
\text { branches, specifically with } \\
\text { radiofrequency neurotomy }\end{array}$ \\
\hline \multicolumn{4}{|l|}{ Influence of Gender/Smoking } \\
\hline $\begin{array}{l}\text { DePalma et al, } 2012 \text { (421) } \\
\text { Lumbar } \\
\text { Assessment of relationships } \\
\text { between age, gender, and } \\
\text { body mass index and } \\
\text { source of chronic low back } \\
\text { pain }\end{array}$ & $\begin{array}{l}153 \text { patients with chronic low back } \\
\text { pain were evaluated in a retrospective } \\
\text { evaluation with dual diagnostic } \\
\text { blocks with } 1 \% \text { lidocaine and } 0.5 \% \\
\text { bupivacaine with concordant relief of } \\
75 \% \text { of the criterion standard. }\end{array}$ & $\begin{array}{l}\text { These findings suggest a significant } \\
\text { relationship among gender and chronic } \\
\text { low back pain. Facet joint pain is more } \\
\text { prevalent in females with increased body } \\
\text { mass index. }\end{array}$ & $\begin{array}{l}\text { Based on this study it appears that } \\
\text { women with higher body mass } \\
\text { index may have higher prevalence } \\
\text { of facet joint pain. }\end{array}$ \\
\hline $\begin{array}{l}\text { Manchikanti et al, } 2002 \\
(489) \\
\text { Lumbar } \\
\text { Evaluation of the influence } \\
\text { of gender, occupational } \\
\text { injury, and smoking on } \\
\text { prevalence of facet joint } \\
\text { pain }\end{array}$ & $\begin{array}{l}320 \text { patients were evaluated with } \\
\text { controlled diagnostic blocks performed } \\
\text { with } 75 \% \text { pain relief with the ability to } \\
\text { perform previously painful movements } \\
\text { utilized as the criterion standard. }\end{array}$ & $\begin{array}{l}\text { Facet joint pain was present in } 38 \% \\
\text { of men compared to } 43 \% \text { of women. } \\
\text { Smokers had prevalence of } 43 \% \\
\text { compared to nonsmokers of } 41 \% \text { in heavy } \\
\text { smokers. Patients with occupational } \\
\text { injury reported } 28 \% \text { of prevalence of facet } \\
\text { joint pain compared to } 44 \% \text { with patients } \\
\text { with gradual onset without injury. False- } \\
\text { positive rates varied from } 28 \% \text { to } 46 \% \text {. }\end{array}$ & $\begin{array}{l}\text { The study showed the prevalence } \\
\text { of facet joint pain to be less in } \\
\text { men. There were no differences } \\
\text { based on smoking. }\end{array}$ \\
\hline \multicolumn{4}{|c|}{ Influence of Sedation and Opioid Exposure } \\
\hline $\begin{array}{l}\text { Manchikanti et al, } 2004 \\
(492) \\
\text { Lumbar } \\
\text { Assessment of the effect of } \\
\text { sedation as a confounding } \\
\text { factor in the diagnostic } \\
\text { validity of lumbar facet } \\
\text { joint pain }\end{array}$ & $\begin{array}{l}180 \text { patients with confirmed diagnosis } \\
\text { of facet joint pain following controlled } \\
\text { comparative local anesthetic blocks } \\
\text { were injected intravenously with } \\
\text { sodium chloride solution, midazolam, } \\
\text { or fentanyl. }\end{array}$ & $\begin{array}{l}\text { Pain relief of } 80 \% \text { was noted in } 2 \% \text { of } \\
\text { the patients in sodium chloride group, } \\
5 \% \text { of the patients in midazolam group, } \\
\text { and } 7 \% \text { of the patients receiving fentanyl. } \\
\text { However, pain relief of } 50 \% \text { or greater } \\
\text { was noted in } 7 \% \text { of the patients in sodium } \\
\text { chloride group, } 5 \% \text { of the patients in } \\
\text { midazolam group, and } 13 \% \text { of the } \\
\text { patients receiving fentanyl. }\end{array}$ & $\begin{array}{l}\text { Overall there was no significant } \\
\text { difference with placebo response } \\
\text { with either sodium chloride } \\
\text { solution, midazolam, or fentanyl } \\
\text { intravenous injections. The } \\
\text { administration of sedation with } \\
\text { midazolam or fentanyl may be a } \\
\text { confounding factor, specifically } \\
\text { if 50\% relief is used as a criterion } \\
\text { standard. }\end{array}$ \\
\hline $\begin{array}{l}\text { Manchikanti et al, } 2006 \\
\text { (452) } \\
\text { Lumbar and cervical } \\
\text { Assessment of placebo } \\
\text { and nocebo effects } \\
\text { of perioperative } \\
\text { administration of sedatives } \\
\text { and opioids in patients } \\
\text { with facet joint pain. } \\
\text { Randomized, double- } \\
\text { blind, placebo control }\end{array}$ & $\begin{array}{l}\text { A total of } 360 \text { patients were evaluated } \\
\text { in this randomized, controlled trial } \\
\text { on validity of facet joint nerve blocks } \\
\text { in patients suffering a combination of } \\
\text { lumbar and cervical facet joint pain. }\end{array}$ & $\begin{array}{l}\text { Overall } 50 \% \text { of the patients in the placebo } \\
\text { group and } 100 \% \text { of the patients in the } \\
\text { midazolam and fentanyl groups were } \\
\text { relaxed or sedated. } \geq 80 \% \text { relief was } \\
\text { observed in } 5 \% \text { of the patients in the } \\
\text { placebo group, } 10 \% \text { in the midazolam } \\
\text { group, and } 10 \% \text { in the fentanyl group. } \\
\geq 50 \% \text { relief was observed in } 5 \% \text { in the } \\
\text { placebo group, } 15 \% \text { in the midazolam } \\
\text { group, and } 15 \% \text { in the fentanyl group }\end{array}$ & $\begin{array}{l}\text { This study is unique in that it } \\
\text { evaluated both cervical and } \\
\text { lumbar facet joint pain with no } \\
\text { significant difference noted in } \\
\text { the diagnostic validity whether } \\
\text { midazolam or fentanyl is utilized } \\
\text { with } 80 \% \text { as the criterion } \\
\text { standard. With } 50 \% \text { pain relief } \\
\text { as the criterion standard, } 15 \% \text { of } \\
\text { the patients in the cervical region } \\
\text { reported pain relief. }\end{array}$ \\
\hline
\end{tabular}


Table 18. (cont.) Assessment of factors influencing prevalence and false-positive rates of facet joint pain in lumbar, cervical, and thoracic regions.

\begin{tabular}{|c|c|c|c|}
\hline Study & Methods and Assessment Criteria & Results & Comments \\
\hline $\begin{array}{l}\text { Manchikanti et al, } 2005 \\
(453) \\
\text { Lumbar and cervical } \\
\text { Effect of placebo and } \\
\text { nocebo }\end{array}$ & $\begin{array}{l}\text { This study evaluated the role of placebo } \\
\text { and nocebo effects of perioperative } \\
\text { administration of sedatives and opioids } \\
\text { in interventional pain management in } \\
360 \text { patients, } 180 \text { patients with chronic } \\
\text { low back pain, in a placebo controlled } \\
\text { randomized, double-blind evaluation. }\end{array}$ & $\begin{array}{l}\text { Between } 13 \% \text { and } 30 \% \text { of all patients } \\
\text { across all } 3 \text { groups of the study, rated their } \\
\text { pain relief following injection as better } \\
\text { than their previous experience. A small } \\
\text { proportion, } 3 \% \text { to } 8 \% \text { of patients in all } 3 \\
\text { groups rated their experience following } \\
\text { injection as worse than their previous } \\
\text { experience. }\end{array}$ & $\begin{array}{l}\text { This study shows it is not only } \\
\text { placebo effect that influences the } \\
\text { patients experience, but also the } \\
\text { nocebo effect even when opioid } \\
\text { and benzodiazepine are used. }\end{array}$ \\
\hline $\begin{array}{l}\text { Manchikanti et al, } 2004 \\
(491) \\
\text { Cervical } \\
\text { Randomized, double- } \\
\text { blind, placebo control }\end{array}$ & $\begin{array}{l}\text { The study was undertaken in an } \\
\text { interventional pain management } \\
\text { practice with inclusion of } 180 \text { patients } \\
\text { randomized into } 3 \text { groups. All patients } \\
\text { suffered with neck pain and had } \\
\text { undergone diagnostic and therapeutic } \\
\text { facet joint nerve blocks. }\end{array}$ & $\begin{array}{l}\geq 80 \% \text { pain relief } \\
\text { Placebo }=5 \% \\
\text { Midazolam }=8 \% \\
\text { Fentanyl }=8 \% \\
\text { Pain relief of } 50 \% \text { to } 79 \% \\
\text { Sodium chloride solution }=8 \% \\
\text { Midazolam }=13 \% \\
\text { Fentanyl }=27 \%\end{array}$ & $\begin{array}{l}\text { This study showed that when } \\
\text { higher relief }(80 \%) \text { is utilized, the } \\
\text { false-positive rate of diagnostic } \\
\text { cervical facet joint nerve blocks } \\
\text { is extremely low with } 8 \% \text { in } \\
\text { midazolam and fentanyl groups } \\
\text { compared to } 5 \% \text { in the placebo } \\
\text { group } \\
\text { At } 50 \% \text { to } 79 \% \text { pain relief there } \\
\text { was a higher proportion with } \\
8 \%, 13 \% \text {, and } 27 \% \text { with positive } \\
\text { response. The advantages of this } \\
\text { study are practical setting in } \\
\text { which patients already have been } \\
\text { diagnosed with facet joint pain. }\end{array}$ \\
\hline $\begin{array}{l}\text { Manchikanti et al, } 2008 \\
\text { (487) } \\
\text { Cervical, thoracic, and } \\
\text { lumbar } \\
\text { Retrospective }\end{array}$ & $\begin{array}{l}\text { Data were evaluated from } 438 \\
\text { patients with chronic spinal pain who } \\
\text { underwent diagnostic facet joint nerve } \\
\text { blocks based on the level of opioid use } \\
\text { with no opioid use, low opioid use, } \\
\text { moderate opioid use, and high opioid } \\
\text { use. }\end{array}$ & $\begin{array}{l}\text { No opioid use: } \\
\text { Prevalence }=33 \% \\
\text { False-positive rate }=53 \% \\
\text { Heavy opioid use: } \\
\text { Prevalence }=37 \% \text { to } 53 \% \\
\text { False-positive rate }=38 \%\end{array}$ & $\begin{array}{l}\text { This study evaluated the influence } \\
\text { of prior opioid exposure on } \\
\text { diagnostic facet joint nerve } \\
\text { blocks. This appears to be the } \\
\text { first study performed in a large } \\
\text { proportion of patients in a private } \\
\text { practice setting with controlled, } \\
\text { comparative local anesthetic } \\
\text { blocks }\end{array}$ \\
\hline \multicolumn{4}{|c|}{ Influence of Diagnostic Blocks on Therapeutic Outcomes } \\
\hline $\begin{array}{l}\text { Pampati et al, } 2009 \text { (446) } \\
\text { Lumbar } \\
\text { Diagnostic validity study }\end{array}$ & $\begin{array}{l}\text { Authors evaluated } 152 \text { patients } \\
\text { diagnosed with lumbar facet joint pain } \\
\text { utilizing controlled comparative local } \\
\text { anesthetic blocks, with lidocaine } 1 \% \\
\text { or bupivacaine } 0.25 \% \text { with concordant } \\
\text { relief with criterion standard of } 80 \% \\
\text { the accuracy of diagnostic lumbar facet } \\
\text { joint nerve blocks. Assessment was } \\
\text { carried out at a } 2 \text { year follow-up. }\end{array}$ & $\begin{array}{l}\text { At the end one year, } 93 \% \text { of the patients } \\
\text { and at the end of } 2 \text { years } 89.5 \% \text { of the } \\
\text { patients were considered to have lumbar } \\
\text { facet joint pain. }\end{array}$ & $\begin{array}{l}\text { Controlled comparative local } \\
\text { anesthetic blocks with } 80 \% \text { pain } \\
\text { relief showed validity. }\end{array}$ \\
\hline $\begin{array}{l}\text { Cohen et al, } 2010 \text { (455) } \\
\text { Lumbar } \\
\text { Evaluation of the role of } \\
\text { diagnostic blocks without } \\
\text { any diagnostic blocks, with } \\
\text { a single diagnostic block, } \\
\text { or dual diagnostic block }\end{array}$ & $\begin{array}{l}\text { Authors evaluated } 151 \text { patients with } \\
\text { suspected lumbar facet joint pain for } \\
\text { radiofrequency neurotomy. Group I was } \\
\text { treated with radiofrequency denervation } \\
\text { without diagnostic blocks, Group II with } \\
\text { a positive response for a single diagnostic } \\
\text { block with } 50 \% \text { relief, and Group III } \\
\text { underwent radiofrequency neurotomy in } \\
\text { patients who were positive with controlled } \\
\text { comparative local anesthetic blocks with a } \\
50 \% \text { relief of criterion standard. }\end{array}$ & $\begin{array}{l}\text { In "0"group, } 17 \text { patients ( } 33 \% \text { ) obtained a } \\
\text { successful outcome at } 3 \text { months versus } 8 \\
\text { patients (16\%) in "1" and "2" group (22\%) } \\
\text { patients in group " } 2 \text { ". Denervation success } \\
\text { rates in groups } 0,1 \text {, and } 2 \text { were } 33,39 \text {, and } \\
64 \% \text {, respectively. }\end{array}$ & $\begin{array}{l}\text { This study showed clearly that } \\
\text { dual diagnostic blocks were } \\
\text { superior to either no diagnostic } \\
\text { block or a single diagnostic block, } \\
\text { despite miscalculation of cost } \\
\text { effectiveness. }\end{array}$ \\
\hline $\begin{array}{l}\text { Manchikanti et al, } 2010 \\
(448) \\
\text { Lumbar } \\
\text { Assessment of the accuracy } \\
\text { of diagnostic lumbar facet } \\
\text { joint nerve blocks with either } \\
50 \% \text { relief or } 80 \% \text { relief as } \\
\text { the criterion standard with } \\
\text { controlled comparative local } \\
\text { anesthetic blocks }\end{array}$ & $\begin{array}{l}\text { Controlled comparative local anesthetic } \\
\text { blocks were performed with lidocaine, } \\
\text { bupivacaine, with either } 50 \% \text { to } 79 \% \\
\text { relief or over } 80 \% \text { relief as the criterion } \\
\text { standard with ability to perform } \\
\text { previously painful movements. }\end{array}$ & $\begin{array}{l}\text { At the end of one year, the diagnosis was } \\
\text { confirmed in } 75 \% \text { of the group with } 50 \% \\
\text { relief, whereas it was } 93 \% \text { in the group } \\
\text { with } 80 \% \text { relief. At the end of } 2 \text {-year } \\
\text { follow-up, the diagnosis of lumbar facet } \\
\text { joint pain was sustained in } 51 \% \text { of the } \\
\text { patients in the group with } 50 \% \text { relief, } \\
\text { whereas it was sustained in } 89.5 \% \text { of the } \\
\text { patients with } 80 \% \text { relief. }\end{array}$ & $\begin{array}{l}\text { Application of } 80 \% \text { relief with } \\
\text { controlled comparative local } \\
\text { anesthetic blocks provides a } \\
\text { robust diagnostic criteria. }\end{array}$ \\
\hline
\end{tabular}


Table 18. (cont.) Assessment of factors influencing prevalence and false-positive rates of facet joint pain in lumbar, cervical, and thoracic regions.

\begin{tabular}{|c|c|c|c|}
\hline Study & Methods and Assessment Criteria & Results & Comments \\
\hline $\begin{array}{l}\text { Manchikanti et al, } 2003 \\
(447) \\
\text { Lumbar } \\
\text { Evaluation of the accuracy } \\
\text { of diagnostic facet joint } \\
\text { nerve blocks with a long- } \\
\text { term follow-up }\end{array}$ & $\begin{array}{l}\text { The diagnosis was established with } \\
\text { dual blocks with } 80 \% \text { pain relief with } \\
\text { ability to perform previously painful } \\
\text { movements. }\end{array}$ & $\begin{array}{l}85 \% \text { of the patients available for follow- } \\
\text { up withstood the diagnosis of facet joint } \\
\text { pain at the end of } 2 \text { years, whereas this } \\
\text { proportion decreased to } 75 \% \text { if all the } \\
\text { patients in the study were included in the } \\
\text { intent-to-treat analysis. }\end{array}$ & $\begin{array}{l}\text { The study shows that diagnostic } \\
\text { lumbar medial branch blocks are } \\
\text { valid and the diagnosis of facet } \\
\text { joint pain is sustainable after } 2 \\
\text { years. }\end{array}$ \\
\hline \multicolumn{4}{|c|}{ Miscellaneous (Volume of Local Anesthetic ) } \\
\hline $\begin{array}{l}\text { Cohen et al, } 2010 \text { (474) } \\
\text { Cervical } \\
\text { Randomized }\end{array}$ & $\begin{array}{l}24 \text { patients with chronic neck pain } \\
\text { were allocated to receive cervical } \\
\text { medial branch blocks. Patients were } \\
\text { selected with predominance of axial } \\
\text { cervical pain for more than } 3 \text { months, } \\
\text { with failure to respond to conservative } \\
\text { therapy, and asymmetry in laterality. }\end{array}$ & $\begin{array}{l}\text { Prevalence }=55 \% \text { with low volume and } \\
25 \% \text { with high volume. }\end{array}$ & $\begin{array}{l}\text { A very small proportion of } \\
\text { patients were included with } \\
12 \text { patients in each group. The } \\
\text { results are perplexing in that } \\
\text { volume spread and the specificity } \\
\text { of the blocks had no relevance to } \\
\text { positive response. }\end{array}$ \\
\hline
\end{tabular}

Adapted and modified from: Boswell MV, et al. A best-evidence systematic appraisal of the diagnostic accuracy and utility of facet (zygapophysial) joint injections in chronic spinal pain. Pain Physician 2015; 18:E497-E533 (18).

$(291,421)$, assessed 153 patients showing the results that lumbar facet joint pain was the most likely source of chronic low back pain for men who were approximately 54 years of age, regardless of body mass index (BMI). However, for women who were 65 years old, facet joint pain was most likely. Manchikanti et al (483) in a study of 100 patients, showed a significantly higher prevalence of facet joint pain in those over 65 years old.

\subsubsection{Psychological Factors}

Psychological aspects of chronic musculoskeletal pain have been discussed extensively (520-525). Cognitive and emotional factors have a surprisingly important influence on pain perception and these relationships are interrelated to the regions of the brain controlling pain perception, attention or expectation, and emotional states (525). There are multiple studies that patients with chronic pain have alterations in brain regions involved in cognitive and emotional modulation of pain (520). This interplay has been described over the years as psychogenic rheumatism (521), functional somatic syndromes (522), and polysymptomatic distress (523). Diagnostic and Statistical Manual of Mental Disorders (DSM-V) has replaced the previous category of somatoform disorders with "somatic symptom disorder (SSD)" (524). The diagnosis is characterized by distressing somatic symptoms plus abnormal thoughts, feelings, and behaviors in response to these symptoms. Consequently, the influence of psychological factors on the diagnosis and management of facet joint pain is crucial.

The influence of psychological factors was assessed in 2 studies $(488,493)$. Manchikanti et al (488) assessed 438 patients undergoing controlled comparative local anesthetic blocks showing the prevalence of facet joint to range from $25 \%$ to $40 \%$ in those who had no psychopathology, whereas it ranged from $28 \%$ to $43 \%$ in those diagnosed with either major depression, generalized anxiety disorder, or somatization disorder, compared to $23 \%$ to $39 \%$ in patients with a negative psychological diagnosis. Further, they also showed that regional facet joint pain prevalence and false-positive rates were higher in the cervical region in patients with major depression. However, no differences were identified in the lumbar and thoracic regions. Wasan et al (493) also assessed the influence of psychological factors in lumbar and cervical facet joint pain in a small sample size of 86 patients. They concluded that the low psychopathology group reported a mean $23 \%$ improvement in pain at one month, while the high psychopathology group reported worsening of pain.

\subsubsection{Body Mass Index}

The influence of BMI was assessed in 2 studies $(421,484)$. In these assessments, DePalma et al (421) in a study of 153 patients with chronic low back pain showed that there was correlation between significant increases in facet joint pain based on BMI. However, Manchikanti et al (484) showed a similar prevalence of $36 \%$ versus $40 \%$ in both groups.

\subsubsection{Influence of Surgery}

The influence of surgery was assessed in multiple studies in the lumbar spine and one study in the cervi- 
cal spine $(177,178,189,190-192)$. Overall, these results showed prevalence of facet joint pain was lower in patients after surgical intervention in the lumbar spine $(177,189,190)$ with no difference in the cervical spine (178). In the assessment by Manchikanti et al (177) showed prevalence of facet joint pain in $16 \%$ of the patients. The number of patients studied was too low to reach any conclusions in the studies by DePalma and colleagues.

\subsubsection{Influence of Opioid Exposure}

Many patients presented to interventional pain management on long-term opioid therapy. There have not been many studies related to opioid exposure and subsequent validity of diagnostic blockade or diagnostic accuracy of facet joint pain with noninvasive measures. Manchikanti et al (487) assessed the influence of prior opioid exposure on diagnostic facet joint nerve blocks in 438 patients. They divided the patients into no opioid use group, low opioid use group, moderate opioid use group, and heavy opioid use group. The results showed no correlation to prior and current opioid use in reference to the diagnostic validity of the controlled comparative local anesthetic blocks. The results also showed that there was no significant difference in patients who were exposed to opioids prior to undergoing facet joint nerve blocks with a prevalence of $33 \%$ and a false-positive rate of $53 \%$ in patients without opioid exposure and in those with heavy opioid use, prevalence ranged from $37 \%$ to $53 \%$ with a false-positive rate of $38 \%$ (481). Cohen et al (458) also reported that opioid use was associated with failure of the treatment with lumbar radiofrequency neurotomy.

\subsubsection{Influence of Sedation}

Influence of sedation was discussed extensively and also elicits significant discussions among proponents and opponents of the sedation. Sedation during interventional techniques, specifically facet joint interventions, is a controversial area. Sedation for interventional techniques costs over $\$ 300$ million a year, with $\$ 90$ million in FFS Medicare. Consequently, if facet joint interventions constitute approximately $40 \%$ of the interventional techniques, without including procedures such as spinal cord stimulation, at least $\$ 80$ million may be expended on sedation itself, which is a significant expense for these procedures. Multiple authors have investigated the necessity for sedation and the potential influence of sedation on diagnostic validity of facet joint nerve blocks $(491,492,494-498)$.
Manchikanti et al $(491,492,494,498)$ assessed the influence of sedation, either with midazolam, fentanyl, or midazolam with fentanyl in multiple controlled trials. In a prospective, randomized, double blind, placebocontrolled evaluation (492), the authors showed that placebo group with administration of either sodium chloride solution or 2 experimental groups receiving either midazolam or fentanyl were assessed in patients who had confirmed diagnosis of lumbar facet joint pain. The evaluation was performed prior to lumbar facet joint nerve block treatment with significant return of pain. The results showed that $80 \%$ or greater pain relief was noted in $2 \%$ of the patients in the sodium chloride group, $5 \%$ of the patients in midazolam group, and $7 \%$ in the fentanyl group. In contrast, pain relief of $50 \%$ or more was noted in $7 \%$ of the patients in sodium chloride group, $5 \%$ of the patients in midazolam group, and $13 \%$ of the patients in fentanyl group. They concluded that utilizing criterion standard of $80 \%$ pain relief with ability to perform previously painful movements, there was no confounding. However, there may be some confounding, specifically with administration of fentanyl and use of $50 \%$ pain relief as the criterion standard.

In another study, Manchikanti et al (491) assessed the role of sedation in cervical facet joint pain utilizing the same protocol as described above. The results of this study showed when $80 \%$ pain relief was used as the criterion standard with ability to perform previously painful movements, $5 \%$ of the patients in sodium chloride group reported pain relief, $8 \%$ in midazolam group, and $8 \%$ in fentanyl group. However, when $50 \%$ relief was considered as the criterion standard, $8 \%$ of the patients in the sodium chloride group, $13 \%$ in midazolam group, and $27 \%$ in fentanyl group were shown to be positive. Consequently, with $80 \%$ pain relief, there was no major confounding. However, there is significant confounding with $50 \%$ pain relief.

Manchikanti et al (494) also assessed similarities in population with involvement in cervical and lumbar regions and effect of sedation. Overall, in these patients with combined cervical and lumbar facet joint pain, $50 \%$ of the patients were relaxed or sedated in the placebo group and $10 \%$ of the patients reported significant relief of $\geq 80 \%$ with ability to perform previously painful movements. In contrast, $100 \%$ of the patients in the midazolam and fentanyl groups were relaxed or sedated. As many as $10 \%$ of the patients reported significant relief ( $80 \%$ or greater) with ability to perform prior painful movements. Thus, patients with lumbar 
facet joint pain alone, cervical facet joint pain alone, or combination of lumbar and cervical facet joint pain behave differently.

In addition, Manchikanti et al (498) assessed the role of placebo and nocebo effects of perioperative administration of sedatives and opioids in interventional pain management. Surprisingly, they found that between $13 \%$ to $30 \%$ of the patients across all 3 groups of the study related their pain relief following injection as better than their previous experience. A smaller proportion, $3 \%-8 \%$ of the patients, in all 3 groups rated their experience following injection as worse than their previous experience. The majority of patients, $67 \%$ to $79 \%$, regardless of groups, described no significant differences as compared to their previous experience with sedation and treatment for cervical or lumbar facet joint pain.

Cohen et al (495) described the effect of sedation on accuracy and treatment of outcomes for diagnostic injections, which included sacroiliac joint injections and sympathetic blocks. They concluded that the use of sedation during diagnostic injections may increase the rate of false-positive blocks and lead to misdiagnosis and unnecessary procedures, but has no effect on satisfaction for outcomes. However, they also discussed that in some scenarios in which the judicious use of anxiolytics and even analgesics, may enhance accuracy including technically challenging procedures (e.g., obesity) in extremely anxious individuals and in cognitively challenged patients who may not be able to distinguish their index pain from procedure-induced comfort. In another study (496), discussion was carried out in reference to if sedation was indicated before spinal injections in 301 consecutive spinal injection patients. The results showed that $58 \%$ of patients chose to be sedated. The patients who requested sedation were more anxious. The majority of patients were satisfied with their decision regarding sedation, and diazepam effectively controlled anxiety in $90 \%$ of the patients. They concluded that routine sedation does not seem to be required for patients receiving spinal injections, but more anxious patients benefit from sedation before an injection. In a survey of conscious sedation with epidural and zygapophysial injections (497), 500 consecutive patients undergoing spinal injections were assessed. In this survey, only $17 \%$ of patients requested sedation before an injection; however, $28 \%$ would request sedation if they were to have a second injection.

Thus, opinions are highly variable based on philosophies, type of practice, and the availability of facilities. Kaye et al (110) also has published guidelines for seda- tion and fasting of patients undergoing interventional pain management procedures, with discussions on a multitude of issues related to complications associated with monitored anesthesia care and heavy sedation.

Overall, there is no literature to support monitored anesthesia care specifically utilizing separate personnel from an anesthesia department costing additional resources and expenditures to be indicated or beneficial in any of the settings. All local coverage determinations (LCDs) and medical policies state sedation is not necessary; however, they continue to reimburse and thereby add it to the cost of interventional techniques.

\subsubsection{Volume of Injection}

Volume of injection for diagnostic blocks has been a frequently discussed issue $(18,283,285,289,441-444)$. It has been recommended to use volumes of less than $0.5 \mathrm{~mL}$ per level for diagnostic blocks. In one study, Cohen et al (474) studied the effect of different injectate volumes in the cervical spine, which paradoxically provided contradictory results to the hypothesis that low volumes must be used showing a higher prevalence of $55 \%$ of facet joint pain when low volume was utilized in contrast to a prevalence of $25 \%$ when high volume was utilized.

\subsubsection{Influence of Diagnostic Blocks on Their Outcomes}

Multiple authors have studied the value and validity of diagnostic blockade, not only for the diagnosis of facet joint pain, but also subsequent therapeutic outcomes. Multiple issues raised include the role of single blocks compared to dual blocks, pain relief threshold of $50 \%, 80 \%$ or $100 \%$, medial branch blocks versus intraarticular injections, and involvement of single region versus 2 regions, or involvement of a single region versus multiple regions. The validity of lumbar facet joint nerve blocks as a gold standard in the diagnosis of lumbar facet joint pain; however, continues to be questioned. Various reference standards applied in surgical situations, such as biopsy, surgery, or autopsy, are difficult to apply in diagnosing chronic low back pain of facet joint origin and the pain relief following the diagnostic block, even with relief of pain after provocation following diagnostic blocks are looked at with skepticism. The long-term follow-up appears to be the only standard to be applied in confirming the validity of facet joint nerve blocks and establishing them as the gold standard. This has been achieved in numerous studies. However, the outcomes were also evaluated 
specifically based on judging the accuracy in multiple studies. Pampati et al (446) assessed the accuracy of diagnostic lumbar facet joint nerve blocks with follow-up for 2 years after a positive diagnosis. In this study, a total of 491 patients were assessed with a prevalence rate of $31 \%$ and a false-positive rate of $42 \%$ with dual block positive patients of 152 . Subsequently, these patients were treated with therapeutic lumbar facet joint nerve blocks. At the end of one year, $93 \%$ of the patients continued to respond to the therapeutic facet joint nerve blocks and at the end of 2 years, $89.5 \%$ of the patients were considered to have lumbar facet joint pain.

Manchikanti et al (448) also assessed the implications of $50 \%$ relief and $80 \%$ relief single block or controlled diagnostic blocks. In this assessment, they compared the data from Pampati et al (446) of 152 patients with sustained diagnosis of lumbar facet joint pain at the end of 2 years in $89.5 \%$ when the diagnosis was made with dual blocks with at least $80 \%$ relief. In this evaluation, they compared the results of 110 patients undergoing lumbar facet joint nerve blocks with positive criteria of at least $50 \%$ relief and follow-up of 2 years. In this group of patients, at the end of 2 years, the diagnosis of lumbar facet joint pain was sustained only in $51 \%$ of the patients compared to $89.5 \%$ of the patients with $80 \%$ pain relief. The study also showed single blocks to result in inordinately high positive rates with $50 \%$ relief of single block prevalence of $73 \%$, whereas it was $61 \%$ with dual blocks. In contrast with $80 \%$ criterion standard, single block prevalence was $53 \%$ and dual block prevalence was $31 \%(459,474)$.

In contrast, Cohen et al $(455,458,459)$ have published multiple manuscripts contradicting prognostic effectiveness of facet joint nerve blocks and also the role of dual blocks with $80 \%$ pain relief. All their studies included only $50 \%$ relief as the criterion standard with a single block. In a study of medial branch blocks or intraarticular injections as a prognostic tool before lumbar facet joint radiofrequency denervation (458), they showed that a total of $70.3 \%$ of medial branch patients experienced $50 \%$ or more pain relief at the 3-month follow-up versus $60.8 \%$ in those who underwent intraarticular injections. Even though they went on postulating various theories and the role of how their patients responded to radiofrequency neurotomy, they do show that diagnostic facet joint injections provide significant long-term relief. Cohen et al (459) also assessed an optimum cutoff threshold for diagnostic lumbar facet blocks in a prospective correlational study. They concluded that there were no significant differences in radiofrequency outcomes based on any medial branch block relief cutoff over $50 \%$. Cohen et al (455) also assessed the role of 0,1 , and 2 diagnostic medial branch block treatment paradigms before lumbar facet radiofrequency denervation. In this analysis, they clearly showed that dual blocks were superior in the response, yet they continued to claim that single block or no block is effective in managing facet joint pain. In a recent study (95), they assessed the effectiveness of lumbar facet joint blocks prior to radiofrequency neurotomy and once again they demonstrated some improvement with diagnostic blocks. They also utilized criteria of positive outcome at one month prior to radiofrequency neurolysis. Once again, they propagated the theory that facet joint nerve blocks are not therapeutic based on their flawed theory.

The role of facet joint pain and the prevalence was also studied in patients with involvement of a single region or multiple regions (486). Manchikanti et al (486) in a study of correlation of facet joint pain in lumbar and cervical spine in patients with involvement of both regions showed that cervical facet joint pain was present in $67 \%$ of the patients with a false-positive rate of $63 \%$ with a single block, whereas the prevalence of lumbar facet joint pain was seen in $40 \%$ of the patients with a $30 \%$ false-positive rate with a single block in patients presenting with chronic low back pain. There was no significant difference noted in the prevalence or falsepositive rate based on involvement of a single region or both cervical and lumbar regions. However, in chronic low back pain of facet joint origin with involvement of single or multiple regions, the prevalence of lumbar facet joint in patients with low back only was $21 \%$, compared to $41 \%$ of the patients with low back pain with involvement of other regions of the spine with controlled comparative local anesthetic blocks. A false-positive rate of $17 \%$ in patients with low back pain only and $21 \%$ in patients with involvement of multiple regions of the spine was demonstrated with single blocks (485). The authors concluded that incidence of facet joint pain is lower when only a single spine region is involved rather than multiple regions ( $21 \%$ versus $41 \%)$.

Summary of evidence is as follows:

- The level of evidence is II for intraoperative opioids may affect the diagnostic validity of facet joint nerve blocks, with moderate recommendation to avoid opioids.

- The level of evidence is II showing benzodiazepines do not affect the validity of diagnostic facet joint nerve blocks with moderate recommendation that 
they may be utilized.

- The level of evidence is II that moderate sedation may be required and utilized during performance of facet joint interventions with moderate recommendation to provide the sedation and analgesia during therapeutic interventions.

- The level of evidence is I for monitored anesthesia care for facet joint interventions with strong recommendation against the use of monitored anesthesia care for diagnostic or therapeutic interventions, except in extremely rare circumstances.

- The level of evidence is III that prevalence of facet joint pain and false-positive results may be higher in patients with multiple region involvement, prevalence of facet joint pain lower in post-surgery syndrome, and higher prevalence in older age population, with moderate recommendation to take these factors into consideration in providing appropriate diagnosis and therapy.

- The level of evidence is III for influence of psychological factors affecting the outcomes with moderate recommendation to exercise caution in patients with combined depression, anxiety, and somatization disorder.

- The level of evidence is II that interventional diagnostic approaches be applied in the chronic phase after 3 months of onset, failure of conservative modalities of management with medical therapy, structured exercise program, and physical therapy, with noninvasive diagnostic assessment leading towards diagnostic facet joint nerve blocks; with strong recommendation to follow the guidance.

\subsection{Therapeutic Facet Joint Interventional TECHNIQUES}

Key Question 6: Are the available therapeutic facet joint interventional therapies in managing chronic spinal pain effective?

The value of diagnostic tests is only academic if a treatment cannot be provided. The treatment cannot be provided without appropriate diagnosis. Based on the present evidence for diagnostic appropriateness of controlled diagnostic blocks, 3 types of therapeutic interventions are available: intraarticular injections, facet joint nerve blocks, and radiofrequency neurotomy.

Multiple systematic reviews $(19,22,24,33,35,42,519)$, RCTs and observational studies $(19,22,24,33-36)$ and guidelines $(6,23)$ have been published. The latter 2 interventions have been shown to be clinically appropriate with clinical evidence and cost utility in favor of them.
Prior to initiating on either diagnostic or therapeutic interventional procedures, all patients are treated with conservative management with structured exercise program, education, and if needed, physical therapy and drug therapy. However, failure of conservative management leads to therapeutic interventional techniques with intraarticular injections, facet joint nerve blocks, and radiofrequency neurotomy.

\subsection{Methods}

Methodology included identification of systematic reviews and studies for the review, which included relevant RCTs and observational studies with description of appropriate outcomes and follow-up. All the studies must have included the primary outcome parameter of pain relief and other secondary outcomes such as functional status improvement. For therapeutic modalities, short-term relief was considered as anything less than 6 months of improvement in pain and function, whereas at least one year of pain relief with improvement in functional status was considered as long-term improvement.

\subsubsection{Literature Search}

All available literature in all languages from all countries providing appropriate management with outcome evaluations were considered for inclusion. Searches were performed from the following sources without language restrictions:

1. PubMed from 1966 www.ncbi.nlm.nih.gov/sites/ entrez?db=pubmed

2. Cochrane Library www.thecochranelibrary.com/ view/0/index.html

3. Google Scholar https://scholar.google.com/

4. US National Guideline Clearinghouse (NGC) www. guideline.gov/

5. Previous systematic reviews and cross references

6. Clinical Trials clinicaltrials.gov/

7. All other sources including non-indexed journals and abstracts

The search period was from 1966 through March 2020.

\subsubsection{Search Strategy}

The search strategy emphasized chronic cervical, mid back, and low back pain, facet or zygapophysial joint pain, cervical, thoracic, and lumbar facet joint interventions including radiofrequency neurotomy, intraarticular injections and facet joint nerve blocks. 
Search criteria were as follows: ic low back pain) OR chronic back pain) OR chronic neck pain OR chronic thoracic pain) OR disc herniation) OR discogenic pain) OR facet joint pain) OR herniated lumbar discs) OR nerve root compression) OR lumbosciatic pain) OR postlaminectomy) OR lumbar surgery syndrome) OR radicular pain) OR radiculitis) OR sciatica) OR spinal fibrosis) OR spinal stenosis) OR zygapophysial)) AND (((()(facet joint) OR zygapophyseal) OR zygapophysial) OR medial branch block) OR diagnostic block) OR radiofrequency) OR intraarticular injection)

\subsubsection{Methodologic Quality or Bias Assessment}

Methodologic quality assessment of RCTs and observational studies utilizing Cochrane review criteria (Appendix Table 2) (526), and Interventional Pain Management techniques - Quality Appraisal of Reliability and Risk of Bias Assessment (IPM-QRB) for RCTs and Appendix Table 3) (527), and Interventional Pain Management Techniques - Quality Appraisal of Reliability and Risk of Bias Assessment for Nonrandomized Studies (IPM-QRBNR) was utilized for observational studies, as shown in Appendix Table 4 (528).

\subsubsection{Data Collection Analysis}

Data collection and analysis with appropriate inclusion and exclusion criteria, methodologic quality assessment, data extraction and management, measurement of treatment effects in data synthesis with qualitative and quantitative analysis, and analysis of evidence was performed as described in previous guidelines and systematic reviews $(19,24,28-32)$. The data analysis was conducted utilizing best evidence synthesis using 5 levels of evidence ranging from strong (Level $\mathrm{I}$ ) to opinion or consensus-based (Level V) as shown in Table 1 (119-121).

Review criteria utilized for Cochrane review was categorized as high quality, moderate quality, and low quality with a score of at least 8 to 13,4 to 7 , and less than 4, respectively. For IPM-QRB and IPM-QRBNR criteria utilized were less than 16 as low quality, 16 to 31 as moderate quality, and 32 to 48 as high quality. Analysis was performed only if new studies were available since the previous publications $(19,22)$.

\subsection{Results}

Based on comprehensive search criteria there were multiple studies considered for inclusion $(19,22,24,33$ $36,95,508-513,519,529-606)$ from multiple studies identified $(19,22,24,33-36,508-513,519,529-613)$. The results are shown in Fig. 12.

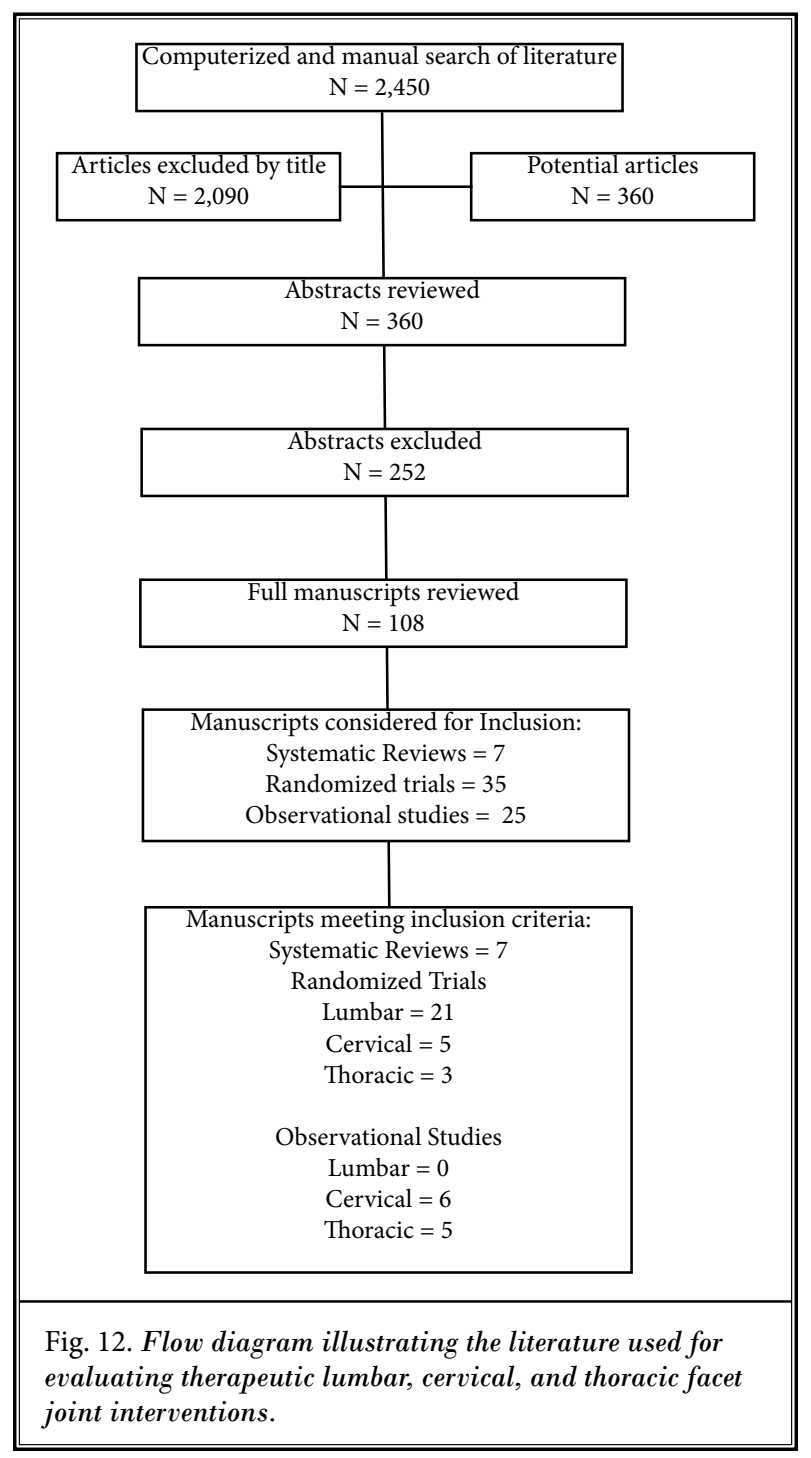

\subsubsection{Systematic Reviews}

Multiple systematic reviews have been performed based on methodological assessments; however, some or many of the systematic reviews appear to have displayed significant bias and contained methodological errors. Among the systematic reviews since 2015, the Cochrane review by Maas et al (34) assessed radiofrequency neurotomy utilizing RCTs only in chronic low back pain who had a positive response to a diagnostic block. They assessed 12 studies of suspected facet joint pain. They showed that there was moderate evidence suggesting that facet joint radiofrequency denervation has a greater effect on pain compared with placebo over the short-term. However, they also concluded that 
low quality evidence indicated that facet joint radiofrequency denervation is more effective than placebo for function over the short-term and over the long-term. Evidence of very low to low quality showed that facet joint radiofrequency denervation was more effective for pain than steroid injections over the short, intermediate, and long-term.

Manchikanti et al (19) evaluated in a systematic review and best evidence synthesis of effectiveness of therapeutic facet joint interventions in managing chronic spinal pain. They included all 3 regions (cervical, thoracic, and lumbar) and 3 types of interventions (intraarticular, facet joint nerve blocks, and facet joint radiofrequency neurotomy). Overall, they included 21 randomized trials and 5 observational studies. They performed strict methodologic quality assessment utilizing Cochrane review criteria, IPM-QRB, and IPMQRBNR $(526,527)$. The level of evidence was classified at levels from Level I to Level V. Data sources included through March 2015. They showed that there was Level II evidence for radiofrequency neurotomy and lumbar facet joint nerve blocks and Level III evidence for lumbosacral intraarticular injections in the lumbar spine. In the cervical spine, there was Level II evidence for radiofrequency neurotomy and facet joint nerve blocks, and Level IV evidence for cervical intraarticular injections. In the thoracic spine, evidence was Level II for thoracic facet joint nerve blocks and Level IV for radiofrequency neurotomy for long-term improvement.

Schneider et al (519) performed a systematic review of effectiveness of lumbar medial branch thermal neurotomy, stratified for diagnostic methods and procedural technique. They attempted to stratify the effectiveness based on different selection criteria and procedural techniques. Their results showed variation based on the selection criteria and procedural technique. They showed that at 6 months, $26 \%$ of patients selected via a single medial branch block with $50 \%$ relief and treated via perpendicular technique achieved at least $50 \%$ pain relief. In contrast, $49 \%$ of the patients selected after controlled diagnostic medial branch blocks with $50 \%$ pain relief and treated with parallel technique achieved at least $50 \%$ pain relief. The most rigorous patient selection and technique with 2 diagnostic medial branch blocks with 100\% pain relief and parallel electrode placement, resulted in $56 \%$ of patients experiencing $100 \%$ relief of pain at 6 months. In addition, they also assessed $70 \%$ to $80 \%$ relief of pain after diagnostic blocks, reports showing $57 \%$ of patients at 6 months after radiofrequency thermoneurolysis showing $50 \%$ relief and $22 \%$ showing at least $80 \%$ relief (519).

However, the assessment suffers because of significant issues with the authors' bias towards a parallel technique, $100 \%$ relief with diagnostic block and $100 \%$ relief with treatment response. Further, methodologic quality assessment was not performed appropriately; there was no meta-analysis. The disadvantages include lack of methodologic quality and bias assessment and bias of the authors engrained with their own society and their procedural guidelines rather than clinical guidelines.

Manchikanti et al (24) evaluated the effectiveness of interventional pain management strategies in the cervical spine. In this analysis, they showed Level II evidence for the long-term effectiveness of radiofrequency neurotomy and facet joint nerve blocks in managing cervical facet joint pain (22).

Manchikanti et al (22) assessed the effectiveness of lumbar facet joint interventions. They assessed a total of 14 randomized, controlled trials with assessment of the efficacy of intraarticular injections, facet joint nerve blocks, and radiofrequency neurotomy of the innervation of the facet joints. They showed variable evidence with appropriate methodologic quality assessment and best evidence synthesis. They showed variable evidence from Level II to III, with Level II evidence for lumbar facet joint nerve blocks and radiofrequency neurotomy for long-term improvement of longer than 6 months, and Level III evidence for lumbosacral facet joint intraarticular injections for short-term improvement only.

Lee et al (33) evaluated the efficacy of conventional radiofrequency denervation in patients with chronic low back pain originating from the facet joints. They included data from 7 trials involving 454 patients who had undergone radiofrequency denervation in 231 patients and controlled treatments such as sham or epidural block procedures in 223 patients. The radiofrequency group exhibited significantly greater improvements in back pain score when compared with the control group for one-year follow-up even though the average improvement VAS scores exceeded the minimum clinically important difference (MCID), the lower limit of the $95 \%$ $\mathrm{Cl}$ encompassed the MCID. The subgroup of patients who responded very well to diagnostic block procedures demonstrated significant improvements in back pain relative to the control group at the time. Overall, they concluded that conventional radiofrequency denervation resulted in significant reductions in low back pain originating from the facet joints in patients showing 
the best response to diagnostic blocks over the first 12 months when compared to with sham procedures.

Engel et al (35) evaluated the effectiveness and risks of fluoroscopically guided cervical medial branch thermal radiofrequency neurotomy with a systematic review and comprehensive analysis of the published data. The disadvantages include lack of methodologic quality and bias assessment and bias of the authors engrained with their own society and their procedural guidelines rather than clinical guidelines. Engel et al (35) showed that the majority of patients were pain free at 6 months and over a third were pain free at one year. The number needed to treat for complete relief at 6 months was 2. Authors (35) contended that the evidence of effectiveness was of high quality based on 8 primary publications. However, for safety assessment, they utilized 12 studies, most side effects were minor and temporary. No serious complications have been reported from the procedures performed according to their own published guidelines.

\subsection{Evidence Synthesis}

The evidence was synthesized based on the modality of treatment for each region.

\subsubsection{Lumbar Spine}

Table 19 shows methodologic quality criteria assessment of RCTs of lumbar facet joint interventions utilizing Cochrane review criteria.

Table 20 shows methodologic quality criteria assessment utilizing IPM-QRB criteria for lumbar facet joint interventions.

The evidence of effectiveness of lumbar radiofrequency neurotomy, facet joint nerve blocks, and intraarticular injection is shown in Table 21. A total of 21 randomized trials $(36,94,455,508,509,529$ $536,538,544,545,548,550,551,566,572)$ met inclusion criteria with 11 trials evaluating lumbar radiofrequency neurotomy $(36,455,531-536,544,545,566), 3$ studies evaluating therapeutic lumbar facet joint nerve blocks $(508,509,535)$, and 9 studies evaluating lumbar intraarticular injections $(94,529,530,536,538,548,550,55$ 1,572). Even though, there were only 3 trials evaluating therapeutic lumbar facet joint nerve blocks, there were no observational studies available meeting the inclusion criteria.

Table 22 shows study characteristics of RCTs and observational studies assessing radiofrequency neurotomy, facet joint nerve blocks, and intraarticular injections.

\subsubsection{Radiofrequency Ablation}

Of the 11 trials meeting the inclusion criteria, 2 trials $(36,532)$ showed lack of effectiveness and were judged to be negative. Of the remaining 9 studies, all of them showed short-term effectiveness; however, long-term effectiveness at one year was demonstrated only in 4 studies $(533-535,541)$. Further, all the trials had small number of patients with 50 patients in one study undergoing conventional radiofrequency neurotomy (535), 20 patients in another study (534), the third study included only 15 patients (533), and finally the fourth study also included only 45 patients (566) with a total of 130 patients. Thus, evidence is only moderate for long-term effectiveness. Further, negative studies are strong with Juch et al study (36) even though it faced substantial criticism (75-82) it was published in JAMA and included a large number of patients with 125 patients randomized to intervention group. Systematic reviews also provided discordant opinions. Maas et al (34) showed lack of effectiveness. Manchikanti et al (19) showed Level II evidence. Schneider et al (519) showed it to be effective only in patients with $100 \%$ pain relief and utilizing a parallel needle placement with relief in approximately $57 \%$ of the patients. Lee et al (33) also performed a meta-analysis and concluded that conventional radiofrequency denervation resulted in significant reduction in low back pain originating from the facet joints, showing the best response to diagnostic blocks over the first 12 months when compared with sham procedures. The analysis was performed in 231 patients undergoing denervation procedures.

Starr et al (607) described repeat procedure and prescription opioid use after lumbar medial branch nerve radiofrequency ablation in commercially insured patients from 2007 to 2016 . In this study, they identified 44,936 patients undergoing initial radiofrequency ablation. They showed that among these, $33.1 \%$ of the patients underwent staged radiofrequency ablations, meaning a practice often representing a bilateral or multilevel radiofrequency ablation that has been performed on different dates, due to insurance plan restrictions or provider preference. Repeat radiofrequency ablations were performed for $14.6 \%, 33.5 \%$, and $45.7 \%$ of the patients, through 1,3 , and 7 years respectively.

Multiple authors also have looked at lumbar radiofrequency neurotomy in patients with hardware. Abd-Elsayed et al (613) described a case series and concluded that radiofrequency ablation can be safely and effectively performed close to hardware. While heating 
Pain Physician: May/June 2020 23:S1-S127

Table 19. Methodological quality assessment of randomized trials of lumbar facet joint interventions utilizing Cochrane review criteria.

\begin{tabular}{|c|c|c|c|c|c|c|c|c|c|c|}
\hline & $\begin{array}{l}\text { Manchikanti } \\
\text { et al (508) }\end{array}$ & $\begin{array}{l}\text { Carette } \\
\text { et al } \\
\text { (529) }\end{array}$ & $\begin{array}{l}\text { Fuchs } \\
\text { et al } \\
\text { (530) }\end{array}$ & $\begin{array}{l}\text { Nath } \\
\text { et al } \\
\text { (531) }\end{array}$ & \begin{tabular}{|c} 
van \\
Wijk et \\
al (532)
\end{tabular} & $\begin{array}{l}\text { van } \\
\text { Kleef et } \\
\text { al (533) }\end{array}$ & $\begin{array}{l}\text { Tekin } \\
\text { et al } \\
\text { (534) }\end{array}$ & $\begin{array}{c}\text { Civelek } \\
\text { et al } \\
\text { (535) }\end{array}$ & $\begin{array}{l}\text { Dobrogowski } \\
\text { et al (544) }\end{array}$ & $\begin{array}{l}\text { Cohen } \\
\text { et al } \\
\text { (455) }\end{array}$ \\
\hline Randomization adequate & $\mathrm{Y}$ & $\mathrm{Y}$ & $\mathrm{Y}$ & $\mathrm{Y}$ & $\mathrm{Y}$ & $\mathrm{Y}$ & Y & Y & Y & $\mathrm{Y}$ \\
\hline Concealed treatment allocation & $\mathrm{Y}$ & $\mathrm{Y}$ & $\mathrm{N}$ & $\mathrm{Y}$ & $\mathrm{Y}$ & $\mathrm{Y}$ & $\mathrm{Y}$ & $\mathrm{Y}$ & $\mathrm{U}$ & $\mathrm{N}$ \\
\hline Patient blinded & $\mathrm{Y}$ & $\mathrm{Y}$ & $\mathrm{Y}$ & $\mathrm{Y}$ & $\mathrm{Y}$ & $\mathrm{Y}$ & $\mathrm{Y}$ & $\mathrm{N}$ & $\mathrm{Y}$ & $\mathrm{N}$ \\
\hline Care provider blinded & Y & Y & $\mathrm{N}$ & $\mathrm{Y}$ & Y & Y & Y & $\mathrm{N}$ & Y & $\mathrm{U}$ \\
\hline Outcome assessor blinded & $\mathrm{N}$ & Y & Y & Y & Y & Y & Y & $\mathrm{U}$ & $\mathrm{U}$ & $\mathrm{U}$ \\
\hline Drop-out rate described & Y & Y & $\mathrm{N}$ & Y & Y & Y & Y & Y & Y & Y \\
\hline All randomized participants analyzed in group & $\mathrm{Y}$ & Y & Y & Y & Y & Y & Y & Y & Y & Y \\
\hline $\begin{array}{l}\text { Reports of the study free of suggestion of } \\
\text { selective outcome reporting }\end{array}$ & $\mathrm{Y}$ & $\mathrm{Y}$ & $\mathrm{Y}$ & $\mathrm{Y}$ & $\mathrm{Y}$ & Y & Y & Y & $\mathrm{Y}$ & $\mathrm{Y}$ \\
\hline $\begin{array}{l}\text { Groups similar at baseline regarding most } \\
\text { important prognostic indicators }\end{array}$ & $\mathrm{Y}$ & Y & Y & Y & $\mathrm{Y}$ & Y & Y & Y & $\mathrm{Y}$ & Y \\
\hline Co-intervention avoided or similar in all groups & Y & $\mathrm{N}$ & $\mathrm{N}$ & $\mathrm{Y}$ & $\mathrm{Y}$ & Y & $\mathrm{Y}$ & Y & Y & Y \\
\hline Compliance acceptable in all groups & $\mathrm{Y}$ & Y & $\mathrm{Y}$ & $\mathrm{Y}$ & $\mathrm{Y}$ & Y & Y & Y & $\mathrm{Y}$ & Y \\
\hline $\begin{array}{l}\text { Time of outcome assessment similar in } \\
\text { all groups }\end{array}$ & $\mathrm{Y}$ & Y & Y & Y & Y & Y & $\mathrm{Y}$ & Y & $\mathrm{Y}$ & $\mathrm{Y}$ \\
\hline Are other sources of potential bias not likely & $\mathrm{Y}$ & $\mathrm{N}$ & $\mathrm{U}$ & $\mathrm{Y}$ & $\mathrm{Y}$ & $\mathrm{Y}$ & $\mathrm{U}$ & $\mathrm{U}$ & $\mathrm{U}$ & $\mathrm{U}$ \\
\hline SCORE & $12 / 13$ & $11 / 13$ & $8 / 13$ & $13 / 13$ & $13 / 13$ & $13 / 13$ & $12 / 13$ & 9/13 & $10 / 13$ & $8 / 13$ \\
\hline
\end{tabular}

\begin{tabular}{|c|c|c|c|c|c|c|c|c|c|}
\hline & \begin{tabular}{|l|} 
Ribeiro \\
et al (94)
\end{tabular} & \begin{tabular}{|l} 
Moon et \\
al (545) \\
\end{tabular} & $\begin{array}{l}\text { Lakemeier } \\
\text { et al (536) }\end{array}$ & $\begin{array}{l}\text { Yun et } \\
\text { al (572) }\end{array}$ & \begin{tabular}{|l|} 
Manchikanti \\
et al (509)
\end{tabular} & \begin{tabular}{|l|} 
Annaswamy \\
et al (551)
\end{tabular} & \begin{tabular}{|l} 
Kennedy \\
et al (550)
\end{tabular} & $\begin{array}{l}\text { Kennedy } \\
\text { et al (548) }\end{array}$ & $\begin{array}{l}\text { Do et al } \\
\text { (538) }\end{array}$ \\
\hline Randomization adequate & $\mathrm{Y}$ & $\mathrm{Y}$ & $\mathrm{Y}$ & $\mathrm{Y}$ & $\mathrm{N}$ & $\mathrm{Y}$ & $\mathrm{Y}$ & $\mathrm{Y}$ & $\mathrm{Y}$ \\
\hline Concealed treatment allocation & $\mathrm{Y}$ & $\mathrm{Y}$ & $\mathrm{Y}$ & $\mathrm{Y}$ & $\mathrm{N}$ & $\mathrm{Y}$ & $\mathrm{Y}$ & $\mathrm{Y}$ & $\mathrm{N}$ \\
\hline Patient blinded & $\mathrm{Y}$ & $\mathrm{Y}$ & $\mathrm{Y}$ & $\mathrm{N}$ & $\mathrm{Y}$ & $\mathrm{Y}$ & $\mathrm{Y}$ & $\mathrm{Y}$ & $\mathrm{Y}$ \\
\hline Care provider blinded & $\mathrm{N}$ & Y & $\mathrm{N}$ & $\mathrm{N}$ & $\mathrm{Y}$ & $\mathrm{Y}$ & $\mathrm{Y}$ & $\mathrm{Y}$ & $\mathrm{N}$ \\
\hline Outcome assessor blinded & $\mathrm{N}$ & $\mathrm{Y}$ & $\mathrm{N}$ & $\mathrm{N}$ & $\mathrm{N}$ & $\mathrm{Y}$ & $\mathrm{Y}$ & $\mathrm{Y}$ & $\mathrm{Y}$ \\
\hline Drop-out rate described & $\mathrm{Y}$ & $\mathrm{Y}$ & $\mathrm{Y}$ & $\mathrm{Y}$ & $\mathrm{N}$ & $\mathrm{Y}$ & $\mathrm{Y}$ & $\mathrm{Y}$ & $\mathrm{Y}$ \\
\hline $\begin{array}{l}\text { All randomized participants } \\
\text { analyzed in the group }\end{array}$ & $\mathrm{Y}$ & $\mathrm{N}$ & $\mathrm{Y}$ & $\mathrm{Y}$ & $\mathrm{N}$ & $\mathrm{Y}$ & $\mathrm{Y}$ & $\mathrm{Y}$ & $\mathrm{Y}$ \\
\hline $\begin{array}{l}\text { Reports of the study free of } \\
\text { suggestion of selective outcome } \\
\text { reporting }\end{array}$ & $\mathrm{Y}$ & Y & $\mathrm{Y}$ & $\mathrm{Y}$ & $\mathrm{Y}$ & $\mathrm{Y}$ & $\mathrm{Y}$ & $\mathrm{Y}$ & $\mathrm{Y}$ \\
\hline $\begin{array}{l}\text { Groups similar at baseline } \\
\text { regarding most important } \\
\text { prognostic indicators }\end{array}$ & $\mathrm{Y}$ & Y & Y & $\mathrm{Y}$ & $\mathrm{Y}$ & $\mathrm{Y}$ & $\mathrm{Y}$ & $\mathrm{Y}$ & Y \\
\hline $\begin{array}{l}\text { Co-intervention avoided or } \\
\text { similar in all groups }\end{array}$ & $\mathrm{Y}$ & $\mathrm{Y}$ & $\mathrm{Y}$ & $\mathrm{Y}$ & $\mathrm{Y}$ & $\mathrm{Y}$ & $\mathrm{Y}$ & $\mathrm{Y}$ & $\mathrm{Y}$ \\
\hline $\begin{array}{l}\text { Compliance acceptable in all } \\
\text { groups }\end{array}$ & $\mathrm{Y}$ & $\mathrm{N}$ & $\mathrm{N}$ & $\mathrm{Y}$ & $\mathrm{N}$ & $\mathrm{Y}$ & $\mathrm{Y}$ & $\mathrm{Y}$ & $\mathrm{Y}$ \\
\hline $\begin{array}{l}\text { Time of outcome assessment in } \\
\text { all groups similar }\end{array}$ & $\mathrm{Y}$ & $\mathrm{N}$ & $\mathrm{Y}$ & $\mathrm{Y}$ & $\mathrm{Y}$ & $\mathrm{Y}$ & $\mathrm{Y}$ & $\mathrm{Y}$ & $\mathrm{Y}$ \\
\hline $\begin{array}{l}\text { Are other sources of potential } \\
\text { bias not likely }\end{array}$ & $\mathrm{U}$ & $\mathrm{U}$ & $\mathrm{U}$ & $\mathrm{U}$ & $\mathrm{Y}$ & $\mathrm{N}$ & $\mathrm{N}$ & $\mathrm{U}$ & $\mathrm{U}$ \\
\hline SCORE & $10 / 13$ & $9 / 13$ & $9 / 13$ & $9 / 13$ & $7 / 13$ & $12 / 13$ & $12 / 13$ & $12 / 13$ & $10 / 13$ \\
\hline
\end{tabular}


Table 19 (cont). Methodological quality assessment of randomized trials of lumbar facet joint interventions utilizing Cochrane review criteria.

\begin{tabular}{|l|c|c||}
\hline & Juch et al (36) & Çetin \& Yektaş (566) \\
\hline Randomization adequate & $\mathrm{Y}$ & $\mathrm{N}$ \\
\hline Concealed treatment allocation & $\mathrm{N}$ & $\mathrm{N}$ \\
\hline Patient blinded & $\mathrm{N}$ & $\mathrm{Y}$ \\
\hline Care provider blinded & $\mathrm{N}$ & $\mathrm{N}$ \\
\hline Outcome assessor blinded & $\mathrm{N}$ & $\mathrm{Y}$ \\
\hline Drop-out rate described & $\mathrm{N}$ & $\mathrm{Y}$ \\
\hline All randomized participants analyzed in the group & $\mathrm{N}$ & $\mathrm{Y}$ \\
\hline Reports of the study free of suggestion of selective outcome reporting & $\mathrm{N}$ & $\mathrm{Y}$ \\
\hline Groups similar at baseline regarding most important prognostic indicators & $\mathrm{Y}$ & $\mathrm{Y}$ \\
\hline Co-intervention avoided or similar in all groups & $\mathrm{Y}$ & $\mathrm{Y}$ \\
\hline Compliance acceptable in all groups & $\mathrm{Y}$ & $\mathrm{Y}$ \\
\hline Time of outcome assessment in all groups similar & $\mathrm{Y}$ & $\mathrm{Y}$ \\
\hline Are other sources of potential bias not likely & $\mathrm{Y}$ & $\mathrm{U}$ \\
\hline SCORE & $6 / 13$ & \\
\hline
\end{tabular}

$\mathrm{Y}=$ yes; $\mathrm{N}=$ no; $\mathrm{U}=$ unclear. Source: Furlan AD, et al; Editorial Board of the Cochrane Back, Neck Group. 2015 Updated Method Guideline for Systematic Reviews in the Cochrane Back and Neck Group. Spine (Phila Pa 1976) 2015; 40:1660-1673 (526).

of the hardware can happen which can theoretically lead to tissue injury or decreased heat going to target nerve, this does not seem to be of clinical significance. Ellwood et al (612) in a retrospective review of spinal radiofrequency neurotomy procedures with metallic posterior spinal instrumentation showed that of the 507 patients undergoing radiofrequency neurotomy, it was performed on 36 patients with metallic hardware. They performed a total of 56 ablations at a level with metallic spinal hardware of which 44 were lumbar. There were no complications found among their patient population in any of the serious complications' category, including increase in temperature. Lamer et al (614) also looked at the safety of lumbar spine radiofrequency procedures in patients who have posterior spinal hardware with 10 lumbar medial branch nerve radiofrequency lesion procedures performed on 6 patients, with placement of the probe on the fusion hardware to continuously monitor the temperature of the hardware throughout the radiofrequency procedure. The temperature of the fusion hardware increased in 6 of the 10 radiofrequency lesion procedures. During 2 of the procedures, the temperature rose rapidly to $42^{\circ}$ $C$, at which time the procedure ceased at that level. The authors concluded that this case series demonstrated that radiofrequency lesioning to treat symptomatic facet joint pain in patients who have adjacent posterior lumbar fusion hardware may result in heat energy being transferred to the adjacent hardware. Conse- quently, they hypothesized that this may increase the risk of injury to the patient. This is in contrast to more recent report.

The effect of repeated zygapophysial joint radiofrequency neurotomy on pain, disability, and improvement duration was assessed (556-560). Rambaransingh et al (556) assessed 104 patients who underwent repeat radiofrequency neurotomy for chronic neck or back pain prospectively using a Pain Disability Questionnaire-Spine (PDQ-S). They gathered data on 596 patients undergoing radiofrequency neurotomy over a period of 5 years. Among these, 104 patients, 20 in cervical region and 84 in lumbar region, eventually underwent repeat radiofrequency neurotomy of the same zygapophysial joints. The results showed pain intensity, pain frequency, and patient-specific disability measures were significantly improved post-initial, second, and third radiofrequency neurotomy. Further, there was no statistically significant difference between the duration of the relief after the first radiofrequency neurotomy and pain relief after the second neurotomy. They concluded that repeated cervical and lumbar radiofrequency neurotomy reduces pain and disability with equal effectiveness for approximately 10 months in patients with chronic neck and back pain originating from facet joints.

Numerous studies have investigated the effectiveness of repeat radiofrequency neurotomy (557-560). Schofferman et al (559) in assessing the effectiveness of repeated radiofrequency neurotomy for lumbar 
Pain Physician: May/June 2020 23:S1-S127

Table 20. Methodologic quality assessment of randomized trials of lumbar facet joint interventions utilizing IPM - QRB criteria.

\begin{tabular}{|c|c|c|c|c|c|c|c|c|c|c|c|}
\hline & & $\begin{array}{l}\text { Manchikanti } \\
\text { et al (508) }\end{array}$ & $\begin{array}{l}\text { Carette } \\
\text { et al } \\
\text { (529) }\end{array}$ & $\begin{array}{l}\text { Fuchs } \\
\text { et al } \\
(530)\end{array}$ & $\begin{array}{l}\text { Nath } \\
\text { et al } \\
\text { (531) }\end{array}$ & $\begin{array}{l}\text { van } \\
\text { Wijk et } \\
\text { al (532) }\end{array}$ & $\begin{array}{l}\text { vanKleef } \\
\text { et al } \\
(533)\end{array}$ & $\begin{array}{l}\text { Tekin } \\
\text { et al } \\
\text { (534) }\end{array}$ & $\begin{array}{c}\text { Civelek } \\
\text { et al } \\
(535)\end{array}$ & $\begin{array}{l}\text { Dobrogowski } \\
\text { et al (544) }\end{array}$ & $\begin{array}{l}\text { Cohenet } \\
\text { al (455) }\end{array}$ \\
\hline I. & $\begin{array}{l}\text { TRIAL DESIGN AND } \\
\text { GUIDANCE REPORTING }\end{array}$ & & & & & & & & & & \\
\hline 1. & CONSORT or SPIRIT & 3 & 3 & 3 & 3 & 2 & 2 & 2 & 2 & 2 & 3 \\
\hline II. & DESIGN FACTORS & & & & & & & & & & \\
\hline 2. & Type and Design of Trial & 2 & 3 & 2 & 3 & 3 & 3 & 3 & 2 & 2 & 2 \\
\hline 3. & Setting/Physician & 2 & 1 & 1 & 3 & 3 & 3 & 2 & 2 & 2 & 2 \\
\hline 4. & Imaging & 3 & 3 & 2 & 3 & 3 & 3 & 3 & 3 & 2 & 3 \\
\hline 5. & Sample Size & 3 & 2 & 2 & 1 & 1 & 1 & 1 & 1 & 1 & 3 \\
\hline 6. & Statistical Methodology & 1 & 1 & 1 & 1 & 1 & 1 & 1 & 1 & 1 & 1 \\
\hline III. & PATIENT FACTORS & & & & & & & & & & \\
\hline 7. & Inclusiveness of Population & & & & & & & & & & \\
\hline & $\begin{array}{l}\text { - For facet or sacroiliac joint } \\
\text { interventions: }\end{array}$ & 2 & 1 & 0 & 2 & 1 & 1 & 1 & 0 & 1 & 1 \\
\hline 8. & Duration of Pain & 2 & 2 & 1 & 2 & 2 & 3 & 2 & 0 & 2 & 0 \\
\hline 9. & Previous Treatments & 2 & 0 & 0 & 0 & 0 & 0 & 1 & 2 & 0 & 0 \\
\hline 10. & $\begin{array}{l}\text { Duration of Follow-up with } \\
\text { Appropriate Interventions }\end{array}$ & 3 & 2 & 1 & 2 & 2 & 2 & 2 & 2 & 1 & 0 \\
\hline IV. & OUTCOMES & & & & & & & & & & \\
\hline 11. & $\begin{array}{l}\text { Outcomes Assessment Criteria } \\
\text { for Significant Improvement }\end{array}$ & 4 & 4 & 2 & 4 & 4 & 2 & 2 & 2 & 2 & 0 \\
\hline 12. & $\begin{array}{l}\text { Analysis of all Randomized } \\
\text { Participants in the Groups }\end{array}$ & 2 & 2 & 2 & 2 & 2 & 2 & 2 & 2 & 2 & 2 \\
\hline 13. & Description of Drop Out Rate & 2 & 1 & 2 & 2 & 2 & 2 & 2 & 2 & 2 & 2 \\
\hline 14. & $\begin{array}{l}\text { Similarity of Groups at } \\
\text { Baseline for Important } \\
\text { Prognostic Indicators }\end{array}$ & 2 & 2 & 2 & 2 & 2 & 2 & 2 & 2 & 2 & 2 \\
\hline 15. & Role of Co-Interventions & 1 & 0 & 0 & 1 & 1 & 1 & 1 & 1 & 1 & 1 \\
\hline V. & RANDOMIZATION & & & & & & & & & & \\
\hline 16. & Method of Randomization & 2 & 2 & 2 & 2 & 2 & 2 & 2 & 2 & 2 & 2 \\
\hline VI. & $\begin{array}{l}\text { ALLOCATION } \\
\text { CONCEALMENT } \\
\end{array}$ & & & & & & & & & & \\
\hline 17. & $\begin{array}{l}\text { Concealed Treatment } \\
\text { Allocation }\end{array}$ & 2 & 2 & 1 & 2 & 2 & 2 & 2 & 2 & 2 & 0 \\
\hline VII. & BLINDING & & & & & & & & & & \\
\hline 18. & Patient Blinding & 1 & 1 & 0 & 1 & 1 & 1 & 1 & 0 & 1 & 0 \\
\hline 19. & Care Provider Blinding & 1 & 1 & 0 & 1 & 1 & 1 & 1 & 0 & 1 & 0 \\
\hline 20. & Outcome Assessor Blinding & 0 & 1 & 0 & 0 & 1 & 0 & 0 & 0 & 0 & 0 \\
\hline VIII. & CONFLICTS OF INTEREST & & & & & & & & & & \\
\hline 21. & Funding and Sponsorship & 2 & 3 & 1 & 2 & 0 & 3 & 2 & 0 & 0 & 2 \\
\hline 22. & Conflicts of Interest & 3 & 3 & 1 & 3 & 0 & 3 & 2 & 0 & 0 & 2 \\
\hline \multicolumn{2}{|c|}{ TOTAL } & 45 & 40 & 26 & 42 & 36 & 40 & 37 & 28 & 29 & 28 \\
\hline
\end{tabular}


Facet Joint Interventions Guidelines 2020

Table 20 (cont.). Methodologic quality assessment of randomized trials of lumbar facet joint interventions utilizing IPM - QRB criteria.

\begin{tabular}{|c|c|c|c|c|c|c|c|c|c|c|}
\hline & & $\begin{array}{l}\text { Ribeiro } \\
\text { et al } \\
(94)\end{array}$ & $\begin{array}{l}\text { Moon } \\
\text { et al } \\
(545)\end{array}$ & $\begin{array}{l}\text { Lakemeier } \\
\text { et al (536) }\end{array}$ & $\begin{array}{l}\text { Yun } \\
\text { et al } \\
(572)\end{array}$ & $\begin{array}{l}\text { Manchikanti } \\
\text { et al (501) }\end{array}$ & $\begin{array}{l}\text { Annaswamy } \\
\text { et al (551) }\end{array}$ & $\begin{array}{l}\text { Kennedy } \\
\text { et al }(550)\end{array}$ & $\begin{array}{c}\text { Kennedy } \\
\text { et al } \\
(548)\end{array}$ & $\begin{array}{l}\text { Do et al } \\
(538)\end{array}$ \\
\hline I. & $\begin{array}{l}\text { TRIAL DESIGN AND } \\
\text { GUIDANCE REPORTING }\end{array}$ & & & & & & & & & \\
\hline 1. & CONSORT or SPIRIT & 2 & 2 & 2 & 2 & 2 & 2 & 2 & 2 & 2 \\
\hline II. & DESIGN FACTORS & & & & & & & & & \\
\hline 2. & Type and Design of Trial & 2 & 2 & 2 & 2 & 2 & 2 & 2 & 2 & 2 \\
\hline 3. & Setting/Physician & 2 & 2 & 1 & 1 & 3 & 2 & 2 & 2 & 2 \\
\hline 4. & Imaging & 3 & 3 & 3 & 3 & 3 & 3 & 3 & 3 & 3 \\
\hline 5. & Sample Size & 2 & 2 & 2 & 2 & 2 & 1 & 0 & 0 & 1 \\
\hline 6. & Statistical Methodology & 1 & 1 & 1 & 1 & 1 & 1 & 1 & 1 & 1 \\
\hline III. & PATIENT FACTORS & & & & & & & & & \\
\hline 7. & Inclusiveness of Population & & & & & & & & & \\
\hline & $\begin{array}{l}\text { - For facet or sacroiliac joint } \\
\text { interventions: }\end{array}$ & 0 & 2 & 1 & 0 & 2 & 1 & 2 & 2 & 2 \\
\hline 8. & Duration of Pain & 0 & 2 & 2 & 0 & 2 & 1 & 2 & 2 & 2 \\
\hline 9. & Previous Treatments & 0 & 2 & 2 & 1 & 2 & 2 & 1 & 1 & 1 \\
\hline 10. & $\begin{array}{l}\text { Duration of Follow-up with } \\
\text { Appropriate Interventions }\end{array}$ & 1 & 1 & 2 & 1 & 3 & 1 & 0 & 0 & 1 \\
\hline IV. & OUTCOMES & & & & & & & & & \\
\hline 11. & $\begin{array}{l}\text { Outcomes Assessment Criteria } \\
\text { for Significant Improvement }\end{array}$ & 2 & 2 & 2 & 1 & 2 & 2 & 1 & 1 & 2 \\
\hline 12. & $\begin{array}{l}\text { Analysis of all Randomized } \\
\text { Participants in the Groups }\end{array}$ & 2 & 0 & 2 & 2 & 0 & 2 & 2 & 2 & 2 \\
\hline 13. & Description of Drop Out Rate & 2 & 2 & 2 & 2 & 0 & 2 & 2 & 2 & 2 \\
\hline 14. & $\begin{array}{l}\text { Similarity of Groups at Baseline for } \\
\text { Important Prognostic Indicators }\end{array}$ & 2 & 2 & 2 & 2 & 2 & 2 & 2 & 2 & 2 \\
\hline 15. & Role of Co-Interventions & 1 & 1 & 1 & 1 & 1 & 1 & 1 & 1 & 1 \\
\hline V. & RANDOMIZATION & & & & & & & & & \\
\hline 16. & Method of Randomization & 2 & 2 & 2 & 2 & 0 & 2 & 2 & 2 & 2 \\
\hline VI. & $\begin{array}{l}\text { ALLOCATION } \\
\text { CONCEALMENT }\end{array}$ & & & & & & & & & \\
\hline 17. & Concealed Treatment Allocation & 2 & 2 & 2 & 2 & 0 & 2 & 2 & 2 & 1 \\
\hline VII. & BLINDING & & & & & & & & & \\
\hline 18. & Patient Blinding & 1 & 1 & 1 & 0 & 1 & 1 & 1 & 1 & 1 \\
\hline 19. & Care Provider Blinding & 0 & 1 & 0 & 0 & 1 & 1 & 1 & 1 & 0 \\
\hline 20. & Outcome Assessor Blinding & 0 & 1 & 0 & 0 & 0 & 1 & 1 & 1 & 1 \\
\hline VIII. & CONFLICTS OF INTEREST & & & & & & & & & \\
\hline 21. & Funding and Sponsorship & 2 & 2 & 2 & 1 & 2 & 0 & 2 & 2 & 1 \\
\hline 22. & Conflicts of Interest & 3 & 3 & 3 & 0 & 3 & 1 & 1 & 1 & 1 \\
\hline \multicolumn{2}{|c|}{ TOTAL } & 32 & 38 & 37 & 26 & 34 & 33 & 33 & 33 & 33 \\
\hline
\end{tabular}


Pain Physician: May/June 2020 23:S1-S127

Table 20 (cont.). Methodologic quality assessment of randomized trials of lumbar facet joint interventions utilizing IPM - QRB criteria.

\begin{tabular}{|c|c|c|c|}
\hline & & Juch et al (36) & Çetin \& Yektaş (566) \\
\hline I. & TRIAL DESIGN AND GUIDANCE REPORTING & & \\
\hline 1. & CONSORT or SPIRIT & 2 & 2 \\
\hline II. & DESIGN FACTORS & & \\
\hline 2. & Type and Design of Trial & 2 & 2 \\
\hline 3. & Setting/Physician & 2 & 2 \\
\hline 4. & Imaging & 3 & 3 \\
\hline 5. & Sample Size & 2 & 2 \\
\hline 6. & Statistical Methodology & 1 & 1 \\
\hline III. & PATIENT FACTORS & & \\
\hline 7. & Inclusiveness of Population & & \\
\hline & - For facet or sacroiliac joint interventions: & 2 & 2 \\
\hline 8. & Duration of Pain & 2 & 2 \\
\hline 9. & Previous Treatments & 1 & 2 \\
\hline 10. & Duration of Follow-up with Appropriate Interventions & 1 & 3 \\
\hline IV. & OUTCOMES & & \\
\hline 11. & Outcomes Assessment Criteria for Significant Improvement & 1 & 2 \\
\hline 12. & Analysis of all Randomized Participants in the Groups & 0 & 2 \\
\hline 13. & Description of Drop Out Rate & 0 & 2 \\
\hline 14. & Similarity of Groups at Baseline for Important Prognostic Indicators & 2 & 2 \\
\hline 15. & Role of Co-Interventions & 1 & 1 \\
\hline V. & RANDOMIZATION & & \\
\hline 16. & Method of Randomization & 2 & 0 \\
\hline VI. & ALLOCATION CONCEALMENT & & \\
\hline 17. & Concealed Treatment Allocation & 0 & 0 \\
\hline VII. & BLINDING & & \\
\hline 18. & Patient Blinding & 0 & 1 \\
\hline 19. & Care Provider Blinding & 0 & 0 \\
\hline 20. & Outcome Assessor Blinding & 0 & 1 \\
\hline VIII. & CONFLICTS OF INTEREST & & \\
\hline 21. & Funding and Sponsorship & 2 & 2 \\
\hline 22. & Conflicts of Interest & 0 & 0 \\
\hline \multicolumn{2}{|c|}{ TOTAL } & 26 & 34 \\
\hline
\end{tabular}

Source: Manchikanti L, et al. Assessment of methodologic quality of randomized trials of interventional techniques: Development of an interventional pain management specific instrument. Pain Physician 2014; 17:E263-E290 (527).

facet joint pain, showed mean duration of relief of lumbar radiofrequency was 10.5 months with each repeat radiofrequency being successful in $85 \%$ of the patients in whom initial lumbar radiofrequency neurotomy was successful. There was no significant difference between the first procedure and subsequent procedures in reference to the duration of the relief or any other factors.

Burnham and Holitski (557) in a prospective out- come study on the effects of facet joint radiofrequency denervation on pain in lumbar spine assessed 44 consecutive patients with 101 facet joints with diagnosis established by dual diagnostic blocks with more than $50 \%$ pain relief reported after radiofrequency denervation, significant improvement in pain, analgesic requirement, satisfaction, disability, and direct costs occurred. However, the benefits peaked at 3 to 6 months and gradually diminished thereafter. 
Facet Joint Interventions Guidelines 2020

Table 21. Effectiveness of lumbar radiofrequency, facet joint nerve blocks, and intraarticular injections.

\begin{tabular}{|c|c|c|c|c|c|c|c|c|c|}
\hline \multirow{3}{*}{$\begin{array}{l}\text { Study } \\
\text { Study Characteristic } \\
\text { Methodological Quality } \\
\text { Scoring }\end{array}$} & \multirow{3}{*}{ Patients } & \multirow{3}{*}{ Interventions } & \multicolumn{3}{|c|}{ Pain Relief and Function } & \multicolumn{3}{|c|}{ Results } & \multirow{3}{*}{ Comments } \\
\hline & & & \multirow[b]{2}{*}{3 mos. } & \multirow[b]{2}{*}{6 mos. } & \multirow{2}{*}{$\begin{array}{l}12 \\
\text { mos. }\end{array}$} & \multirow{2}{*}{$\begin{array}{l}\text { Short- } \\
\text { Term } \\
\leq 6 \mathrm{mos} \text {. }\end{array}$} & \multicolumn{2}{|c|}{ Long-Term } & \\
\hline & & & & & & & $\begin{array}{l}>6 \\
\text { mos. }\end{array}$ & $\begin{array}{l}\geq 1 \\
\text { year }\end{array}$ & \\
\hline \multicolumn{10}{|c|}{ LUMBAR RF NEUROTOMY } \\
\hline $\begin{array}{l}\text { Civelek et al, } 2012 \text { (535) } \\
\text { RA, AC } \\
\text { Quality Scores: } \\
\text { Cochrane }=9 / 13 \\
\text { IPM-QRB = 28/48 }\end{array}$ & 100 & $\begin{array}{l}\text { CRF }=50 \\
\text { Facet joint nerve } \\
\text { blocks }=50\end{array}$ & NA & $92 \%$ vs. $75 \%$ & $\begin{array}{c}90 \% \\
\text { vs. } \\
69 \%\end{array}$ & NA & $\mathrm{P}$ & $\mathrm{P}$ & $\begin{array}{l}\text { Effective for } \\
\text { short and long- } \\
\text { term }\end{array}$ \\
\hline $\begin{array}{l}\text { Cohen et al, } 2010 \text { (455) } \\
\text { RA, DB } \\
\text { Quality Scores: } \\
\text { Cochrane = 8/13 } \\
\text { IPM-QRB = 28/48 }\end{array}$ & $\begin{array}{l}\text { "0" block = 51 } \\
\text { One block = 20 } \\
\text { Two blocks = } 14\end{array}$ & CRF & $\begin{array}{l}\text { "0" group = } \\
33 \% \\
\text { One block } \\
=39 \% \\
\text { Two blocks } \\
=64 \%\end{array}$ & NA & NA & $\begin{array}{l}\mathrm{P} \text { in dual } \\
\text { block } \\
\text { group }\end{array}$ & NA & NA & $\begin{array}{l}\text { Effective in } \\
\text { short-term } \\
\text { results with } \\
\text { application of } \\
\text { dual blocks } \\
\text { Not effective } \\
\text { with no } \\
\text { or single } \\
\text { diagnostic } \\
\text { blocks. }\end{array}$ \\
\hline $\begin{array}{l}\text { Nath et al, } 2008 \text { (531) } \\
\text { RA, DB, Sham control } \\
\text { Quality Scores: } \\
\text { Cochrane }=13 / 13 \\
\text { IPM-QRB }=42 / 48\end{array}$ & 40 & $\begin{array}{l}\mathrm{RF}=20 \\
\text { Sham }=20\end{array}$ & NA & $\begin{array}{l}\text { Significant } \\
\text { proportion } \\
\text { of patients in } \\
\text { interventional } \\
\quad \text { group }\end{array}$ & NA & $\begin{array}{l}\text { P for RF } \\
\mathrm{N} \text { for } \\
\text { sham or } \\
\text { active }\end{array}$ & $\begin{array}{l}\text { P for } \\
\mathrm{RF} \\
\mathrm{N} \text { for } \\
\text { sham } \\
\text { or } \\
\text { active }\end{array}$ & NA & $\begin{array}{l}\text { Effective for } \\
\text { short-term }\end{array}$ \\
\hline $\begin{array}{l}\text { Tekin et al, } 2007 \text { (534) } \\
\text { RA, AC and sham, DB } \\
\text { Quality Scores: } \\
\text { Cochrane }=12 / 13 \\
\text { IPM-QRB }=37 / 48\end{array}$ & 60 & $\begin{array}{l}\mathrm{CRF}=20 \\
\mathrm{PRF}=20 \\
\text { Control }=20\end{array}$ & NA & SI with CRF & $\begin{array}{c}\text { SI } \\
\text { with } \\
\text { CRF }\end{array}$ & NA & $\begin{array}{l}\text { P for } \\
\text { RF } \\
\mathrm{N} \text { for } \\
\text { sham }\end{array}$ & $\begin{array}{l}\mathrm{P} \text { for } \\
\mathrm{RF} \\
\mathrm{N} \text { for } \\
\text { sham }\end{array}$ & $\begin{array}{l}\text { Effective in } \\
\text { long-term }\end{array}$ \\
\hline $\begin{array}{l}\text { van Wijk et al, } 2005 \\
\text { (532) } \\
\text { RA, DB, Sham control } \\
\text { Quality Scores: } \\
\text { Cochrane }=13 / 13 \\
\text { IPM-QRB }=36 / 48\end{array}$ & 81 & $\begin{array}{l}\mathrm{RF}=40 \text { Sham } \\
=41\end{array}$ & $\begin{array}{c}27.5 \% \text { vs. } \\
29.3 \%\end{array}$ & $\begin{array}{c}27.5 \% \text { vs. } \\
29.3 \%\end{array}$ & $\begin{array}{c}27.5 \% \\
\text { vs. } \\
29.3 \%\end{array}$ & $\mathrm{~N}$ & $\mathrm{~N}$ & $\mathrm{~N}$ & $\begin{array}{l}\text { Lack of } \\
\text { effectiveness } \\
\text { with short- and } \\
\text { long-term }\end{array}$ \\
\hline $\begin{array}{l}\text { Dobrogowski et al, } 2005 \\
(544) \\
\text { RA, AC } \\
\text { Quality Scores: } \\
\text { Cochrane }=10 / 13 \\
\text { IPM-QRB }=29 / 48 \\
\end{array}$ & 45 & CRF & NA & $60 \%$ & NA & NA & $\mathrm{P}$ & NA & $\begin{array}{l}\text { Short-term } \\
\text { effectiveness }\end{array}$ \\
\hline $\begin{array}{l}\text { van Kleef et al, } 1999 \\
(533) \\
\text { RA, DB, sham control } \\
\text { Quality Scores: } \\
\text { Cochrane }=13 / 13 \\
\text { IPM-QRB }=40 / 48\end{array}$ & 31 & $\begin{array}{l}\mathrm{RF}=15 \\
\text { Sham = } 16\end{array}$ & $\begin{array}{c}60 \% \text { vs. } \\
25 \%\end{array}$ & $47 \%$ vs. $19 \%$ & $\begin{array}{c}47 \% \\
\text { vs. } \\
13 \%\end{array}$ & $\begin{array}{l}\text { P for RF } \\
\mathrm{N} \text { for } \\
\text { sham or } \\
\text { active }\end{array}$ & $\begin{array}{l}\text { P for } \\
\text { RF } \\
\mathrm{N} \text { for } \\
\text { sham }\end{array}$ & $\begin{array}{l}\mathrm{P} \text { for } \\
\mathrm{RF} \\
\mathrm{N} \text { for } \\
\text { sham }\end{array}$ & $\begin{array}{l}\text { Effectiveness } \\
\text { with short- and } \\
\text { long-term }\end{array}$ \\
\hline $\begin{array}{l}\text { Moon et al, 2013 (545) } \\
\text { Prospective, RA, } \\
\text { comparative study } \\
\text { Quality Scores: } \\
\text { Cochrane = 9/13 } \\
\text { IPM-QRB }=38 / 48\end{array}$ & $\begin{array}{l}\text { Total }=82 \\
\text { Tunnel vision } \\
\text { approach group } \\
-41 \text { patients } \\
\text { included and } 34 \\
\text { patients analyzed. }\end{array}$ & $\begin{array}{l}\text { RF neurotomy } \\
\text { distal approach }\end{array}$ & $\begin{array}{l}\text { SI in both } \\
\text { groups }\end{array}$ & $\begin{array}{l}\text { SI in both } \\
\text { groups }\end{array}$ & NA & $\mathrm{P}$ & $\mathrm{P}$ & NA & $\begin{array}{l}\text { Short-term } \\
\text { effectiveness }\end{array}$ \\
\hline $\begin{array}{l}\text { Lakemeier et al (536) } \\
\text { RA, DB } \\
\text { Quality Scores: } \\
\text { Cochrane }=9 / 13 \\
\text { IPM-QRB }=37 / 48\end{array}$ & $\begin{array}{l}\text { Total }=56 \\
\text { Steroid group }=29 \\
\text { patients } \\
\text { RF group }=27 \\
\text { patients }\end{array}$ & $\begin{array}{l}\text { Intraarticular } \\
\text { lumbar facet joint } \\
\text { steroid injections } \\
\text { compared to } \\
\text { lumbar facet joint } \\
\text { RF denervation }\end{array}$ & NA & $\begin{array}{l}\text { SI in both } \\
\text { groups }\end{array}$ & NA & $\mathrm{P}$ & $\mathrm{P}$ & NA & $\begin{array}{l}\text { Short -term } \\
\text { effectiveness }\end{array}$ \\
\hline
\end{tabular}


Pain Physician: May/June 2020 23:S1-S127

Table 21 (cont.). Effectiveness of lumbar radiofrequency, facet joint nerve blocks, and intraarticular injections.

\begin{tabular}{|c|c|c|c|c|c|c|c|c|c|}
\hline \multirow{3}{*}{$\begin{array}{l}\text { Study } \\
\text { Study Characteristic } \\
\text { Methodological Quality } \\
\text { Scoring }\end{array}$} & \multirow{3}{*}{ Patients } & \multirow{3}{*}{ Interventions } & \multicolumn{3}{|c|}{ Pain Relief and Function } & \multicolumn{3}{|c|}{ Results } & \multirow{3}{*}{ Comments } \\
\hline & & & \multirow[b]{2}{*}{3 mos. } & \multirow[b]{2}{*}{6 mos. } & \multirow{2}{*}{$\begin{array}{c}12 \\
\text { mos. }\end{array}$} & \multirow{2}{*}{$\begin{array}{l}\text { Short- } \\
\text { Term } \\
\leq 6 \text { mos. }\end{array}$} & \multicolumn{2}{|c|}{ Long-Term } & \\
\hline & & & & & & & $\begin{array}{l}>6 \\
\text { mos. }\end{array}$ & $\begin{array}{l}\geq 1 \\
\text { year }\end{array}$ & \\
\hline $\begin{array}{l}\text { Juch et al (36) } \\
\text { MINT randomized, } \\
\text { non-blinded, pragmatic } \\
\text { clinical trial } \\
\text { Quality Scores: } \\
\text { Cochrane }=6 / 13 \\
\text { IPM-QRB }=26 / 48\end{array}$ & $\begin{array}{l}\text { A total of } 251 \\
\text { patients were } \\
\text { randomized into } \\
\text { facet trial with } \\
126 \text { patients } \\
\text { in the control } \\
\text { group receiving } \\
\text { exercise program } \\
\text { as randomized. } \\
125 \text { patients were } \\
\text { randomized to } \\
\text { intervention } \\
\text { group. }\end{array}$ & $\begin{array}{l}\text { Patients in the } \\
\text { intervention group, } \\
\text { RF ablation after } \\
\text { testing positive } \\
\text { with at least } 50 \% \\
\text { relief with a single } \\
\text { block of facet joint } \\
\text { nerves with pain } \\
\text { reduction within } \\
30 \text { to } 90 \text { minutes } \\
\text { after the block. RF } \\
\text { neurotomy was } \\
\text { performed with a } \\
\text { conventional RF } \\
\text { ablation procedure } \\
\text { with a } 22 \text { gauge } \\
\text { electrode. }\end{array}$ & NSD & NSD & NSD & $\mathrm{N}$ & $\mathrm{N}$ & $\mathrm{N}$ & $\begin{array}{l}\text { Lack of } \\
\text { effectiveness }\end{array}$ \\
\hline $\begin{array}{l}\text { Çetin \& Yektaş (566) } \\
\text { Randomized, double- } \\
\text { blind, controlled trial } \\
\text { Quality Scores: } \\
\text { Cochrane = 9/13 } \\
\text { IPM-QRB }=34 / 48\end{array}$ & $\begin{array}{l}118 \text { patients were } \\
\text { randomized to } \\
\text { Group } 1 \text { to receive } \\
\text { pulsed RF and } \\
\text { Group } 2 \text { with } 45 \\
\text { patients receiving } \\
\text { conventional RF. } \\
\end{array}$ & $\begin{array}{l}\text { Pulsed RF vs. } \\
\text { conventional RF }\end{array}$ & SI & SI & SI & $\mathrm{P}$ & $\mathrm{P}$ & $\mathrm{P}$ & $\begin{array}{l}\text { Positive trial } \\
\text { for CRF }\end{array}$ \\
\hline \multicolumn{10}{|c|}{ LUMBAR FACET JOINT NERVE BLOCKS } \\
\hline $\begin{array}{l}\text { Civelek et al, } 2012 \text { (535) } \\
\text { RA, AC } \\
\text { Quality Scores: } \\
\text { Cochrane = 9/13 } \\
\text { IPM-QRB = } 28 / 48\end{array}$ & 100 & $\begin{array}{l}\text { LA with steroid } \\
=50 \\
\mathrm{CRF}=50\end{array}$ & NA & $75 \%$ vs. $92 \%$ & $\begin{array}{l}69 \% \\
\text { vs. } \\
90 \%\end{array}$ & NA & $\mathrm{P}$ & $\mathrm{P}$ & $\begin{array}{l}\text { Long-term } \\
\text { effectiveness }\end{array}$ \\
\hline $\begin{array}{l}\text { Manchikanti et al, } 2010 \\
\text { (508) } \\
\text { RA, DB, AC } \\
\text { Quality Scores: } \\
\text { Cochrane }=12 / 13 \\
\text { IPM-QRB }=45 / 48\end{array}$ & 120 & $\begin{array}{l}\text { LA with steroid } \\
=60 \\
\text { LA }=60\end{array}$ & $\begin{array}{c}82 \% \text { vs. } \\
83 \%\end{array}$ & $93 \%$ vs. $83 \%$ & $\begin{array}{c}85 \% \\
\text { vs. } \\
84 \%\end{array}$ & $\mathrm{P}$ & $\mathrm{P}$ & $\mathrm{P}$ & $\begin{array}{l}\text { Short- and } \\
\text { long-term } \\
\text { effectiveness }\end{array}$ \\
\hline $\begin{array}{l}\text { Manchikanti et al, } 2001 \\
\text { (509) } \\
\text { RA, AC } \\
\text { Quality Scores: } \\
\text { Cochrane }=6 / 13 \\
\text { IPM-QRB }=34 / 48\end{array}$ & 73 & $\begin{array}{l}\text { LA with steroid } \\
=41 \\
\text { LA }=32\end{array}$ & $\begin{array}{c}100 \% \text { vs } \\
100 \%\end{array}$ & $75 \%$ vs $80 \%$ & $\begin{array}{l}75 \% \\
\text { vs } \\
80 \%\end{array}$ & $\mathrm{P}$ & $\mathrm{P}$ & $\mathrm{P}$ & $\begin{array}{l}\text { Positive short } \\
\text { and long-term } \\
\text { results }\end{array}$ \\
\hline \multicolumn{10}{|c|}{ LUMBAR INTRAARTICULAR INJECTIONS } \\
\hline $\begin{array}{l}\text { Carette et al, 1991 (529) } \\
\text { RA, DB, PC or AC } \\
\text { Quality Scores: } \\
\text { Cochrane }=11 / 13 \\
\text { IPM-QRB }=40 / 48\end{array}$ & 97 & $\begin{array}{l}\text { Methylprednisolone } \\
\text { acetate }=49 \\
\text { Isotonic saline }=48 \\
\text { patients }\end{array}$ & $\begin{array}{c}33 \% \text { vs. } \\
42 \%\end{array}$ & $22 \%$ vs. $10 \%$ & NA & $\mathrm{N}$ & $\mathrm{N}$ & NA & $\begin{array}{l}\text { Lack of } \\
\text { effectiveness }\end{array}$ \\
\hline $\begin{array}{l}\text { Fuchs et al, } 2005 \text { (530) } \\
\text { R, DB, AC } \\
\text { Quality Scores: } \\
\text { Cochrane }=8 / 13 \\
\text { IPM-QRB }=26 / 48\end{array}$ & 60 & $\begin{array}{l}\text { Hyaluronic } \\
\text { acid versus } \\
\text { glucocorticoid } \\
\text { with } 6 \text { injections. }\end{array}$ & $\begin{array}{l}\text { Significant } \\
\text { proportion } \\
\text { of patients }\end{array}$ & $\begin{array}{l}\text { Significant } \\
\text { proportion } \\
\text { of patients }\end{array}$ & NA & $\mathrm{U}$ & $\mathrm{U}$ & NA & $\begin{array}{c}\text { Effectiveness } \\
\text { undetermined }\end{array}$ \\
\hline $\begin{array}{l}\text { Ribeiro et al, 2013 (94) } \\
\text { RA, DB, AC } \\
\text { Quality Scores: } \\
\text { Cochrane }=10 / 13 \\
\text { IPM-QRB }=32 / 48\end{array}$ & 60 & $\begin{array}{l}\text { Intraarticular } \\
\text { injection group }=31 \\
\text { Intramuscular } \\
\text { steroid injection } \\
\text { group }=29\end{array}$ & $52 \%$ vs $45 \%$ & $55 \%$ vs $38 \%$ & NA & $\mathrm{P}$ & $\mathrm{P}$ & NA & $\begin{array}{l}\text { Short -term } \\
\text { effectiveness }\end{array}$ \\
\hline
\end{tabular}


Facet Joint Interventions Guidelines 2020

Table 21 (cont.). Effectiveness of lumbar radiofrequency, facet joint nerve blocks, and intraarticular injections.

\begin{tabular}{|c|c|c|c|c|c|c|c|c|c|}
\hline \multirow{3}{*}{$\begin{array}{l}\text { Study } \\
\text { Study Characteristic } \\
\text { Methodological Quality } \\
\text { Scoring }\end{array}$} & \multirow{3}{*}{ Patients } & \multirow{3}{*}{ Interventions } & \multicolumn{3}{|c|}{ Pain Relief and Function } & \multicolumn{3}{|c|}{ Results } & \multirow{3}{*}{ Comments } \\
\hline & & & \multirow[b]{2}{*}{3 mos. } & \multirow[b]{2}{*}{6 mos. } & \multirow{2}{*}{$\begin{array}{c}12 \\
\text { mos. }\end{array}$} & \multirow{2}{*}{$\begin{array}{l}\text { Short- } \\
\text { Term } \\
\leq 6 \text { mos. }\end{array}$} & \multicolumn{2}{|c|}{ Long-Term } & \\
\hline & & & & & & & $\begin{array}{l}>6 \\
\text { mos. }\end{array}$ & $\begin{array}{l}\geq 1 \\
\text { year }\end{array}$ & \\
\hline $\begin{array}{l}\text { Lakemeier et al, } 2013 \\
(536) \\
\text { RA, DB } \\
\text { Quality Scores: } \\
\text { Cochrane = 9/13 } \\
\text { IPM-QRB = 37/48 } \\
\end{array}$ & $\begin{array}{l}\text { Total }=56 \\
\text { Steroid group }=29 \\
\text { patients } \\
\text { RF group }=27 \\
\text { patients }\end{array}$ & $\begin{array}{l}\text { Intraarticular } \\
\text { lumbar facet joint } \\
\text { steroid injections } \\
\text { compared to } \\
\text { lumbar facet joint } \\
\text { RF denervation } \\
\end{array}$ & NA & $\begin{array}{l}\text { SI in both } \\
\text { groups }\end{array}$ & NA & $\mathrm{P}$ & $\mathrm{P}$ & NA & $\begin{array}{l}\text { Short-and } \\
\text { long-term } \\
\text { effectiveness }\end{array}$ \\
\hline $\begin{array}{l}\text { Yun et al, } 2012(572) \\
\text { RA } \\
\text { Quality Scores: } \\
\text { Cochrane }=9 / 13 \\
\text { IPM-QRB = } 26 / 48\end{array}$ & $\begin{array}{l}\text { Total }=57 \\
\text { Fluoroscopy group } \\
=32 \\
\text { Ultrasonography } \\
\text { group }=25\end{array}$ & $\begin{array}{l}\text { Intraarticular } \\
\text { injection of local } \\
\text { anesthetic and } \\
\text { steroid }\end{array}$ & $\begin{array}{l}\text { SI in both } \\
\text { groups }\end{array}$ & NA & NA & $\mathrm{P}$ & NA & NA & $\begin{array}{l}\text { Short-term } \\
\text { effectiveness }\end{array}$ \\
\hline $\begin{array}{l}\text { Do et al (538) } \\
\text { Randomized, double } \\
\text { blind, active controlled } \\
\text { trial } \\
\text { Quality Scores: } \\
\text { Cochrane }=10 / 13 \\
\text { IPM-QRB }=33 / 48\end{array}$ & $\begin{array}{l}60 \text { patients } \\
\text { Group 1 } \\
\text { intraarticular pulsed } \\
\text { RF. } \\
\text { Group 2 } \\
\text { intraarticular } \\
\text { lumbar facet joint } \\
\text { corticosteroid } \\
\text { injection. }\end{array}$ & $\begin{array}{l}\text { Intraarticular } \\
\text { injection of } \\
\text { corticosteroid }\end{array}$ & $>50 \%$ & $46.7 \%$ & NA & $\mathrm{P}$ & NA & NA & $\begin{array}{l}\text { Intraarticular } \\
\text { steroid with } \\
\text { local anesthetic } \\
\text { is effective } \\
\text { short-term }\end{array}$ \\
\hline $\begin{array}{l}\text { Kennedy et al (548) } \\
\text { Randomized, double- } \\
\text { blind, placebo control } \\
\text { trial } \\
\text { Quality Scores: } \\
\text { Cochrane }=12 / 13 \\
\text { IPM-QRB }=33 / 48\end{array}$ & $\begin{array}{l}28 \text { patients } \\
\text { - Intraarticular } \\
\text { corticosteroid } \\
\text { triamcinolone } \\
20 \mathrm{mg} \\
\text { - Saline } 0.5 \mathrm{~mL}\end{array}$ & $\begin{array}{l}\text { Intraarticular } \\
\text { placebo injection } \\
\text { with sodium } \\
\text { chloride solution } \\
\text { or with steroid. }\end{array}$ & NA & NA & NA & $\mathrm{N}$ & NA & NA & $\begin{array}{l}\text { Negative with } \\
\text { steroid alone }\end{array}$ \\
\hline $\begin{array}{l}\text { Kennedy et al ( } 550) \\
\text { Randomized, double- } \\
\text { blind, placebo } \\
\text { controlled trial } \\
\text { Quality Scores: } \\
\text { Cochrane = } 12 / 13 \\
\text { IPM-QRB = 33/48 }\end{array}$ & $\begin{array}{l}\text { Triamcinolone, } \\
20 \mathrm{mg} \text {, of whom } \\
24 \text { had a positive } \\
\text { confirmatory } \\
\text { block. } \\
\text { - } 29 \text { patients } \\
20 \mathrm{mg} \text { of } \\
\text { intraarticular } \\
\text { steroid } \\
\text { - } 27 \text { patients } 0.5 \\
\text { mL of saline }\end{array}$ & $\begin{array}{l}\text { Intraarticular } \\
\text { sodium chloride } \\
\text { injection or with } \\
\text { steroid }\end{array}$ & NA & NA & NA & $\mathrm{N}$ & NA & NA & $\begin{array}{l}\text { Negative with } \\
\text { steroid alone }\end{array}$ \\
\hline $\begin{array}{l}\text { Annaswamy et al (551) } \\
\text { Double-blind, } \\
\text { randomized, controlled } \\
\text { trial, active control } \\
\text { design } \\
\text { Quality Scores: } \\
\text { Cochrane }=12 / 13 \\
\text { IPM-QRB = 33/48 }\end{array}$ & $\begin{array}{l}30 \text { patients } \\
\text { were randomly } \\
\text { assigned to receive } \\
\text { bilateral L3 to S1 } \\
\text { lumbar facet joint } \\
\text { injections with } \\
\text { triamcinolone or } \\
\text { Synvisc 1 }\end{array}$ & $\begin{array}{l}\text { Intraarticular } \\
\text { injection of } \\
\text { triamcinolone }\end{array}$ & NE & $\mathrm{NE}$ & NA & $\mathrm{N}$ & $\mathrm{N}$ & NA & $\begin{array}{c}\text { Negative } \\
\text { without local } \\
\text { anesthetic }\end{array}$ \\
\hline
\end{tabular}

$\mathrm{RA}=$ randomized $\mathrm{DB}=$ double-blind $\mathrm{AC}=$ active control; $\mathrm{ST}=$ steroid LA = local anesthetic $\mathrm{SAL}=$ saline; $\mathrm{SI}=$ significant improvement; $\mathrm{U}=$ undetermined; $\mathrm{NSD}=$ no significant difference; $\mathrm{NE}$ = not effective; $\mathrm{CRF}$ - cooled radiofrequency; $\mathrm{P}=$ positive; $\mathrm{N}$ = negative; $\mathrm{NA}=$ not applicable Adapted and modified from: Manchikanti L, Kaye AD, Boswell MV, et al. A systematic review and best evidence synthesis of the effectiveness of therapeutic facet joint interventions in managing chronic spinal pain. Pain Physician 2015; 18:E535-E582 (19). 
Pain Physician: May/June 2020 23:S1-S127

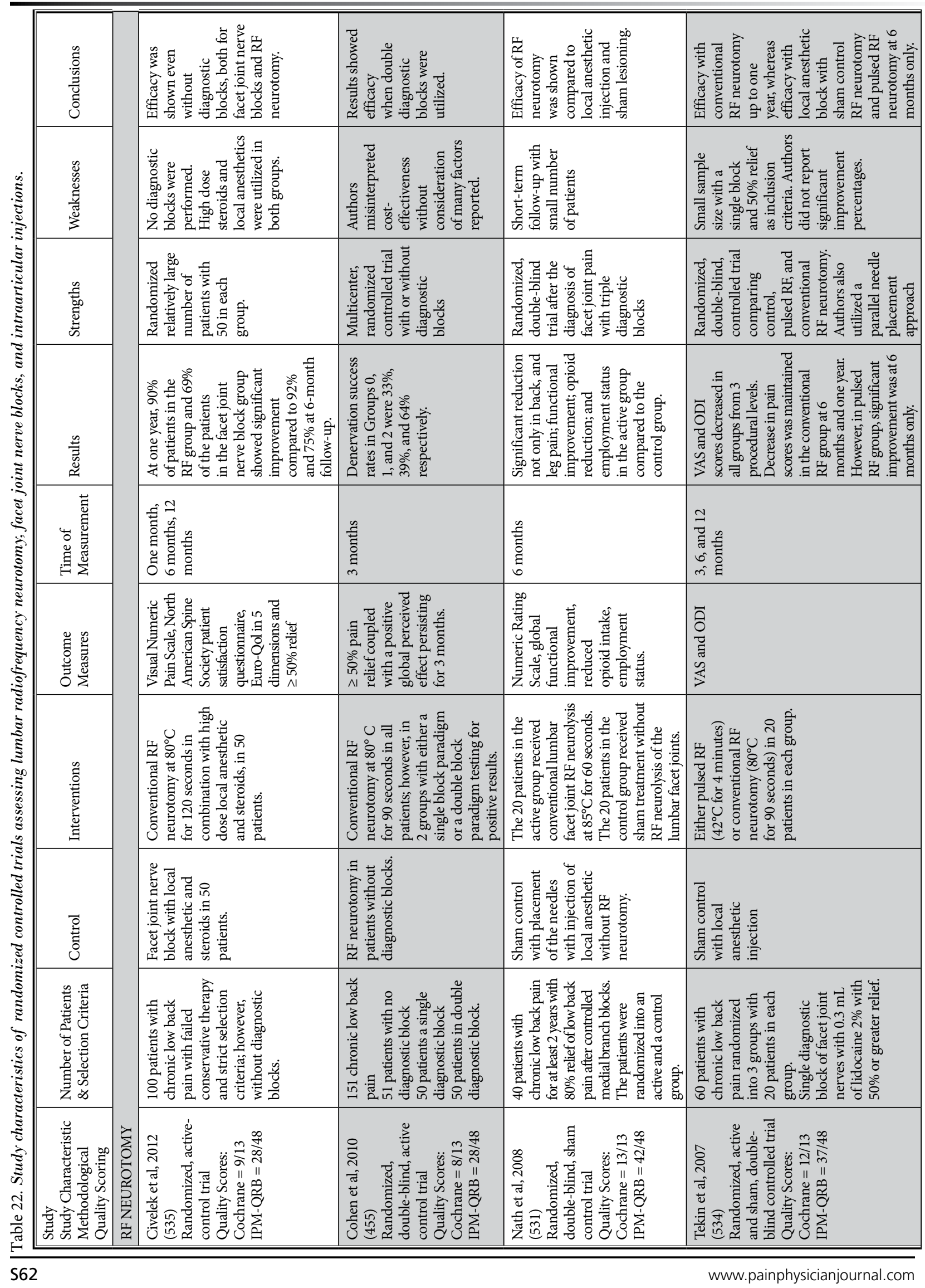


Facet Joint Interventions Guidelines 2020

\begin{tabular}{|c|c|c|c|}
\hline 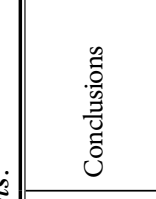 & 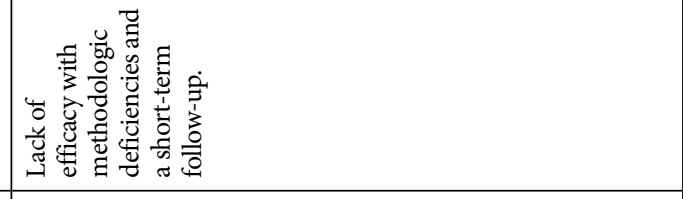 & 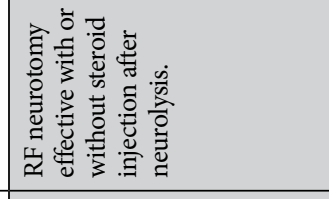 & 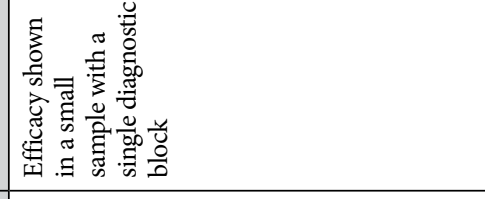 \\
\hline 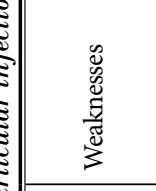 & 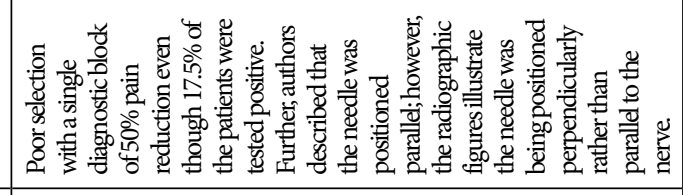 & 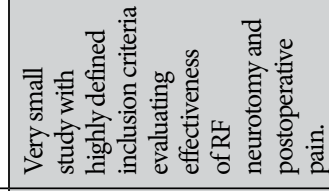 & 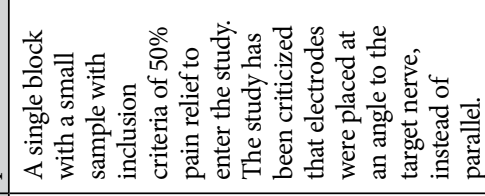 \\
\hline 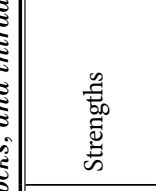 & 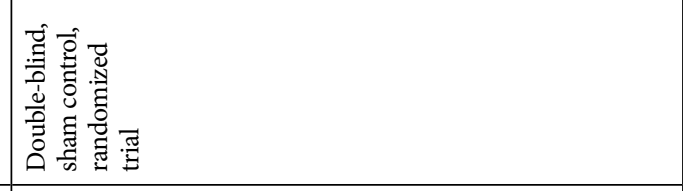 & 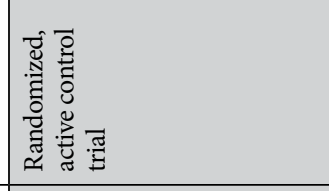 & 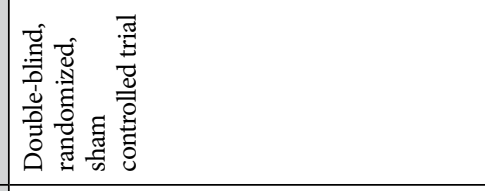 \\
\hline 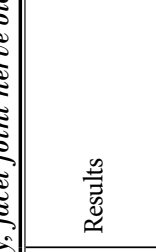 & 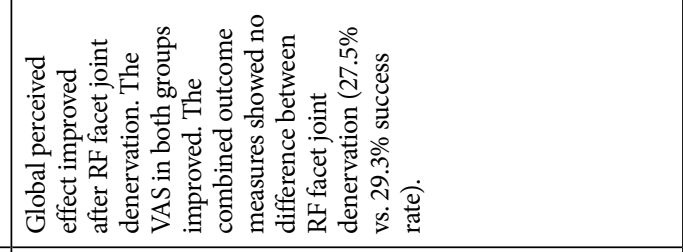 & 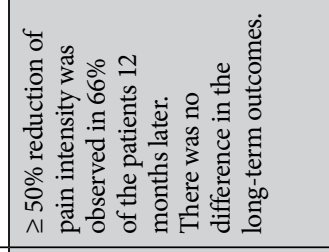 & 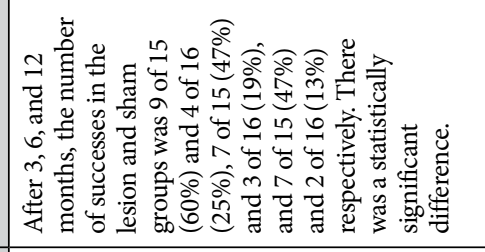 \\
\hline : & 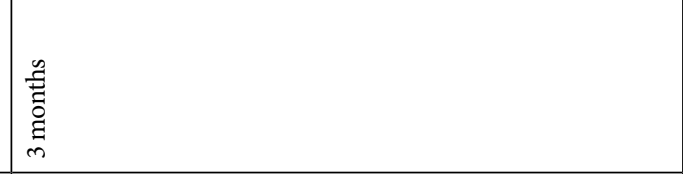 & 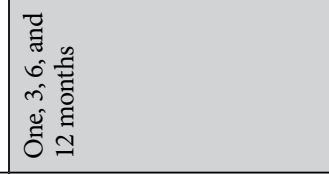 & 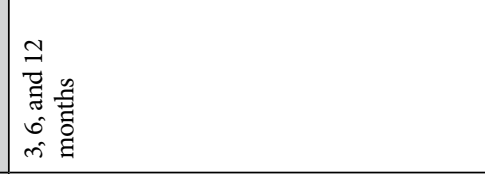 \\
\hline : & 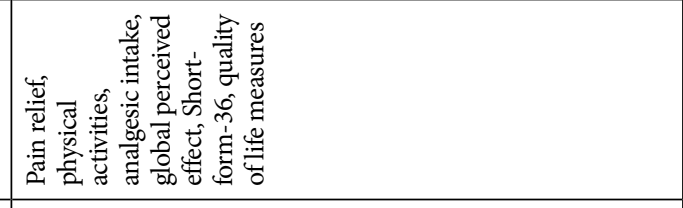 & 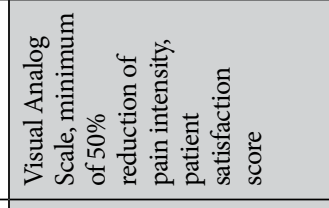 & 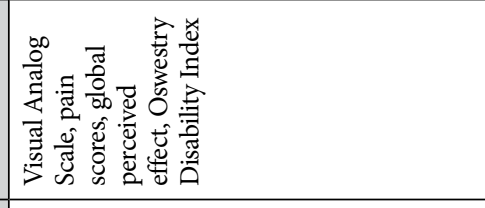 \\
\hline 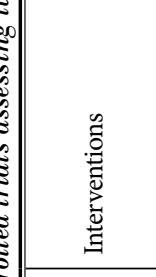 & 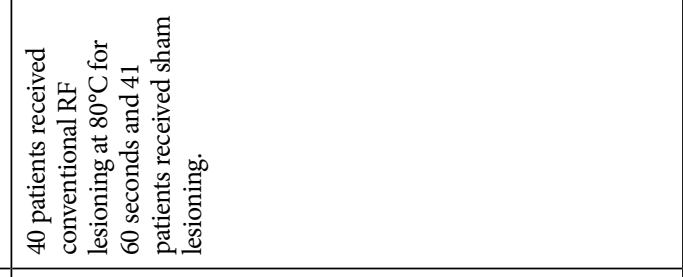 & 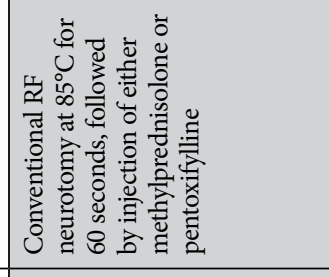 & 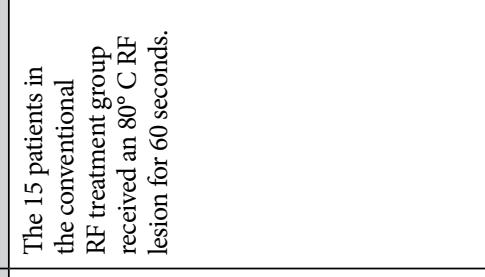 \\
\hline $\begin{array}{l}\overrightarrow{0} \\
\text { 离 }\end{array}$ & 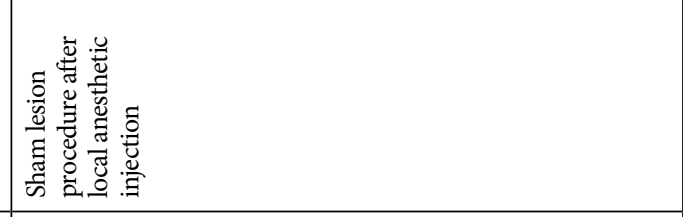 & 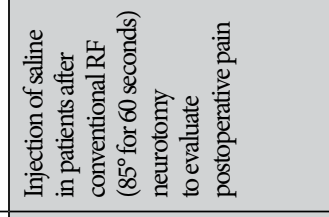 & 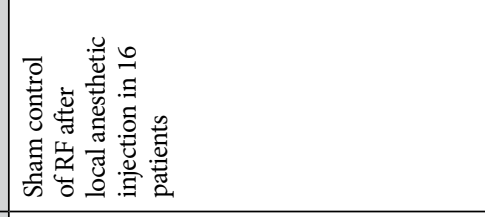 \\
\hline 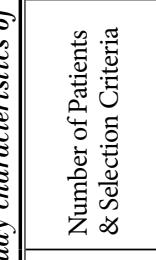 & 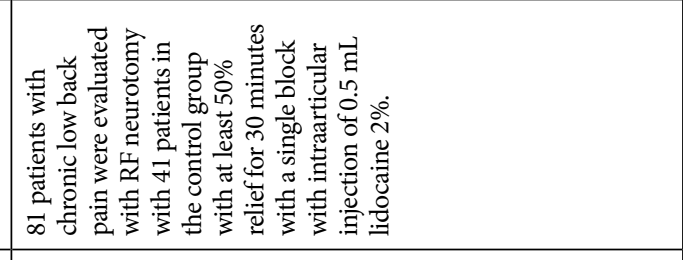 & 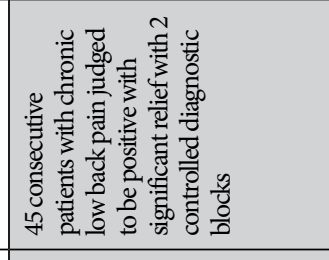 & 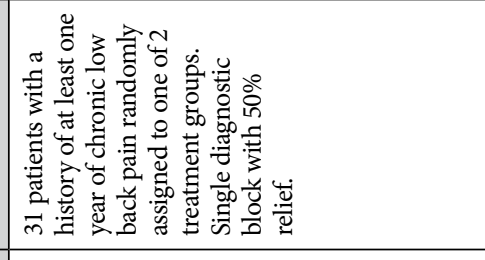 \\
\hline 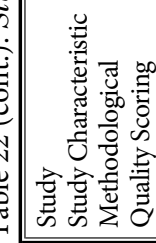 & 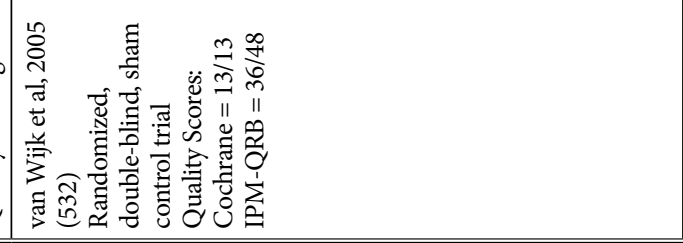 & 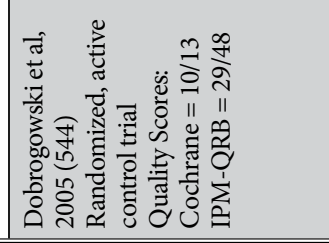 & 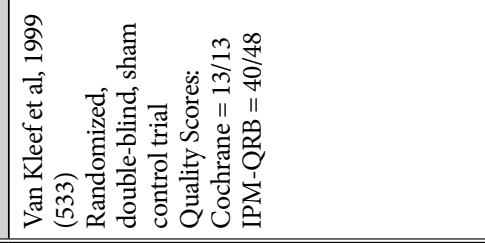 \\
\hline
\end{tabular}


Pain Physician: May/June 2020 23:S1-S127

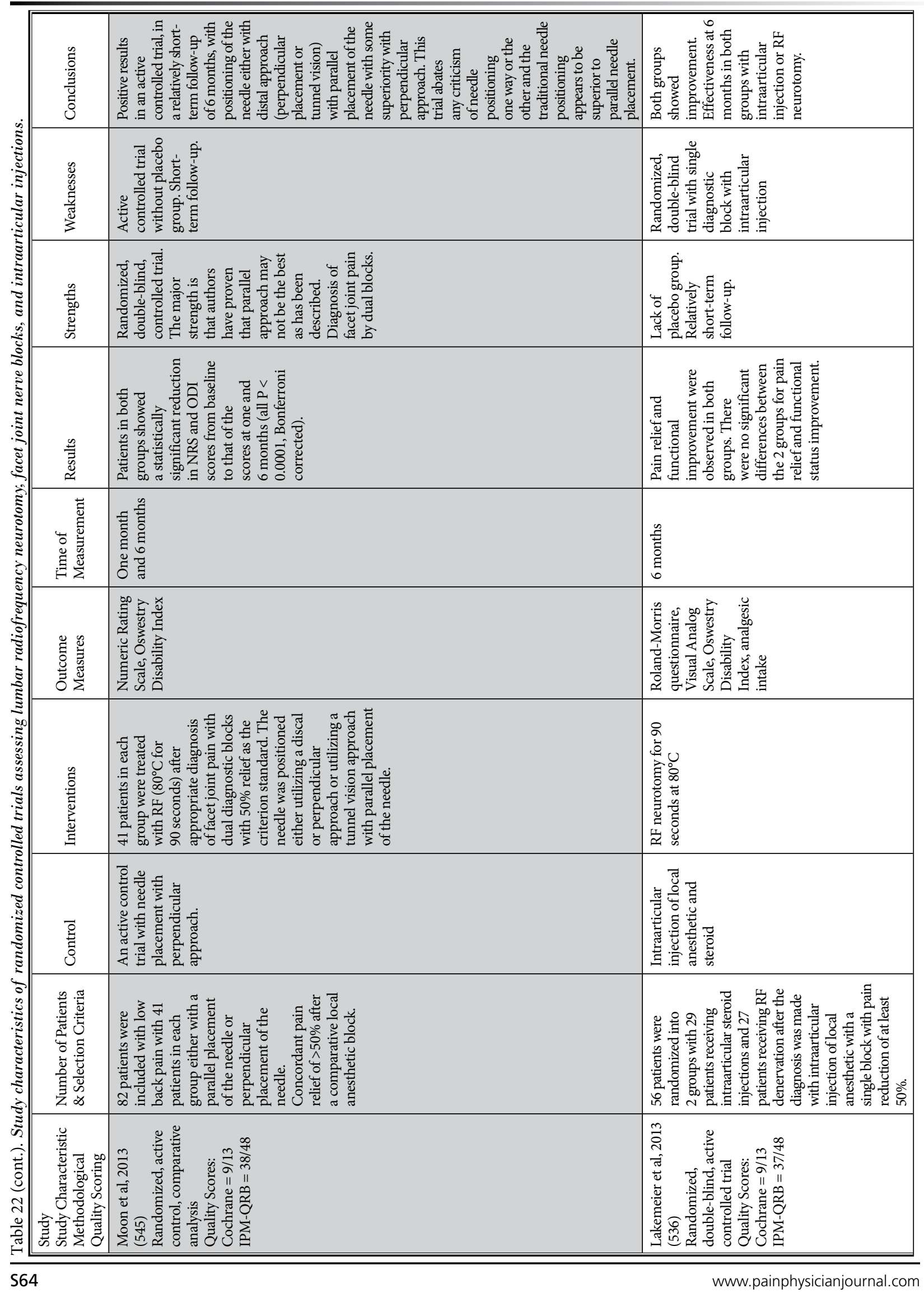




\begin{tabular}{|c|c|c|}
\hline 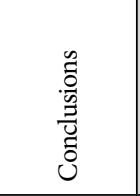 & 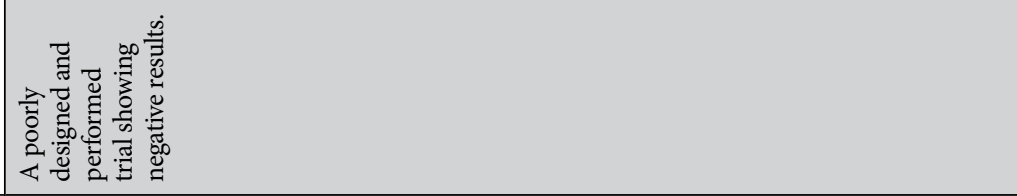 & 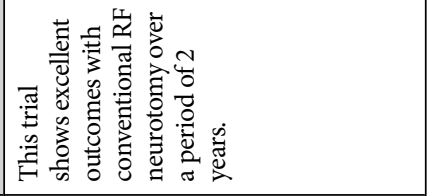 \\
\hline 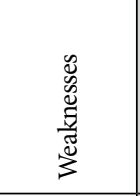 & 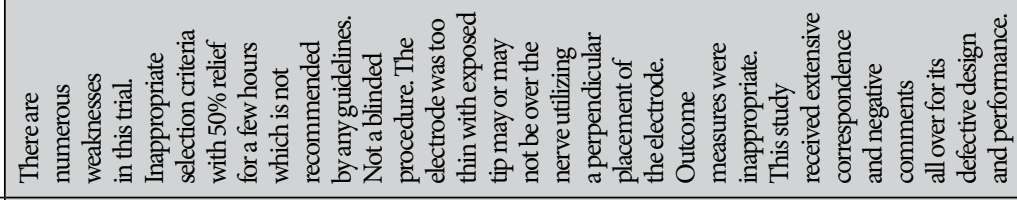 & 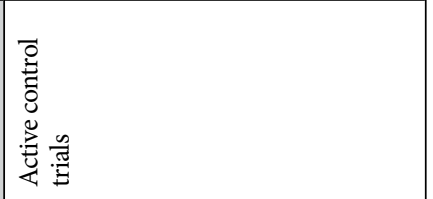 \\
\hline 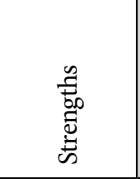 & 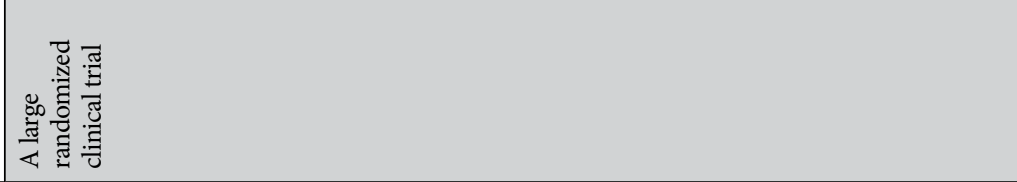 & 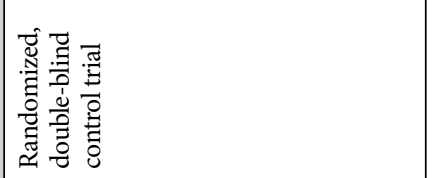 \\
\hline 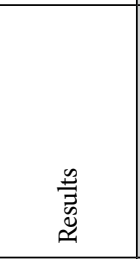 & 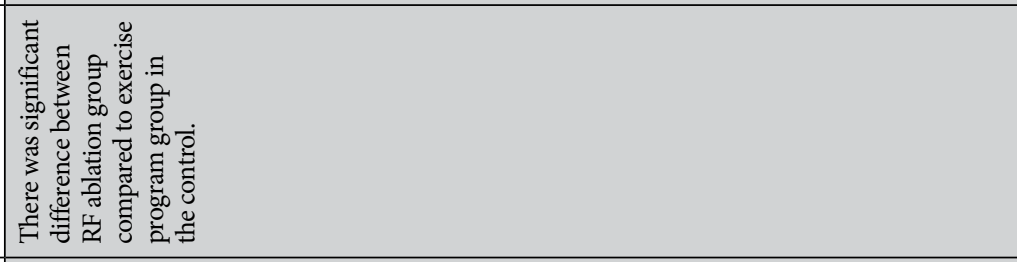 & 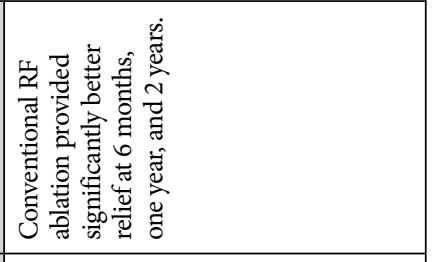 \\
\hline 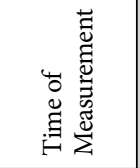 & 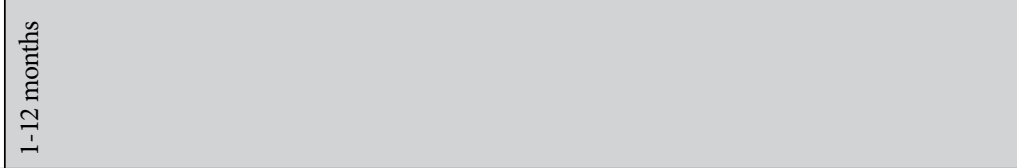 & 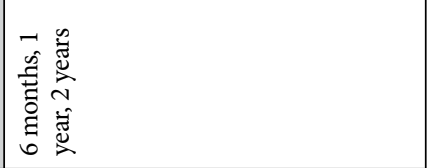 \\
\hline 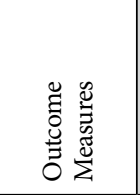 & 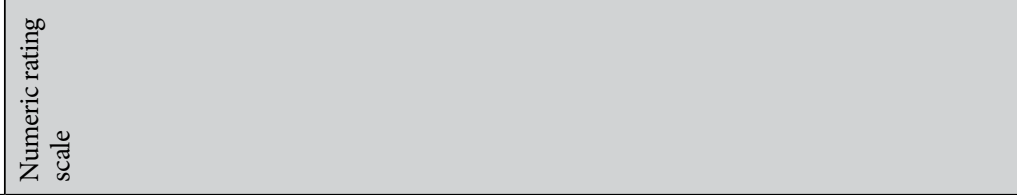 & 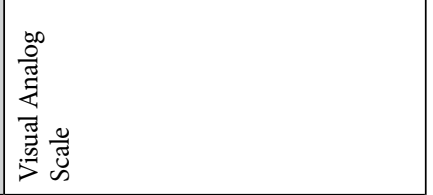 \\
\hline 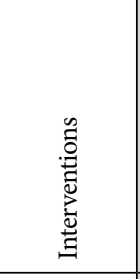 & 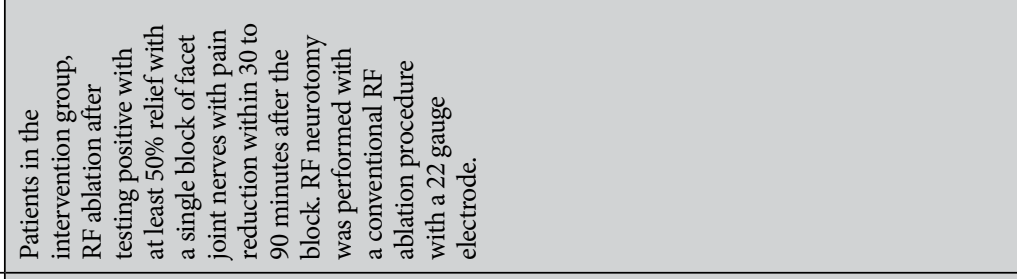 & 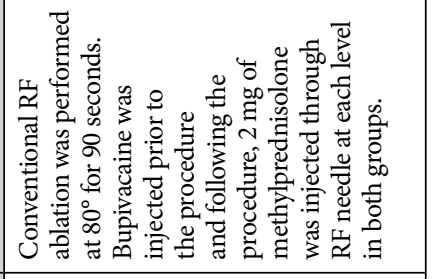 \\
\hline 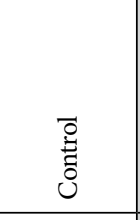 & 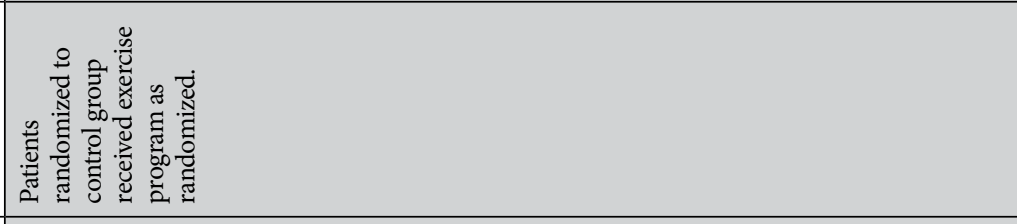 & 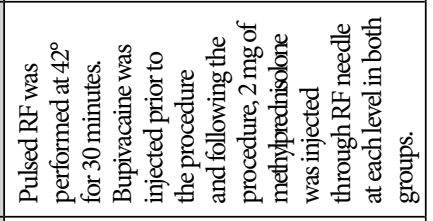 \\
\hline 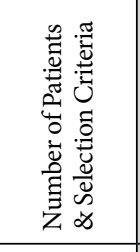 & 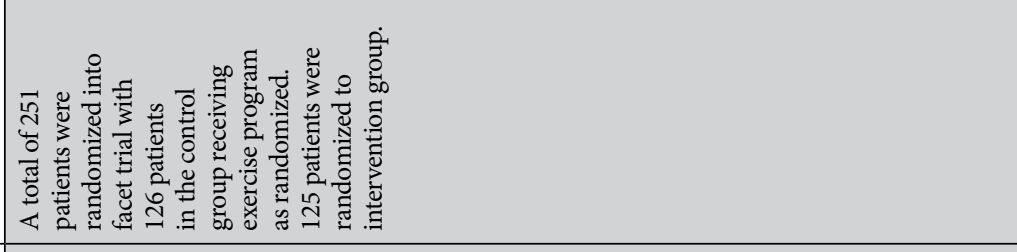 & 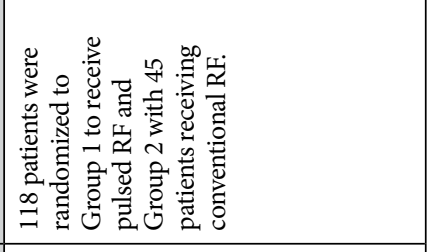 \\
\hline 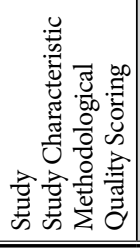 & 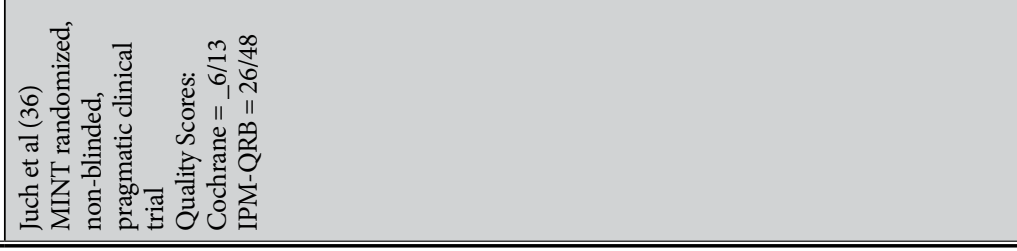 & 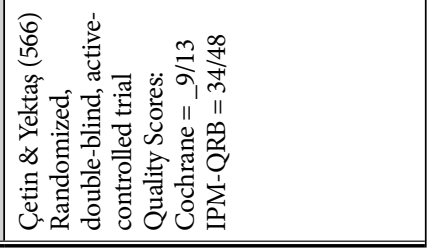 \\
\hline
\end{tabular}


Pain Physician: May/June 2020 23:S1-S127

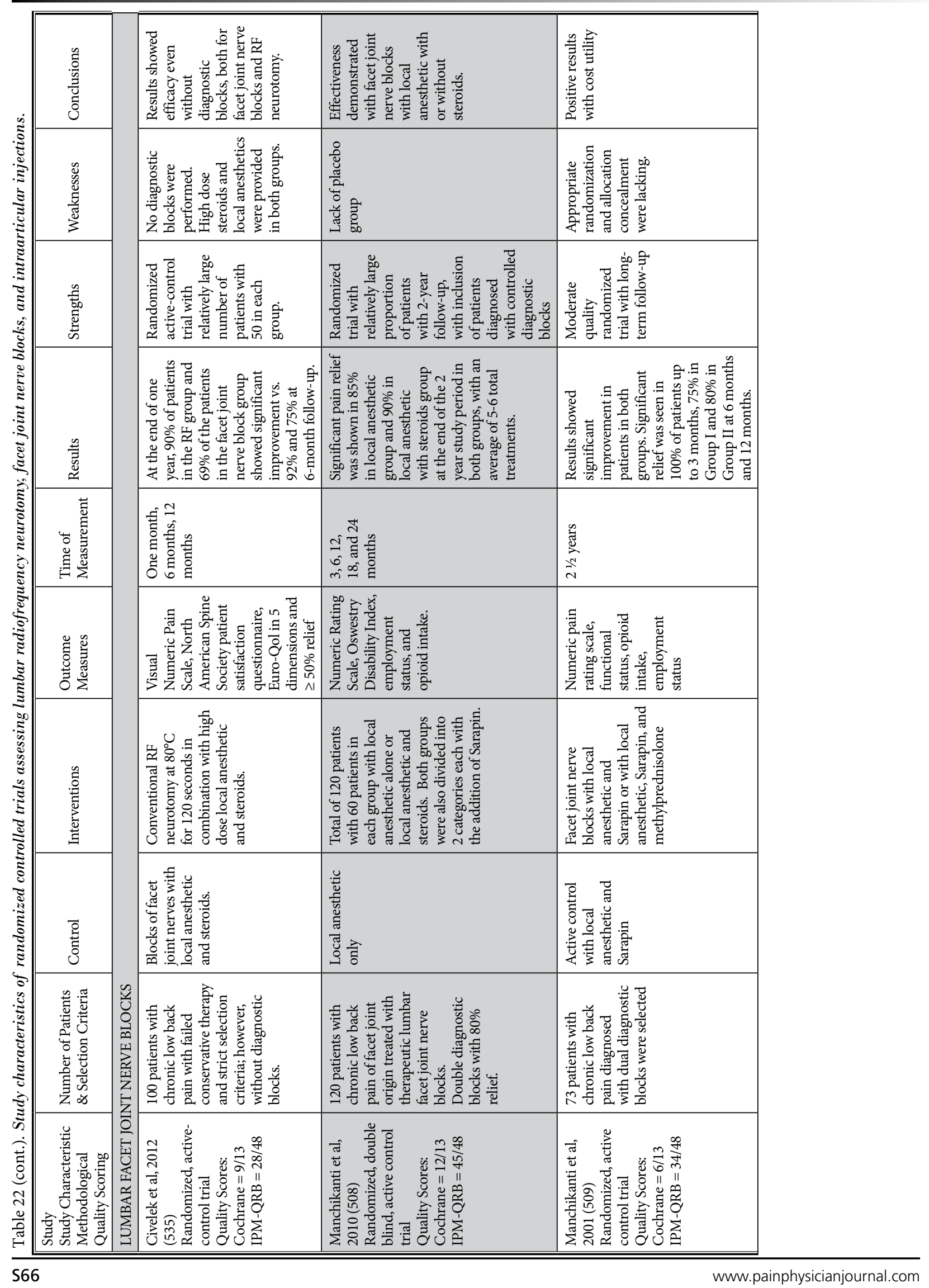


Facet Joint Interventions Guidelines 2020

\begin{tabular}{|c|c|c|c|}
\hline 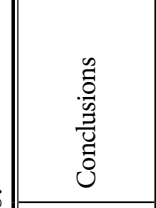 & 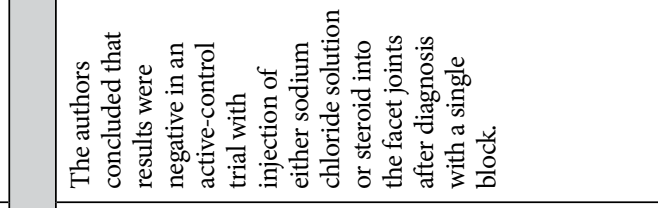 & 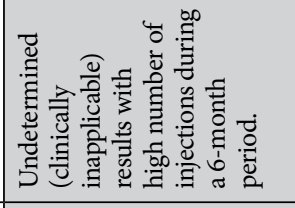 & 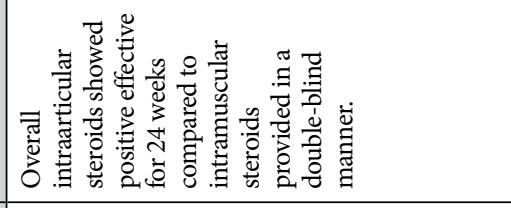 \\
\hline 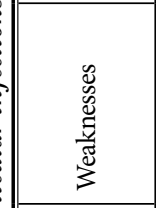 & 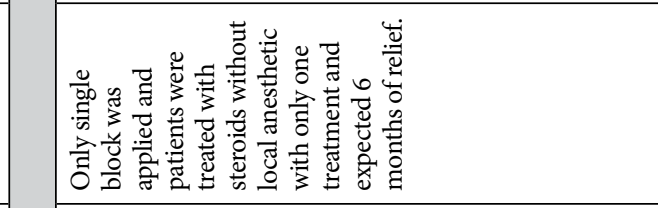 & 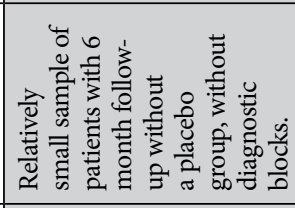 & 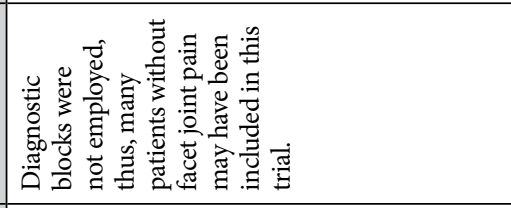 \\
\hline 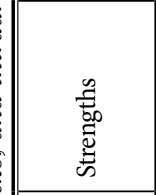 & 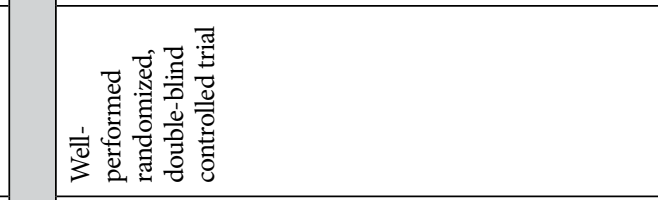 & 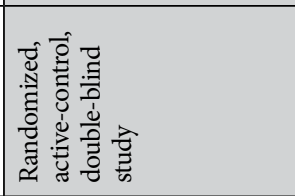 & 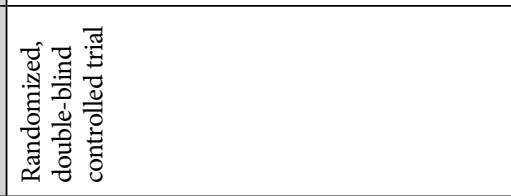 \\
\hline 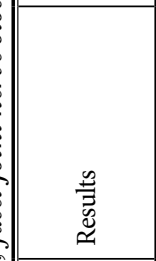 & 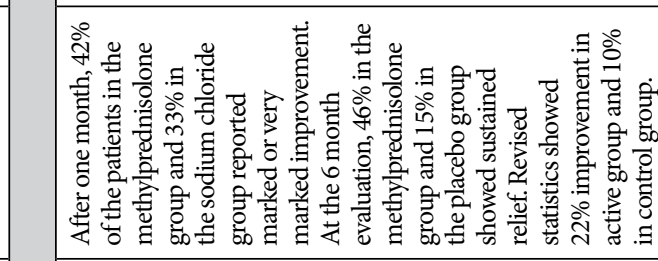 & 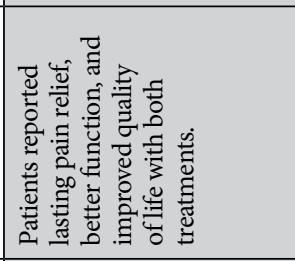 & 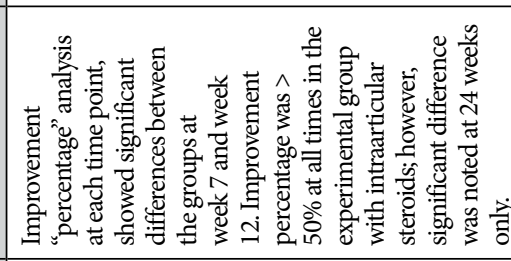 \\
\hline 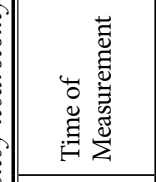 & 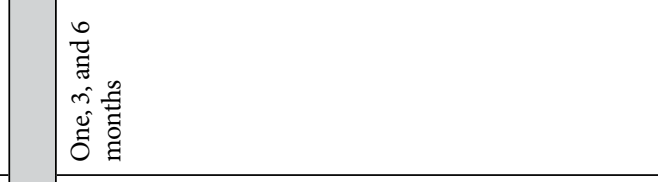 & 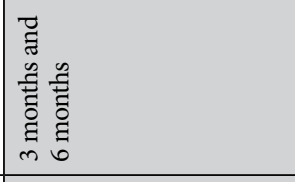 & 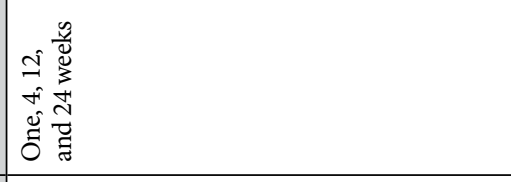 \\
\hline 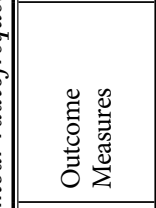 & 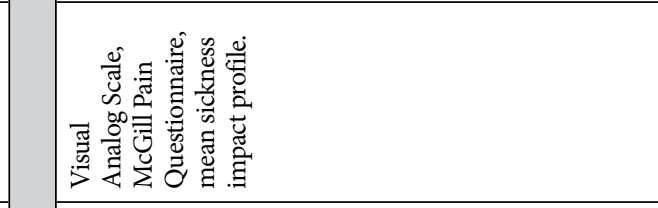 & 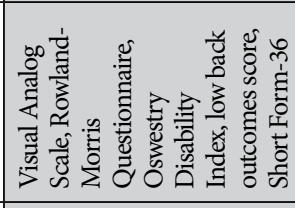 & 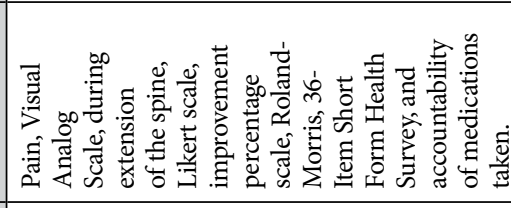 \\
\hline 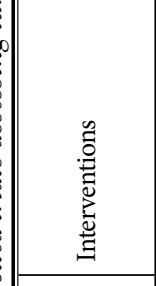 & 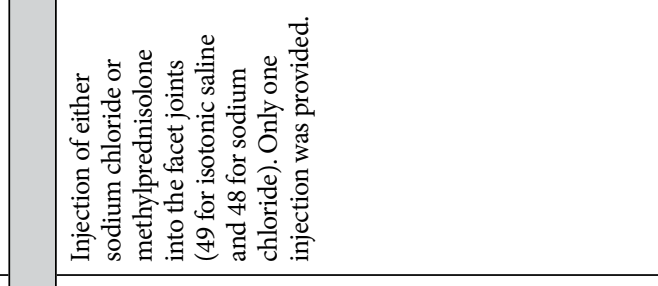 & 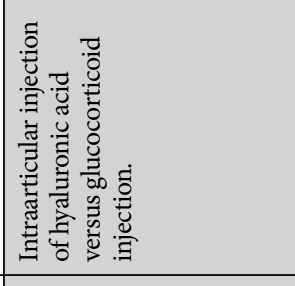 & 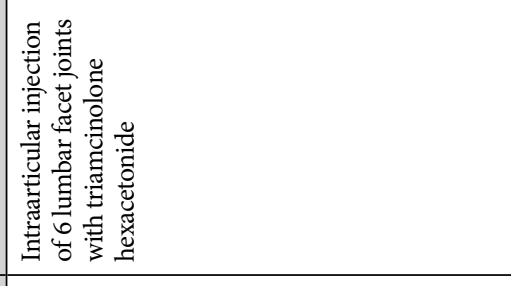 \\
\hline $\begin{array}{l}\overrightarrow{0} \\
\overline{0} \\
\overline{0}\end{array}$ & 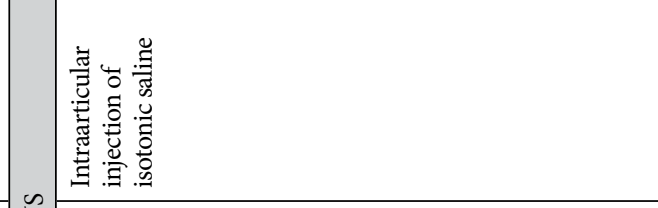 & 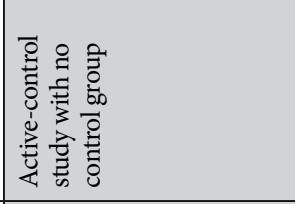 & 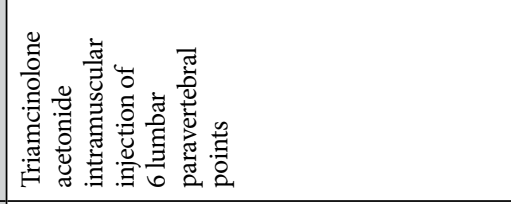 \\
\hline 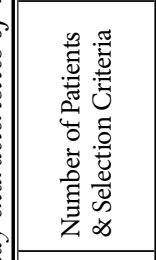 & 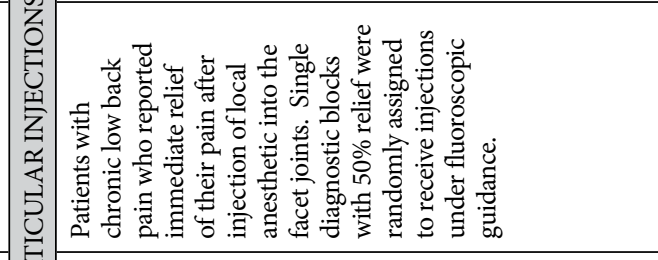 & 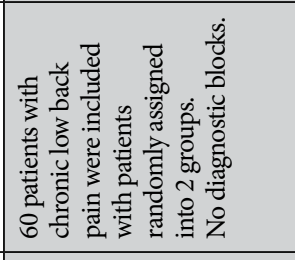 & 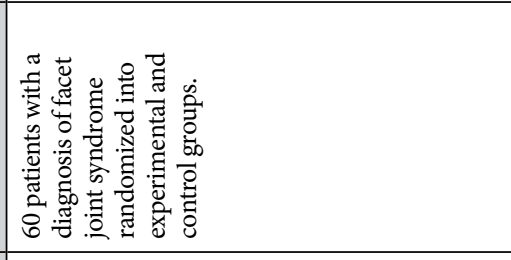 \\
\hline 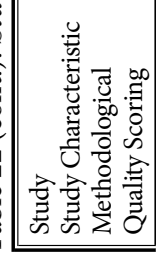 & 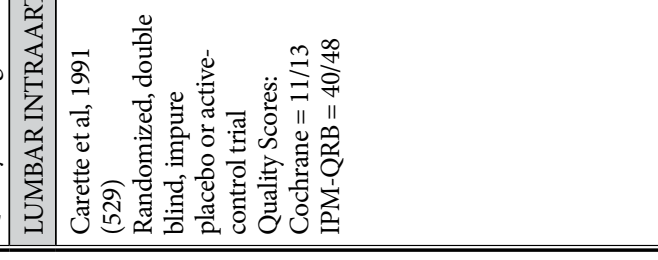 & 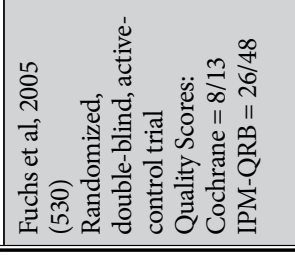 & 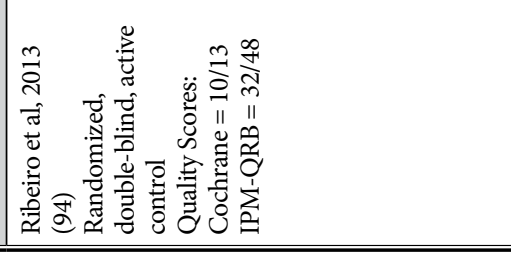 \\
\hline
\end{tabular}


Pain Physician: May/June 2020 23:S1-S127

\begin{tabular}{|c|c|c|c|c|}
\hline & 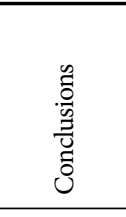 & 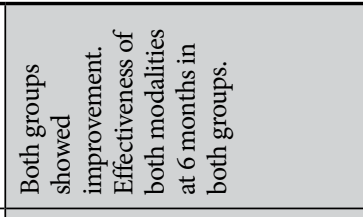 & 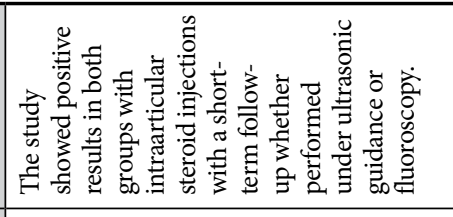 & 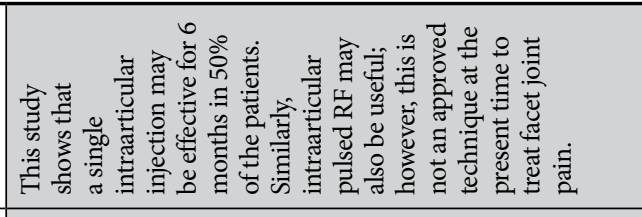 \\
\hline & 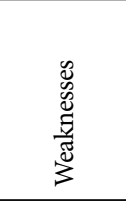 & 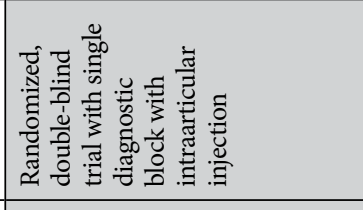 & 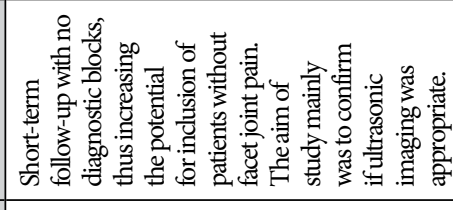 & 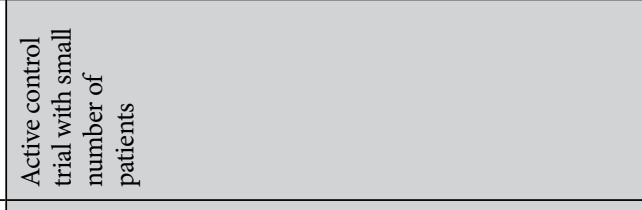 \\
\hline 8 & 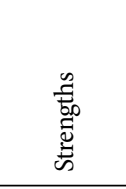 & 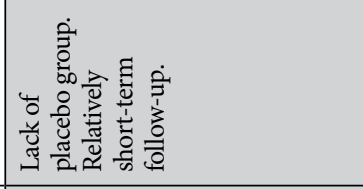 & 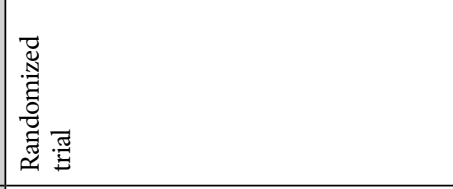 & 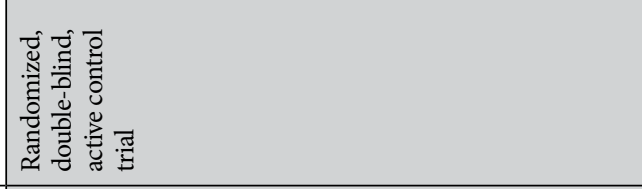 \\
\hline : & 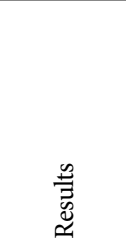 & 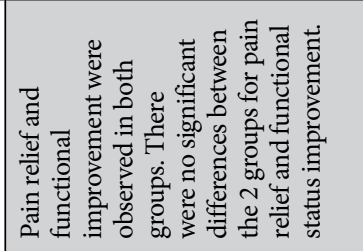 & 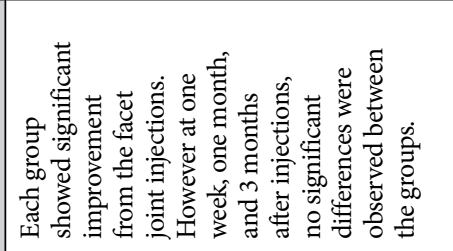 & 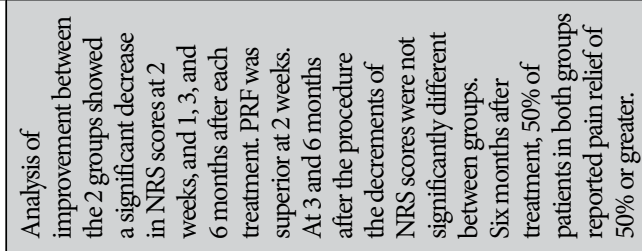 \\
\hline 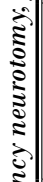 & 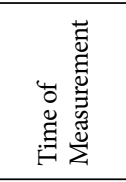 & 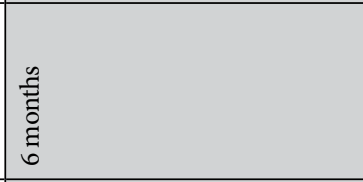 & 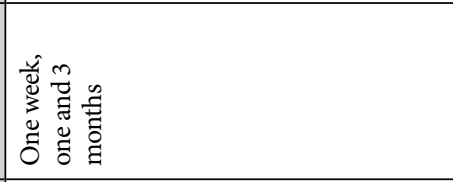 & 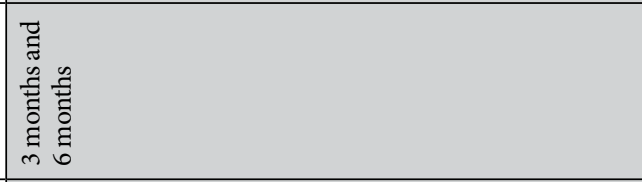 \\
\hline & 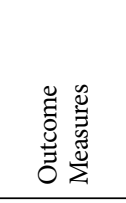 & 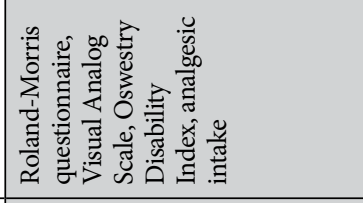 & 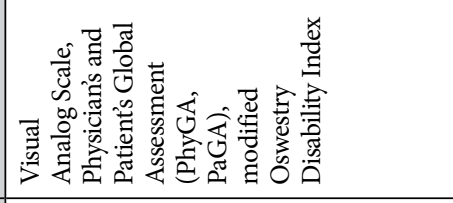 & 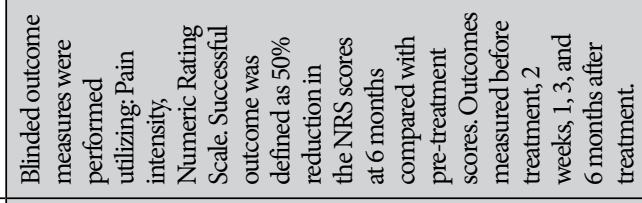 \\
\hline 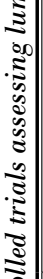 & 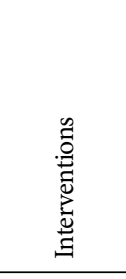 & 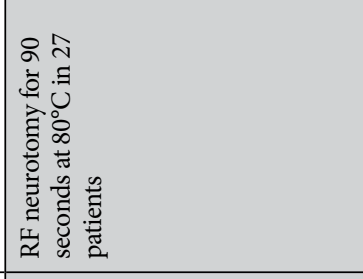 & 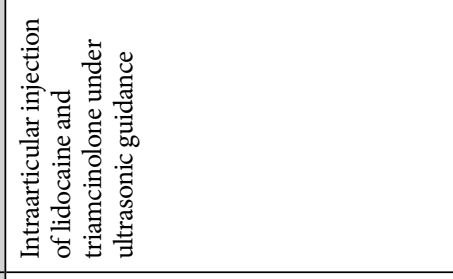 & 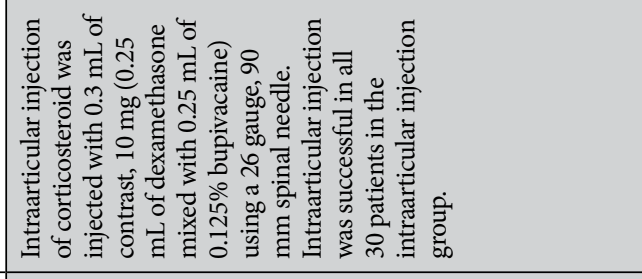 \\
\hline | & $\begin{array}{l}\overrightarrow{0} \\
\text { : } \\
\text { Oें }\end{array}$ & 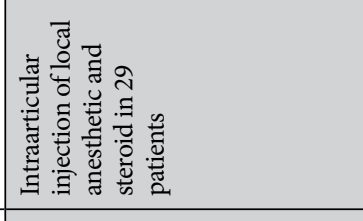 & 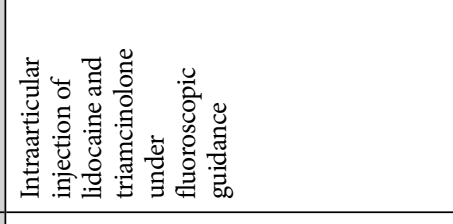 & 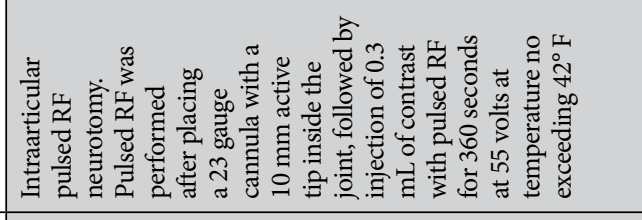 \\
\hline | & 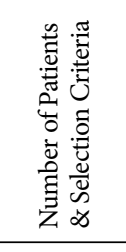 & 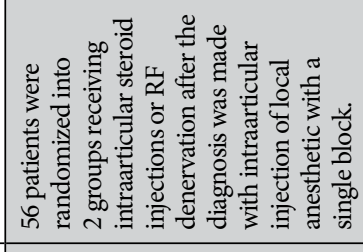 & 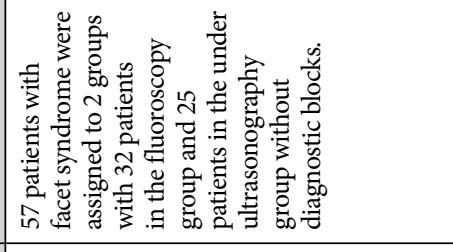 & 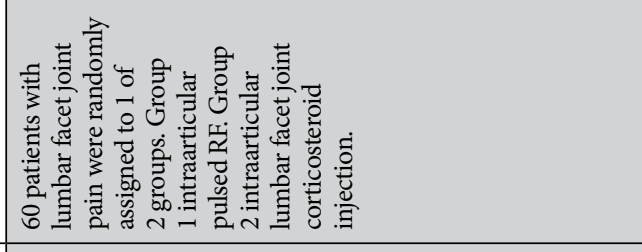 \\
\hline 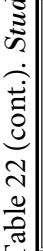 & 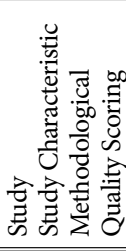 & 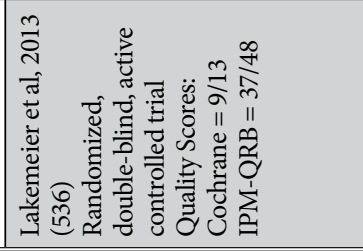 & 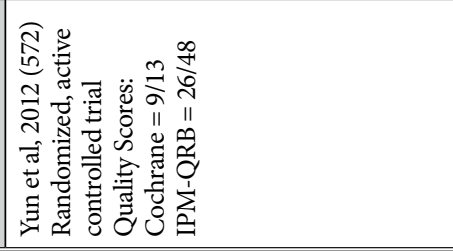 & 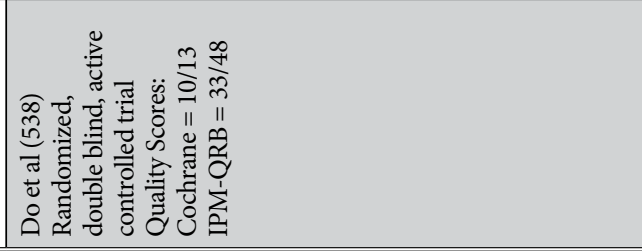 \\
\hline
\end{tabular}




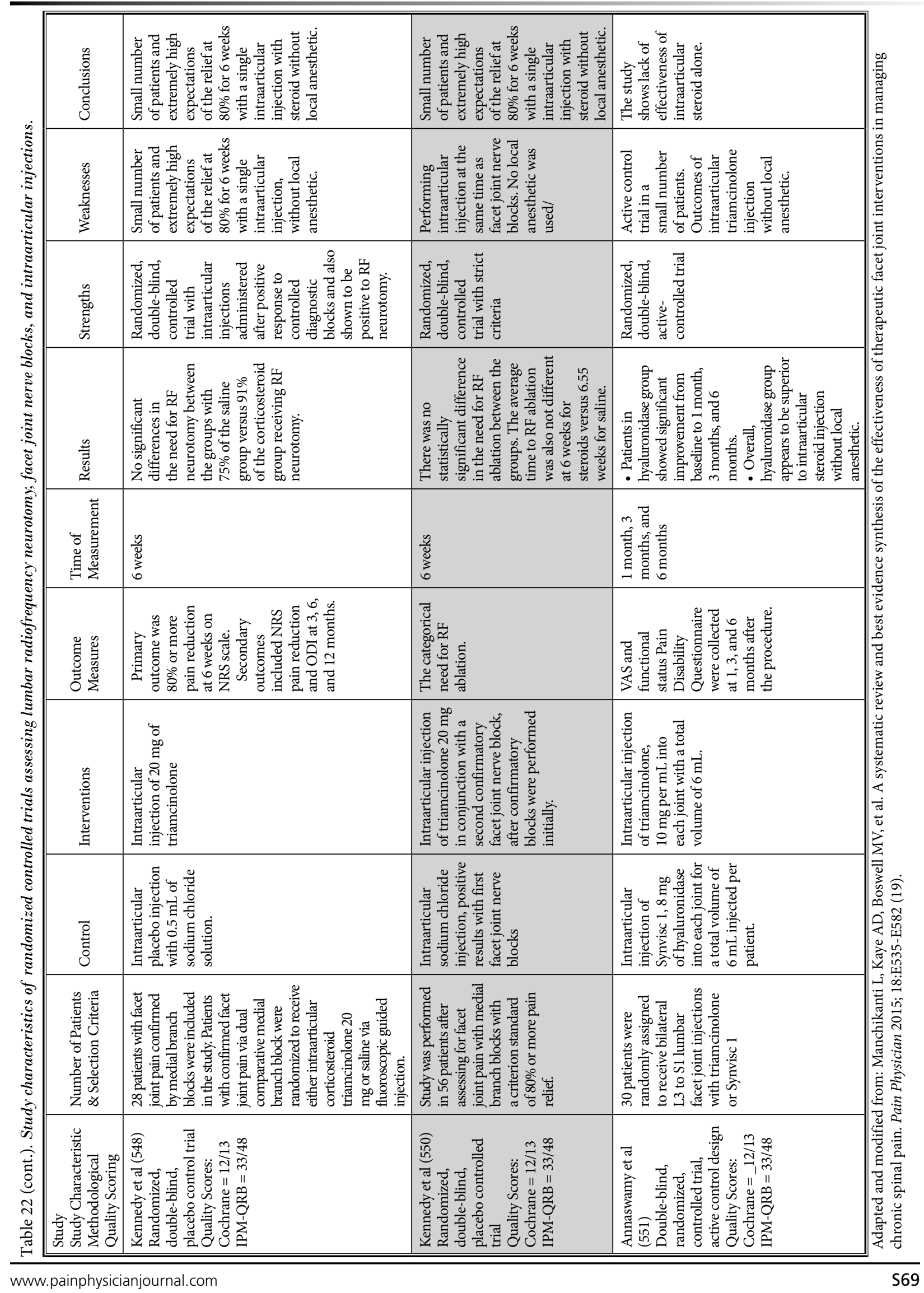


Gofeld et al (558) published a 10-year experience in a prospective clinical audit. Their results showed that of the 209 patients, 174 completed the study and 35 were lost to follow-up or did not provide complete data for assessment. Of the 174 patients with complete data, 55 $(31.6 \%)$, experienced no benefit from the procedure, 119 patients $(68.4 \%$ ) had good ( $\geq 50 \%$ ) to excellent ( $\geq 80 \%$ ) pain relief lasting from 6 to 24 months. This study shows that all in all, slightly less than $50 \%$ of the patients responded with approximately $15 \%$ lost to follow-up and approximately $32 \%$ of the patients with follow-up also experienced no benefit from the procedure. Overall, 90 of 209 patients appears to have not been benefited.

These results are similar to our own experience with approximately $30 \%$ of the patients receiving radiofrequency neurotomy prefer not to receive the procedure at a later date or move on to a different procedure such as therapeutic facet joint nerve blocks.

Further, Singh et al (601) also showed the lack of impact of local steroid administration on the incidence of neuritis following lumbar facet radiofrequency neurotomy.

Thus, based on available evidence with systematic reviews and RCTs, the evidence is Level II for long-term with moderate strength of recommendation to perform lumbar radiofrequency neurotomy in patients after testing positive for dual blocks with $80 \%$ criterion standard.

\subsubsection{Therapeutic Lumbar Facet Joint Nerve Blocks}

Therapeutic lumbar facet joint nerve blocks were assessed in 2 high-quality RCTs $(508,535)$ and one moderate-quality RCT (509), including 293 patients either with local anesthetic alone or local anesthetic with steroid in 92 patients and conventional radiofrequency neurotomy in 50 patients. All 3 studies showed positive effectiveness of long-term and short-term relief. The improvement was seen in $69 \%$ of the patients with local anesthetic with steroids by Civelek et al (535), whereas it was seen in $75 \%$ and $85 \%$ of the patients in the studies by Manchikanti et al $(508,509)$. Only the systematic review by Manchikanti et al (19) assessed the evidence for therapeutic facet joint nerve blocks. They showed Level II evidence for lumbar facet joint nerve blocks for short-term and long-term relief.

Overall, therapeutic lumbar facet joint nerve blocks have been shown to be not only effective with repeat treatments, but also well accepted by patients, because of the simplicity, ability to provide the procedure in spite of hardware, with avoidance of side effects related to radiofrequency neurotomy. Utilizing principles of Getting it Right First Time (GIRFT) from National Health Service (NHS), which is designed to improve the quality of care within the NHS by reducing unwarranted variations, multiple procedures were assessed. Under this program, data from many NHS sources is considered and analyzed to provide a detailed national picture of a particular area of practice. This process highlights variations in care decisions, patient outcomes, costs and other factors across the NHS. For low back and radicular pain, they found wide variation in the management of lower back and radicular pain across the NHS Trust. Consequently, they looked at multiple injections if they were repeated within 2 months and what they considered as of limited value (609). Based on this, Onafowokan et al (610) with other members of GIRFT program assessed facet joint injections or medial branch blocks. The investigation was based on the latest National Institute for Health and Clinical Excellence (NICE) guidance, which advocated the use of single diagnostic medial branch block instead of facet joint injections and following positive response, radiofrequency ablation to be offered (611). Consequently, they have undertaken the systematic review for evidence supporting the practice of multiple facet joint injections and or medial branch blocks, and reported on the variations in the NHS England framework using GIRFT data. As the name indicates, their fundamental concept appears to be one treatment to provide long-term improvement. Ironically, this review utilized modified grading of qualitative evidence with best evidence synthesis for diagnostic accuracy and therapeutic interventions by Manchikanti et al (121). They utilized 2 studies for medial branch blocks by Manchikanti et al $(508,509)$. Even though they included a multitude of studies $(n=44)$, they included only 3 studies in the qualitative synthesis. These included 2 studies by Manchikanti et al $(508,509)$ and Fuchs et al (530). They also included the data from NHS and showed that 236 healthcare providers treated at least 20 patients with 3 or more facet joint injections in any 12 month period and were included in this comparative practice of repeated facet joint injections. They concluded that the findings based on the Manchikanti et al studies $(508,509)$ appears to offer some support for the use of medial branch blocks in treating lumbar facet joint pain, rather than facet joint injections. However, they did not discuss the value of diagnostic facet joint nerve blocks; that is what is utilized in England. 
Thus, the evidence for therapeutic lumbar facet joint nerve blocks is Level II for short-term and longterm improvement with moderate strength of recommendation, when performed after the appropriate selection of the patients positive with controlled comparative local anesthetic blocks with $80 \%$ criterion standard of pain relief.

\subsubsection{Intraarticular Injections}

There were 9 RCTs meeting the inclusion criteria for lumbar intraarticular injections $(94,529,530,536,53$ $8,548,550,551,572)$. In the past, the evidence for lumbar intraarticular injection steroids was shown to be Level III (19), based on 3 high quality RCTs $(94,536,572)$ with short-term effectiveness. Evidence was limited for long-term effectiveness (19). Further, negative studies also have grown since the last systematic reviews and publications with additional negative publications $(538,548,550,551)$. The common denominator in all of the negative studies is lack of effectiveness secondary to using steroids only rather than with local anesthetic. All the studies which showed negative results were performed without local anesthetic injection $(529,538,548,550,551)$.

There was also positive evidence from an observational study (555). Campos et al (555) identified the predictors of pain recurrence after lumbar facet joint injections. They studied prospectively 43 consecutive patients and treated them with facet joint intraarticular injections. After 6 month follow-up, 32 patients (74.4 $\%)$ showed a clinically significant reduction of pain and $27(62.8 \%)$ reported a clinically significant improvement of disability. The difference of this study compared to all the negative trials is that they injected all the joints with $10 \mathrm{~mL}$ of ropivacaine, $10 \mathrm{mg}$ per $\mathrm{mL}$, and $2 \mathrm{~mL}$ of Diprospan suspension equivalent to $7 \mathrm{mg}$ per $\mathrm{mL}$ of betamethasone. They identified that facet joint injections reduce low back pain and disability of patients with unresponsive low back pain. They also concluded that pain related cognitive and behavioral factors determined by pain catastrophizing and smoking were independently associated with pain recurrence after lumbar facet joint injections. Onafowokan et al (610) in a study of multiple injections for low back pain, agreed with the recommendation of NICE (611) that medial branch blocks were preferable to facet joint injections; however, they only showed Level III evidence for medial branch blocks also.

Thus, the evidence for lumbar intraarticular injections without the use of local anesthetic for therapeu- tic purposes is Level III for short-term relief with weak recommendation, when performed after appropriate diagnosis achieved by dual diagnostic facet joint nerve blocks with $80 \%$ criterion standard.

The evidence for long-term improvement is Level IV. Consequently, the strength of recommendation is weak.

\subsubsection{Cervical Spine}

There was a total of 11 studies $(512,513,579,582,585$ $587,590,591,599,600)$ meeting inclusion criteria for assessment of evidence in the cervical spine. Of these, there was one RCT assessing cervical radiofrequency neurotomy (579), 3 prospective studies assessing radiofrequency neurotomy $(582,585,599)$, one RCT assessing cervical facet joint nerve blocks (504) with 3 observational studies $(513,590,591)$, and 3 RCTs assessing cervical intraarticular injections $(586,587,600)$.

Table 23 shows methodologic quality criteria assessment of RCTs of cervical facet joint interventions utilizing Cochrane review criteria.

Table 24 shows methodologic quality criteria assessment utilizing IPM-QRB criteria for cervical facet joint interventions.

Table 25 shows methodologic quality criteria assessment utilizing IPM-QRBNR criteria for cervical facet joint interventions.

Table 26 shows the study characteristics of randomized trials and observational studies assessing cervical radiofrequency neurotomy, facet joint nerve blocks, and intraarticular injections.

Table 27 shows the effectiveness data of cervical radiofrequency neurotomy, facet joint nerve blocks, and intraarticular injections.

\subsubsection{Cervical Radiofrequency Ablation}

A single randomized trial (580) showed positive short-term and long-term relief with $58 \%$ of the patients reporting improvement in the active treatment group. However, only 12 patients were studied in the intervention group. Among the observational studies, one study by Sapir and Gorup (582) included 50 patients with 32 litigants and 18 non-litigants, and showed $66 \%$ improvement in litigants and $71 \%$ improvement in non-litigants, MacVicar et al (599) in study of 104 patients showed $74 \%$ improvement at one-year with long-term effectiveness, and finally Speldewinde (585) also studied 130 patients showing $76 \%$ improvement.

Manchikanti et al in a systematic review (19) showed Level II evidence for short-term and long-term 
Table 23. Methodological quality assessment of randomized trials of cervical facet joint interventions utilizing Cochrane review criteria.

\begin{tabular}{|l|c|c|c|c|c|}
\hline & $\begin{array}{c}\text { Barnsley et al } \\
(586)\end{array}$ & $\begin{array}{c}\text { Manchikanti et } \\
\text { al (512) }\end{array}$ & Lord et al (579) & $\begin{array}{c}\text { Park \& Kim } \\
(587)\end{array}$ & Lim et al (600) \\
\hline Randomization adequate & $\mathrm{Y}$ & $\mathrm{Y}$ & $\mathrm{Y}$ & $\mathrm{N}$ & $\mathrm{Y}$ \\
\hline Concealed treatment allocation & $\mathrm{Y}$ & $\mathrm{Y}$ & $\mathrm{Y}$ & $\mathrm{N}$ & $\mathrm{N}$ \\
\hline Patient blinded & $\mathrm{Y}$ & $\mathrm{Y}$ & $\mathrm{Y}$ & $\mathrm{N}$ & $\mathrm{N}$ \\
\hline Care provider blinded & $\mathrm{Y}$ & $\mathrm{Y}$ & $\mathrm{Y}$ & $\mathrm{N}$ & $\mathrm{Y}$ \\
\hline Outcome assessor blinded & $\mathrm{Y}$ & $\mathrm{N}$ & $\mathrm{Y}$ & $\mathrm{Y}$ & $\mathrm{Y}$ \\
\hline Drop-out rate described & $\mathrm{Y}$ & $\mathrm{Y}$ & $\mathrm{Y}$ & $\mathrm{Y}$ & $\mathrm{Y}$ \\
\hline All randomized participants analyzed in the group & $\mathrm{Y}$ & $\mathrm{Y}$ & $\mathrm{Y}$ & $\mathrm{Y}$ & $\mathrm{Y}$ \\
\hline $\begin{array}{l}\text { Reports of the study free of suggestion of selective } \\
\text { outcome reporting }\end{array}$ & $\mathrm{Y}$ & $\mathrm{Y}$ & $\mathrm{Y}$ & $\mathrm{Y}$ & $\mathrm{Y}$ \\
\hline $\begin{array}{l}\text { Groups similar at baseline regarding most } \\
\text { important prognostic indicators }\end{array}$ & $\mathrm{Y}$ & $\mathrm{Y}$ & $\mathrm{Y}$ & $\mathrm{Y}$ & $\mathrm{Y}$ \\
\hline Co-intervention avoided or similar in all groups & $\mathrm{Y}$ & $\mathrm{Y}$ & $\mathrm{Y}$ & $\mathrm{Y}$ \\
\hline Compliance acceptable in all groups & $\mathrm{Y}$ & $\mathrm{Y}$ & $\mathrm{Y}$ & $\mathrm{N}$ & $\mathrm{Y}$ \\
\hline Time of outcome assessment in all groups similar & $\mathrm{Y}$ & $\mathrm{Y}$ & $\mathrm{N}$ & $\mathrm{Y}$ & $\mathrm{Y}$ \\
\hline Are other sources of potential bias not likely & $\mathrm{Y}$ & $\mathrm{Y}$ & $\mathrm{Y}$ & $\mathrm{U}$ & $\mathrm{Y}$ \\
\hline SCORE & $13 / 13$ & $12 / 13$ & $12 / 13$ & $6 / 13$ & $11 / 13$ \\
\hline
\end{tabular}

$\mathrm{Y}=$ yes; $\mathrm{N}=$ no; $\mathrm{U}=$ unclear

Source: Furlan AD, et al; Editorial Board of the Cochrane Back, Neck Group. 2015 Updated Method Guideline for Systematic Reviews in the Cochrane Back and Neck Group. Spine (Phila Pa 1976) 2015; 40:1660-1673 (526).

effectiveness. Engel et al (35) in a comprehensive review of thermal radiofrequency neurotomy showed that the majority of patients were pain free at 6 months. Over a third were pain free at one-year.

Rambaransingh et al (556) assessed the role of repeated zygapophysial joint radiofrequency neurotomy. In this assessment they mostly included lumbar treatments; however, they also included 20 cervical repeat radiofrequency neurotomies. or 118 cervical radiofrequency neurotomies. They concluded that repeated cervical radiofrequency reduces cervical pain and disability with equal effectiveness for approximately 10 months in patients with chronic neck of facet joint origin.

Husted et al (560) also found that the mean duration of relief of the initial cervical radiofrequency neurolysis was 12.5 months, and repeat radiofrequency neurolysis was effective in $95 \%$ of the patients in whom the initial cervical radiofrequency neurolysis was successful. The mean duration of relief after cervical radiofrequency neurolysis was 11.5 months with little or no variation among several subsequent procedures. Overall, other studies also have shown significant continued improvement after the initial procedure with or without repeat procedures. As continuation of RCT by
Lord et al, which showed long-term improvement with cervical radiofrequency neurotomy (579), McDonald et al (588) showed continued positive results with longterm follow-up. Wallis et al (597) published resolution of psychological distress of whiplash patients following treatment by radiofrequency neurotomy. Barnsley (589) also published percutaneous radiofrequency neurotomy results in chronic neck pain in a series of consecutive patients.

Thus, the evidence for long-term improvement with cervical radiofrequency neurotomy is Level II with moderate strength of recommendation, when performed after the diagnosis of cervical facet joint pain with controlled comparative local anesthetic blocks utilizing $80 \%$ pain relief criterion standard.

\subsubsection{Therapeutic Cervical Facet Joint Nerve Blocks}

Evidence for cervical facet joint nerve blocks included one RCT (512) and a prospective study (513) including 120 and 100 patients showed $85 \%$ long-term improvement in the RCT at one-year, whereas, the prospective study showed $56 \%$ of the patients reporting significant improvement. A new study by Hahn et al (590) was performed in vertigo patients showing 62.4 $\%$ of the patients experiencing significant improve- 
Facet Joint Interventions Guidelines 2020

Table 24. Methodologic quality assessment of randomized trials of cervical facet joint interventions utilizing IPM - QRB criteria.

\begin{tabular}{|c|c|c|c|c|c|c|}
\hline & & $\begin{array}{l}\text { Barnsley et } \\
\text { al (586) }\end{array}$ & $\begin{array}{l}\text { Manchikanti } \\
\text { et al (512) }\end{array}$ & $\begin{array}{l}\text { Lord et al } \\
\quad(579)\end{array}$ & $\begin{array}{l}\text { Park \& Kim } \\
\quad(587)\end{array}$ & $\begin{array}{l}\text { Lim et al } \\
\quad(600)\end{array}$ \\
\hline I. & $\begin{array}{l}\text { TRIAL DESIGN AND GUIDANCE } \\
\text { REPORTING }\end{array}$ & & & & & \\
\hline 1. & CONSORT or SPIRIT & 2 & 3 & 3 & 2 & 2 \\
\hline II. & DESIGN FACTORS & & & & & \\
\hline 2. & Type and Design of Trial & 2 & 2 & 3 & 2 & 2 \\
\hline 3. & Setting/Physician & 2 & 2 & 2 & 2 & 2 \\
\hline 4. & Imaging & 3 & 3 & 3 & 3 & 3 \\
\hline 5. & Sample Size & 1 & 3 & 1 & 3 & 1 \\
\hline 6. & Statistical Methodology & 1 & 1 & 1 & 1 & 1 \\
\hline III. & PATIENT FACTORS & & & & & \\
\hline 7. & Inclusiveness of Population & & & & & \\
\hline & - For facet or sacroiliac joint interventions: & 2 & 2 & 2 & 2 & 2 \\
\hline 8. & Duration of Pain & 2 & 2 & 2 & 2 & 2 \\
\hline 9. & Previous Treatments & 0 & 2 & 2 & 2 & 2 \\
\hline 10. & $\begin{array}{l}\text { Duration of Follow-up with Appropriate } \\
\text { Interventions }\end{array}$ & 1 & 3 & 2 & 2 & 2 \\
\hline IV. & OUTCOMES & & & & & \\
\hline 11. & $\begin{array}{l}\text { Outcomes Assessment Criteria for Significant } \\
\text { Improvement }\end{array}$ & 2 & 4 & 4 & 2 & 2 \\
\hline 12. & $\begin{array}{l}\text { Analysis of all Randomized Participants in the } \\
\text { Groups }\end{array}$ & 2 & 2 & 2 & 2 & 2 \\
\hline 13. & Description of Drop Out Rate & 1 & 2 & 2 & 2 & 2 \\
\hline 14. & $\begin{array}{l}\text { Similarity of Groups at Baseline for Important } \\
\text { Prognostic Indicators }\end{array}$ & 2 & 2 & 2 & 2 & 2 \\
\hline 15. & Role of Co-Interventions & 0 & 1 & 1 & 0 & 1 \\
\hline V. & RANDOMIZATION & & & & & \\
\hline 16. & Method of Randomization & 2 & 2 & 2 & 2 & 2 \\
\hline VI. & ALLOCATION CONCEALMENT & & & & & \\
\hline 17. & Concealed Treatment Allocation & 2 & 2 & 2 & 0 & 2 \\
\hline VII. & BLINDING & & & & & \\
\hline 18. & Patient Blinding & 1 & 1 & 1 & 0 & 1 \\
\hline 19. & Care Provider Blinding & 1 & 1 & 1 & 0 & 1 \\
\hline 20. & Outcome Assessor Blinding & 1 & 0 & 1 & 0 & 1 \\
\hline VIII. & CONFLICTS OF INTEREST & & & & & \\
\hline 21. & Funding and Sponsorship & 3 & 2 & 3 & 2 & 2 \\
\hline 22. & Conflicts of Interest & 3 & 3 & 3 & 2 & 2 \\
\hline \multicolumn{2}{|c|}{ TOTAL } & 36 & 45 & 45 & 35 & 39 \\
\hline
\end{tabular}

Source: Manchikanti L, et al. Assessment of methodologic quality of randomized trials of interventional techniques: Development of an interventional pain management specific instrument. Pain Physician 2014; 17:E263-E290 (527). 
Table 25. IPM checklist for assessment of nonrandomized or observational studies of cervical facet joint interventions of IPM techniques utilizing IPM-QRBNR.

\begin{tabular}{|c|c|c|c|c|c|c|c|}
\hline & & $\begin{array}{c}\text { Sapir \& Gorup } \\
(582)\end{array}$ & $\begin{array}{c}\text { MacVicar et al } \\
\text { (599) }\end{array}$ & $\begin{array}{l}\text { Speldewinde } \\
\text { (585) }\end{array}$ & $\begin{array}{l}\text { Manchikanti } \\
\text { et al (513) }\end{array}$ & $\begin{array}{l}\text { Hahn et al } \\
\quad(590)\end{array}$ & $\begin{array}{l}\text { Lee\& Huston } \\
\quad(591)\end{array}$ \\
\hline I. & $\begin{array}{l}\text { STUDY DESIGN AND } \\
\text { GUIDANCE REPORTING }\end{array}$ & & & & & & \\
\hline 1. & $\begin{array}{l}\text { STROBE or TREND } \\
\text { GUIDANCE }\end{array}$ & 3 & 3 & 3 & 3 & 2 & 2 \\
\hline II. & DESIGN FACTORS & & & & & & \\
\hline 2. & Study Design and Type & 4 & 4 & 4 & 4 & 2 & 2 \\
\hline 3. & Setting/Physician & 2 & 2 & 2 & 2 & 2 & 2 \\
\hline 4. & Imaging & 3 & 3 & 3 & 3 & 3 & 3 \\
\hline 5. & Sample Size & 2 & 1 & 1 & 1 & 2 & 2 \\
\hline 6. & Statistical Methodology & 2 & 2 & 2 & 2 & 2 & 2 \\
\hline III. & PATIENT FACTORS & & & & & & \\
\hline \multirow[t]{2}{*}{7.} & Inclusiveness of Population & & & & & & \\
\hline & $\begin{array}{l}\text { - For facet or sacroiliac joint } \\
\text { interventions: }\end{array}$ & 4 & 4 & 4 & 4 & 4 & 4 \\
\hline 8. & Duration of Pain & 2 & 2 & 2 & 2 & 2 & 2 \\
\hline 9. & Previous Treatments & 2 & 2 & 2 & 2 & 2 & 2 \\
\hline 10. & $\begin{array}{l}\text { Duration of Follow-up with } \\
\text { Appropriate Interventions }\end{array}$ & 3 & 3 & 3 & 3 & 1 & 3 \\
\hline IV. & OUTCOMES & & & & & & \\
\hline 11. & $\begin{array}{l}\text { Outcomes Assessment Criteria } \\
\text { for Significant Improvement }\end{array}$ & 2 & 4 & 4 & 4 & 2 & 3 \\
\hline 12. & Description of Drop Out Rate & 1 & 1 & 1 & 1 & 1 & 1 \\
\hline 13. & $\begin{array}{l}\text { Similarity of Groups at Baseline } \\
\text { for Important Prognostic } \\
\text { Indicators }\end{array}$ & 2 & 0 & 0 & 0 & 0 & 0 \\
\hline 14. & Role of Co-Interventions & 2 & 2 & 2 & 2 & 2 & 2 \\
\hline V. & ASSIGNMENT & & & & & & \\
\hline 15. & $\begin{array}{l}\text { Method of Assignment of } \\
\text { Participants }\end{array}$ & 4 & 4 & 4 & 2 & 2 & 2 \\
\hline VI. & CONFLICTS OF INTEREST & & & & & & \\
\hline 16. & Funding and Sponsorship & 2 & 1 & 2 & 2 & 2 & 2 \\
\hline \multicolumn{2}{|c|}{ TOTAL } & 40 & 38 & 39 & 37 & 31 & 34 \\
\hline
\end{tabular}

Source: Manchikanti L, et al. Development of an interventional pain management specific instrument for methodologic quality assessment of nonrandomized studies of interventional techniques. Pain Physician 2014; 17:E291-E317 (528).

ment. Another new study by Lee and Huston (591) was performed with therapeutic medial branch blocks in patients with recurrence of pain after dual diagnostic blocks with $80 \%$ pain relief as the criterion standard. They reported long-term improvement.

Thus, evidence for therapeutic cervical facet joint nerve blocks is Level II for short-term and long-term improvement with moderate strength recommendation in patients after appropriate diagnosis with controlled comparative local anesthetic blocks utilizing a criterion standard of $80 \%$.

\subsubsection{Cervical Intraarticular Injections}

The evidence for cervical intraarticular injections was presented in 3 RCTs $(586,587,600)$. Two RCTs $(586,587)$ showed lack of effectiveness, whereas, one 
Facet Joint Interventions Guidelines 2020

\begin{tabular}{|c|c|c|c|}
\hline 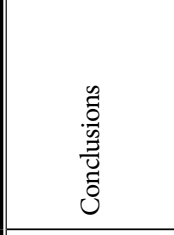 & 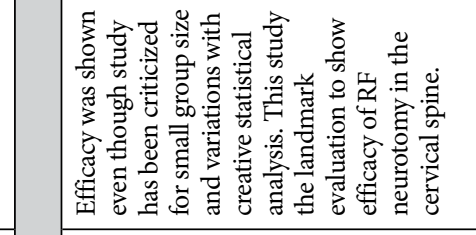 & 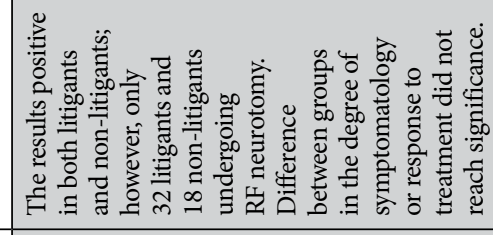 & 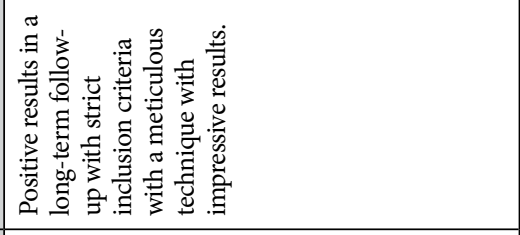 \\
\hline 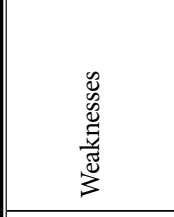 & 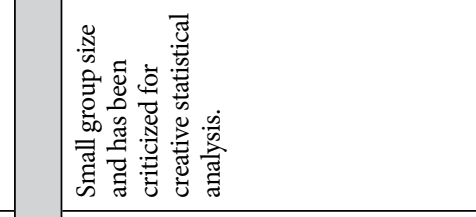 & 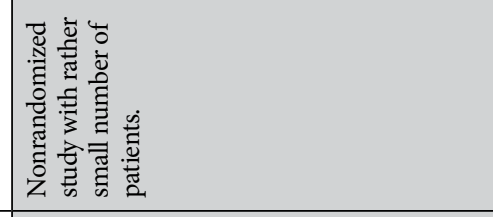 & 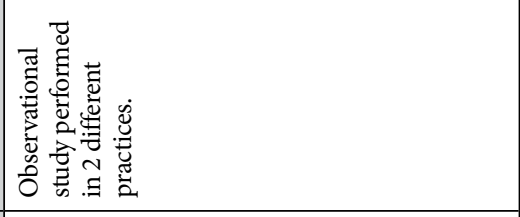 \\
\hline 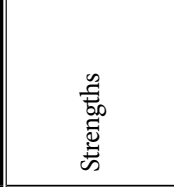 & 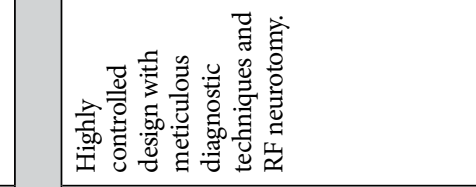 & 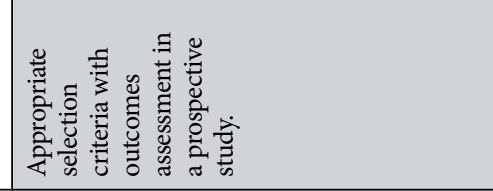 & 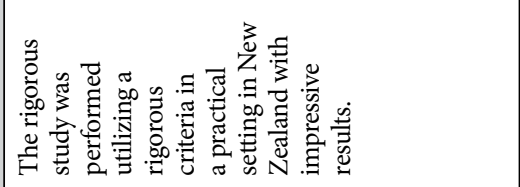 \\
\hline 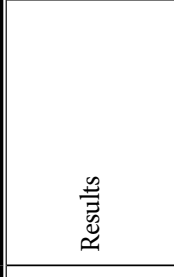 & 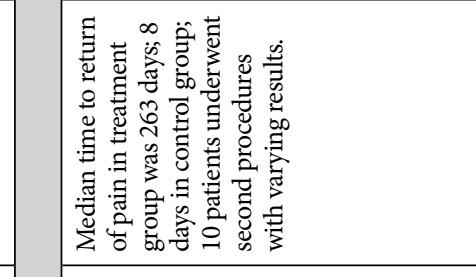 & 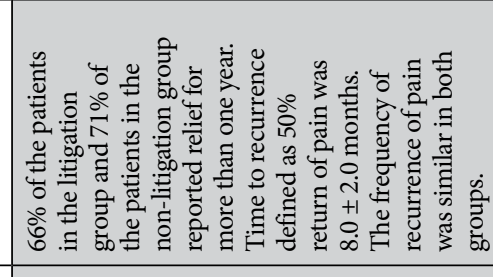 & 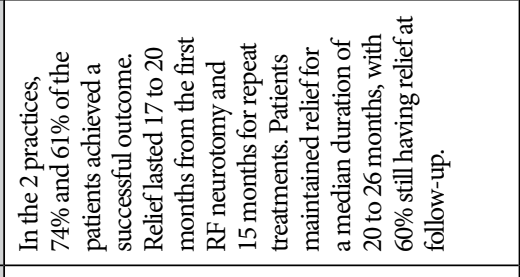 \\
\hline 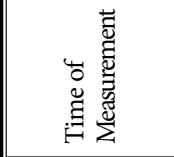 & 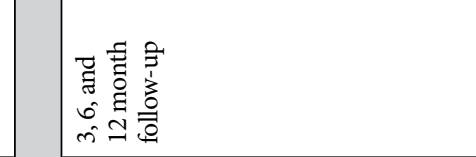 & 哭 & 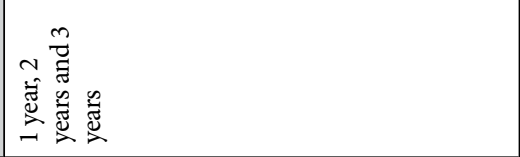 \\
\hline 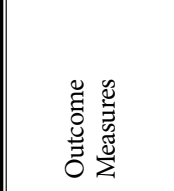 & 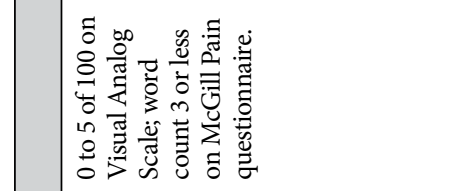 & 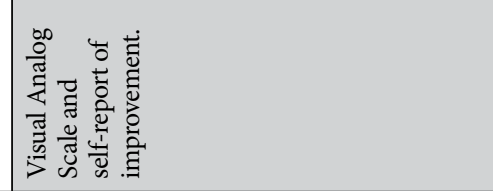 & 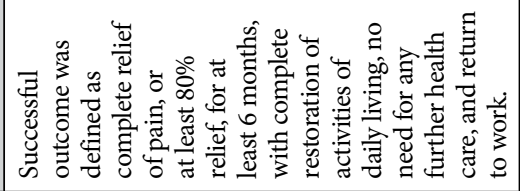 \\
\hline 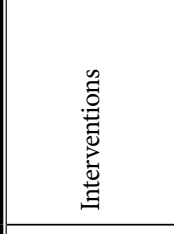 & 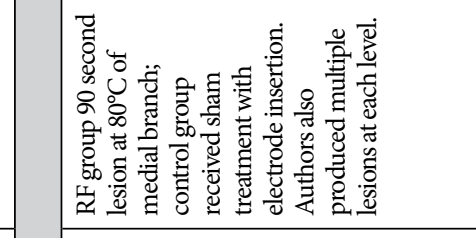 & 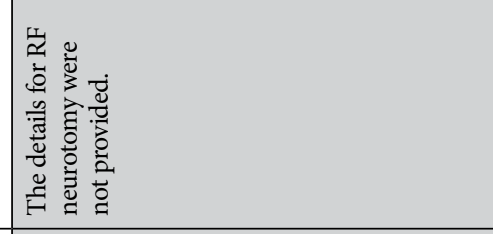 & 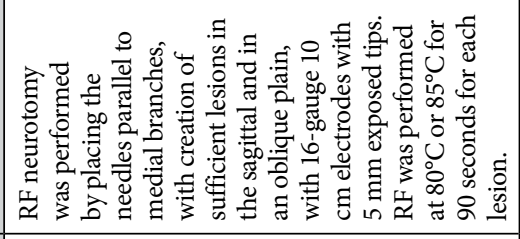 \\
\hline $\begin{array}{l}\overline{\mathrm{c}} \\
\overline{0}\end{array}$ & 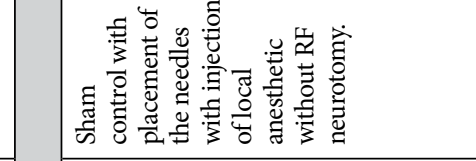 & 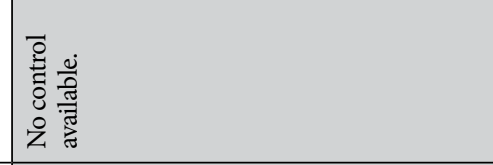 & 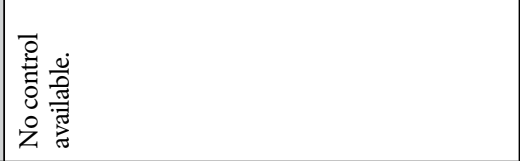 \\
\hline 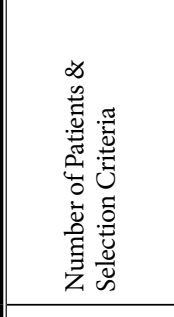 & 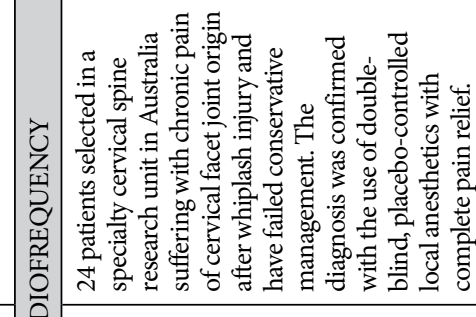 & 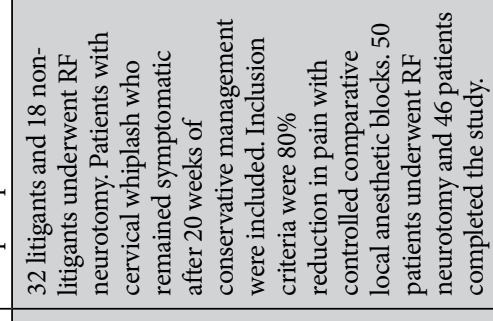 & 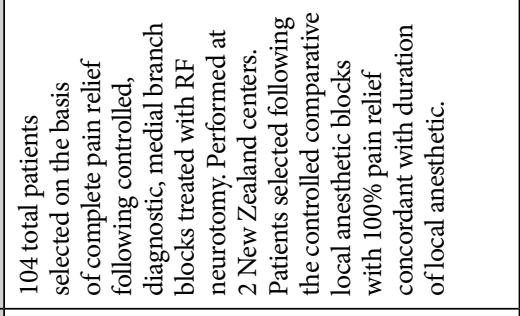 \\
\hline 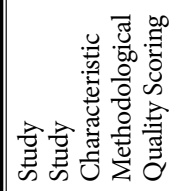 & 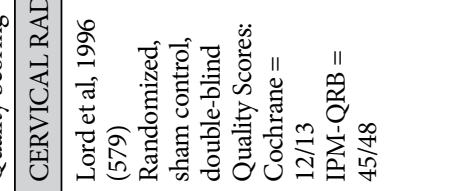 & 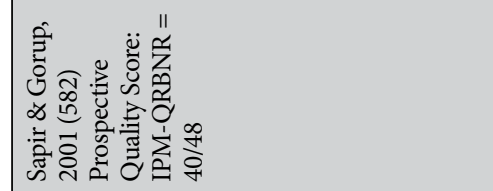 & 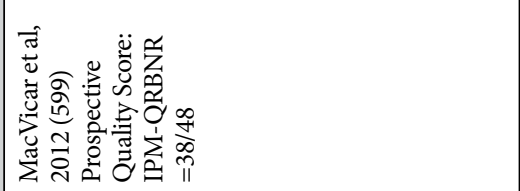 \\
\hline
\end{tabular}




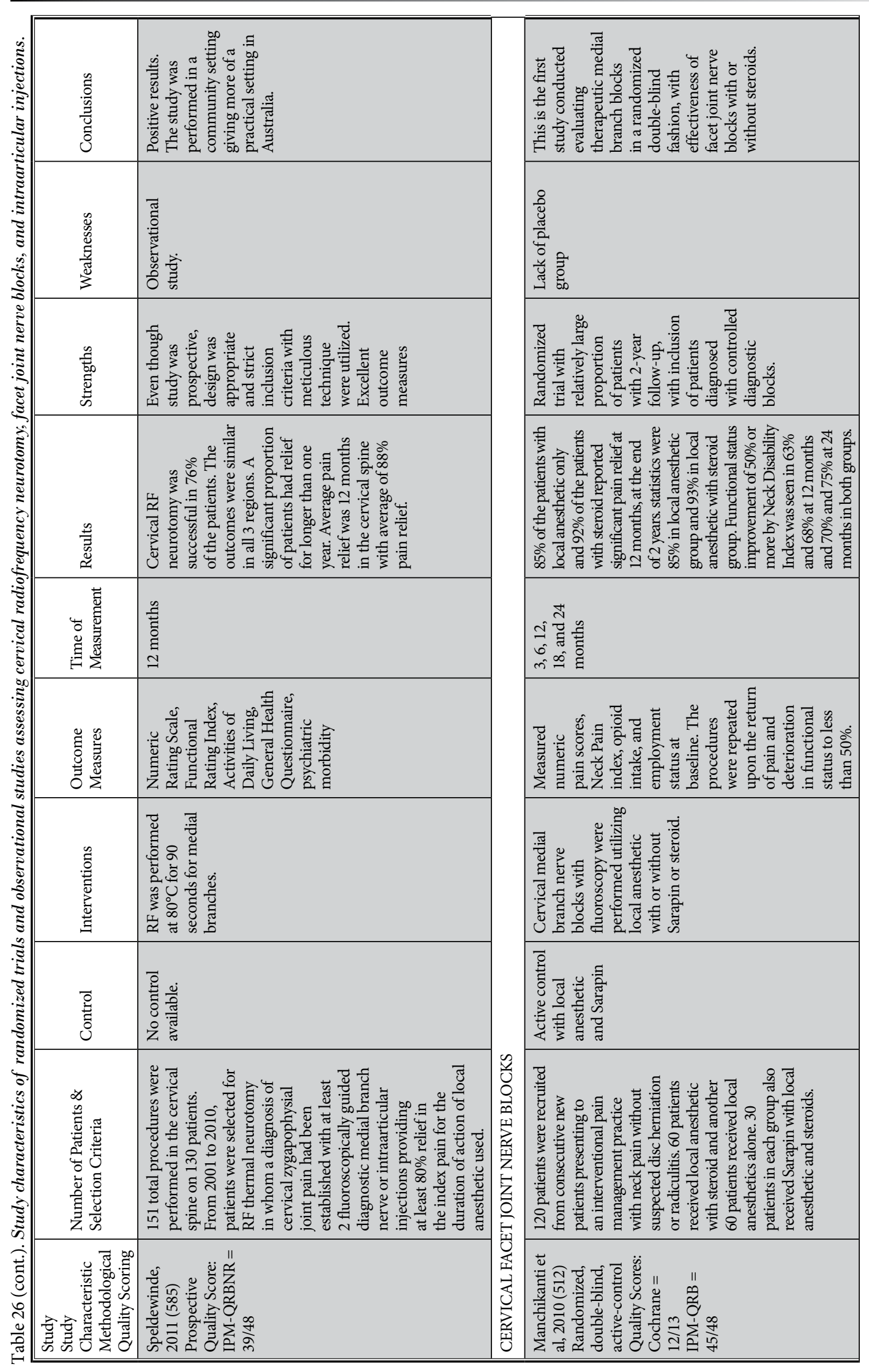


Facet Joint Interventions Guidelines 2020

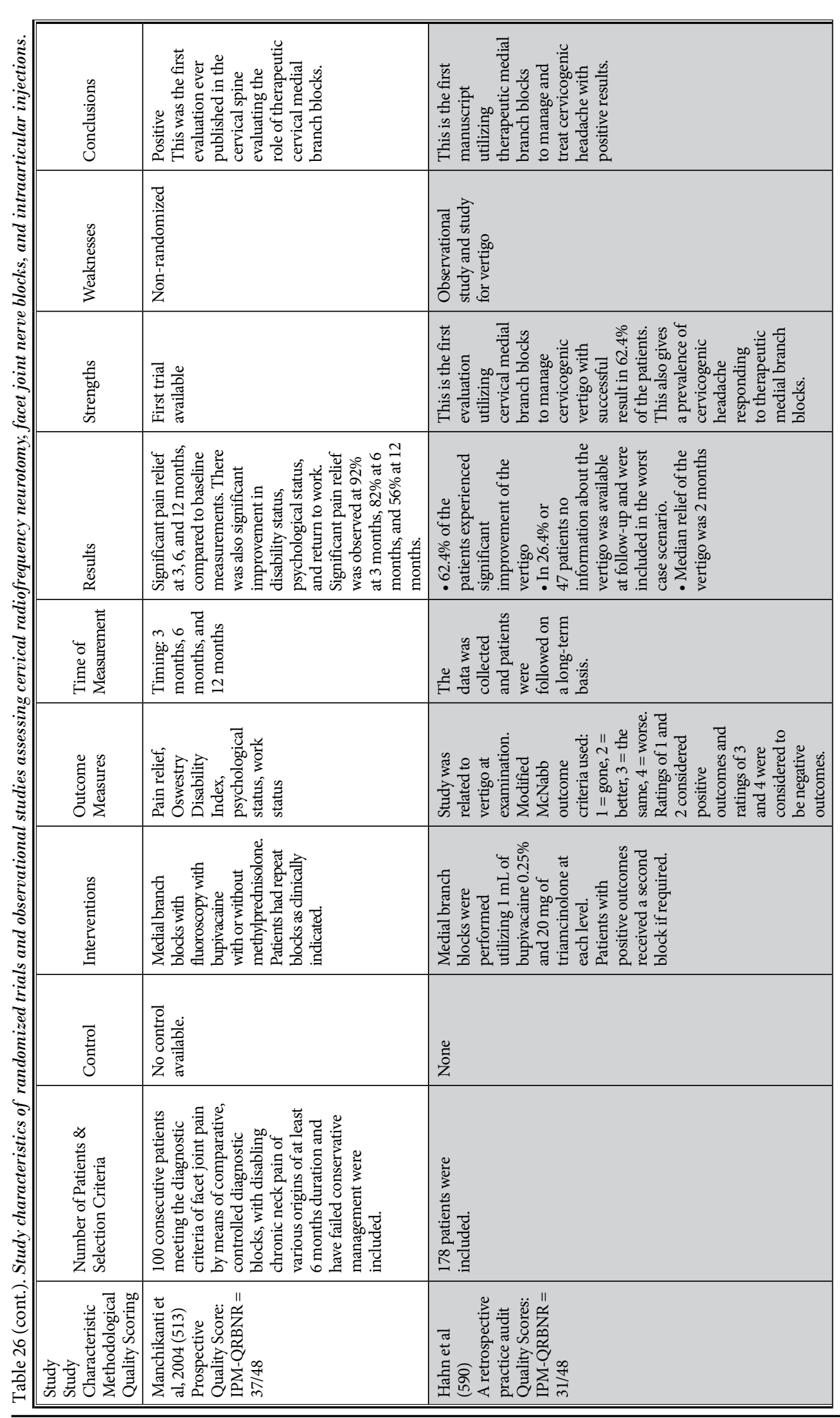

www.painphysicianjournal.com 
Pain Physician: May/June 2020 23:S1-S127

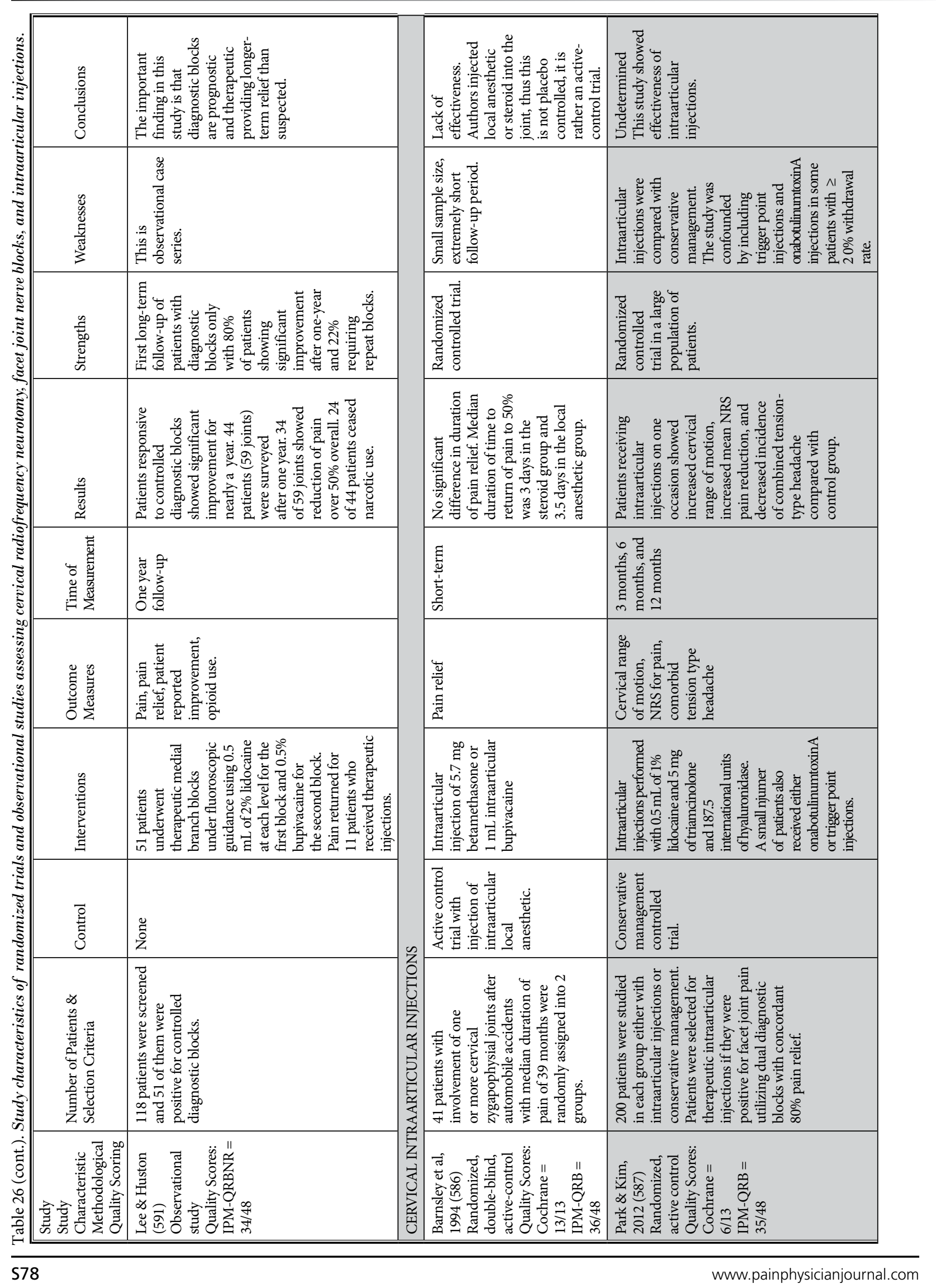




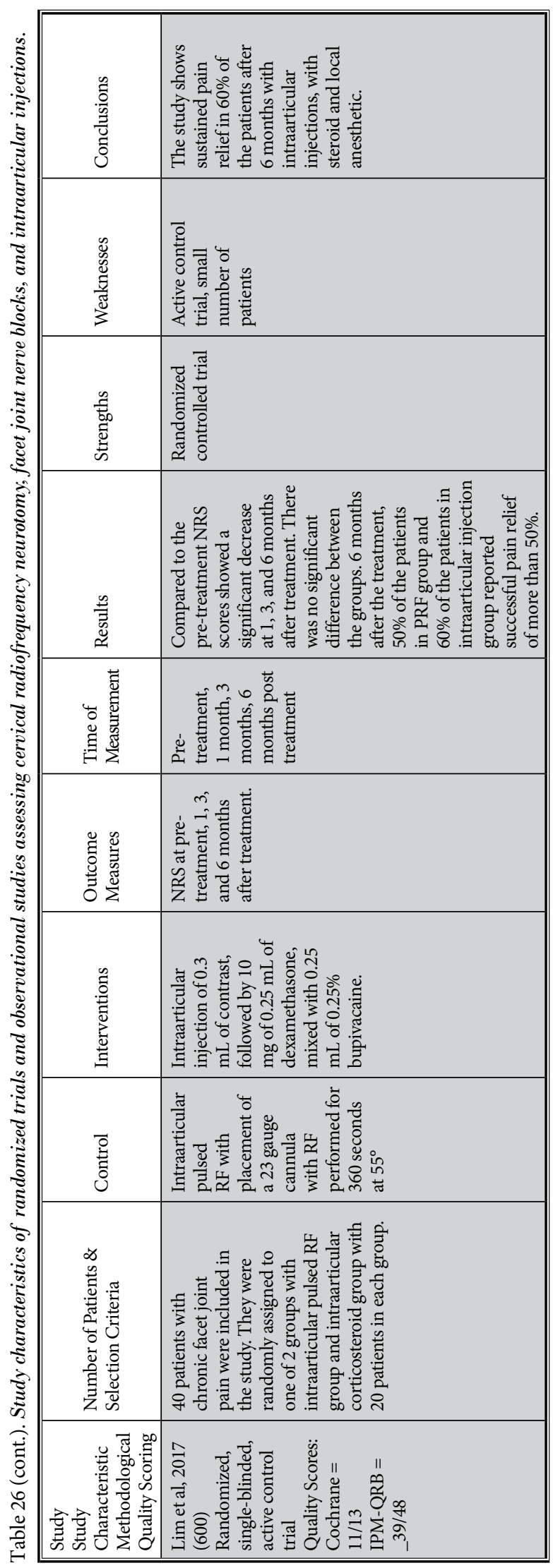

study (600) showed improvement at 6 month followup. A systematic review by Manchikanti et al (19) provided Level IV evidence for cervical intraarticular injections.

Thus, evidence is Level III for short-term improvement and Level $\mathbf{V}$ for long-term improvement with weak strength of recommendation.

\subsubsection{Thoracic Spine}

Table 28 shows methodologic quality assessment utilizing Cochrane Review criteria. Table 29 shows methodologic quality assessment utilizing IPM-QRB criteria. Finally, Table 30 shows methodologic quality assessment criteria utilizing IPM-QRBNR.

Table 31 shows the descriptive characteristics of effectiveness studies of thoracic radiofrequency neurotomy, facet joint nerve blocks, and intraarticular injections.

Table 32 shows the effectiveness of thoracic radiofrequency neurotomy, facet joint nerve blocks, and intraarticular injections.

\subsubsection{Thoracic Radiofrequency Ablation}

Radiofrequency ablation was studied in one RCT (553) with 40 patients undergoing radiofrequency neurotomy showing significant improvement at 6 month follow-up yielding short-term effectiveness of radiofrequency neurotomy. The new studies included 3 observational studies of radiofrequency ablation of thoracic facet joint nerves $(576,579,581)$ of which one was cooled radiofrequency (579). Further, one study was of pulsed radiofrequency (576), even though it did show significant improvement. A previous systematic review showed Level IV evidence for thoracic radiofrequency ablation.

Thus, evidence is Level III for thoracic radiofrequency ablation with weak to moderate strength of recommendation with emerging evidence, in patients with appropriate diagnosis by controlled comparative local anesthetic blocks with $80 \%$ criterion standard of pain relief.

\subsubsection{Therapeutic Thoracic Facet Joint Nerve Blocks}

Evidence for thoracic facet joint nerve blocks included one high quality RCT (510) showing $80 \%$ improvement with local anesthetic alone. The second RCT (575) evaluated intraarticular thoracic facet joint injection compared to medial branch blocks reporting $40 \%$ improvement at 6 months. However, these patients had not undergone diagnostic blocks. Only 
Pain Physician: May/June 2020 23:S1-S127

Table 27. Effectiveness of cervical radiofrequency neurotomy, facet joint, nerve blocks and intraarticular injections.

\begin{tabular}{|c|c|c|c|c|c|c|c|c|c|}
\hline \multirow{3}{*}{$\begin{array}{c}\text { Study } \\
\text { Study Characteristic } \\
\text { Methodological } \\
\text { Quality Scoring }\end{array}$} & \multirow{3}{*}{ Patients } & \multirow{3}{*}{ Interventions } & \multicolumn{3}{|c|}{ Pain Relief and Function } & \multicolumn{3}{|c|}{ Results } & \multirow{3}{*}{ Comments } \\
\hline & & & \multirow[b]{2}{*}{3 mos. } & \multirow[b]{2}{*}{6 mos. } & \multirow[b]{2}{*}{12 mos. } & \multirow{2}{*}{$\begin{array}{c}\text { Short- } \\
\text { Term } \\
\leq 6 \mathrm{mos}\end{array}$} & \multicolumn{2}{|c|}{ Long-Term } & \\
\hline & & & & & & & $\begin{array}{l}>6 \\
\text { mos. }\end{array}$ & $\begin{array}{l}\geq 1 \\
\text { year }\end{array}$ & \\
\hline \multicolumn{10}{|c|}{ CERVICAL RADIOFREQUENCY } \\
\hline $\begin{array}{l}\text { Lord et al, } 1996 \text { (579) } \\
\text { RA, sham control, DB } \\
\text { Quality Scores: } \\
\text { Cochrane }=12 / 13 \\
\text { IPM-QRB }=45 / 48\end{array}$ & 24 & $\begin{array}{l}\text { Conventional } \\
\text { RFTN } 80^{\circ} \mathrm{C}, 90 \\
\text { seconds } \\
\text { Sham }=12 \\
\text { Intervention }=12\end{array}$ & NA & $\begin{array}{l}\text { One of } \\
\text { sham } \\
7 \text { of } \\
\text { active }\end{array}$ & $\begin{array}{l}58 \% \text { in } \\
\text { active } \\
\text { treatment } \\
\text { group }\end{array}$ & $\mathrm{P}$ & $\mathrm{P}$ & $\mathrm{P}$ & $\begin{array}{l}\text { Short- and } \\
\text { long-term } \\
\text { effectiveness }\end{array}$ \\
\hline $\begin{array}{l}\text { Sapir \& Gorup, } 2001 \text { (582) } \\
\text { Prospective } \\
\text { Quality Score: } \\
\text { IPM-QRBNR = 40/48 }\end{array}$ & 50 & $\begin{array}{l}\text { Conventional RFTN } \\
80^{\circ} \mathrm{C}, 90 \text { seconds } \\
\text { Litigants }=32 \\
\text { Non-litigants }=18\end{array}$ & NA & NA & $\begin{array}{l}66 \% \\
\text { litigant } \\
71 \% \text { non- } \\
\text { litigant }\end{array}$ & NA & NA & $\mathrm{P}$ & $\begin{array}{l}\text { Long-term } \\
\text { effectiveness }\end{array}$ \\
\hline $\begin{array}{l}\text { MacVicar et al, } 2012 \text { (599) } \\
\text { Prospective } \\
\text { Quality Score: } \\
\text { IPM-QRBNR =38/48 }\end{array}$ & 104 & $\begin{array}{l}\text { Conventional } \\
\text { RFTN } 80^{\circ} \mathrm{C}, 90 \\
\text { seconds } \\
2 \text { practices }\end{array}$ & NA & NA & $\begin{array}{l}74 \% \text { vs } \\
61 \%\end{array}$ & $\mathrm{NA}$ & NA & $\mathrm{P}$ & $\begin{array}{l}\text { Long-term } \\
\text { effectiveness }\end{array}$ \\
\hline $\begin{array}{l}\text { Speldewinde, } 2011(585) \\
\text { Prospective } \\
\text { Quality Score: } \\
\text { IPM-QRBNR = 39/48 }\end{array}$ & 130 & $\begin{array}{l}\text { Conventional } \\
\text { RFTN } 80^{\circ} \mathrm{C}, 90 \\
\text { seconds }\end{array}$ & NA & NA & $76 \%$ & NA & NA & $\mathrm{P}$ & $\begin{array}{l}\text { Long-term } \\
\text { effectiveness }\end{array}$ \\
\hline \multicolumn{10}{|c|}{ CERVICAL FACET JOINT NERVE BLOCKS } \\
\hline $\begin{array}{l}\text { Manchikanti et al, } 2010 \text { (512) } \\
\text { RA, DB, AC } \\
\text { Quality Scores: } \\
\text { Cochrane }=12 / 13 \\
\text { IPM-QRB }=45 / 48\end{array}$ & 120 & $\begin{array}{l}\text { Local anesthetic } \\
=60 \\
\text { Local anesthetic } \\
\text { with steroid }=60\end{array}$ & \begin{tabular}{|l}
$83 \%$ \\
versus \\
$85 \%$
\end{tabular} & \begin{tabular}{|l}
$87 \%$ \\
versus \\
$95 \%$
\end{tabular} & $\begin{array}{l}85 \% \\
\text { versus } \\
92 \%\end{array}$ & $\mathrm{P}$ & $\mathrm{P}$ & $\mathrm{P}$ & $\begin{array}{l}\text { Short- and } \\
\text { long-term } \\
\text { effectiveness }\end{array}$ \\
\hline $\begin{array}{l}\text { Manchikanti et al, } 2004 \text { (513) } \\
\text { Prospective } \\
\text { Quality Score: } \\
\text { IPM-QRBNR = 37/48 }\end{array}$ & 100 & \begin{tabular}{|l} 
Therapeutic \\
medical branch \\
blocks
\end{tabular} & $92 \%$ & $82 \%$ & $56 \%$ & $P$ & $P$ & $\mathrm{P}$ & $\begin{array}{l}\text { Long-term } \\
\text { effectiveness }\end{array}$ \\
\hline $\begin{array}{l}\text { Hahn et al (590) } \\
\text { A retrospective practice } \\
\text { audit } \\
\text { Quality Score: } \\
\text { IPM-QRBNR = } 31 / 48\end{array}$ & $\begin{array}{l}178 \text { patients were } \\
\text { included. }\end{array}$ & $\begin{array}{l}\text { Medial branch } \\
\text { blocks }\end{array}$ & $62.4 \%$ & $62.4 \%$ & $62.4 \%$ & $\mathrm{P}$ & $\mathrm{P}$ & $\mathrm{P}$ & $\begin{array}{l}\text { Long-term } \\
\text { effectiveness }\end{array}$ \\
\hline $\begin{array}{l}\text { Lee et al (591) } \\
\text { Observational study } \\
\text { Quality Score: } \\
\text { IPM-QRBNR = 34/48 }\end{array}$ & $\begin{array}{l}51 \text { patients } \\
\text { were positive } \\
\text { for controlled } \\
\text { diagnostic blocks }\end{array}$ & $\begin{array}{l}\text { Therapeutic } \\
\text { medical branch } \\
\text { blocks }\end{array}$ & $86 \%$ & $86 \%$ & $86 \%$ & $\mathrm{P}$ & $\mathrm{P}$ & $\mathrm{P}$ & $\begin{array}{l}\text { Long-term } \\
\text { effectiveness }\end{array}$ \\
\hline \multicolumn{10}{|c|}{ CERVICAL INTRAARTICULAR INJECTIONS } \\
\hline $\begin{array}{l}\text { Barnsley et al, } 1994 \text { (586) } \\
\text { RA, DB, AC } \\
\text { Quality Scores: } \\
\text { Cochrane }=13 / 13 \\
\text { IPM-QRB }=36 / 48\end{array}$ & 41 & $\begin{array}{l}\mathrm{LA}=20 \\
\text { Steroid }=21\end{array}$ & $20 \%$ & $20 \%$ & $20 \%$ & $\mathrm{~N}$ & $\mathrm{~N}$ & $\mathrm{~N}$ & $\begin{array}{l}\text { Lack of } \\
\text { effectiveness }\end{array}$ \\
\hline $\begin{array}{l}\text { Park \& Kim, } 2012 \text { (587) } \\
\text { RA, AC } \\
\text { Quality Scores: } \\
\text { Cochrane }=6 / 13 \\
\text { IPM-QRB }=35 / 48\end{array}$ & 306 & \begin{tabular}{|l|} 
Non-injection \\
group = 151 \\
Nerve blocks = 155
\end{tabular} & $\mathrm{U}$ & $\mathrm{U}$ & $\mathrm{U}$ & $\mathrm{U}$ & $\mathrm{U}$ & $\mathrm{U}$ & $\begin{array}{l}\text { Unable to } \\
\text { determine } \\
\text { effectiveness }\end{array}$ \\
\hline $\begin{array}{l}\text { Lim et al }(600) \\
\text { Randomized, single- } \\
\text { blinded, active control trial } \\
\text { Quality Scores: } \\
\text { Cochrane }=11 / 13 \\
\text { IPM-QRB }=39 / 48\end{array}$ & $\begin{array}{l}40 \text { patients } \\
\text { Intraarticular } \\
\text { pulsed } \mathrm{RF}=20 \\
\text { Intraarticular } \\
\text { corticosteroid } \\
=20\end{array}$ & $\begin{array}{l}\text { Intraarticular } \\
\text { steroid }\end{array}$ & SI & SI & NA & $\mathrm{P}$ & $\mathrm{P}$ & NA & $\begin{array}{l}6 \text { months of } \\
\text { improvement } \\
\text { with local } \\
\text { anesthetic and } \\
\text { steroid }\end{array}$ \\
\hline
\end{tabular}

$\mathrm{RA}=$ randomized; $\mathrm{DB}=$ double-blind; $\mathrm{AC}=$ active control; $\mathrm{ST}=$ steroid; $\mathrm{LA}=$ local anesthetic; $\mathrm{U}=$ undetermined; $\mathrm{SI}=$ significant improvement; RFTN = radiofrequency thermoneurolysis; $\mathrm{P}=$ positive; $\mathrm{N}$ = negative; $\mathrm{NA}=$ not applicablel; $\mathrm{RF}=$ radiofrequency 
Table 28. Methodological quality assessment of randomized trials of thoracic facet joint interventions utilizing Cochrane review criteria.

\begin{tabular}{|l|c|c|c|}
\hline & $\begin{array}{c}\text { Manchikanti } \\
\text { et al (510) }\end{array}$ & $\begin{array}{c}\text { Joo } \\
\text { et al } \\
\mathbf{( 5 5 3 )}\end{array}$ & $\begin{array}{c}\text { Lee } \\
\text { et al } \\
\mathbf{( 5 7 5 )}\end{array}$ \\
\hline Randomization adequate & $\mathrm{Y}$ & $\mathrm{Y}$ & $\mathrm{Y}$ \\
\hline $\begin{array}{l}\text { Concealed treatment } \\
\text { allocation }\end{array}$ & $\mathrm{Y}$ & $\mathrm{Y}$ & $\mathrm{Y}$ \\
\hline Patient blinded & $\mathrm{Y}$ & $\mathrm{Y}$ & $\mathrm{Y}$ \\
\hline Care provider blinded & $\mathrm{Y}$ & $\mathrm{N}$ & $\mathrm{N}$ \\
\hline $\begin{array}{l}\text { Outcome assessor } \\
\text { blinded }\end{array}$ & $\mathrm{N}$ & $\mathrm{N}$ & $\mathrm{Y}$ \\
\hline Drop-out rate described & $\mathrm{Y}$ & $\mathrm{Y}$ & $\mathrm{Y}$ \\
\hline $\begin{array}{l}\text { All randomized } \\
\text { participants analyzed in } \\
\text { the group }\end{array}$ & $\mathrm{Y}$ & $\mathrm{Y}$ & $\mathrm{Y}$ \\
\hline $\begin{array}{l}\text { Reports of the study free } \\
\text { of suggestion of selective } \\
\text { outcome reporting }\end{array}$ & $\mathrm{Y}$ & $\mathrm{Y}$ & $\mathrm{Y}$ \\
\hline $\begin{array}{l}\text { Groups similar at baseline } \\
\text { regarding most important } \\
\text { prognostic indicators }\end{array}$ & $\mathrm{N}$ & $\mathrm{Y}$ & $\mathrm{Y}$ \\
\hline $\begin{array}{l}\text { Co-intervention avoided } \\
\text { or similar in all groups }\end{array}$ & $\mathrm{Y}$ & $\mathrm{Y}$ & $\mathrm{Y}$ \\
\hline $\begin{array}{l}\text { Compliance acceptable in } \\
\text { all groups }\end{array}$ & $\mathrm{Y}$ & $\mathrm{Y}$ & $\mathrm{Y}$ \\
\hline $\begin{array}{l}\text { Time of outcome } \\
\text { assessment in all groups } \\
\text { similar }\end{array}$ & $\mathrm{Y}$ & $\mathrm{Y}$ & $\mathrm{Y}$ \\
\hline $\begin{array}{l}\text { Are other sources of } \\
\text { potential bias not likely }\end{array}$ & $\mathrm{Y}$ & $\mathrm{U}$ & $\mathrm{Y}$ \\
\hline SCORE & $11 / 13$ & $10 / 13$ & $12 / 13$ \\
\hline $\mathrm{Y}$ & & & \\
\hline fes; & & & $\mathrm{Y}$ \\
\hline
\end{tabular}

$\mathrm{Y}=$ yes; $\mathrm{N}=$ no; $\mathrm{U}=$ unclear

Source: Furlan AD, et al; Editorial Board of the Cochrane Back, Neck Group. 2015 Updated Method Guideline for Systematic Reviews in the Cochrane Back and Neck Group. Spine (Phila Pa 1976) 2015 ; 40:1660-1673 (526).

20 patients were involved, but it shows positive evidence. The next study (582) was performed in patients with osteoporotic fractures showing $78 \%$ improvement at 12 months. The study by Chang (576) also is of significance since this study showed significant improvement with therapeutic medial branch blocks. They attempted to perform pulsed radiofrequency in only the patients who failed to respond to therapeutic medial branch blocks. The study subjects received only one or 2 procedures during 6 month period.
Table 29. Methodologic quality assessment of randomized trials of thoracic facet joint interventions utilizing IPM - QRB criteria.

\begin{tabular}{|c|c|c|c|c|}
\hline & & $\begin{array}{c}\text { Manchikanti } \\
\text { et al (510) }\end{array}$ & $\begin{array}{c}\text { Joo } \\
\text { et al } \\
(\mathbf{5 5 3})\end{array}$ & $\begin{array}{c}\text { Lee } \\
\text { et al } \\
(\mathbf{5 7 5})\end{array}$ \\
\hline I. & $\begin{array}{l}\text { TRIAL DESIGN AND } \\
\text { GUIDANCE REPORTING }\end{array}$ & & & \\
\hline 1. & CONSORT or SPIRIT & 3 & 2 & 2 \\
\hline II. & DESIGN FACTORS & & & \\
\hline 2. & Type and Design of Trial & 2 & 2 & 2 \\
\hline 3. & Setting/Physician & 2 & 2 & 2 \\
\hline 4. & Imaging & 3 & 3 & 3 \\
\hline 5. & Sample Size & 3 & 1 & 1 \\
\hline 6. & Statistical Methodology & 1 & 1 & 1 \\
\hline III. & PATIENT FACTORS & & & \\
\hline 7. & Inclusiveness of Population & & & \\
\hline & $\begin{array}{l}\text { - For facet or sacroiliac joint } \\
\text { interventions: }\end{array}$ & 2 & 2 & 2 \\
\hline 8. & Duration of Pain & 2 & 2 & 2 \\
\hline 9. & Previous Treatments & 2 & 2 & 2 \\
\hline 10. & $\begin{array}{l}\text { Duration of Follow-up with } \\
\text { Appropriate Interventions }\end{array}$ & 3 & 2 & 2 \\
\hline IV. & OUTCOMES & & & \\
\hline 11. & $\begin{array}{l}\text { Outcomes Assessment Criteria } \\
\text { for Significant Improvement }\end{array}$ & 4 & 2 & 2 \\
\hline 12. & $\begin{array}{l}\text { Analysis of all Randomized } \\
\text { Participants in the Groups }\end{array}$ & 2 & 2 & 2 \\
\hline 13. & Description of Drop Out Rate & 2 & 2 & 2 \\
\hline 14. & $\begin{array}{l}\text { Similarity of Groups at } \\
\text { Baseline for Important } \\
\text { Prognostic Indicators }\end{array}$ & 2 & 2 & 2 \\
\hline 15. & Role of Co-Interventions & 1 & 1 & 1 \\
\hline V. & RANDOMIZATION & & & \\
\hline 16. & Method of Randomization & 2 & 2 & 2 \\
\hline VI. & $\begin{array}{l}\text { ALLOCATION } \\
\text { CONCEALMENT }\end{array}$ & & & \\
\hline 17. & $\begin{array}{l}\text { Concealed Treatment } \\
\text { Allocation }\end{array}$ & 2 & 2 & 2 \\
\hline VII. & BLINDING & & & \\
\hline 18. & Patient Blinding & 1 & 1 & 1 \\
\hline 19. & Care Provider Blinding & 1 & 0 & 1 \\
\hline 20. & Outcome Assessor Blinding & 0 & 0 & 1 \\
\hline VIII. & CONFLICTS OF INTEREST & & & \\
\hline 21. & Funding and Sponsorship & 2 & 2 & 2 \\
\hline 22. & Conflicts of Interest & 3 & 3 & 2 \\
\hline \multicolumn{2}{|c|}{ TOTAL } & 45 & 38 & 39 \\
\hline
\end{tabular}

Source: Manchikanti L, et al. Assessment of methodologic quality of randomized trials of interventional techniques: Development of an interventional pain management specific instrument. Pain Physician 2014; 17:E263-E290 $(527)$ 
Table 30. IPM checklist for assessment of nonrandomized or observational studies of thoracic facet joint interventions of IPM techniques utilizing IPM-QRBNR.

\begin{tabular}{|c|c|c|c|c|c|c|}
\hline & & $\begin{array}{l}\text { Rohof \& Chen } \\
\quad(581)\end{array}$ & $\begin{array}{l}\text { Manchikanti et } \\
\text { al (511) }\end{array}$ & $\begin{array}{l}\text { Park et al } \\
\quad(583)\end{array}$ & $\begin{array}{c}\text { Gungor \& } \\
\text { Candan } \\
(580)\end{array}$ & $\begin{array}{c}\text { Chang } \\
(576)\end{array}$ \\
\hline I. & STUDY DESIGN AND GUIDANCE REPORTING & & & & & \\
\hline 1. & STROBE or TREND GUIDANCE & 2 & 3 & 2 & 2 & 2 \\
\hline II. & DESIGN FACTORS & & & & & \\
\hline 2. & Study Design and Type & 2 & 4 & 2 & 2 & 2 \\
\hline 3. & Setting/Physician & 2 & 2 & 2 & 2 & 2 \\
\hline 4. & Imaging & 3 & 3 & 3 & 3 & 3 \\
\hline 5. & Sample Size & 2 & 1 & 1 & 1 & 1 \\
\hline 6. & Statistical Methodology & 1 & 2 & 1 & 1 & 1 \\
\hline III. & PATIENT FACTORS & & & & & \\
\hline \multirow[t]{2}{*}{7.} & Inclusiveness of Population & & & & & \\
\hline & - For facet or sacroiliac joint interventions: & 2 & 4 & 4 & 4 & 4 \\
\hline 8. & Duration of Pain & 2 & 2 & 2 & 2 & 2 \\
\hline 9. & Previous Treatments & 2 & 2 & 2 & 2 & 2 \\
\hline 10. & $\begin{array}{l}\text { Duration of Follow-up with Appropriate } \\
\text { Interventions }\end{array}$ & 3 & 3 & 2 & 2 & 2 \\
\hline IV. & OUTCOMES & & & & & \\
\hline 11. & $\begin{array}{l}\text { Outcomes Assessment Criteria for Significant } \\
\text { Improvement }\end{array}$ & 3 & 4 & 1 & 1 & 3 \\
\hline 12. & Description of Drop Out Rate & 1 & 1 & 1 & 1 & 1 \\
\hline 13. & $\begin{array}{l}\text { Similarity of Groups at Baseline for Important } \\
\text { Prognostic Indicators }\end{array}$ & 0 & 0 & 0 & 0 & 0 \\
\hline 14. & Role of Co-Interventions & 2 & 2 & 2 & 2 & 2 \\
\hline V. & ASSIGNMENT & & & & & \\
\hline 15. & Method of Assignment of Participants & 2 & 2 & 2 & 2 & 2 \\
\hline VI. & CONFLICTS OF INTEREST & & & & & \\
\hline 16. & Funding and Sponsorship & 2 & 2 & 2 & 2 & 2 \\
\hline \multicolumn{2}{|c|}{ TOTAL } & 31 & 37 & 29 & 29 & 31 \\
\hline
\end{tabular}

Source: Manchikanti L, et al. Development of an interventional pain management specific instrument for methodologic quality assessment of nonrandomized studies of interventional techniques. Pain Physician 2014; 17:E291-E317 (528).

Overall, the evidence synthesis in one systematic review (19) showed long-term improvement with Level II evidence.

Thus, the evidence is Level II for thoracic facet joint nerve blocks for short-term and long-term improvement, with moderate strength recommendation, in patients diagnosed with thoracic facet joint pain utilizing controlled comparative local anesthetic blocks with $80 \%$ criterion standard.

\subsubsection{Thoracic Intraarticular Injections}

In reference to intraarticular injections, there was not much evidence in the past; however, Lee et al (575) performed a randomized active control trial with intraarticular injection of steroid and local anesthetic, showing improvement in $65 \%$ of the patients at 6 months. Overall, showing positive results; however, the evidence continues to be limited. Thus, the evidence for thoracic intraarticular injections is Level III, with weak to moderate strength of recommendation, with emerging evidence in patients with appropriate diagnosis of facet joint pain utilizing $80 \%$ pain relief criterion standard with controlled comparative local anesthetic blocks. 


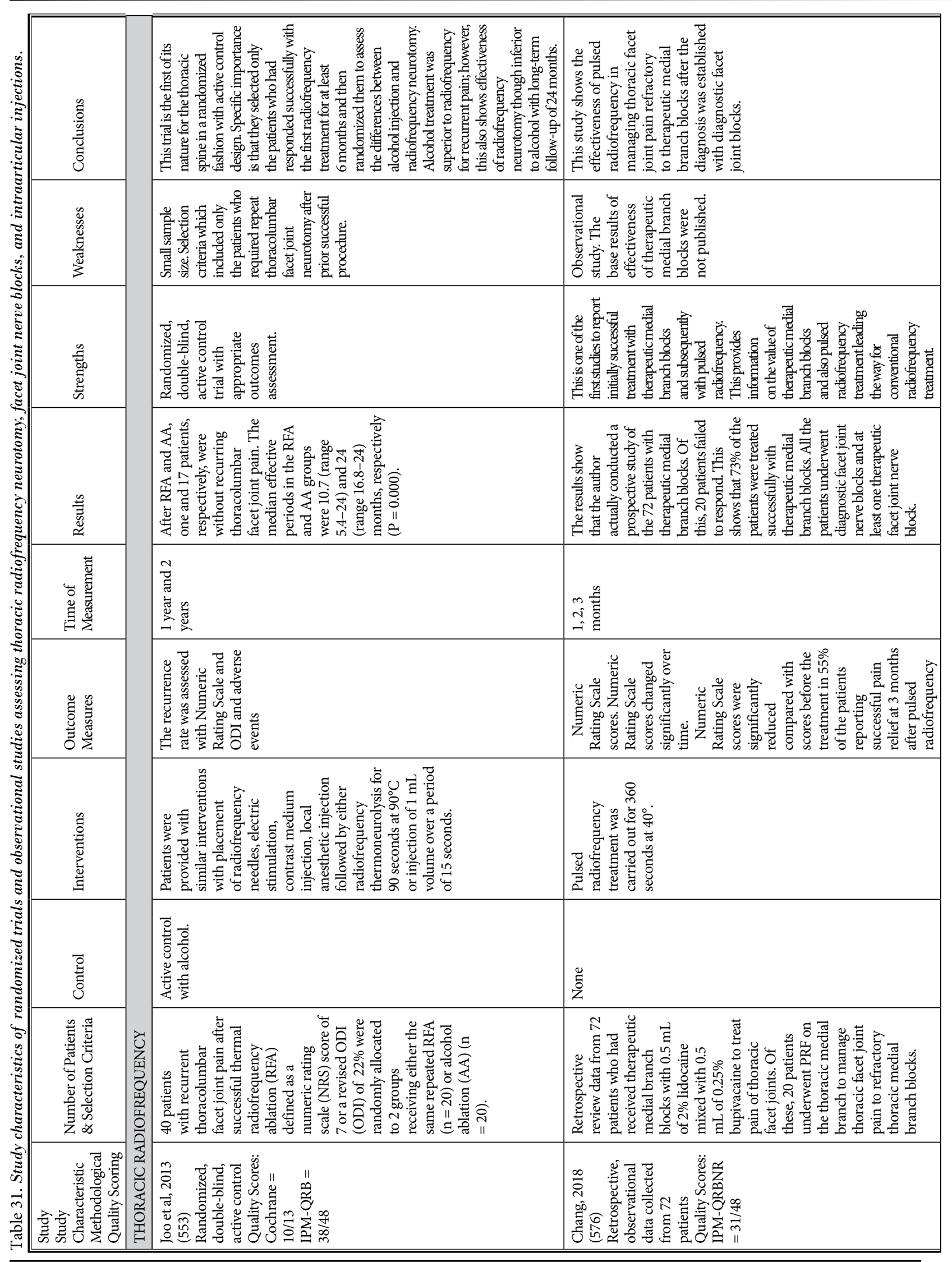


Pain Physician: May/June 2020 23:S1-S127

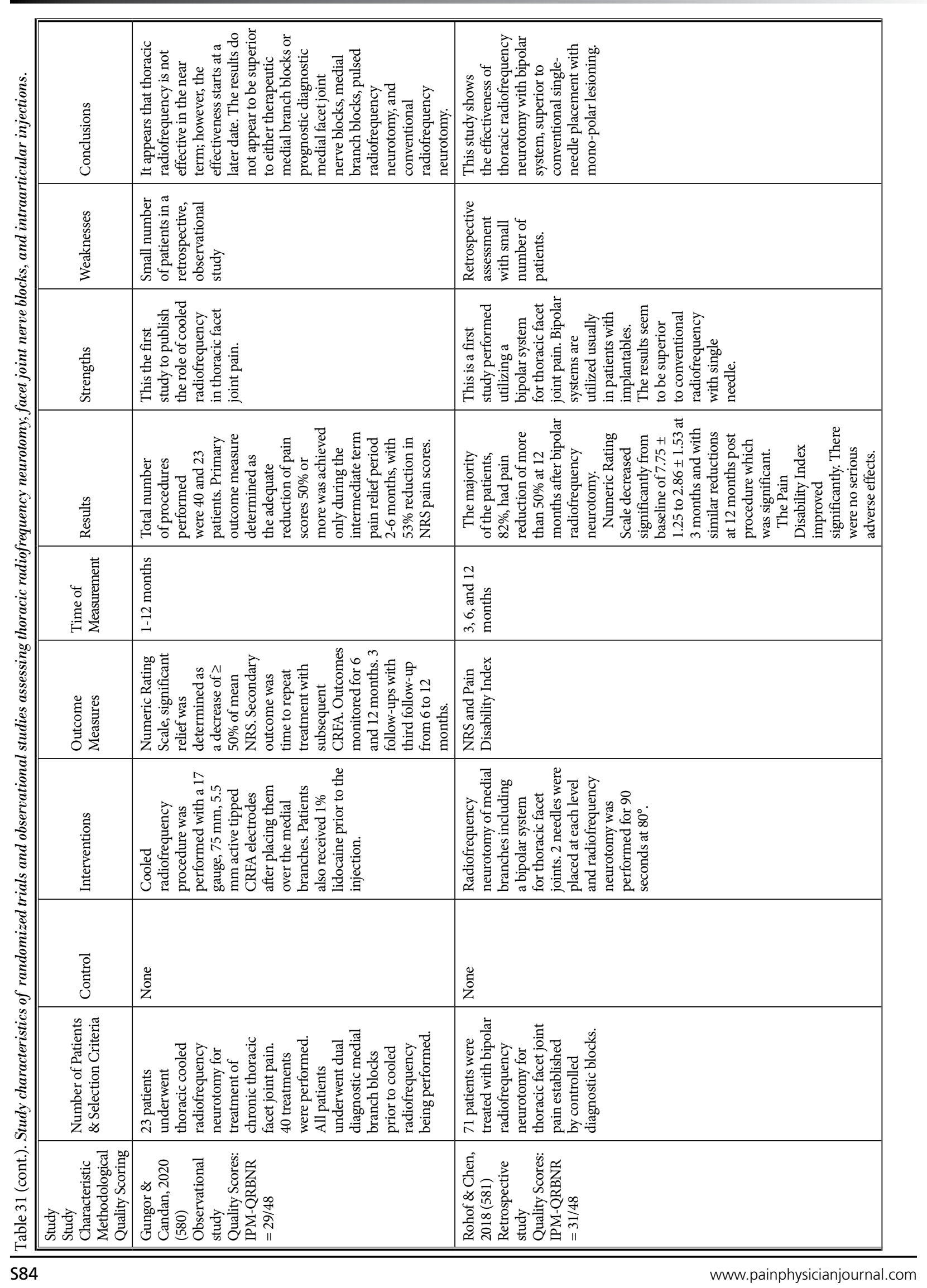




\begin{tabular}{|c|c|c|c|c|c|}
\hline & 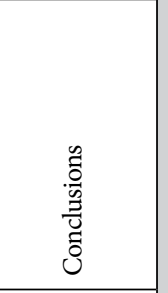 & & 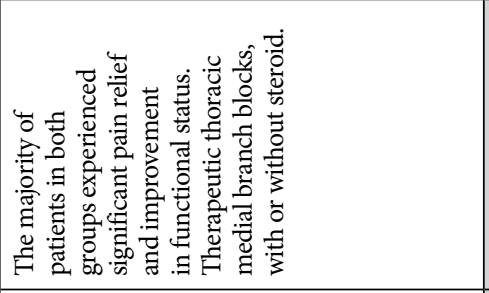 & 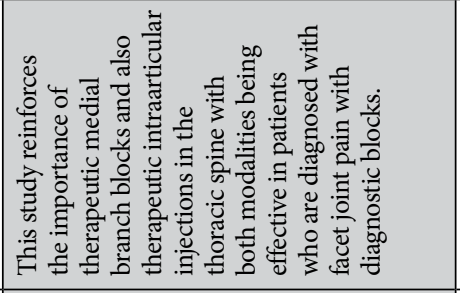 & 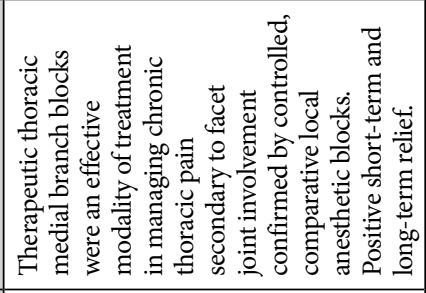 \\
\hline & 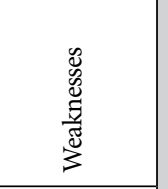 & & 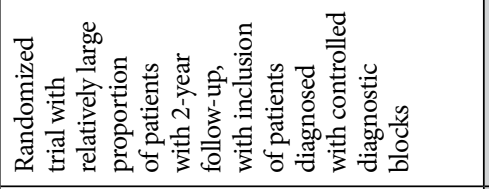 & 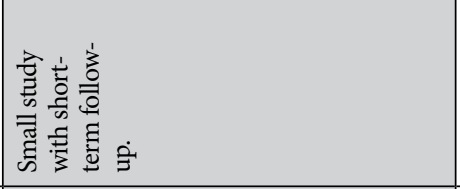 & 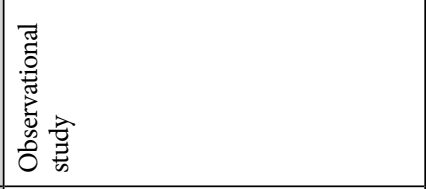 \\
\hline & 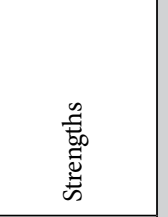 & & 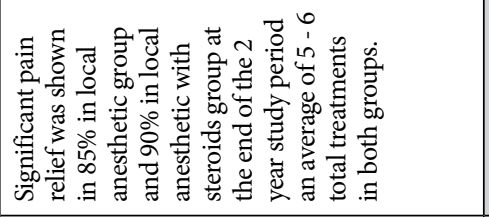 & 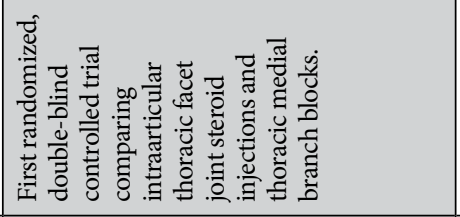 & 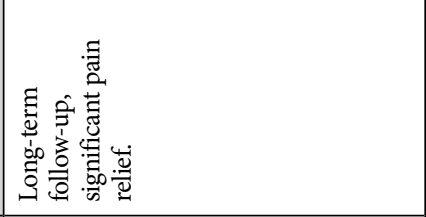 \\
\hline & $\begin{array}{l}\text { 㺃 } \\
\simeq \\
\simeq\end{array}$ & & 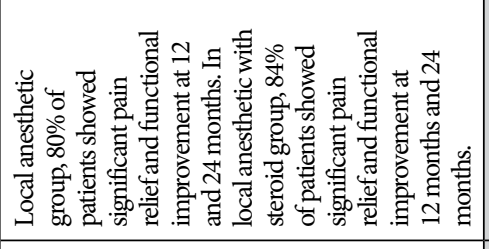 & 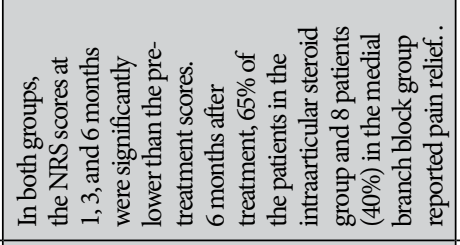 & 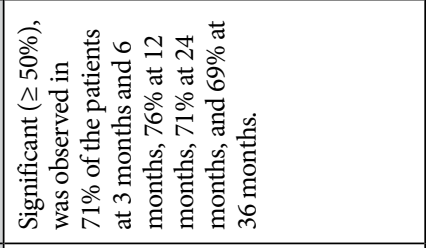 \\
\hline & 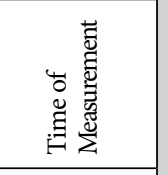 & & 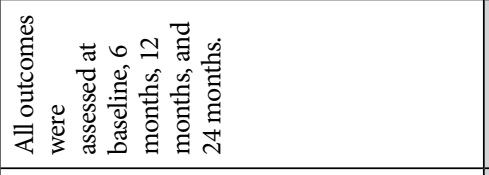 & 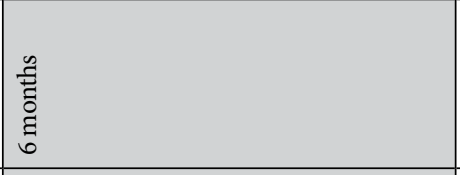 & 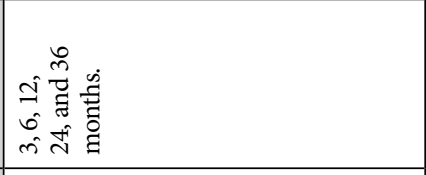 \\
\hline & 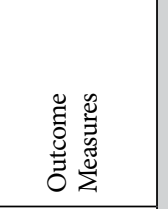 & & 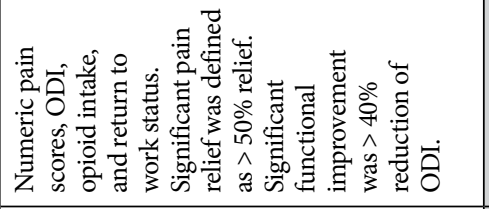 & 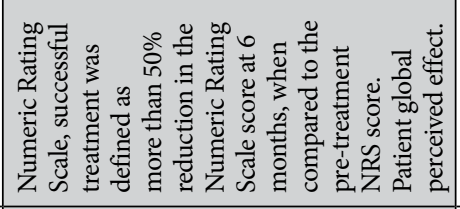 & 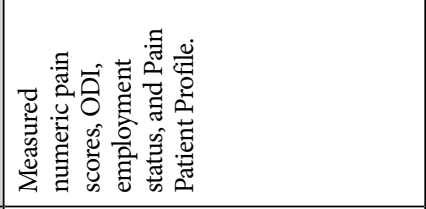 \\
\hline & 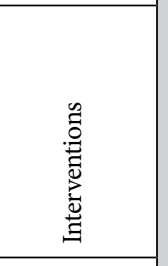 & & 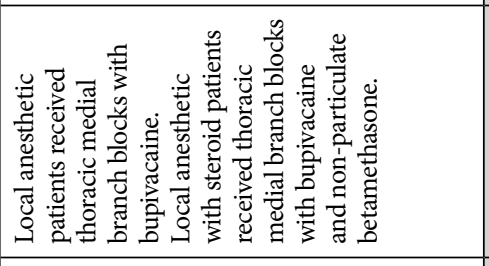 & 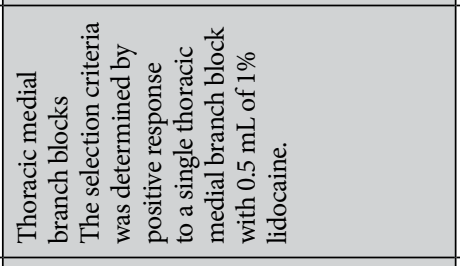 & 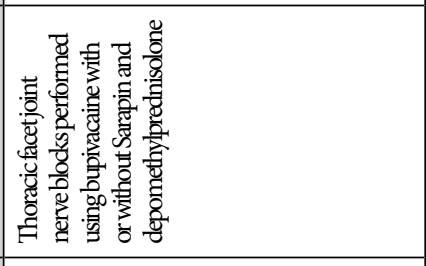 \\
\hline & $\begin{array}{l}\overrightarrow{0} \\
\text { 苛 }\end{array}$ & 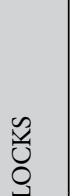 & 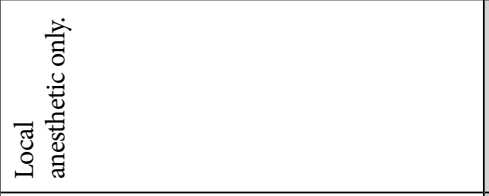 & 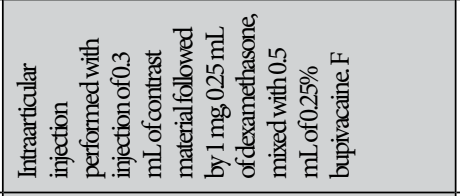 & 芩 \\
\hline & 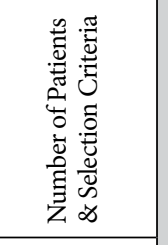 & 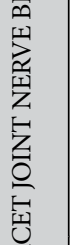 & 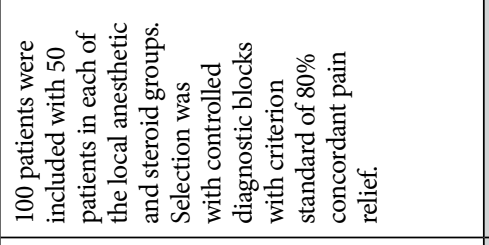 & 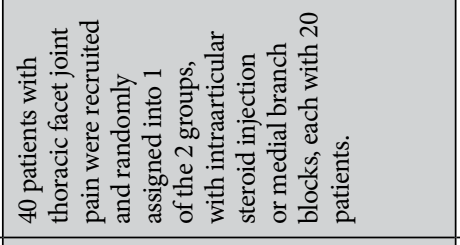 & 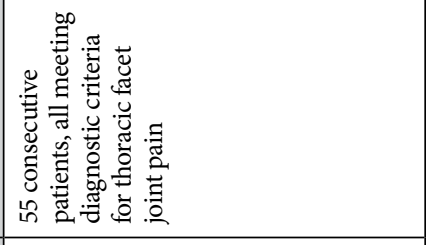 \\
\hline & 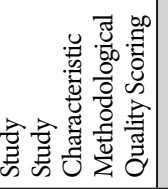 & 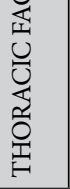 & 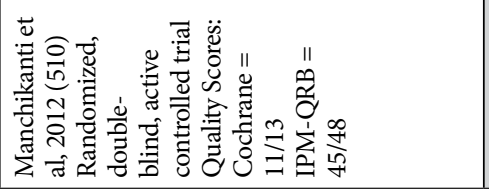 & 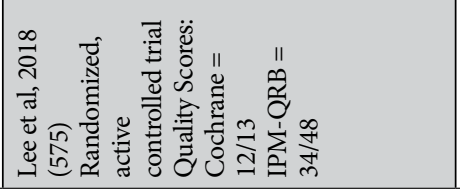 & 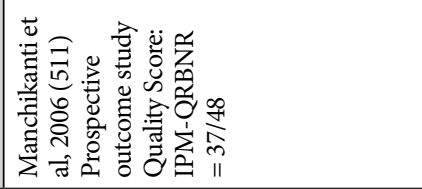 \\
\hline
\end{tabular}




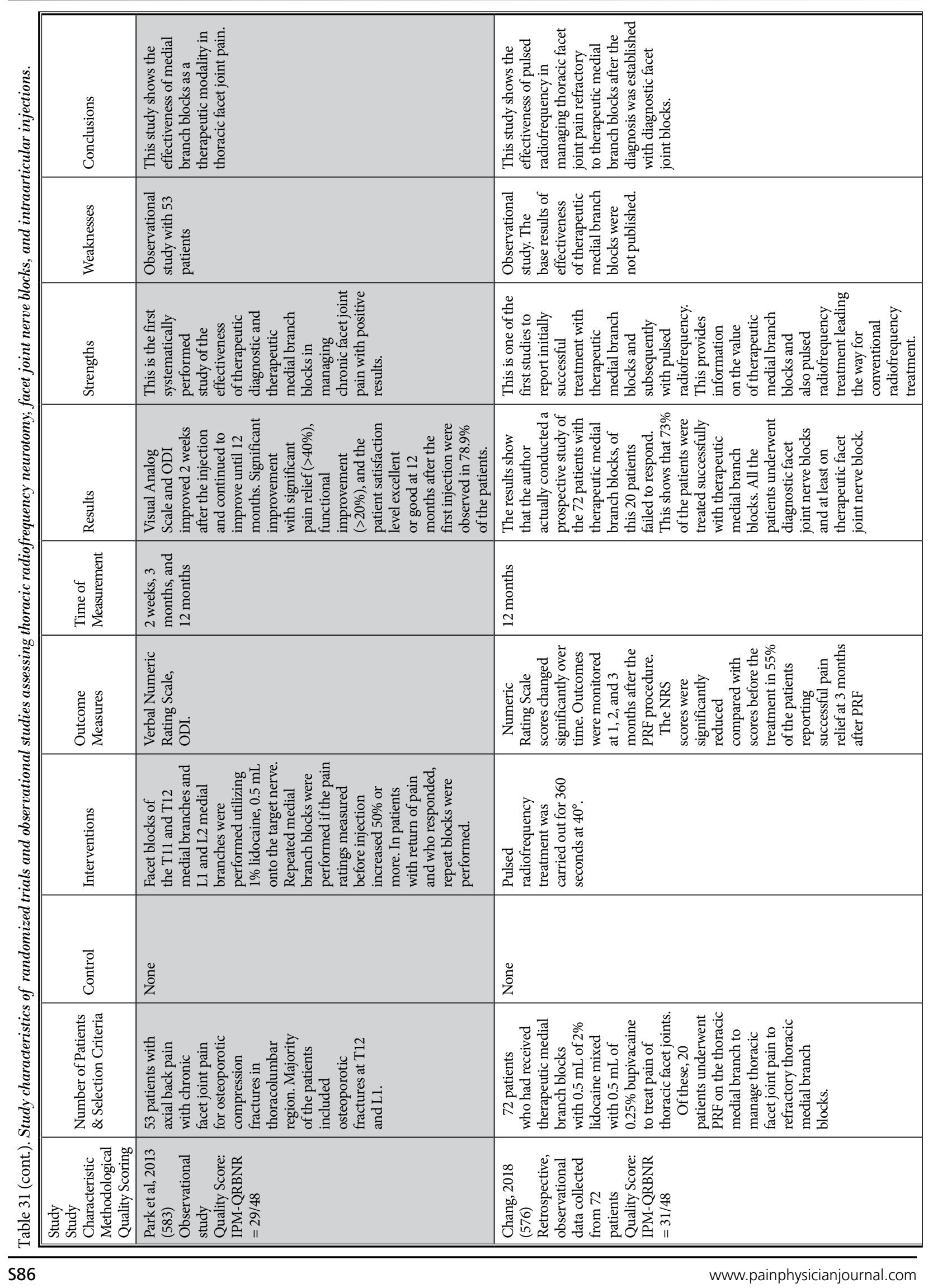




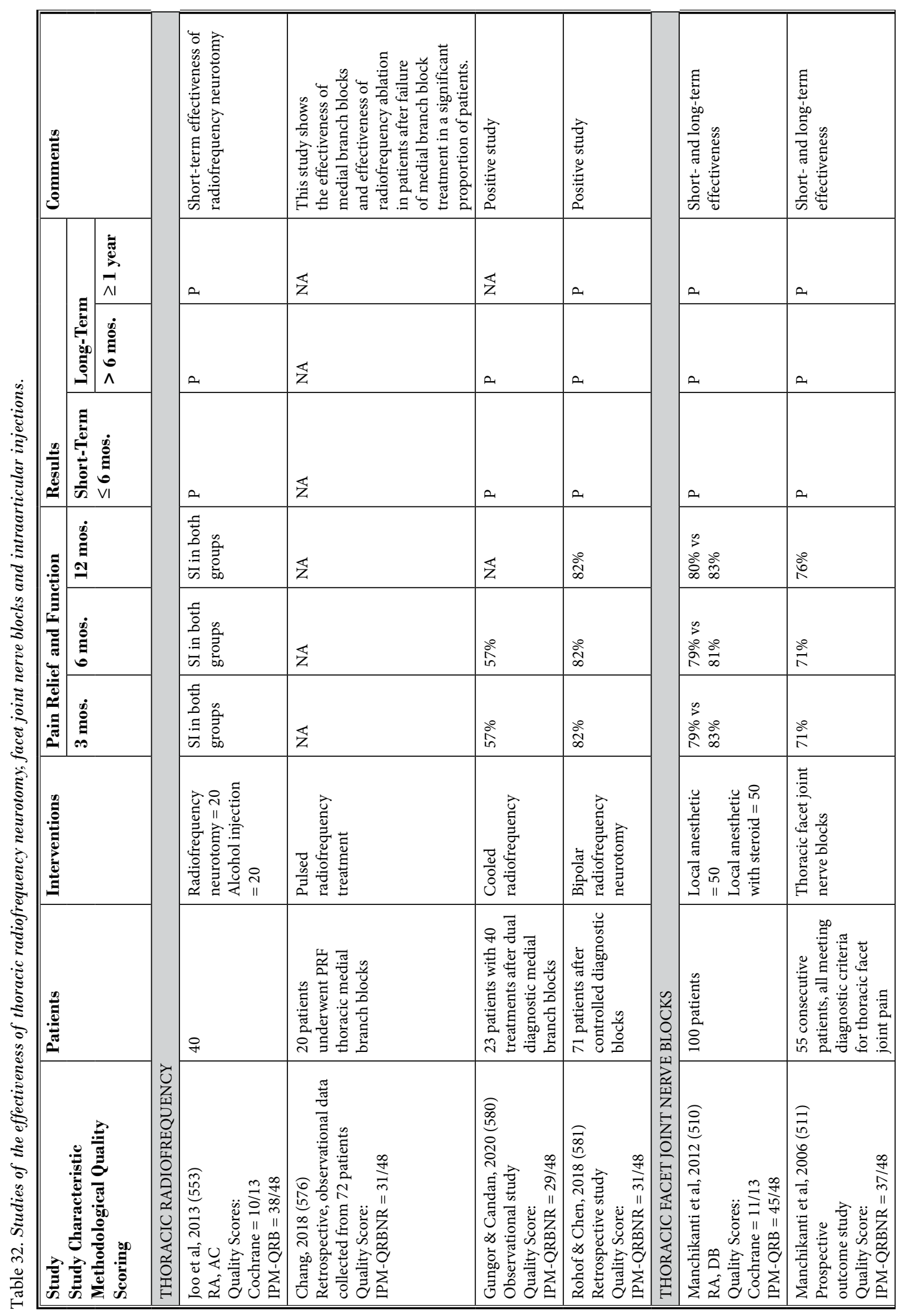




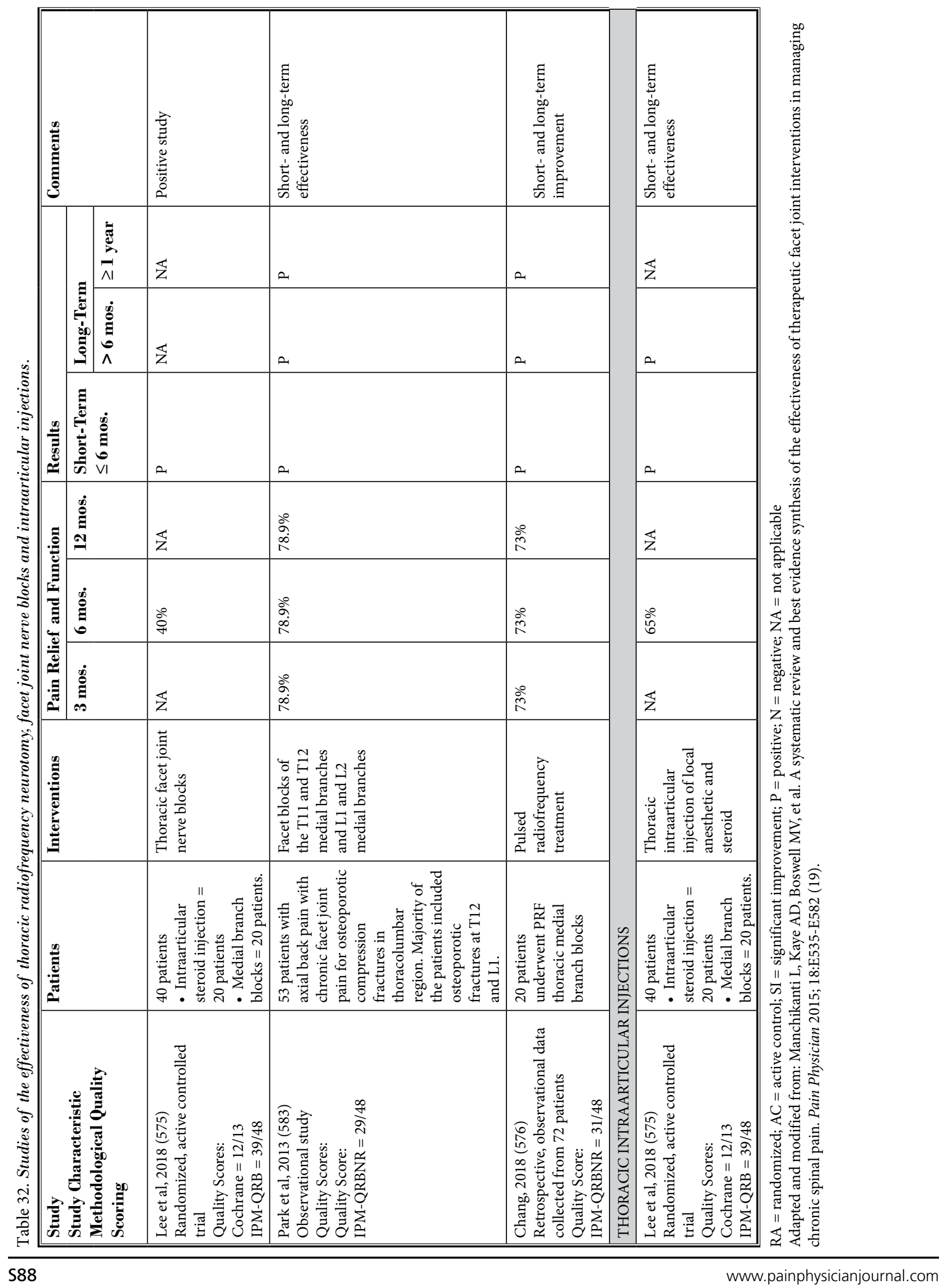




\subsection{Cost Utility Analysis}

Key Question 7: What is the evidence for costeffectiveness of interventional techniques in managing spinal facet joint pain?

Cost utility analysis has emerged over the years as an important tool in provision of value-based health care by merging patients centered outcomes with utilization of health care resources (96-102,614-618). The cost utility analysis or cost effectiveness analysis allows policy makers and providers to compare treatment strategies among different disciplines and identify the relative priorities for optimal resource allocation among various interventions (104-107,615-635). In the analysis of costs, it is relatively simple to utilize direct costs. However, indirect costs are difficult to assess. In interventional pain management, cost utility analysis was calculated based on direct expenses of around $60 \%$ plus $40 \%$ of indirect expenses $(196-102,629,630)$, which is on the higher side than what is shown in most of the analyses, showing that cost utility analysis may be overestimating the cost rather than underestimating. Further, based on the ACA, cost effectiveness is not utilized as a basis for coverage or other analysis in the United States (104-107). Even then, cost effectiveness and cost utility analysis are frequently utilized as the basis for coverage in other countries including the United Kingdom (611). These assessments are based on health technology assessment guidance in the United Kingdom. Despite the fact that the US does not openly consider cost utility analysis for coverage, the importance of high quality with low expense has been stressed with numerous public policy decisions including the ACA, physician quality reporting systems, value-based payment systems, merit-based incentive payment systems, and accountable interventional pain management $(104-107,623)$. Thus, the present analysis shows appropriate cost utility for facet joint nerve blocks. It should be noted that cost utility analysis is forthcoming for other interventions such as radiofrequency neurotomy.

Multiple cost utility or effectiveness analysis studies and reviews have been published over the years in managing various types of spinal pain from physical therapy to complex surgical fusions $(96-102,168,615,619,620,624-$ 631). However, there are very few studies assessing the cost utility of nonsurgical techniques in managing neck pain (168,620-631). Among the interventional techniques, a few, clinically relevant, methodologically sound cost utility studies were performed (96-102). There also have been multiple studies assessing the cost utility of spinal cord stimulation, which was shown to be effective compared to conventional medical management of $€ 5,624$ per quality adjusted life year (QALY) (632). Caudal epidural injections (101) were shown to be effective at a cost of $\$ 3,628$ per QALY in managing

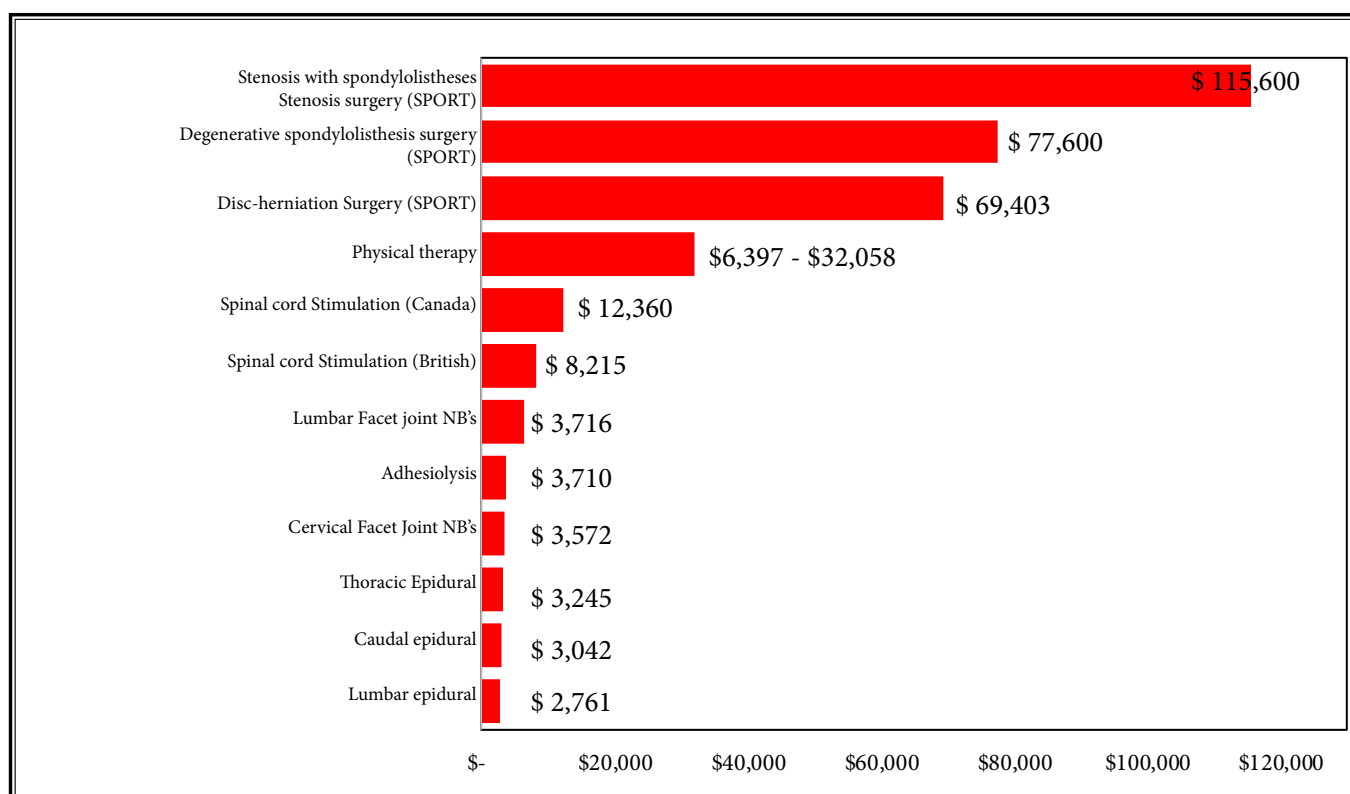

Fig. 13. Ranges of cost utility analysis in various commonly utilized procedures in the United States. 
disc herniation, spinal stenosis, discogenic pain, or post surgery syndrome, which included direct procedural costs and indirect expenses. Percutaneous adhesiolysis (102) was shown to be effective at a cost of $\$ 4,426$ per QALY in recalcitrant post surgery syndrome and spinal stenosis. Lumbar interlaminar epidural injections in the treatment of disc herniation, central spinal stenosis, and axial or discogenic low back pain in the lumbar spine shows the clinical effectiveness and cost utility of these injections of $\$ 1,976.58$ for direct costs with a total cost of $\$ 3,301$ per QALY. Cervical interlaminar epidural injections in the treatment of disc herniation, post-surgery syndrome and axial or discogenic neck pain shows $\$ 2,267.57$ for direct costs with a total cost of $\$ 3,785.89$ per QALY. Thoracic interlaminar epidural injections showed direct procedural cost of USD $\$ 1943.19$, whereas total estimated costs year per QALY were USD $\$ 3245.12$. Finally, there were 2 appropriately performed cost utility analysis studies of cervical and lumbar therapeutic facet joint nerve blocks in managing chronic spinal pain $(96,97)$. The study of cost utility analysis of cervical therapeutic medial branch blocks in managing chronic neck pain (96), based on cost utility analysis performed with direct payment data for the procedure for a total of 120 patients over a period of 2 years was based on actual reimbursement of 2016. The payment data provided direct procedural costs without inclusion of drug treatments. An additional $40 \%$ was added to procedural costs with multiplication of a factor of 1.67 to provide estimated total costs including direct and indirect costs based on highly regarded surgical literature $(629,630)$. Outcome measures included significant improvement defined at least a $50 \%$ improvement with reduction in pain and disability status with a combined $50 \%$ or more reduction in pain in Neck Disability Index (NDI). This cost utility analysis showed overall costs of $\$ 4,261$ per QALY (97). Similarly, therapeutic lumbar facet joint nerve blocks were cost effective at $\$ 4,432$ per QALY with overall estimated cost. There were multiple other studies arguably inappropriate for epidural injections in the lumbar spine. However, none exist for other regions or for axial pain.

It has been repeatedly shown that cost utility is crucial in managing health care, even though cost is not taken into consideration in governmental programs. However, this is addressed in multiple ways by reducing utilization, reimbursement, or coverage policies. The purpose of cost utility analysis in health economics is to estimate the ratio between the cost of a health-related intervention and the benefit it pro- duces in terms of numbers of years lived in full health by the beneficiaries. Thus, it is considered as a special case of cost effectiveness analysis, and both the terms are often used interchangeably. In the scenario of cost utility analysis, cost is measured in monetary units. However, in cost benefit analysis, benefits do not have to be expressed in monetary terms. Among the studies assessing cost effectiveness of various treatments in managing chronic neck pain $(96,615,619,620,631)$, one study (619) assessed patient-centered quality of life and health economics based on surgery for degenerative cervical myelopathy. A second study (615) evaluated the effect of obesity on cost per QALY's gained followed anterior cervical discectomy and fusion in elective degenerative pathology. In the earlier study (619), the results showed QALY gained over a 24-month study period was 0.139 and the mean 2-year cost of treatment was CAD $\$ 19,217 \pm$ CAD $\$ 12,404$, with costs associated with operation comprising $65.7 \%$ of the total. They estimated lifetime incremental cost to utility ratios as of surgical intervention of CAD $\$ 20,547$ per QALY gained. Multiple studies also assessed nonsurgical and noninterventional treatments $(620,621)$. Among these studies (631), the authors showed that inflation-adjusted costs of home exercise and advice with additional spinal manipulative therapy would result in inflation-adjusted to $2014 \$ 65,731$ per QALY gained. All other assessments showed improvements in the QALY, but without cost per QALY determined. Figure 13 shows ranges of cost utility analysis in various commonly utilized procedures in the United States.

In managing low back pain, specifically classified as nonspecific low back pain, incremental cost effectiveness of $\$ 4,594$ per QALY was shown with physical therapy (636). A favorable cost utility of $\$ 2,216$ per QALY for spinal stabilization physiotherapy was demonstrated with individual physiotherapy (637). Physiotherapy was also shown to be more cost effective than advice alone in low back pain of 6-week duration, at a cost utility of $\$ 6,379$ per QALY (638). In addition, a study of cost effectiveness of primary care management, with or without early physical therapy for acute low back pain (633) showed that early physical therapy resulted in higher total one-year cost and better quality of life after one year. However, this assessment showed the incremental cost effectiveness ratio was $\$ 32,058$ per QALY. Despite these high costs for early physical therapy, the authors reached the conclusion that early physical therapy is a cost-effective modality relative to usual primary care after one year for patients with acute, nonspecific 
low back pain. In addition, the authors of the above manuscript (633) also quoted the literature derived from observational research showing that delaying referral to physical therapy is associated with increased overall health care costs and a greater risk for receiving advanced imaging or invasive procedures for low back pain $(634,635,639)$. Overall analysis of complementary and alternative medical treatments for cost effectiveness compared to no treatment, a placebo, physical therapy or usual care in reducing pain immediately or at short-term after initiation of the treatment, revealed significantly greater effectiveness of complementary and alternative medicine treatments (620).

In reference to spinal cord stimulators, another study of the management of chronic pain of failed back surgery syndrome, complex regional pain syndrome, peripheral arterial disease, and refractory and angina pectoris, showed CAD \$9,293, CAD \$11,216, CAD $\$ 93,050$, and CAD $\$ 99,084$ for failed back surgery syndrome, complex regional pain syndrome, peripheral arterial disease, and refractory angina pectoris, respectively, per QALY gained (627).

Among the earlier publications, Kepler et al (624) showed that one-year cost of QALY gained was less than $\$ 100,000$ in only $45 \%$ of the studies assessed. In another study, Indrakanti et al (625) showed that a greater value was placed on studies of nonoperative treatments compared to surgical interventions. In a systematic review, highly variable costs for QALY were demonstrated ranging from $\$ 304,000$ to $\$ 579,527$ with a median cost of $\$ 13,000$. Generally, costs of surgical interventions are considered to be the highest in managing spinal pain. The most common intervention, namely surgical lumbar discectomy, showed surgical care demonstrating a significant incremental benefit and outcome advantage over nonoperative care. Multiple assessments were performed from the data from the Spine Patient Outcomes Research Trial (SPORT). From this, Tosteson et al (629) showed cost effectiveness of surgical treatment for lumbar disc herniation at $\$ 69,403$ per QALY for the general population and $\$ 34,355$ for the Medicare population per QALY. They also showed the cost effectiveness of spinal stenosis surgeries (630) was $\$ 77,600$ per QALY gained, whereas, it was $\$ 115,600$ per QALY gained for degenerative spondylolisthesis. In the cervical spine, the cost effectiveness analysis of posterior cervical fusion showed $\$ 20,547$ per QALY in one study (615) and anterior cervical discectomy and fusion in obese patients $\$ 52,816$ in another study.

\subsection{Complications and Side Effects}

Key Question 8: What are the adverse consequences and harms and related precautions in providing facet joint interventions?

The literature addressing the safety and adverse consequences, complications and harms, and appropriate precautions is sparse. Facet joint interventions include intraarticular injections, facet joint nerve blocks, and facet joint ablation. Even though complications are rare, the most common and worrisome complications are related to needle placement and drug administration. These complications include issues related to bleeding with or without intravascular entry, infection, dural puncture and spinal anesthesia, neural trauma, spinal cord trauma, pneumothorax, radiation exposure, hematoma formation, neuropathic type of pain after radiofrequency ablation, steroid side effects and sedation $(4,6,109,110,640-661)$. In one of the reports of intraarticular facet joint steroid injection related adverse events, Kim et al (641) from January 2007 to December 2017, showed that approximately 12,000 facet joint steroid injections were performed in 6,066 patients with a mean age of 66.8 years ranging from 15 to 97 years in a radiology department. All procedures were performed by a radiologist and were administered with steroids and local anesthetic. They reported that there were 101 facet joint injection related adverse event cases in 99 patients with an overall incidence of facet joint injection related adverse events of $0.84 \%$ per case and $1.63 \%$ per patient. They also reported that the incidence of procedure-related complications and drug related systemic adverse events or $0.07 \%$ in 8 patients, and $0.15 \%$ in 18 patients respectively. The rate of uncertain etiology events was $0.63 \%$ in 75 of 11,980 patients. All 8 procedure related complications involved major complications with 7 cases of infectious spondylitis and one progressing to systemic aspergillosis to the spine. One patient died of an uncontrolled infection with infective endocarditis, and 2 patients experienced partial recovery with neurological sequelae. They concluded that the overall incidence of facet joint injection related adverse events is low, and procedure related major complications are rare without dural puncture or epidural hematoma. They hypothesized that nevertheless, infection can occur, resulting in serious outcomes.

However, most of the reports of complications have been only case reports, while intravascular injections, bleeding, infection, have been evaluated (641-646). In an evaluation of the incidence of intravascular penetra- 
Table 33. Potential complications of cervical facet joint interventions.

\begin{tabular}{|l|l|}
\hline - Pain & - Trauma \\
- Pain at the site of the needle & - Soft tissue \\
- Exacerbation of existing pain & - Medial branch \\
- Nerve root \\
- Pain in the spine & - Spinal cord \\
\hline - Infection & - Inadvertent injection \\
- Soft tissue abscess & - Dural puncture \\
- Epidural abscess & - Subdural injection \\
- Facet joint abscess & - Epidural injection \\
- Meningitis & - Foraminal injection \\
- Encephalitis & - Intravascular injection \\
\hline - Bleeding & - Radiofrequency \\
- Soft tissue hematoma & - Nerve root ablation \\
- Epidural hematoma & - Spinal cord ablation \\
- Spinal cord hematoma & - Dysesthesias \\
- Nerve root sheath hematoma & - Allodynia \\
\hline - Steroid effects & - Hypoesthesia \\
\hline & - Local anesthetic effects \\
\hline
\end{tabular}

Source: Manchikanti L, Schultz DM, Falco FJE, Singh V. Cervical facet joint interventions. In: Manchikanti L, Kaye AD, Falco FJE, Hirsch JA (eds). Essentials of Interventional Techniques in Managing Chronic Spinal Pain. Springer, New York, NY, 2018, pp 387-412 (281).

tion and medial branch blocks in cervical, thoracic, and lumbar regions, with assessment of 14,312 separate medial branch blocks over a period of 3 years it was demonstrated that the overall incidence of intravascular penetration in facet joint nerve blocks was rare with an overall rate of $3.5 \%$ (642). They also showed differential intravascular injection for various levels of the spine with the cervical spine 3.9\%, lumbar spine $3.7 \%$, and the thoracic spine with $0.7 \%$ (642). In another investigation (643) of 1,433 injections of lumbar medial branch blocks, intravascular penetration was demonstrated in $6.1 \%$. Yet another study (644) showed $6.1 \%$ intravascular injections in the lumbar spine. One of the largest prospective evaluations of facet joint nerve blocks with 7,500 episodes with 43,000 nerve blocks (640) showed no major complications. The procedures were performed in sterile settings in an operating room in ambulatory surgery centers (ASCs). Multiple side effects and complications in this study observed were intravascular penetration in $11.4 \%$ of the episodes with $20 \%$ in the cervical region, $4 \%$ in the lumbar region, and $6 \%$ in the thoracic region. Other complications included local bleeding in $76.3 \%$ of the episodes with the highest in the thoracic region and lowest in the cervical region. Similarly, oozing was noted in almost $20 \%$ of the encounters. Local hematoma was seen in only $1.2 \%$ of the patients with profuse bleeding, bruis- ing, soreness, nerve root irritation, and all other effects such as vasovagal reactions observed in $1 \%$ or less of the episodes.

Reported complications of radiofrequency thermoneurolysis include a worsening of the usual pain, burning or dysesthesias, decreased sensation and allodynia in the paravertebral skin or the facets denervated, transient pain and inadvertent lesioning of the spinal nerve or ventral ramus resulting in motor deficits, sensory loss, and possible deafferentation pain. A spinal cord lesion can lead to paraplegia, loss of motor, proprioception, and sensory function. In addition, these patients may also suffer bowel and bladder dysfunction, BrownSequard Syndrome and spinal cord infarction. Infection specifically with corona, resulting in COVID-19 will become a major issue in the upcoming days and months $(128,131-135,647-662)$.

Multiple precautions must be observed in relation to anticoagulant or antiplatelet therapy and also the drugs which may result in antiplatelet activity or bleeding. Complications from intra-articular injections or medial branch blocks in the cervical spine are exceedingly rare $(6,19,109,279-281,387,640)$. However, serious complications with cervical facet joint injections may occur. Complications include those related to placement of the needle and those related to the administration of various drugs. The needle's proximity to the vertebral artery, spinal cord, and nerve root creates risk for injury and makes precise and accurate needle placement exceedingly important. Complications may include dural puncture, spinal cord trauma, subdural injection, neural trauma, injection into the intervertebral foramen and intravertebral arteries, intravascular injection into veins or vertebral arteries, infectious complications including epidural abscess and bacterial meningitis, and side effects related to the administration of steroids, local anesthetics, and other drugs (Table 33).

Sterile atmosphere and infection are more important in today's surgical procedures due to the corona pandemic compared with the past. It is crucial that physicians follow CDC guidelines with infection control utilizing sterile preparation and sterile procedure. During the corona pandemic, appropriate precautions must be taken and risk stratification must be observed. It may be essential to inquire about issues related to corona infection and vaccination when it is available in the future for a long period of time.

Local anesthetic and steroid side effects are crucial. Generally, steroids are not extensively utilized for facet joint interventions except in very small doses and rarely. 
The effectiveness of steroids has been shown to be very minimal and also debated. Steroids are only indicated in intraarticular injections; however, intraarticular injections do not show significant evidence in any region. Consequently, the issue related to steroids with increased weight, redistribution of fat, immunosuppression, hormonal imbalance, and adrenal suppression have to be monitored.

Based on the available literature, facet joint interventions are considered to be a moderate risk. Consequently, based on the medical condition, these may be continued without major interruption except for Coumadin; however, a higher international normalized ratio (INR) than 1.5 may be permitted for these procedures, as high as 3.0 based on the overall condition of the patient.

\subsection{Guidelines for Diagnostic and THERAPEUTIC INTERVENTIONS}

Key Question 9: What are the guidelines for diagnostic and therapeutic interventions in managing spinal facet joint pain?

The diagnostic interventions are based on nonconservative approaches and after the failure of appropriate conservative management with diagnostic facet joint interventions. Therapeutic interventions are based on appropriate diagnosis for spinal facet joint pain.

The approach described here is based on the best available evidence on the epidemiology of various identifiable sources of chronic spinal pain $(6,236,238,663-665)$. This approach is designed to promote the efficient use of IPM techniques based on the best available evidence. However, this may not be applicable in each and every patient. The purpose of the described algorithmic approach is to provide a disciplined approach to the use of spinal interventional techniques in managing spinal pain. This approach includes evaluation, diagnostic, and therapeutic approaches, which in turn avoid unnecessary care as well as poorly documented practices.

This approach does not dictate standard of care - these are guidelines. Furthermore, with space constraints, comprehensive initial evaluations and all the findings are not provided.

\subsection{Documentation Requirements}

Documentation is to provide evidence of information. Documentation includes evaluation and management services, procedural services, and billing and coding. While the purpose of documentation is to provide information, it reflects the competency and character of the physician (4-6,663-666).

Medical necessity requires appropriate diagnosis and coding by the International Classification of Diseases, 10th Revision, (ICD-10-CM) to justify services rendered and indicates the severity of a patient's condition (667). The Balanced Budget Act (HR 2015, Section 4317) requires all physicians to provide diagnostic information for all Medicare/Medicaid patients starting from January $1,1998(667,668)$. Medical necessity is defined in numerous ways (669-673):

- The CMS (671) defines medical necessity as, "no payment may be made under Part A or Part B for any expense incurred for items or services which ... are not reasonable and necessary for the diagnosis or treatment of illness or injury or to improve the functioning of a participant."

- The American Medical Association (AMA) (673) defines medical necessity as, "health care services or procedures that a prudent physician would provide to a patient for the purpose of preventing, diagnosing or treating an illness, injury, disease or its symptoms in a manner that is:

- In accordance with generally accepted standards of medical practice.

- Clinically appropriate in terms of type, frequency, extent, site, and duration.

- Not primarily for the convenience of the patient, physician or other healthcare provider."

To meet medical necessity and reasonable and necessary criteria, the service must be:

- Safe and effective

- Not experimental or investigational

Appropriate, including the duration and frequency that is considered appropriate for the service in terms of whether it is:

Furnished in accordance with accepted standards of medical practice for the diagnosis or treatment of the patient's condition or to improve the patient's function

- Furnished in a setting appropriate to the patient's medical needs and condition

- Ordered and/or furnished by qualified personnel

- One that meets, but does not exceed, the patient's medical need

- At least as beneficial as an existing and available medically appropriative alternative.

\subsubsection{Elements of Documentation}

Federal, state, third party payer, and managed 
care plans rely heavily on provider documentation when assessing the claims for various parameters $(4,6,236,238,674-683)$. These include:

- Was the billed service actually rendered or provided to the patient?

- Was the level of service or extent of the service accurately reported?

- Was the service or procedure medically necessary?

- Was the claim sent to the correct primary insurer for the service or procedure performed?

\subsubsection{Types of Documentation}

Documentation includes evaluation and management services and interventional techniques $(665,666,680)$. Documentation for spinal interventional techniques may vary based on whether the procedure was performed in a facility setting such as hospital outpatient department (HOPD) or ASC versus in a physician's office.

\subsubsection{Documentation of Interventional Procedures} All spinal interventional techniques are considered surgical procedures $(238,666,680)$.

Documentation requirements are as follows:

- History and physical.

- Indications and medical necessity.

- Intra-operative procedural description.

- Post-operative monitoring and ambulation.

- Discharge/disposition.

\subsubsection{History and Physical}

The physician's history should include the following elements:

- Documentation of the signs and symptoms warranting the interventional procedure.

- A listing of the patient's current medications including dosages, route, and frequency of admission.

- Any existing co-morbid conditions and previous surgeries.

- Documentation of any social history or conditions which would have an impact on the patient's care upon discharge from the facility following the procedure.

The physician's physical examination should not only reflect the relevance of the interventional procedure, but also the type of anesthesia planned. Generally, for interventional techniques, if no anesthesia is to be administered, the physical examination is limited to the assessment of the patient's mental status and an examination specific to the proposed procedure, including any co-morbid conditions $(238,666,680)$.

However, if intravenous sedation or any other type of anesthesia is planned, the physical examination should also include documentation of the results of an auscultatory examination of the heart and lungs, and an assessment and written statement about the patient's general health, in addition to the assessment of mental status and an examination specific to the proposed procedure and any co-morbid conditions (666).

\subsubsection{Documentation of Indications and Medical} Necessity

Medical necessity must be established for each and every procedure and encounter $(238,665,666,668$ 673,680-682). General documentation requirements for spinal interventional techniques for indications and medical necessity are as follows:

1. Complete initial evaluation including history and physical examination.

2. Physiological and functional assessment, as necessary and feasible.

3. Definition of indications and medical necessity, as follows:

- Suspected organic problem.

- Non-responsiveness to conservative modalities of treatment.

- Pain and disability of moderate-to-severe degree.

- No evidence of contraindications such as severe spinal stenosis resulting in intraspinal obstruction, infection, or predominantly psychogenic pain.

- Responsiveness to prior interventions with improvement in physical and functional status for repeat blocks or other interventions.

- Repeating interventions only upon return of pain and deterioration in functional status.

\subsubsection{Procedural Documentation}

This includes a description of the procedure, post-operative monitoring, and discharge/disposition $(238,666,674,675,680)$ (Table 34).

\subsection{Comprehensive Initial Evaluation}

These guidelines described the impact of chronic spinal pain on lifestyle, economy, and health care in Section 3, trends in the utilization of usage of health care modalities in managing facet joint pain, which continues to increase with utilization patterns and costs 
in Section 4, and pathophysiology and structural basis of spinal facet joint pain in Section 5, detailing various aspects. Further, these guidelines also described noninterventional diagnosis of facet joint pain in Section 6 detailing history, physical examination, signs, symptoms, and results of imaging with various tests. Section 7 provides interventional diagnostic approaches with diagnostic facet joint nerve blocks with comprehensive discussions followed by, in Section 8, therapeutic facet joint interventions. Based on these evaluations and the medical necessity criteria to provide appropriate care without overuse or abuse, a comprehensive initial evaluation is essential (4-6,236,238,663-666).

Figure 14 illustrates an approach for evaluation and management of a chronic pain patient. Appropriate history, physical examination, and medical decisionmaking are essential to the provision of appropriate documentation and patient care. Not covered in this approach are socioeconomic issues and psychosocial factors that may be important in the clinical decisionmaking process. A comprehensive and complete evaluation will assist in complying with regulations, providing appropriate care, and fulfilling an algorithmic approach.

\subsubsection{Chronic Spinal Pain Diagnostic Approach}

The diagnosis of chronic low back pain is determined initially with non-interventional diagnosis initially followed by interventional diagnosis if required. The importance of the history and physical, signs, and symptoms has been described in Section 6 of these guidelines entitled "Non-interventional Diagnosis of Facet Joint Pain." Table 5 in Section 6 shows the positive signs and symptoms in patients who were tested with positive blocks. Axial pain and paraspinal tenderness were shown to be positive in $100 \%$ and $95.5 \%$ confirming the diagnosis. Other important aspects were absence of radicular pattern in $68.2 \%$ of the patients, pain alleviated with rest in $77.3 \%$ of the patients, pain induced by pressure on the facet joint in $68.2 \%$ of the patients with reduced range of motion in $63.6 \%$. However, a sign rarely utilized, namely Kemp's sign was shown to be positive in $81.8 \%$. Further, the proposed diagnostic scale for lumbar pain of facet joint origin is described with similar symptoms and signs as shown in Table 6 . These include 3 symptoms with axial pain improvement with rest, and absence of radicular pattern and 3 signs: Kemp's sign, pain induced by pressure on the facet joints, and facet stress or new lumbar facet sign. Table 7 also shows various features of somatic
Table 34. Procedural documentation guidelines for interventional techniques.

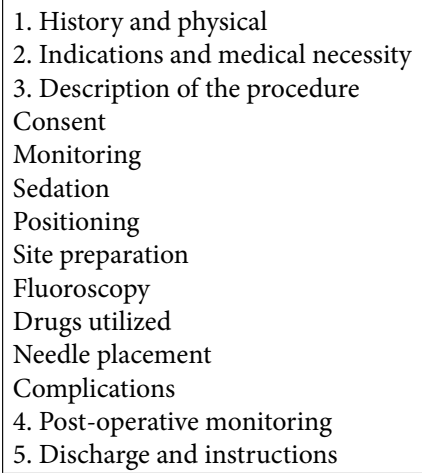

and radicular pain for cervical, thoracic, and lumbar regions, again focusing on the same as axial or somatic with referred pain or radicular pain. This provides additional information for the diagnosis. This section also shows the value of imaging in the diagnosis. Overall, the evidence summary showed that there was Level Il evidence in appropriately selecting the patients for facet joint nerve blocks in patients with chronic pain and failure of conservative management with strong strength of recommendation for physical examination and assessment. Further, these guidelines also showed Level IV evidence for accurate diagnosis of facet joint pain with physical examination based on symptoms and signs with weak strength of recommendation. In reference to the imaging, there is Level III evidence supporting the use of SPECT for identifying the painful lumbar facet joints prior to diagnostic facet joint nerve blocks, with unknown costs, with weak strength of recommendation. Further, scintography, MRI, and CT showed Level $\mathbf{V}$ evidence with weak strength of recommendation. Section 7 shows evidence related to diagnostic facet joint interventions. If non-invasive assessment directs the physician to diagnostic facet joint interventions, these may be performed with significant certainty.

In the cervical spine, the evidence was derived from 10 diagnostic accuracy studies, of which 9 utilized $80 \%$ pain relief as the criterion standard with prevalence ranging from $36 \%$ to $60 \%$, and false-positive rate ranging from $27 \%$ to $63 \%$, with strength of recommendation of moderate.

A philosophical approach with a paradigm shift from acute pain to chronic pain, and various factors influencing diagnostic accuracy including psychological factors and sedation are detailed in this section 7; the influence of diagnostic blocks on their outcomes were 


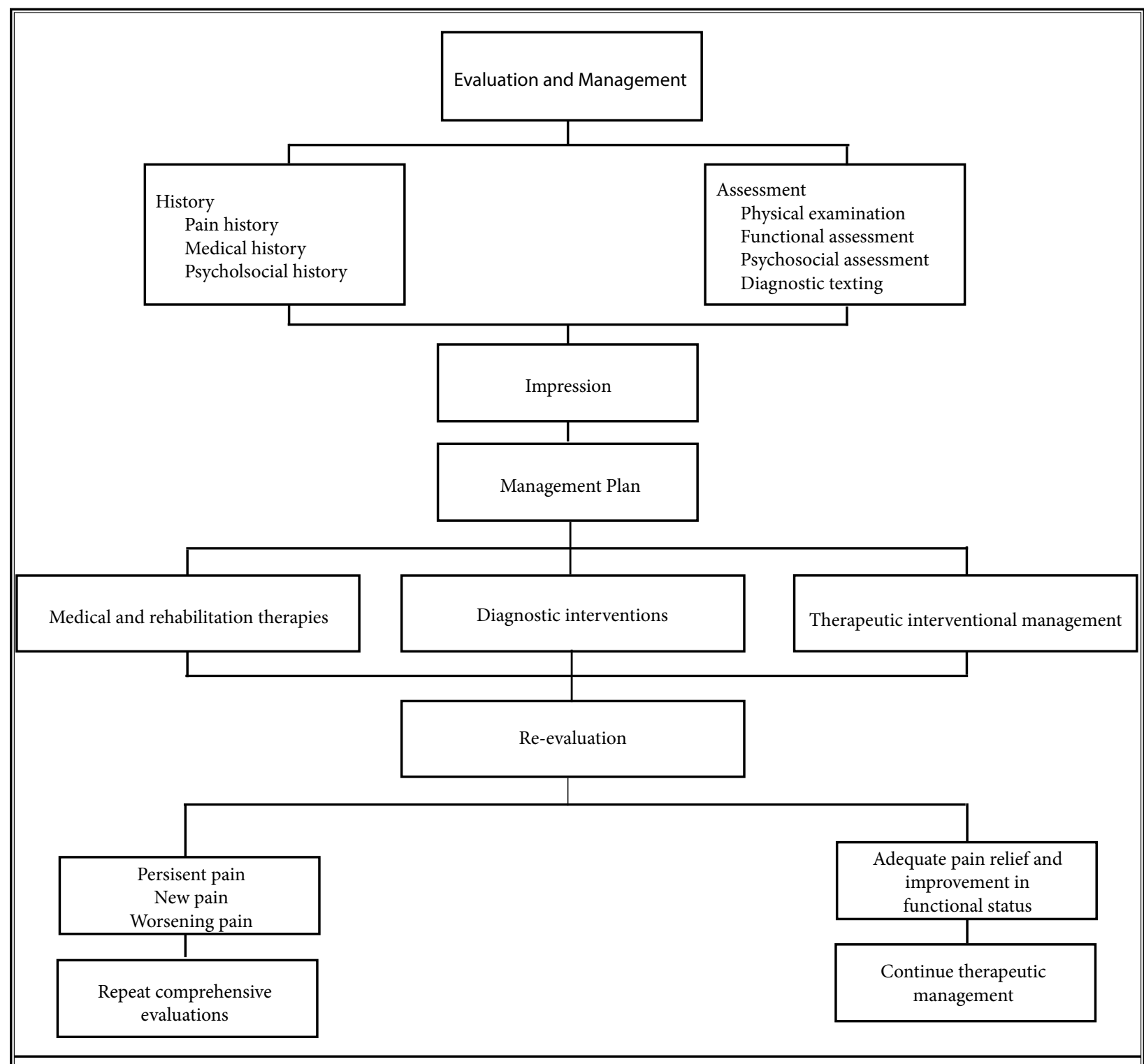

Fig. 14. A comprehensive approach for the evaluation and management of chronic spinal pain.

also discussed, which re-emphasized the importance and accuracy of diagnostic facet joint nerve blocks based on the assessments of the outcomes.

Based on the evidence as shown in these guidelines, sedation must be limited to moderate sedation with benzodiazepines without opioid analgesics.

Figure 15 illustrates a diagnostic approach for chronic low back pain without disc herniation $(4,6,236,238,646)$. This approach for chronic low back pain without disc herniation is based on the best available evidence on the epidemiology of various identifiable sources of chronic low back pain. Facet joint pain, discogenic pain, and sacroiliac joint pain have been proven to be common causes of pain with proven diagnostic techniques $(4,6,18,19,22,24,236,238,258,461-463,647-649)$.

Thus, this approach should include diagnostic interventions with facet joint blocks and sacroiliac joint injections, followed by discography. At the present time, lumbar discography suffers from significant controversy with fair evidence in the lumbar spine only (20). Figure 16 illustrates an approach to the diagnosis of chronic neck pain without disc herniation, radiculitis, spondylotic myelopathy, or spinal stenosis. 


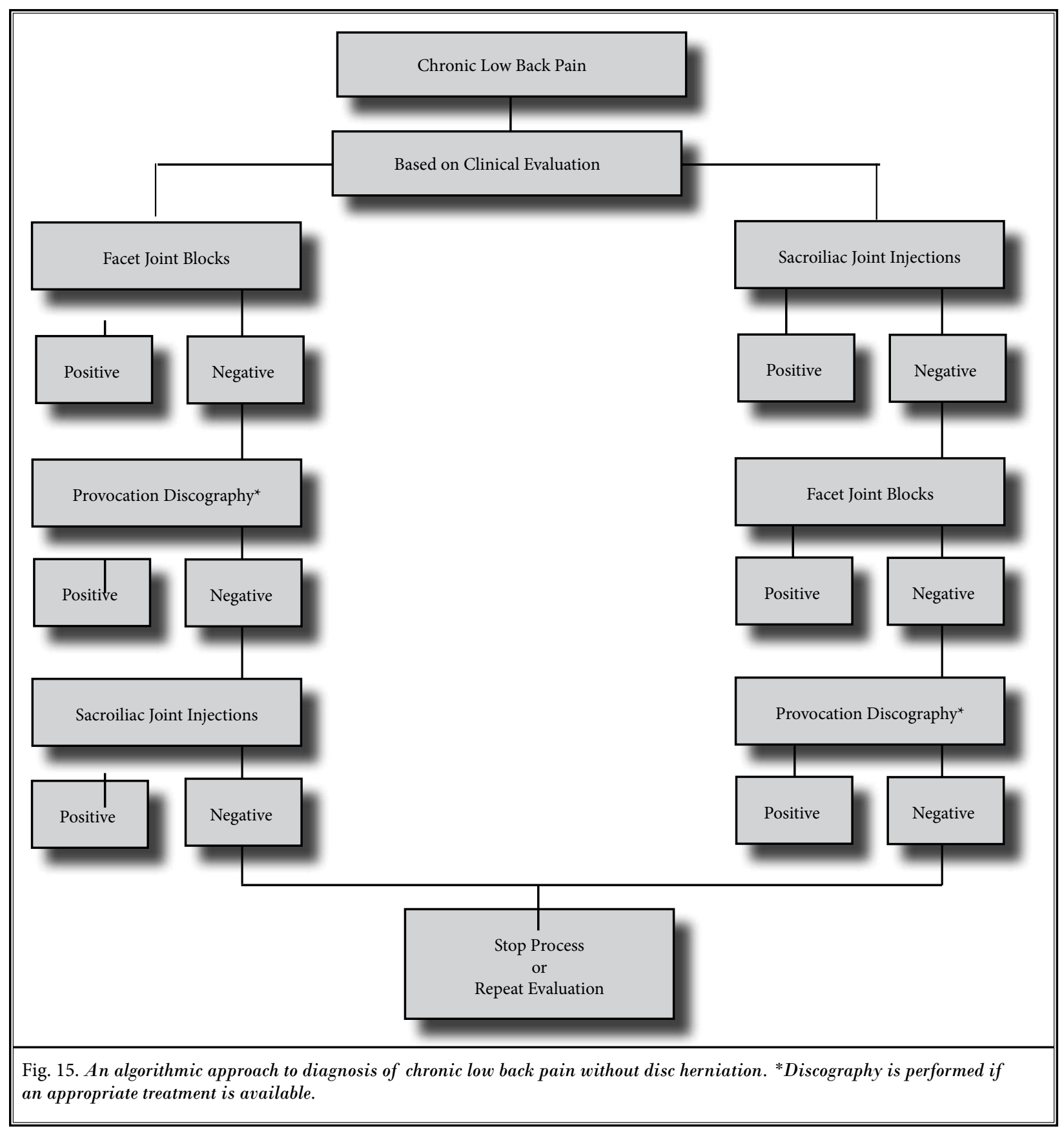

This represents an approach for the investigation of neck pain based on the best available evidence on the epidemiology of various identifiable sources of chronic neck pain.

Figure 17 illustrates the diagnostic approach for chronic thoracic pain without disc herniation or radiculitis.

This approach for investigation of thoracic pain is based on the best available evidence on the epidemiology of various identifiable sources of chronic mid back and upper back pain.

\subsubsection{Therapeutic Approaches for Facet Joint Pain}

These guidelines describe various subjects in separate sections as described earlier. Once the ap- 


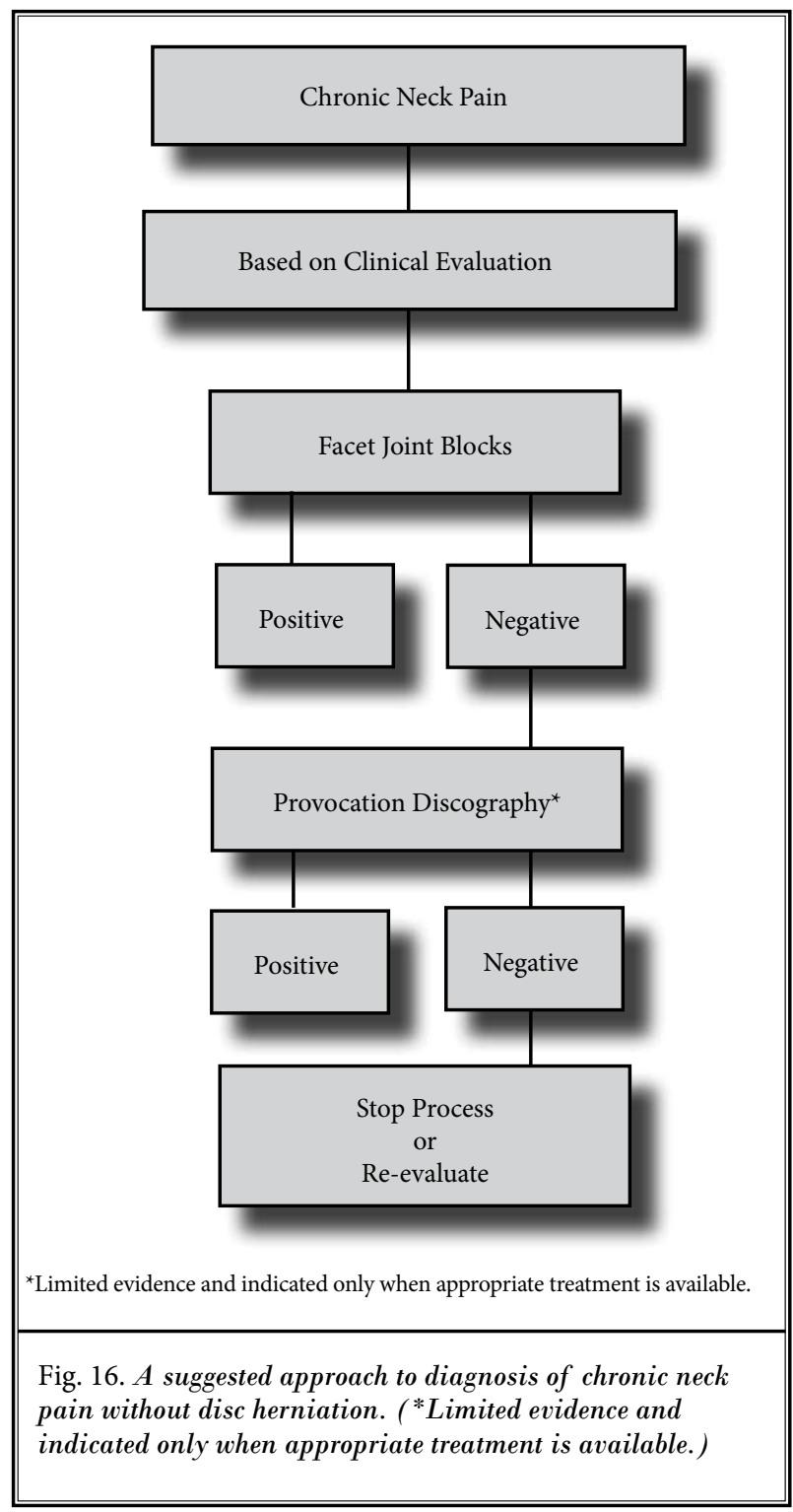

propriate diagnosis is made, appropriate therapy is indicated. The diagnosis is made preferably with diagnostic facet joint nerve blocks utilizing $80 \%$ pain relief as the criterion standard. Section 8 shows the systematic review of the literature available with systematic reviews, RCTs, and observational studies along with repeating of the systematic reviews in all sections. Analysis of the literature showed Level II evidence for lumbar radiofrequency neurotomy and therapeutic lumbar facet joint nerve blocks with moderate strength of recommendation. However, the evidence was Level IV for lumbar intraarticular injections with weak recommendation.

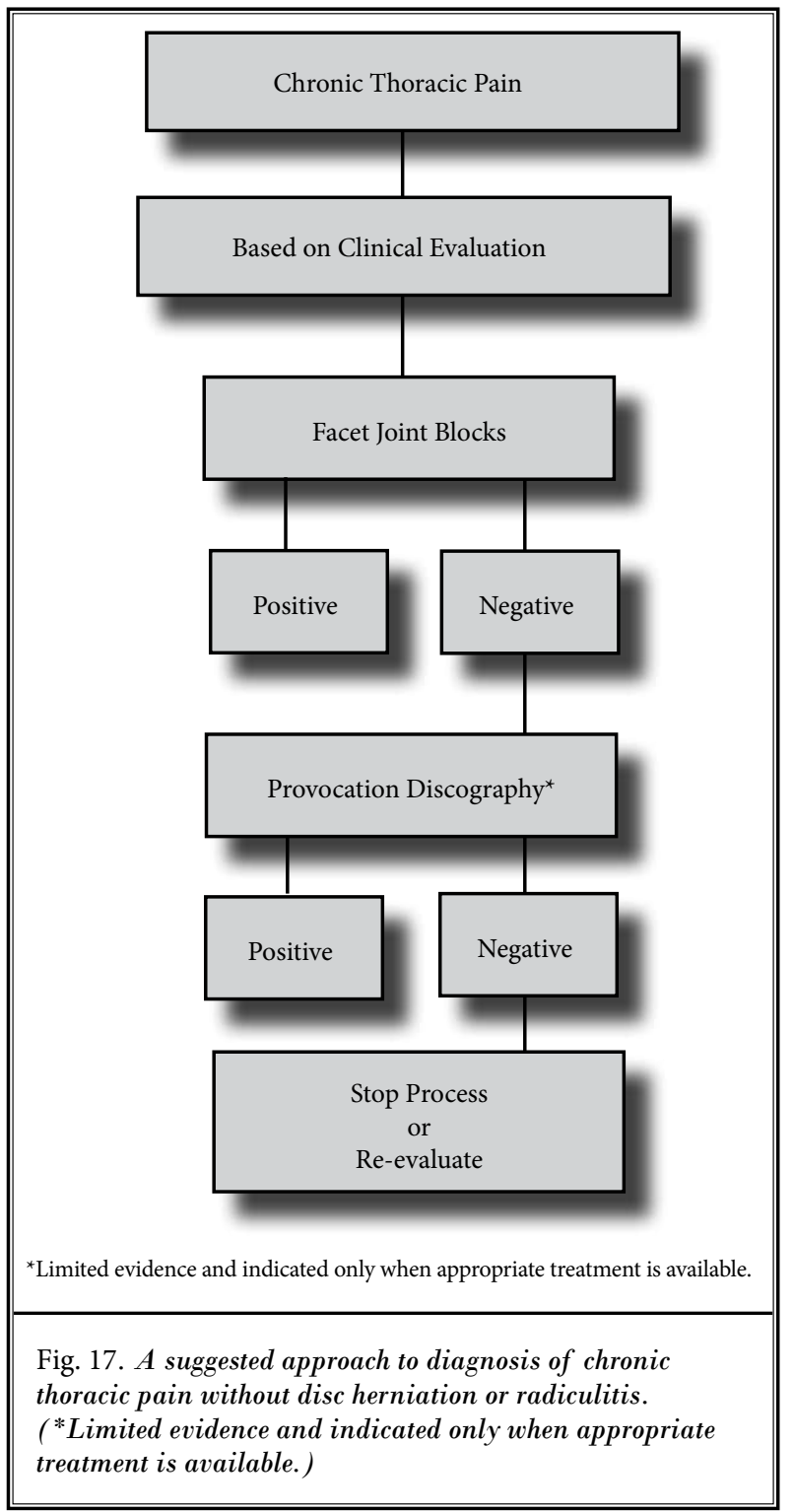

In the cervical spine, radiofrequency neurotomy and cervical therapeutic facet joint nerve blocks showed Level II evidence with moderate strength of recommendation. In reference to intraarticular injections, evidence was Level V with weak recommendation.

With thoracic facet joint interventions, the evidence for radiofrequency neurotomy was Level III with weak strength of recommendation. For therapeutic thoracic facet joint nerve blocks, the evidence was Level II with moderate strength of recommendation. For intraarticular injections the evidence of Level IV with weak strength of recommendation. 
Figure 18 illustrates the therapeutic management of low back pain. The patients testing positive for facet joint pain may undergo either therapeutic facet joint nerve blocks or radiofrequency neurotomy based on the patients' preferences, values, and physician expertise.

As illustrated in Fig. 19 showing the therapeutic management of chronic neck pain, patients testing positive for facet joint pain may undergo either therapeutic facet joint nerve blocks or radiofrequency neurotomy based on patients' preferences, values, and physician expertise.

Under the present approach, which is simple, efficient, and cost-effective, once facet joint pain is excluded, the patient may be treated with epidural injections. Essentially, cervical provocation discography is the last step in the diagnostic approach and is utilized only when appropriate treatment can be offered if the disc abnormality is demonstrated. However, a rare but justifiable indication is to satisfy the patients' impressions if the patient does not improve with any other modalities of treatment. Thus far, studies have demonstrated the effectiveness of epidural injections in the cervical region in discogenic pain $(461,684-687)$.
Figure 19 illustrates therapeutic management. The patients testing positive for facet joint pain may undergo either therapeutic facet joint nerve blocks or radiofrequency neurotomy based on the patient's preferences, values, and physician expertise.

An approach for investigating chronic mid back or upper back pain without disc herniation commences with clinical questions, clinical findings, and findings of imaging. In this approach, investigation of facet joint pain is considered as the prime investigation, ahead of disc stimulation.

Under the present approach, once facet joint pain is excluded, the patient may be treated with epidural injections. Thoracic provocation discography is an extremely rare and last step in the diagnostic algorithm and is utilized only when appropriate treatment can be performed if the disc abnormality is noted. The only very rare exception may be to perform discography to satisfy the patient's impressions if the patient does not improve with any other modalities of treatment.

As illustrated in Fig. 20 displaying a suggested approach to management of chronic thoracic pain, patients testing positive for facet joint pain may undergo thera-

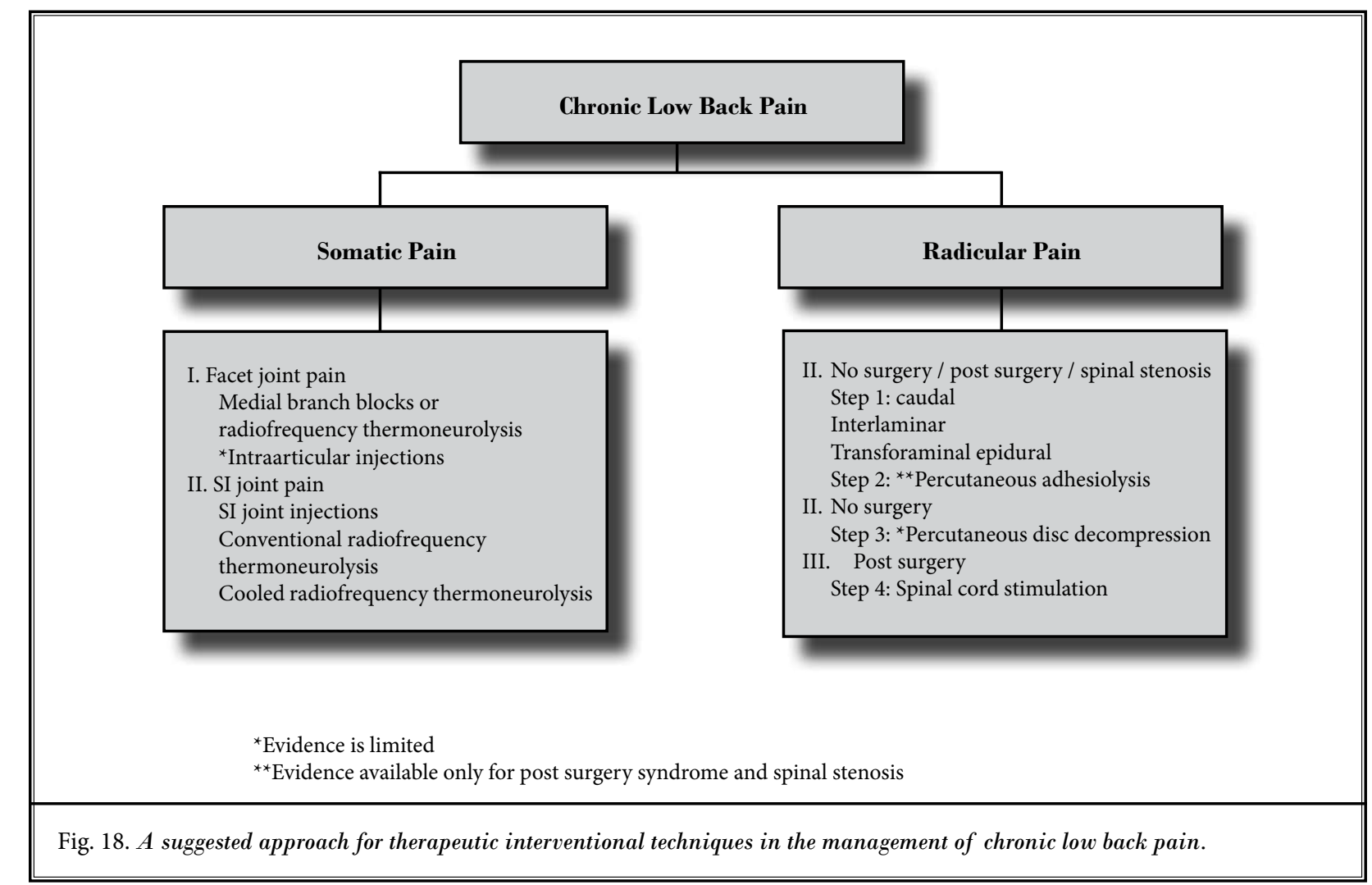



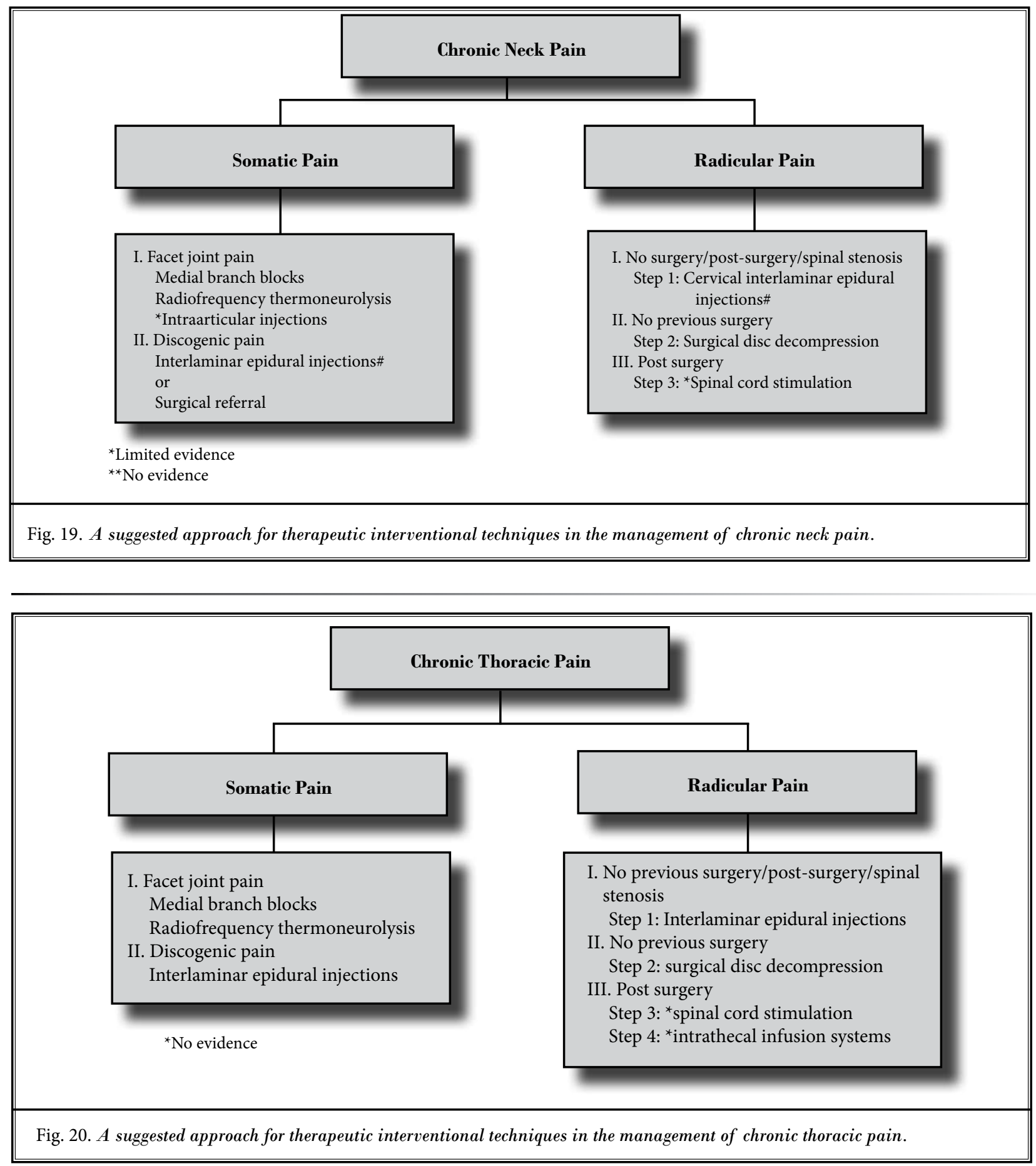

peutic facet joint nerve blocks, however radiofrequency neurotomy may be offered based on the emerging evidence and patients' preferences, values, and physician expertise.

\subsection{Type ANd Frequency of Facet Joint INTERVENTIONS}

Key Question 10: What are the guidelines for type and frequency of diagnostic and therapeutic 
facet joint interventions in managing chronic spinal pain?

The indications, frequency, and total number of interventions have been considered important issues, extensively debated, but poorly addressed. Numerous discordant approaches are often based on individual philosophy, highly variable interpretations of evidence with personal, academic, publication oriented, societal, philosophical, and economic bias. However, there is also overuse, occasional abuse, and rare fraud. Multiple changes have been made in these policies, not only by Medicare, Medicaid, and other governmental agencies, but also by private insurers with ever changing requirements. At the present time, there are requirements in performing these procedures without uniformity, even among Medicare carriers. Despite these investigations and changes, there has not been any significant reductions, instead increases have been made in utilization patterns and expenditures of radiofrequency neurotomy. Further, these reviews, recommendations, and opinions expressed are also debatable.

\subsection{Indications and Frequency}

Facet joint interventions are applied in the cervical, thoracic, and lumbar regions. These include diagnostic, as well as therapeutic interventions. Previous sections provide comprehensive descriptions of multiple aspects and extensive review of the evidence providing appropriate guidance with level of evidence and strength of recommendations for both diagnostic and therapeutic interventions. Further, the various approaches include intraarticular injections, facet joint nerve blocks, conventional radiofrequency neurotomy, and pulsed radiofrequency neurotomy. The evidence is variable for each modality and for each region. The indications described here apply for cervical, thoracic, and lumbar facet joint interventions.

\subsubsection{Diagnostic Facet Joint Nerve Blocks}

Diagnostic facet joint injections may be performed either with an intraarticular approach or by blocking the facet joint nerves. However, the evidence is limited to poor for intraarticular injections, thus the evidence here described is based on diagnostic facet joint nerve blocks. The evidence for diagnostic accuracy of facet joint nerve blocks is Level I to II in the lumbar spine, and Level II in thoracic and cervical spinal regions, with moderate to strong strength of recommendation in lumbar spine and moderate to strong strength of recommendations for thoracic and cervical spine regions.

Common indications for diagnostic facet joint nerve blocks are as follows:

- Somatic or nonradicular neck, mid back, upper back or low back and headache, upper extremity pain, chest wall pain or lower extremity pain of at least 3 months duration.

- Moderate to severe pain causing functional disability.

- $\quad$ Predominantly axial pain which may be associated with somatic upper extremity and lower extremity pain, but not associated with radiculopathy or neurogenic claudication.

- Absence of non-facet pathology that could explain the source of the patient's pain, such as fracture, tumor, infection, or significant spinal deformity.

- Failure to respond to more conservative management, including physical therapy modalities with exercises, chiropractic management, and nonsteroidal anti-inflammatory agents.

- Lack of predominant evidence of discogenic or sacroiliac joint pain.

- Clinical assessment that implicates facet joints as the source of pain based on axial pain and paravertebral or facet joint tenderness with absence of radicular pain, and relief with rest, often associated with worsening with extension.

\subsubsection{Therapeutic Facet Joint Intervention}

Therapeutic facet joint interventions are available for the cervical, thoracic, and lumbosacral regions. Therapeutic facet joint interventions include intraarticular injections, therapeutic facet joint nerve blocks, and radiofrequency neurotomy, either conventional or pulsed. The evidence is Level II for therapeutic facet joint nerve blocks in the lumbar, cervical, and thoracic regions, with strength of recommendation of moderate. The evidence is Level II for radiofrequency neurotomy in the lumbosacral region and in the cervical region with a strength of recommendation of moderate, and Level III in the thoracic region with a weak strength of recommendation. The evidence for intraarticular injections is Level IV to $\mathbf{V}$ in cervical, lumbar, and thoracic regions with a weak recommendation.

- Indications for therapeutic facet joint interventions are based on the diagnosis established with a positive concordant response to controlled diagnostic blocks, either placebo or comparative local anesthetic blocks, with a criterion standard of $80 \%$ 
pain relief with ability to perform painful movements without significant pain.

\subsubsection{Frequency of Interventions}

1. In the diagnostic phase, a patient may receive $2 \mathrm{ep}-$ isodes of diagnostic interventions no sooner than 3 weeks apart, with careful judgment of response.

2. In the therapeutic phase (after the diagnostic phase is completed), the suggested frequency would be 3 months or longer between therapeutic facet joint nerve blocks, provided that $\geq 50 \%$ relief is obtained for $2 \frac{1}{2} 2-3$ months.

3. For facet joint nerve ablation, the suggested frequency would be 6 months or longer (maximum of 2 times per year) between each procedure, provided that $50 \%$ or greater relief is obtained for $5-6$ months.

4. If the interventional procedures are applied for different regions, they may be performed at intervals of no sooner than one week or preferably 2 weeks for most types of procedures, if they are not allowed to be performed in one setting or contraindicated.

5. The therapeutic frequency for medial branch neurotomy should remain at intervals of at least 6 months per each region with multiple regions involved. It is further suggested that all regions be treated at the same time, provided all procedures are performed safely.

6. In the treatment or therapeutic phase, the interventional procedures should be repeated only as necessary according to the medical necessity criteria, and it is suggested that these be limited to a maximum of 4 times for local anesthetic and steroid blocks over a period of one year, per region.

7. Under unusual circumstances with a recurrent injury or cervicogenic headache, procedures may be repeated not exceeding 6 times in a year after stabilization in the treatment phase.

8. Cervical and thoracic are considered as one region and lumbar and sacral are considered as one region for billing purposes.

9. Diagnostic facet joint nerve blocks are required to be repeated only with intermittent trauma or changes in the pain pattern after successful treatment with therapeutic facet joint interventions.

\section{Acknowledgments}

The authors wish to thank Bert Fellows, MA, Direc- tor Emeritus of Psychological Services at Pain Management Centers of American, for manuscript review and Tonie M. Hatton and Diane E. Neihoff, transcriptionists, for their assistance in preparation of this manuscript. We would like to thank the editorial board of Pain Physician for review and criticism in improving the manuscript.

\section{Disclosures}

Dr. Calodney is a consultant for Medtronic, Stryker, Nevro, and Boston Scientific.

Dr. Christo reports personal fees from Daiichi Sankyo and GlaxoSmithKline.

Dr. Abd-Elsayed is a consultant for Medtronic, StimWave, and Avanos.

Dr. Jameson reports consulting and/or research fees from Abbott, Nevro, Boston Scientific, and Stimwave.

Dr. Kaye is a speaker for Merck.

Dr. Racz is a Consultant for and has family ownership of Epimed International, is a Consultant to Cosman RF Company, and has Medtronic patent issues.

Dr. Shah is a consultant for Masimo Corporation and a speaking consultant for Allergan Corporation.

Dr. Soin has authored manuscripts, in addition to this one, in relation with his work at Soin Neuroscience.

\section{Author Affiliations}

Laxmaiah Manchikanti, MD

Dr. Manchikanti is Co-Director, Pain Management Centers of America, Clinical Professor, Anesthesiology and Perioperative Medicine, University of Louisville, Louisville, KY, and Professor of AnesthesiologyResearch, Department of Anesthesiology, School of Medicine, LSU Health Sciences Center, New Orleans, LA

drlm@thepainmd.com

Alan D. Kaye, MD, PhD

Dr. Kaye is Vice-Chancellor of Academic Affairs, Chief Academic Officer, and Provost, Professor of Anesthesiology and Pharmacology, Toxicology, and Neurosciences, Louisiana State University Health Sciences Center, School of Medicine, Shreveport, LA, Professor of Anesthesiology and Pharmacology, LSU School of Medicine, New Orleans, LA, and Professor of Anesthesiology and Pharmacology, Tulane School of Medicine, New Orleans, LA

Amol Soin, MD

Dr. Soin is Medical Director, Ohio Pain Clinic, and 
Clinical Assistant Professor of Surgery at Wright State University, Dayton, $\mathrm{OH}$, USA.

Sheri L. Albers, DO

Dr. Albers is Director of Research, Radiology Research and Consultation, Sacramento, CA, USA

Douglas Beall, MD

Dr. Beall is Chief of Services, Clinical Radiology of Oklahoma, Oklahoma City, OK, USA

Richard Latchaw, MD

Dr. Latchaw is Director of Research, Radiology Research and Consultation, Sacramento, CA, USA

Mahendra Sanapati, MD

Dr. Sanapati is Co-Director, Pain Management Centers of America, Evansville, IN

Shalini Shah, MD

Dr. Shah is Vice-Chair, Dept. of Anesthesiology \& Perioperative Care; Enterprise Director, Pain Services, UCl Health Associate Clinical Professor, University of California Irvine, Orange, CA, USA

Sairam Atluri, MD

Dr. Atluri is Medical Director, Tri-State Spine Care Institute, Cincinnati, OH, USA

Alaa Abd-Elsayed, MD, MPH

Dr. Abd-Elsayed is Medical Director, UW Health Pain Services, and Associate Professor, Anesthesiology, University of Wisconsin School of Medicine and Public Health, Madison, WI, USA

Salahadin Abdi, MD, PhD

Dr. Abdi is Tenured Professor and Chair, Department of Pain Medicine, University of Texas, MD Anderson Cancer Center, Houston, TX.

Steve M. Aydin, DO

Dr. Aydin is Clinical Assistant Professor of PM\&R, Zucker School of Medicine at Hofstra Northwell Health, Manhasset, NY, USA and Chief of PM\&R and Interventional Pain Management, Kayal Orthopaedic Centers, PC, Glen Rock, NJ, USA

Sanjay Bakshi, MD

Dr. Bakshi is an interventional pain management physician at Lenox Hill Hospital, New York, NY, USA
Mark Boswell, MD, PhD

Dr. Boswell is Professor and Chairman, Pain Medicine, Department of Anesthesiology, University of Toledo College of Medicine and Life Sciences, Toledo, $\mathrm{OH}$.

Ricardo Buenaventura, MD

Dr. Buenaventura is Medical Director, Pain Relief of Dayton, Centerville, $\mathrm{OH}$, and Clinical Associate Professor, Department of Surgery, Wright State University School of Medicine, Dayton, $\mathrm{OH}$.

Joseph Cabaret, MD

Dr. Cabaret is founder \& CEO, Genesis Pain Specialists, Camarillo, CA, USA

Aaron K. Calodney, MD

Dr. Calodney is Director of Clinical Research, Precision Spine Care, Tyler, TX and Department of Anesthesiology, Louisiana State University, Shreveport, LA, USA

Kenneth D. Candido, M.D.

Dr. Candido is Chairman, Department of Anesthesiology, Advocate Illinois Masonic Medical Center and Professor of Clinical Anesthesia and Clinical Surgery, University of Illinois College of Medicine, Chicago, IL, USA

Paul J. Christo, MD

Dr. Christo is Associate Professor, Division of Pain Medicine, Department of Anesthesiology and Critical Care Medicine, Johns Hopkins University School of Medicine, Baltimore, MD, USA

Lynn Cintron, MD

Dr. Cintron, Dept. of Anesthesiology and Perioperative Care, Adjunct Associate Clinical Professor, University of California, Irvine School of Medicine, Irvine, CA, USA

Sudhir Diwan, MD

Dr. Diwan is President, Park Avenue Spine and Pain, New York, NY, USA

Christopher G. Gharibo, MD

Dr. Gharibo is Medical Director of Pain Medicine, NYU Langone Health, Associate Professor of Anesthesiology, Peri-Operative Care \& Pain Medicine, and Associate Professor of Orthopedics, NYU School of Medicine, New York, NY, USA.

Jay Grider, DO, PhD 
Dr. Grider, University of Kentucky Department of Anesthesiology, Division of Pain Medicine, Lexington, KY, USA

Myank Gupta, MD

Dr. Gupta is President \& CEO, Kansas Pain Management \& Neuroscience Research Center, LLC, Overland Park, KS, and Adjunct Clinical Assistant Professor, Anesthesiology and Pain Medicine, Kansas City University of Medicine and Biosciences, Kansas City, MO

Bill Haney, MD

Dr. Haney is an interventional pain physician, Pain Management Centers of Paducah, Louisville, KY, USA

Michael E. Harned, MD

Dr. Harned is Associate Professor, Department of Anesthesiology, University of Kentucky, Lexington, KY, USA

Standiford Helm II, MD

Dr. Helm is Medical Director, The Helm Center for Pain Management, Laguna Woods, CA, USAdrhelm@ thehelmcenter.com

Jessica Jameson MD

Dr. Jameson, owner, Axis Spine Center, Coeur d'Alene, ID, USA

Sunny Jha, MD

Dr. Jha is Assistant Clinical Professor of Anesthesiology, University of Southern California, Los Angeles, CA, USA

Adam M. Kaye, PharmD, FASCP, FCPhA

Dr. AM Kaye is Clinical Professor of Pharmacy, Department of Pharmacy Practice, Thomas J. Long School of Pharmacy and Health Sciences, University of the Pacific, Stockton, CA

Nebojsa Nick Knezevic, MD, PhD

Dr. Knezevic is Vice Chair for Research and Education; Department of Anesthesiology; Advocate Illinois Masonic Medical Center, Chicago, IL and Clinical Associate Professor, Department of Anesthesiology and Surgery, and Clinical Associate Professor of Surgery, College of Medicine, University of Illinois, Chicago, IL, USA

Radomir Kosanovic, MD

Dr. Kosanovic is an Interventional Pain Physician at the Pain Management Centers of America, Paducah, KY, USA.

Maanasa V. Manchikanti

Maanasa Manchikanti is a student at the University of Kentucky, Lexington, KY, USA

Annu Navani, MD

Dr. Navani is Medical Director, Comprehensive Spine \& Sports Center, and Advisor, Le Reve Regenerative Wellness, Campbell, CA, USA

Vidyasagar Pampati, MSc

Vidyasagar Pampati is a Statistician, Pain Management Centers of America, Paducah, KY.

Ramarao Pasupuleti, MD

Dr. Pasupuleti is President, Center for Pain Management, Bowling Green, KY, USA.

Cyril Philip, MD

Dr. Philip is Medical Director, Interventional Pain Management Physician, Advocate Aurora Healthcare, Kenosha, WI, USA med_cyrilphilip@yahoo.com

Gabor B. Racz, MD

Dr. Racz is Professor and Chairman Emeritus Anesthesiology, Texas Tech University Health Sciences Center, Lubbock, Texas.

Kartic Rajput, MD

Dr. Rajput, Sutter Gould Medical Foundation, Stockton, CA, USA

Nalini Sehgal, MD

Dr. Sehgal is Chair Division of Rehabilitation Medicine, Vice Chair Department of Orthopedics \& Rehabilitation, University of Wisconsin School of Medicine \& Public Health, and Program Director, Pain Medicine (Multidisciplinary) Fellowship Program, University of Wisconsin, UW Health, Madison, WI, USA

Gururau Sudarshan, MD

Dr. Sudarshan is President and CEO, Cincinnati Pain Management Consultants, Cincinnati, $\mathrm{OH}$.

Rachana Vanaparthy, MBBS

Dr. Vanaparthy is an Experiential Volunteer, Oregon Health and Science University, Portland, OR, USA 
Bradley W. Wargo, DO

Dr. Wargo is an Interventional Pain Management Physician, Crosstown Back \& Pain Institute, Baptist Regional Medical Center, Memphis, TN, and Adjunct Clinical Associate Professor, Kansas Health Science Center, Department of Anesthesiology and Pain Medicine, Wichita, KS, USA
Joshua A. Hirsch, MD

Dr. Hirsch is Vice Chair and Service Line Chief of Neurointerventional Radiology, Chief of Neurointerventional Spine, Massachusetts General Hospital and Harvard Medical School, Boston, MA 


\section{Access Appendices Tables here:}

Appendix Table 1

Appendix Table 2

Appendix Table 3

Appendix Table 4 


\section{References}

1. U.S. Burden of Disease Collaborators. The state of US health, 1990 - 2010: Burden of diseases, injuries, and risk factors. JAMA 2013; 310:591-608.

2. Hoy DG, Bain C, Williams G, et al. A systematic review of the global prevalence of low back pain. Arthritis Rheum 2012; 64:2028-2037.

3. Hoy DG, Protani M, De R, Buchbinder R. The epidemiology of neck pain. Best Pract Res Clin Rheumatol 2010; 24:783-792.

4. Navani A, Manchikanti L, Albers SL, et al. Responsible, safe, and effective use of biologics in the management of low back pain: American Society of Interventional Pain Physicians (ASIPP) guidelines. Pain Physician 2019; 22:S1-S74.

5. Manchikanti L, Kaye AM, Knezevic NN, et al. Responsible, safe, and effective prescription of opioids for chronic non-cancer pain: American Society of Interventional Pain Physicians (ASIPP) guidelines. Pain Physician 2017; 20: $\mathrm{S}_{3}-\mathrm{S}_{92}$.

6. Manchikanti L, Abdi S, Atluri S, et al. An update of comprehensive evidencebased guidelines for interventional techniques of chronic spinal pain: Part II: Guidance and recommendations. Pain Physician 2013; 16:S49-S283.

7. Dieleman JL, Baral R, Birger M, et al. US spending on personal health care and public health, 1996-2013. JAMA 2016; 316:2627-2646.

8. Dieleman JL, Cao J, Chapin A, et al. US health care spending by payer and health condition, 1996-2016. JAMA 2020; 323:863-884.

9. Manchikanti L, Singh V, Falco FJE, Benyamin RM, Hirsch JA. Epidemiology of low back pain in adults. Neuromodulation 2014; 17:3-10.

10. Bekkering GE, Bala MM, Reid K, et al. Epidemiology of chronic pain and its treatment in The Netherlands. Neth J Med 2011; 69:141-153.

11. Roberts SB, Calligeros K, Tsirikos Al. Evaluation and management of paediatric and adolescent back pain: Epidemiology, presentation, investigation, and clinical management: A narrative review. J Back Musculoskelet Rehabil 2019; 32:955-988.

12. Johansson MS, Jensen Stochkendahl M, Hartvigsen J, Boyle E, Cassidy JD. Incidence and prognosis of midback pain in the general population: A systematic review. Eur J Pain 2017; 21:20-28.

13. Ragab A, Deshazo RD. Management of back pain in patients with previous back surgery. Am J Med 2008; 121:272-278.

14. Umer W, Antwi-Afari MF, Li H, Szeto GPY, Wong AYL. The prevalence of musculoskeletal symptoms in the construction industry: A systematic review and meta-analysis. Int Arch Occup Environ Health 2018; 91:125-144.

15. Jun D, Zoe M, Johnston V, O'Leary S. Physical risk factors for developing nonspecific neck pain in office workers: A systematic review and meta-analysis. Int Arch Occup Environ Health 2017; 90:373-410.

16. Yang $\mathrm{H}$, Haldeman $\mathrm{S}$. Chronic spinal pain and financial worries in the US adult population. Spine (Phila Pa 1976) 2020; 45:528-533.

17. Osborn R, Doty MM, Moulds D, Sarnak DO, Shah A. Older Americans were sicker and faced more financial barriers to health care than counterparts in other countries. Health Aff (Millwood) 2017; 36:2123-2132.

18. Boswell MV, Manchikanti L, Kaye AD, et al. A best-evidence systematic appraisal of the diagnostic accuracy and utility of facet (zygapophysial) joint injections in chronic spinal pain. Pain Physician 2015; 18:E497-E533.

19. Manchikanti L, Kaye AD, Boswell MV, et al. A systematic review and best evidence synthesis of the effectiveness of therapeutic facet joint interventions in managing chronic spinal pain. Pain Physician 2015; 18: E535-E582.

20. Manchikanti L, Soin A, Benyamin RM, et al. An update of the systematic appraisal of the accuracy and utility of discography in chronic spinal pain. Pain Physician 2018; 21:91-110.

21. Simopoulos TT, Manchikanti L, Gupta S, et al. Systematic review of the diagnostic accuracy and therapeutic effectiveness of sacroiliac joint interventions. Pain Physician 2015; 18:E713-E756.

22. Manchikanti L, Hirsch JA, Falco FJE, Boswell MF. Management of lumbar zygapophysial (facet) joint pain. World J Orthop 2016; 7:315-337.

23. Cohen SP, Bhaskar A, Bhatia A, et al. Consensus practice guidelines on interventions for lumbar facet joint pain from a multispecialty, international working group. Reg Anesth Pain Med 2020 [Epub ahead of print]

24. Manchikanti L, Hirsch JA, Kaye AD, Boswell MV. Cervical zygapophysial (facet) joint pain: Effectiveness of interventional management strategies.
Postgrad Med 2016; 128:54-68.

25. Kuslich SD, Ulstrom CL, Michael CJ. The tissue origin of low back pain and sciatica: A report of pain response to tissue stimulation during operation on the lumbar spine using local anesthesia. Orthop Clin North Am 1991; 22:181-187.

26. Choi KC, Shim HK, Kim JS, et al. Costeffectiveness of microdiscectomy versus endoscopic discectomy for lumbar disc herniation. Spine J 2019; 19:1162-1169.

27. Chen Z, Zhang L, Dong J, et al. Percutaneous transforaminal endoscopic discectomy versus microendoscopic discectomy for lumbar disc herniation: Two-year results of a randomized controlled trial. Spine (Phila $\mathrm{Pa} \mathrm{1976)} \mathrm{2020;} \mathrm{45:493-503.}$

28. Manchikanti L, Knezevic NN, Sanapati $M R$, Boswell MV, Kaye AD, Hirsch JA. Effectiveness of percutaneous adhesiolysis in managing chronic central lumbar spinal stenosis: A systematic review and meta-analysis. Pain Physician 2019; 22:E523-E550.

29. Manchikanti L, Soin A, Boswell MV, Kaye AD, Sanapati M, Hirsch JA. Effectiveness of percutaneous adhesiolysis in post lumbar surgery syndrome: A systematic analysis of findings of systematic reviews. Pain Physician 2019; 22:307-322.

30. Lee $J \mathrm{H}$, Shin KS, Park SJ, et al. Comparison of clinical efficacy between transforaminal and interlaminar epidural injections in lumbosacral disc herniation: A systematic review and meta-analysis. Pain Physician 2018; 21:433-448.

31. Lee JH, Kim DH, Kim DH, et al. Comparison of clinical efficacy of epidural injection with or without steroid in lumbosacral disc herniation: A systematic review and meta-analysis. Pain Physician 2018; 21:449-468.

32. Manchikanti L, Nampiaparampil DE, Manchikanti KN, et al. Comparison of the efficacy of saline, local anesthetics, and steroids in epidural and facet joint injections for the management of spinal pain: A systematic review of randomized controlled trials. Surg Neurol Int 2015; 6:S194-S235.

33. Lee $\mathrm{CH}$, Chung $\mathrm{CK}$, Kim $\mathrm{CH}$. The efficacy of conventional radiofrequency denervation in patients with chronic low back pain originating from the facet joints: a meta-analysis of randomized controlled trials. Spine J 2017; 17:1770-1780.

34. Maas ET, Ostelo RW, Niemisto L, et al. Radiofrequency denervation for chronic 
low back pain. Cochrane Database Syst Rev 2015; 10:CDoo8572.

35. Engel A, Rappard G, King W, Kennedy DJ; Standards Division of the International Spine Intervention Society. The effectiveness and risks of fluoroscopically-guided cervical medial branch thermal radiofrequency neurotomy: A systematic review with comprehensive analysis of the published data. Pain Med 2016; 17:658-669.

36. Juch JNS, Maas ET, Ostelo RWJG, et al. Effect of radiofrequency denervation on pain intensity among patients with chronic low back pain: The Mint randomized clinical trials. JAMA 2017; 318:68-81.

37. Chou R, Côté P, Randhawa K, et al. The global spine care initiative: Applying evidence-based guidelines on the non-invasive management of back and neck pain to low- and middleincome communities. Eur Spine ] 2018; 27:851-860.

38. Song K, Li Z, Shuang F, et al. Comparison of the effectiveness of radiofrequency neurotomy and endoscopic neurotomy of lumbar medial branch for facetogenic chronic low back pain: A randomized controlled trial. World Neurosurg 2019; 126:e109-e115.

39. Ellard DR, Underwood M, Achana F, et al. Facet joint injections for people with persistent non-specific low back pain (Facet Injection Study): a feasibility study for a randomised controlled trial. Health Technol Assess 2017; 21:1-184.

40. Manchikanti L, Centeno CJ, Atluri S, et al. Bone marrow concentrate (bmc) therapy in musculoskeletal disorders: Evidencebased policy position statement of American Society of Interventional Pain Physicians (ASIPP). Pain Physician 2020; 23:E85-E131.

41. Leschke JM, Chen CC. Supplementing decompression with instrumented fusion for symptomatic lumbar spinal stenosis-a critical appraisal of available randomized controlled trials. Neurosurg Rev 2020 Mar 2. [Epub ahead of print]

42. Chou R, Hashimoto R, Friedly J, et al. Pain Management Injection Therapies for Low Back Pain. Technology Assessment Report ESIBo813. (Prepared by the Pacific Northwest Evidencebased Practice Center under Contract No. HHSA 290-2012-00014-I.) Rockville, MD: Agency for Healthcare Research and Quality; July 10, 2015.

43. Chou R, Hashimoto R, Friedly J, et al. Epidural corticosteroid injections for radiculopathy and spinal stenosis: $A$ systematic review and meta-analysis. Ann Intern Med 2015; 163:373-381.

44. Kim CH, Chung CK, Park CS, Choi B, Kim MJ, Park BJ. Reoperation rate after surgery for lumbar herniated intervertebral disc disease: Nationwide cohort study. Spine (Phila Pa 1976) 2013; 38:581-590.

45. Rushton A, Heneghan NR, Heymans MW, Staal JB, Goodwin P. Clinical course of pain and disability following primary lumbar discectomy: Systematic review and meta-analysis. Eur Spine J 2020 Jan 8. [Epub ahead of print]

46. Best MJ, Buller LT, Eismont FJ. National trends in ambulatory surgery for intervertebral disc disorders and spinal stenosis: A 12-year analysis of the national surveys of ambulatory surgery. Spine (Phila Pa 1976) 2015; 40:1703-1711.

47. Shen J, Xu S, Xu S, Ye S, Hao J. Fusion or not for degenerative lumbar spinal stenosis: A meta-analysis and systematic review. Pain Physician 2018; 21:1-8.

48. Yin S, Du H, Yang W, Duan C, Feng $\mathrm{C}$, Tao $\mathrm{H}$. Prevalence of recurrent herniation following percutaneous endoscopic lumbar discectomy: A metaanalysis. Pain Physician 2018; 21:337-350.

49. Tran ZV, Ivashchenko A, Brooks L. Sacroiliac joint fusion methodology minimally invasive compared to screwtype surgeries: A systematic review and meta-analysis. Pain Physician 2019; 22:29-40.

50. Wu PF, Li YW, Wang B, Jiang B, Tu ZM, Lv $\mathrm{GH}$. Posterior cervical foraminotomy via full-endoscopic versus microendoscopic approach for radiculopathy: A systematic review and meta-analysis. Pain Physician 2019; 22:41-52.

51. Mao Y, Li Y, Cui X. Percutaneous endoscopic debridement and drainage for spinal infection: Systemic review and meta-analysis. Pain Physician 2019; 22:323-330.

52. Li Z, Chen L, Li B, Wei J. Efficacy and safety of surgical interventions for treating multilevel cervical spondylotic myelopathy via anterior approach: A network meta-analysis. Pain Physician 2019; 22:E275-E286.

53. Xiao CM, Yu KX, Deng R, et al. Modified K-hole percutaneous endoscopic surgery for cervical foraminal stenosis: partial pediculectomy approach. Pain Physician 2019; 22:E407-E416.

54. Lad SP, Babu R, Ugiliweneza B, Patil CG, Boakye M. Surgery for spinal stenosis: Long-term reoperation rates, health care cost, and impact of instrumentation. Spine (Phila Pa 1976) 2014; 39:978-987.
55. Singh K, Nandyala SV, Marquez-Lara A, Fineberg SJ. Epidemiological trends in the utilization of bone morphogenetic protein in spinal fusions from 2002 to 2011. Spine (Phila Pa 1976) 2014; 39:491-496.

56. Rajaee SS, Kanim LE, Bae HW. National trends in revision spinal fusion in the USA: Patient characteristics and complications. Bone Joint J 2014; 96-B:807-816.

57. O'Gara T, Kemper KJ, Birkedal J, Curl W, Miller N, Abadie B. Survey of conventional and complementary and alternative therapy in patients with low back pain. J Surg Orthop Adv 2016; 25:27-33.

58. Karvelas DA, Rundell SD, Friedly JL, et al. Subsequent health-care utilization associated with early physical therapy for new episodes of low back pain in older adults. Spine J 2017; 17:380-389.

59. Rajaee SS, Bae HW, Kanim LE, Delamarter RB. Spinal fusion in the United States: Analysis of trends from 1998 to 2008. Spine (Phila Pa 1976) 2012; 37:67-76.

6o. Bae HW, Rajaee SS, Kanim LE. Nationwide trends in the surgical management of lumbar spinal stenosis. Spine (Phila Pa 1976). 2013; 38:916-926.

61. Moore A, Wiffen P, Kalso E. Antiepileptic drugs for neuropathic pain and fibromyalgia. JAMA 2014; 312:182-183.

62. Sclafani JA, Constantin A, Ho PS, Akuthota V, Chan L. Descriptive analysis of spinal neuroaxial injections, surgical interventions, and physical therapy utilization for degenerative lumbar spondylolisthesis within Medicare beneficiaries from 2000 to 2011 . Spine (Phila Pa 1976) 2017; 42:240-246.

63. Pannell WC, Savin DD, Scott TP, Wang JC, Daubs MD. Trends in the surgical treatment of lumbar spine disease in the United States. Spine J 2015; 15:1719-1727.

64. Al Jammal OM, Delavar A, Maguire KR, et al. National trends in the surgical management of lumbar spinal stenosis in adult spinal deformity patients. Spine (Phila Pa 1976) 2019; 44:E1369-E1378.

65. Jain N, Phillips FM, Shimer AL, Khan SN. Surgeon reimbursement relative to hospital payments for spinal fusion: Trends from 10-year Medicare analysis. Spine (Phila Pa 1976) 2018; 43:720-731.

66. Raad M, Reidler JS, EI Dafrawy $\mathrm{MH}$, et al. US regional variations in rates, outcomes, and costs of spinal arthrodesis for lumbar spinal stenosis in working adults aged 40-65 years. J Neurosurg Spine 2018; 30:83-90. 
67. Machado GC, Maher CG, Ferreira PH, et al. Trends, complications, and costs for hospital admission and surgery for lumbar spinal stenosis. Spine (Phila Pa 1976) 2017; 42:1737-1743.

68. Amirdelfan K, Webster L, Poree L, Sukul V, McRoberts P. Treatment options for failed back surgery syndrome patients with refractory chronic pain: An evidence based approach. Spine (Phila $\mathrm{Pa}$ 1976) 2017; 42:S41-S52.

69. Gaudin D, Krafcik BM, Mansour TR, Alnemari A. Considerations in spinal fusion surgery for chronic lumbar pain: Psychosocial factors, rating scales, and perioperative patient education-a review of the literature. World Neurosurg 2017; 98:21-27.

70. Chou R, Hartung D, Turner J, et al. Opioid Treatments for Chronic Pain. Comparative Effectiveness Review, No 229. AHRQ Publication No. 20-EHCo11. Rockville, MD: Agency for Healthcare Research and Quality. April 2020.

71. McDonagh MS, Selph SS, Buckley DI, et al. Nonopioid Pharamacologic Treatments for Chronic Pain. Comparative Effectiveness Review, No. 228. AHRQ Publication No. 20-EHCo1o. Rockville, MD: Agency for Healthcare Research and Quality. April 2020.

72. Skelly AC, Chou R, Dettori JR, et al. Noninvasive Nonpharmacological Treatment for Chronic Pain: A Systematic Review Update. Comparative Effectiveness Review, No. 227. AHRQ Publication No. 20-EHCoog. Rockville, MD: Agency for Healthcare Research and Quality. April 2020.

73. Maas ET, van Dongen JM, Juch JNS, et al. Randomized controlled trials reflected clinical practice when comparing the course of low back pain symptoms in similar populations. J Clin Epidemiol 2019; 116:122-132.

74. Coulter ID, Crawford C, Vernon H, et al. Manipulation and mobilization for treating chronic nonspecific neck pain: A systematic review and meta-analysis for an appropriateness panel. Pain Physician 2019; 22:E55-E70.

75. Vorobeychik $\mathrm{Y}$, Stojanovic MP, McCormick ZL. Radiofrequency denervation for chronic low back pain. JAMA 2017; 318:2254-2255.

76. Rimmalapudi V, Buchalter J, Calodney A. Radiofrequency denervation for chronic low back pain. JAMA 2017; 318:2255-2256.

77. Kao MC, Leong MS, Mackey S. radiofrequency denervation for chronic low back pain. JAMA 2017; 318:2256.
78. Kapural L, Provenzano D, Narouze S. RE: Juch JNS, et al. Effect of Radiofrequency Denervation on Pain Intensity Among Patients With Chronic Low Back Pain: The Mint Randomized Clinical Trials. JAMA 2017;318(1):68-81. Neuromodulation 2017; 20:844.

79. van Kuijk SMJ, Van Zundert J, Hans $\mathrm{G}$, et al J. Flawed study design and incorrect presentation of data negatively impact potentially useful interventional treatments for patients with low back pain: A critical review of JAMA's MinT Study. Pain Pract 2018; 18:292-295.

80. Argyriou AA, Anastopoulou GG, Bruna J. Inconclusive evidence to support the use of minimally-invasive radiofrequency denervation against chronic low back pain. Ann Transl Med 2018; 6:127.

81. Provenzano DA, Buvanendran A, De Leon-Casasola $O$, Narouze $S$, Cohen SP. Interpreting the MINT randomized clinical trials: Let us stick to the facts. Reg Anesth Pain Med 2020; 45:84-86.

82. Provenzano DA, Buvanendran A, de León-Casasola OA, Narouze S, Cohen SP. Interpreting the MINT randomized trials evaluating radiofrequency ablation for lumbar facet and sacroiliac joint pain: A call from ASRA for better education, study design, and performance. Reg Anesth Pain Med 2018; 43:68-71.

83. Manchikanti L, Sanapati MR, Pampati V, Boswell MV, Kaye AD, Hirsch JA. Update on reversal and decline of growth of utilization of interventional techniques in managing chronic pain in the Medicare population from 2000 to 2018. Pain Physician 2019; 22:521-536.

84. Manchikanti L, Soin A, Mann DP, et al. Utilization patterns of facet joint interventions in managing spinal pain: A retrospective cohort study in the US fee-for-service Medicare population. Curr Pain Headache Rep 2019; 23:73.

85. Manchikanti L, Sanapati MR, Pampati $V$, et al. Update of utilization patterns of facet joint interventions in managing spinal pain from 2000 to 2018 in the US fee-for-service Medicare population. Pain Physician 2020; 23:E133-E149.

86. Manchikanti L, Soin A, Mann DP, Bakshi S, Pampati V, Hirsch JA. Comparative analysis of utilization of epidural procedures in managing chronic pain in the Medicare population: Pre and post Affordable Care Act. Spine (Phila Pa 1976) 2019; 44:220-232.

87. Manchikanti L, Sanapati MR, Soin A, et al. An updated analysis of utilization of epidural procedures in managing chronic pain in the Medicare population from 2000 to 2018. Pain Physician 2020; 23:111-126.

88. Starr JB, Gold L, McCormick Z, Suri P, Friedly J. Trends in lumbar radiofrequency ablation utilization from 2007 to 2016. Spine J 2019; 19:1019-1028.

89. Manchikanti L, Pampati V, Benyamin RM, Hirsch JA. Declining utilization of percutaneous epidural adhesiolysis in Medicare population: Evidence-based or over-regulated? IPM Reports 2018; 2:9-18.

90. Manchikanti MV, Manchikanti L, Kaye AD, Pampati V, Hirsch JA. Usage patterns of sacroiliac joint injections - a comparative evaluation of pre and post Affordable Care Act in Medicare population. IPM Reports 2018; 2:157-166.

91. Manchikanti L, Sanapati J, Pampati V, Kaye AD, Hirsch JA. Utilization of vertebral augmentation procedures in the United States: A comparative analysis in medicare fee-for-service population pre- and post-2009 trials. Curr Pain Headache Rep 2020; 24:22.

92. Shanthanna $H$, Bhatia A, Radhakrishna $M$, et al. Interventional pain management for chronic pain: a survey of physicians in Canada. Can J Anaesth 2020; 67:343-352.

93. Gupta S, Sharma M. Interventional pain medicine practice in the UK and the USA: A survey of 242 pain physicians. Pain Physician 2020; 23:127-134.

94. Ribeiro $L H$, Furtado RN, Konai MS, Andreo AB, Rosenfeld A, Natour J. Effect of facet joint injection versus systemic steroids in low back pain: A randomized controlled trial. Spine (Phila Pa 1976) 2013; 38:1995-2002.

95. Cohen SP, Doshi TL, Constantinescu $\mathrm{OC}$, et al. Effectiveness of lumbar facet joint blocks and predictive value before radiofrequency denervation: The Facet Treatment Study (FACTS), a randomized, controlled clinical trial. Anesthesiology 2018; 129:517-535.

96. Manchikanti L, Pampati V, Kaye AD, Hirsch JA. Cost utility analysis of cervical therapeutic medial branch blocks in managing chronic neck pain. Int J Med Sci 2017; 14:1307-1316.

97. Manchikanti L, Pampati V, Kaye AD, Hirsch JA. Therapeutic lumbar facet joint nerve blocks in the treatment of chronic low back pain: Cost utility analysis based on a randomized controlled trial. Korean J Pain 2018; 31:27-38.

98. Manchikanti L, Pampati V, Sanapti SP, Sanapati MR, Kaye AD, Hirsch JA. Evaluation of cost-utility of thoracic interlaminar epidural injections. Curr 
Pain Headache Rep 2020; 24:5.

99. Manchikanti L, Pampati V, Parr III A, et al. Cervical interlaminar epidura injections in the treatment of cervical disc herniation, post surgery syndrome, or discogenic pain: Cost utility analysis from randomized trials. Pain Physician 2019; 22:421-431.

100. Manchikanti L, Pampati V, Benyamin RM, Hirsch JA. Cost utility analysis of lumbar interlaminar epidural injections in the treatment of lumbar disc herniation, central spinal stenosis, and axial or discogenic low back pain. Pain Physician 2017; 20:219-228.

101. Manchikanti L, Falco FJE, Pampati V, Cash KA, Benyamin RM, Hirsch JA. Cost utility analysis of caudal epidural injections in the treatment of lumbar disc herniation, axial or discogenic low back pain, central spinal stenosis, and post lumbar surgery syndrome. Pain Physician 2013; 16:E129-E143.

102. Manchikanti L, Helm S II, Pampati V, Racz GB. Cost utility analysis of percutaneous adhesiolysis in managing pain of post-lumbar surgery syndrome and lumbar central spinal stenosis. Pain Pract 2015; 15:414-422.

103. Manchikanti L, Helm S 2nd, Benyamin $\mathrm{RM}$, et al. A critical analysis of Obamacare: affordable care or insurance for many and coverage for few? Pain Physician 2017; 20:111-138.

104. Obama B. United States health care reform: Progress to date and next steps. JAMA 2016; 316:525-532.

105. Selden TM, Lipton BJ, Decker SL. Medicaid expansion and marketplace eligibility both increased coverage, with trade-offs in access, affordability. Health Aff (Millwood) 2017; 36:2069-2077.

106. Cannon MF. Is Obamacare harming quality? (Part 1). Health affairs blog, January 4, 2018. https:// www.healthaffairs.org/do/10.1377/ hblog20180103.261091/full/

107. Blumenthal D, Collins SR, Fowler EJ. The Affordable Care Act at 10 Years - Its coverage and access provisions. $N$ Engl J Med 2020; 382:963-969.

108. Manchikanti L, Falco FJE, Benyamin RM, Gharibo CG, Candido KD, Hirsch JA. Epidural steroid injections safety recommendations by the MultiSociety Pain Workgroup (MPW): More regulations without evidence or clarification. Pain Physician 2014; 17: $E_{575}-E_{588 .}$

109. Kaye AD, Manchikanti L, Novitch $M B$, et al. Responsible, safe, and effective use of antithrombotics and anticoagulants in patients undergoing interventional techniques: American Society of Interventional Pain Physicians (ASIPP) guidelines. Pain Physician 2019; 22:S75-S128.

110. Kaye AD, Jones MR, Viswanath $\mathrm{O}$, et al. ASIPP guidelines for sedation and fasting status of patients undergoing interventional pain management procedures. Pain Physician 2019; 22:201-207.

111. The National Uniform Claims Committee. Specialty Designation for Interventional Pain Management- o9.

www.cms.hhs.gov/transmittals/Downloads/ r1779b3.pdf

112. Medicare Payment Advisory Commission. Report to the Congress: Paying for interventional pain services in ambulatory settings. Washington, DC: Med- PAC. December. 2001.

http://www.medpac.gov/documents/reports/ december-2001-report-to-thecongresspaying-for-interventionalpain-servicesin-ambulatory-settings.pdf?sfvrsn=0

113. Argyriou C, Georgiadis GS, Georgakarakos EI, et al. Applying evidence-based medicine in actual clinical practice: Can we bridge the gap? A Review of the Literature. Hellenic J Cardiol 2015; 56:373-378.

114. Choi SJ, Jeong WK, Jo AJ, et al. Methodology for developing evidencebased clinical imaging guidelines: Joint Recommendations by Korean Society of Radiology and National EvidenceBased Healthcare Collaborating Agency. Korean J Radiol 2017; 18:208-216.

115. Fehlings MG, Nater A. Development and implementation of guidelines in neurosurgery. Neurosurg Clin $N$ Am 2015; 26:271-282.

116. Murad MH. Clinical Practice Guidelines: A Primer on development and dissemination. Mayo Clin Proc 2017; 92:423-433.

117. Becker M, Neugebauer EA, Eikermann M. Partial updating of clinical practice guidelines often makes more sense than full updating: A systematic review on methods and the development of an updating procedure. J Clin Epidemiol 2014; 67:33-45.

118. Graham R, Mancher M, Wolman DM, Greenfield S, Steinberg E (eds); Committee on Standards for Developing Trustworthy Clinical Practice Guidelines; Institute of Medicine. Clinical Practice Guidelines We Can Trust. The National Academies Press, Washington, DC,
2011.

119. National Guideline Clearinghouse Extent Adherence to Trustworthy Standards (NEATS) instrument.

www.ncbi.nlm.nih.gov/pubmedhealth/ PMHoo79458/

120. Harris RP, Helfand $M$, Woolf $\mathrm{SH}$, et al; Methods Work Group, Third US Preventive Services Task Force. Current methods of the US Preventive Services Task Force. Am J Prevent Med 2001; 20:21-35.

121. Manchikanti L, Falco FJE, Benyamin RM, Kaye AD, Boswell MV, Hirsch JA. A modified approach to grading of evidence. Pain Physician 2014; 17:E319-E325.

122. Centers for Medicare \& Medicaid Services NHE Fact Sheet. https://www. cms.gov/research-statistics-data-andsystems/statistics-trendsand-reports/ nationalhealthexpenddata/nhe-factsheet.html

123. Sisko AM, Truffer CJ, Keehan SP, Poisal JA, Clemens MK, Madison AJ. National health spending projections: The estimated impact of reform through 2019. Health Aff (Millwood) 2010; 29:1933-1941.

124. Centers for Medicare \& Medicaid Services. Historical. Published January 8, 2018. Accessed October 17, 2018.

https://www.cms.gov/ResearchStatistics-Data-and-Systems/ Statistics-Trends-and-Reports/ $\mathrm{NationalHealthExpendData/}$ NationalHealthAccountsHistorical.html

125. Dieleman JL, Squires E, Bui AL, et al. Factors associated with increase in US health care spending, 1996-2013. JAMA 2017; 318:1668-1678.

126. Cavallo JJ, Forman HP. The economic impact of the COVID-19 pandemic on radiology practices. Radiology $2020 \mathrm{Apr}$ 15. [Epub ahead of print]

127. Nicola M, Alsafi Z, Sohrabi C, et al. The Socio-Economic Implications of the Coronavirus and COVID-19 Pandemic: A Review. Int J Surg 2020: 20:30316-30320.

128. Cox C, Rudowitz R, Neuman T, Cubanski J, Rae M. How health costs might change with COVID-19. Health System Tracker April 15, 2020.

https://www.healthsystemtracker.org/brief/ how-health-costs-might-change-withcovid-19/

129. Nguyen TH, Milburn JM, Duszak R, Savoie J, HorDy M, Hirsch JA. Medicare for All: Considerations for Neuroradiologists. AJNR Am J Neuroradiol 2020 [Epub ahead of print]. 
130. Burrill S. 202 will likely be the year of the consumer for health plans and health systems. Deloitte Insights. December 10, 2019.

https://www2.deloitte.com/us/en/blog/ health-care-blog/2019/year-ofconsumer.html

131. Holmes EA, O'Connor RC, Perry VH, et al. Multidisciplinary research priorities for the COVID-19 pandemic: A call for action for mental health science. Lancet Psychiatry 2020; S2215-0366(20)30168-1.

132. Vaccaro AR, Getz CL, Cohen BE, Cole BJ, Donnally CJ 3 rd. Practice management during the COVID-19 pandemic. J Am Acad Orthop Surg 2020 Apr 13. [Epub ahead of print]

133. Puliatti S, Eissa A, Eissa R, et al. COVID-19 and Urology: A comprehensive review of the literature. B]U Int 2020 Apr 6. [Epub ahead of print]

134. Ayittey FK, Ayittey MK, Chiwero NB, Kamasah JS, Dzuvor C. Economic impacts of Wuhan 2019-nCoV on China and the world. J Med Virol 2020; 92:473-475.

135. Hilsenrath PE. Ethics and economic growth in the age of COVID 19: What is a just society to do? J Rural Health 2020 Apr 3. [Epub ahead of print]

136. Kabir M, Afzal MS, Khan A, Ahmed H. COVID-19 pandemic and economic cost; Impact on forcibly displaced people. Travel Med Infect Dis 2020 Apr 6. [Epub ahead of print]

137. Phelps A, Thomas S, Cruse CB. Setting the stage for Medicare for all and the health coverage debate. Deloitte Insights. January 29, 2020.

https://www2.deloitte.com/content/dam/ insights/us/articles/6400_Medicare-forall/DI_Medicare\%2ofor\%2oall.pdf

138. US Burden of Disease Collaborators, Mokdad AH, Ballestros K, Echko M, et al. The State of US Health, 1990-2016: Burden of Diseases, Injuries, and Risk Factors Among US States. JAMA 2018; 319:1444-1472.

139. Gaskin DJ, Richard P. The economic costs of pain in the United States. J Pain 2012; 13:715-724.

140. Manchikanti L, Atluri S, Candido KD, et al. Zohydro ${ }^{\mathrm{TM}}$ approval by Food and Drug Administration: Controversial or frightening? Pain Physician 2014; 17:E437-E450.

141. Martin BI, Turner JA, Mirza SK, Lee MJ, Comstock BA, Deyo RA. Trends in health care expenditures, utilization, and health status among US adults with spine problems, 1997-2006. Spine (Phila $\mathrm{Pa}$ 1976) 2009; 34:2077-2084.

142. Blyth FM, Noguchi N. Chronic musculoskeletal pain and its impact on older people. Best Pract Res Clin Rheumatol 2017; 31:160-168.

143. Institute of Medicine (IOM). Relieving Pain in America: A Blueprint for Transforming Prevention, Care, Education, and Research. The National Academies Press, Washington, DC, June 29, 2011.

www.iom.edu/ /media/Files/Report\%2o Files/2011/Relieving-Pain-in-America-ABlueprint-for-Transforming-PreventionCare-Education-Research/Pain\%20 Research\%202011\%20Report\%20Brief. pdf

144. Hoy D, March L, Brooks $P$, et al. The global burden of low back pain: Estimates from the Global Burden of Disease 2010 study. Ann Rheum Dis 2014; 73:968-974.

145. Mokdad AH, Ballestros K, et al. US Burden of Disease Collaborators, The state of US health, 1990-2016: Burden of diseases, injuries, and risk factors among US states. JAMA 2018; 319:1444-1472.

146. Cassidy JD, Carroll LJ, Côté P. The Saskatchewan Health and Back Pain Survey. The prevalence of low back pain and related disability in Saskatchewan adults. Spine (Phila Pa 1976) 1998; 23:1860-1867.

147. Bressler HB, Keyes WJ, Rochon PA, Badley $\mathrm{E}$. The prevalence of low back pain in the elderly. A systematic review of the literature. Spine (Phila Pa 1976) 1999; 24:1813-1819.

148. Côté P, Cassidy JD, Carroll L. The Saskatchewan Health and Back Pain Survey. The prevalence of neck pain and related disability in Saskatchewan adults. Spine (Phila Pa 1976) 1998; 23:1689-1698.

149. Leboeuf-Yde C, Nielsen J, Kyvik KO, Fejer R, Hartvigsen J. Pain in the lumbar, thoracic or cervical regions: Do age or gender matter? A population-based study of 34,902 Danish twins 20-71 years of age. BMC Musculoskelet Disord 2009; 10:39.

150. Mills SEE, Nicolson KP, Smith $\mathrm{BH}$. Chronic pain: A review of its epidemiology and associated factors in population-based studies. $\mathrm{Br}$ J Anaesth 2019; 123:e273-e283.

151. King $S$, Chambers $C T$, Huguet $A$, et al. The epidemiology of chronic pain in children and adolescents revisited: A systematic review. Pain 2011; 152:2729-2738.
152. Jarvik JG, Gold LS, Tan K, et al. Longterm outcomes of a large, prospective observational cohort of older adults with back pain. Spine J 2018; 18:1540-1551.

153. Dagenais S, Gay RE, Tricco AC, Freeman MD, Mayer JM. NASS contemporary concepts in spine care: Spinal manipulation therapy for acute low back pain. Spine J 2010; 10:918-940.

154. Koyanagi A, Stickley A, Garin N, et al. The association between obesity and back pain in nine countries: $A$ crosssectional study. BMC Public Health 2015; 15:123.

155. Loney PL, Stratford PW. The prevalence of low back pain in adults: a methodological review of the literature. Phys Ther 1999; 79:384-396.

156. Walker BF. The prevalence of low back pain: A systematic review of the literature from 1966 to 1998. J Spinal Disord 2000; 13:205-217.

157. Fejer R, Kyvik KO, Hartvigsen J. The prevalence of neck pain in the world population: A systematic critical review of the literature. Eur Spine J 2006; 15:834-848.

158. Freburger JK, Holmes GM, Agans RP, et al. The rising prevalence of chronic low back pain. Arch Intern Med 2009; 169:251-258.

159. Briggs AM, Cross MJ, Hoy DG, et al. Musculoskeletal health conditions represent a global threat to healthy aging: A report for the 2015 World Health Organization World Report on Ageing and Health. Gerontologist 2016; 56:S243-S255.

160. World Health Organization. World report on ageing and health. World Health Organization, Geneva 2015.

161. AcaroDlu E, Nordin M, Randhawa K, et al. The global spine care initiative: A summary of guidelines on invasive interventions for the management of persistent and disabling spinal pain in low- and middle-income communities. Eur Spine J 2018; 27:870-878.

162. Blyth FM, Briggs AM, Schneider $\mathrm{CH}$, Hoy DG, March LM. The global burden of musculoskeletal pain-where to from here? Am J Public Health 2019; 109:35-40.

163. Chou R, Huffman L. Guideline for the Evaluation and Management of Low Back Pain: Evidence Review. American Pain Society, Glenview, IL, 2009.

http://www.americanpainsociety.org/ uploads/pdfs/LBPEvidRev.pdf

164. Manchikanti L, Datta S, Derby R, Wolfer LR, Benyamin RM, Hirsch JA. 
A critical review of the American Pain Society clinical practice guidelines for interventional techniques: Part 1. Diagnostic interventions. Pain Physician 2010; 13:E141-E174.

165. Manchikanti L, Benyamin RM, Falco FJE, Caraway DL, Datta S, Hirsch JA. Guidelines warfare over interventional techniques: Is there a lack of discourse or straw man? Pain Physician 2012; 15:E1-E26.

166. Manchikanti L, Knezevic NN, Boswell MV, Kaye AD, Hirsch JA. Epidura injections for lumbar radiculopathy and spinal stenosis: A comparative systematic review and meta-analysis. Pain Physician 2016; E365-E410.

167. Boswell MV, Manchikanti L. Appropriate design and methodologic quality assessment, clinically relevant outcomes are essential to determine the role of epidural corticosteroid injections. Commentary RE: Chou R, Hashimoto R, Friedly J, Fu R, Bougatsos C, Dana T, Sullivan SD, Jarvik J. Epidural corticosteroid injections for radiculopathy and spinal stenosis: $A$ systematic review and meta-analysis. Ann Intern Med 2015; 163:373-381. Evid Based Med 2016; 21:89.

168. Dagenais S, Caro J, Haldeman S. A systematic review of low back pain cost of illness studies in the United States and internationally. Spine J 2008; 8:8-20.

169. Yoshihara H, Yoneoka D. National trends in the surgical treatment for lumbar degenerative disc disease: United States, 2000 to 2009. Spine J 2015; 15:265-271.

170. Becker A, Held H, Redaelli M, et al. Low back pain in primary care: Costs of care and prediction of future health care utilization. Spine (Phila Pa 1976) 2010; 35:1714-1720.

171. Ritzwoller DP, Crounse L, Shetterly $S$, Rublee D. The association of comorbidities, utilization and costs for patients identified with low back pain. BMC Musculoskelet Disord 2006; 7:72.

172. Leavitt SB. NSAID dangers may limit pain- relief options. Pain-Topics News/ Research UPDATES, March 14, 2010.

http://updates.pain-topics.org/2010/03/ nsaid-dangers-may-limit-pain-relief. html.

173. Graves JM, Fulton-Kehoe D, Jarvik JG Franklin GM. Health care utilization and costs associated with adherence to clinical practice guidelines for early magnetic resonance imaging among workers with acute occupational low back pain. Health Serv Res 2014; 49:645-665.

174. Gingras MA, Lieu A, Papillon-Ferland L, Lee TC, McDonald EG. Retrospective cohort study of the prevalence of offlabel gabapentinoid prescriptions in hospitalized medical patients. J Hosp Med 2019; 14:E1-E4.

175. U.S. Food and Drug Administration. FDA warms about serious breathing problems with seizure and nerve pain medications gabapentin (Neurontin, Gralise, Horizant) and pregabalin (Lyrica, Lyrica CR) when used with CNS depressants or in patients with lung problems. December 19, 2019.

https://www.fda.gov/drugs/drug-safety-andavailability/fda-warns-about-seriousbreathing-problems-seizure-and-nervepain-medicines-gabapentin-neurontin

176. Zhou J, Wang R, Huo X, Xiong W, Kang $L$, Xue $Y$. Incidence of surgical site infection after spine surgery: A systematic review and meta-analysis. Spine (Phila Pa 1976) 2020 1; 45:208-216.

177. Manchikanti L, Manchukonda R, Pampati V, Damron KS, McManus CD. Prevalence of facet joint pain in chronic low back pain in postsurgical patients by controlled comparative local anesthetic blocks. Arch Phys Med Rehabil 2007; 88:449-455.

178. Manchikanti L, Manchikanti KN, Pampati V, Brandon DE, Giordano J. The prevalence of facet-joint-related chronic neck pain in postsurgical and nonpostsurgical patients: A comparative evaluation. Pain Pract 2008; 8:5-10.

179. Schofferman J, Reynolds J, Herzog R, Covington E, Dreyfuss P, O'Neill C. Failed back surgery: Etiology and diagnostic evaluation. Spine J 2003; 3:400-403.

180. Slipman CW, Shin CH, Patel RK, et al. Etiologies of failed back surgery syndrome. Pain Med 2002; 3:200-214.

181. Fritsch EW, Heisel J, Rupp S. The failed back surgery syndrome: Reasons, intraoperative findings, and longterm results: A report of 182 operative treatments. Spine (Phila Pa 1976) 1996; 21:626-633.

182. Burton CV, Kirkaldy-Willis WH, YongHing K, Heithoff KB. Causes of failure of surgery on the lumbar spine. Clin Orthop Relat Res 1981; 157:191-199.

183. Waguespack A, Schofferman J, Slosar $P$, Reynolds J. Etiology of long-term failures of lumbar spine surgery. Pain
Med 2002; 3:18-22.

184. Katz V, Schofferman J, Reynolds J. The sacroiliac joint: A potential cause of pain after lumbar fusion to the sacrum. ] Spinal Disord Tech 2003;1 6:96-99.

185. Waddell G, Kummel EG, Lotto WN, Graham JD, Hall H, McCulloch JA. Failed lumbar disc surgery and repeat surgery following industrial injuries. J Bone Joint Surg Am 1979; 61:201-207.

186. Deyo RA, Weinstein JN. Low back pain. $N$ Engl J Med 2001; 344:363-370.

187. Kirwan E. Back pain. In: Wall PD, Melzack R, editors. Textbook of Pain. 2nd ed. Edinburgh: Churchill Livingstone; 1989. pp 335-340.

188. Deyo RA, Rainville J, Kent DL. What can the history and physical examination tell us about low back pain? JAMA 1992; 268:760-765.

189. DePalma MJ, Ketchum JM, Saullo TR. Etiology of chronic low back pain in patients having undergone lumbar fusion. Pain Med 2011; 12:732-739.

190. DePalma MJ, Ketchum JM, Saulio TR, Laplante BL. Is the history of a surgical discectomy related to the source of chronic low back pain? Pain Physician 2012; 15:E1-E6.

191. Klessinger S. Zygapophysial joint pain in post lumbar surgery syndrome. The efficacy of medial branch blocks and radiofrequency neurotomy. Pain Med 2013; 14:374-377.

192. Manchikanti L, Pampati V, Baha A, Fellows B, Damron KS, Barnhill RC. Contribution of facet joints to chronic low back pain in postlumbar laminectomy syndrome: A controlled comparative prevalence evaluation. Pain Physician 2001; 4:175-180.

193. Bogduk N, McGuirk B. Causes and sources of chronic low back pain. In: Bogduk N, McGuirk B, editors. Medical Management of Acute and Chronic Low Back Pain. An Evidence-Based Approach: Pain Research and Clinical Management. Vol 13. Amsterdam: Elsevier Sci; 2002. p 115-126.

194. Bogduk N, McGuirk B. An algorithm for precision diagnosis. In: Bogduk $\mathrm{N}$, McGuirk B, editors. Medical Management of Acute and Chronic Low Back Pain. An Evidence-Based Approach: Pain Research and Clinical Management. Vol 13. Amsterdam: Elsevier Sci; 2002. pp 177-186.

195. Bogduk N, editor. Low back pain: Clinical Anatomy of Lumbar Spine and Sacrum. 3rd ed. New York: Churchill Livingstone; 1997. pp 187-213. 
196. Manchikanti L, Pampati V, Falco FJE, Hirsch JA. Growth of spinal interventional pain management techniques: Analysis of utilization trends and Medicare expenditures 2000 to 2008. Spine (Phila Pa 1976) 2013; 38:157-168.

197. Manchikanti L, Pampati V, Soin A, Vanaparthy $R$, Sanapati $M$, Kaye $A D$ Hirsch JA. Trends of expenditures and utilization of facet joint interventions in fee-for-service (FFS) Medicare population from 2009-2018. Pain Physician 2020; in press.

198. Manchikanti L, Sanapati J, Benyamin RM, Atluri S, Kaye AD, Hirsch JA. Reframing the prevention strategies of the opioid crisis: Focusing on prescription opioids, fentanyl, and heroin epidemic. Pain Physician 2018; 21:309-326.

199. Manchikanti L, Singh V, Benyamin RM, Kaye AD, Pampati V, Hirsch JA. Reframing Medicare physician payment policy for 2019: A look at proposed policy. Pain Physician 2018; 21:415-432.

200. Chakravarthy K, Manchikanti L, Kaye $A D$, Christo PJ. Reframing the role of neuromodulation therapy in the chronic pain treatment paradigm. Pain Physician 2018; 21:507-513.

201. Orhan C, Van Looveren E, Cagnie B, Mukhtar NB, Lenoir D, Meeus M. Are pain beliefs, cognitions, and behaviors influenced by race, ethnicity, and culture in patients with chronic musculoskeletal pain: A systematic review. Pain Physician 2018; 21:541-558.

202. Jonan $A B$, Kaye $A D$, Urman RD. Buprenorphine Formulations: Clinical best practice strategies recommendations for perioperative management of patients undergoing surgical or interventional pain procedures. Pain Physician 2018; 21:E1-E12.

203. Moride $Y$, Lemieux-Uresandi D, Castillon $\mathrm{G}$, et al. A systematic review of interventions and programs targeting appropriate prescribing of opioids. Pain Physician 2019; 22:229-240.

204. Wertli MM, Held U, Signorell A, Steurer J, Blozik E, Burgstaller JM. Opioid prescription in Switzerland: Appropriate comedication use in cancer and noncancer pain. Pain Physician 2019; 22:537-548.

205. Fischer B, Jones W, Vojtila L, Kurdyak P. Patterns, changes, and trends in prescription opioid dispensing in Canada, 2005-2016. Pain Physician 2018;
21:219-228.

206. Scholz A, Bothmer J, Kok M, Hoschen K Daniels S. Cebranopadol: A novel, firstin-class, strong analgesic: Results from a randomized phase lla clinical trial in postoperative acute pain. Pain Physician 2018; 21:E193-E206.

207. Singer JA. Stop calling it an opioid crisis - it's a heroin and fentanyl crisis. Cato Institute, January 9, 2018.

https://www.cato.org/blog/stop-callingitopioid-crisis-its-heroin-fentanyl-crisis

208. National Institute on Drug Abuse. Overdose death rates. August 2018 https:/www.drugabuse.gov/ related-topics/trends-statistics/ overdose-death-rates

209. United States Drug Enforcement Administration. DEA proposes reduction to amount of controlled substances to be manufactured in 2018. August 4, 2017.

https://www.dea.gov/divisions/hq/2017/ hq080417.shtml

210. Schuchat A, Houry D, Guy GP Jr. New data on opioid use and prescribing in the United States. JAMA 2017; 318:425-426.

211. Centers for Disease Control and Prevention. Annual Surveillance Report of Drug-Related Risks and Outcomes --United States, 2017 Surveillance Special Report 1. Centers for Disease Control and Prevention, U.S. Department of Health and Human Services. August 31, 2017.

https://www.cdc.gov/drugoverdose/pdf/ pubs/2017-cdc-drug-surveillancereport.pdf

212. Seth P, Rudd RA, Noonan RK, Haegerich TM. Quantifying the epidemic of prescription opioid overdose deaths. Am J Public Health 2018; 108:500-502.

213. IQVIA Institute for Human Data Science Study. Medicine use and spending in the U.S. A review of 2018 and outlook for 2023. May 2019.

https://www.iqvia.com/insights/the-iqviainstitute/reports/medicine-use-andspending-in-the-us-a-review-of-2018and-outlook-to-2023

214. Wilson $N$, Kariisa $M$, Seth $P$, Smith $H$ 4 th, Davis NL. Drug and opioid-involved overdose deaths - United States, 20172018. MMWR Morb Mortal Wkly Rep 2020; 69:290-297.

215. Alexander GC, Stoller KB, Haffajee RL, Saloner B. An epidemic in the midst of a pandemic: Opioid use disorder and COVID-19. Ann Intern Med 2020 Apr 2. [Epub ahead of print]
216. Gladden RM, O'Donnell J, Mattson $\mathrm{CL}$, et al. Changes in opioid-involved overdose deaths by opioid type and presence of benzodiazepines, cocaine, and methamphetamine - 25 States, JulyDecember 2017 to January-June 2018. MMWR Morb Mortal Wkly Rep 2019; 68:737-744.

217. NIDA. Overdose Death Rates. National Institute on Drug Abuse website. January 29, 2019.

https://www.drugabuse.gov/related-topics/ trends-statistics/overdose-death-rates

218. Tracking federal funding to combat the opioid crisis. March 2019.

https://bipartisanpolicy.org/wp-content/ uploads/2019/03/TrackingFederalFunding-to-Combat-theOpioid-Crisis.pdf

219. Gostin LO, Hodge JG, Noe SA. Reframing the opioid epidemic as a national emergency. JAMA 2017; 318:1539-1540.

220. Portenoy RK, Foley KM. Chronic use of opioid analgesics in non-malignant pain: Report of 38 cases. Pain 1986; 25:171-186.

221. Volkow ND, Collins FS. The role of science in the opioid crisis. $N$ Engl ] Med 2017; 377:1798.

222. Kolodny A, Frieden TR. Ten steps the federal government should take now to reverse the opioid addiction epidemic. JAMA 2017; 318:1537-1538.

223. Bonnie RJ, Kesselheim AS, Clark DJ. Both urgency and balance needed in addressing opioid epidemic: A report from the National Academies of Sciences, Engineering, and Medicine. JAMA 2017; 318:423-424.

224. Manchikanti L, Manchikanti KN, Kaye AD, Kaye AM, Hirsch JA. Challenges and concerns of persistent opioid use in cancer patients. Expert Rev Anticancer Ther 2018; 18:705-718.

225. Bao Y, Pan Y, Taylor A, et al. Prescription drug monitoring programs are associated with sustained reductions in opioid prescribing by physicians. Health Aff (Milwood) 2016; 35:1045-1051.

226. Bao $Y$, Wen $K$, Johnson $P$, et al. Assessing the impact of state policies for prescription drug monitoring programs on high-risk opioid prescriptions. Health Aff (Millwood) 2018; 37:1596-1604.

227. Dowell D, Haegerich TM, Chou R. CDC guideline for prescribing opioids for chronic pain--United States, 2016. MMWR Recomm Rep 2016; 65:1-49.

228. HHS guide for clinicians on the 
appropriate dosage reduction or discontinuation of long-term opioid analgesics.

https:/www.hhs.gov/opioids/sites/default/ files/2019-10/Dosage_Reduction_ Discontinuation.pdf

229. Prescribing policies: States confront opioid overdose epidemic.

http://www.ncsl.org/research/health/ prescribingpolicies-states-confrontopioidoverdose-epidemic.aspx

230. Kertesz SG, Gordon AJ. A crisis of opioids and the limits of prescription control: United States. Addiction 2019; 114:169-180.

231. US Department of Health and Human Services Office of Inspector General. Medicare Part D Beneficiaries at Serious Risk of Opioid Misuse or Overdose: A Closer Look. 5/4/2020.

https://oig.hhs.gov/oei/reports/oei-0219-00130.asp 232. George J. CDC guideline harms pain patients, panel says -- 'Clinician's ability to make decisions has been severely interrupted'. MedPage Today, March 11, 2019.

233. Gever J. HHS: Don't withdraw opioids suddenly-Department issues guideline on tapering and discontinuation. MedPage Today, October 10, 2019.

234. Dowell D, Haegerich TM, Chou R. No shortcuts to safer opioid prescribing. $N$ Engl J Med 2019; 380:2285-2287.

235. Pergolizzi JV Jr, Raffa RB, LeQuang JA The Centers for Disease Control and Prevention opioid guidelines: Potential for unintended consequences and will they be abused? J Clin Pharm Ther 2016; 41:592-593.

236. Boswell MV, Trescot AM, Datta S, et al. Interventional techniques: Evidencebased practice guidelines in the management of chronic spinal pain. Pain Physician 2007; 10:7-111.

237. Hancock MJ, Maher CG, Laslett M, Hay E, Koes B. Discussion paper: what happened to the 'bio' in the bio-psychosocial model of low back pain? Eur Spine J 2011; 20:2105-2110.

238. Manchikanti L, Boswell MV, Singh V, et al. Comprehensive evidence-based guidelines for interventional techniques in the management of chronic spinal pain. Pain Physician 2009; 12:699-802.

239. Gagliese L, Katz J. Medically unexplained pain is not caused by psychopathology. Pain Res Manage 2000; 5:251257.

240. Boswell MV, Shah RV, Everett CR, et al. Interventional techniques in the management of chronic spinal pain:
Evidence-based practice guidelines. Pain Physician 2005; 8:1-47.

241. Manchikanti L, Staats PS, Singh V, et al. Evidence-based practice guidelines for interventional techniques in the management of chronic spinal pain. Pain Physician 2003; 6:3-80.

242. Manchikanti L, Singh V, Kloth DS, et al. Interventional techniques in the management of chronic pain: Part 2.0. Pain Physician 2001; 4:24-96.

243. Manchikanti L, Singh V, Bakhit CE, Fellows B. Interventional techniques in the management of chronic pain. Part 1.o. Pain Physician 2000; 3:7-42.

244. Manchikanti L, Hirsch JA, Datta S, Falco FJE. Low back and lumbar radicular pain. In: Manchikanti L, Christo PJ, Trescot AM, Falco FJE (eds). Clinical Aspects of Pain Medicine and Interventional Pain Management: A Comprehensive Review. ASIPP Publishing, Paducah, KY, 2011, pp 87-114.

245. Song Q, Liu X, Chen DJ, et al. Evaluation of MRI and CT parameters to analyze the correlation between disc and facet joint degeneration in the lumbar threejoint complex. Medicine (Baltimore) 2019; 98:e17336.

246. Dudli S, Sing DC, Hu SS, et al. Issls Prize in Basic Science 2017: Intervertebral disc/bone marrow crosstalk with Modic changes. Eur Spine J 2017; 26:1362-1373.

247. Liu YJ, Huang GS, Juan CJ, Yao MS, Ho WP, Chan WP. Intervertebral disk degeneration related to reduced marrow perfusion at dynamic contrastenhanced MRI. AJR Am J Roentgenol 2009; 192:974-979.

248. Videman T, Battie MC, Gill K, et al. Magnetic resonance imaging findings and their relationships in the thoracic and lumbar spine. Insights into the etiopathogenesis of spinal degeneration. Spine (Phila Pa 1976) 1995; 20:928-935.

249. Gellhorn AC, Katz JN, Suri P. Osteoarthritis of the spine: The facet joints. Nat Rev Rheumatol 2013; 9:216-224.

250. Jinkins JR. Acquired degenerative changes of the intervertebral segments at and suprajacent to the lumbosacral junction. A radioanatomic analysis of the nondiscal structures of the spinal column and perispinal soft tissues. Eur J Radiol 2004; 50:134-158.

251. Deyo RA. Fads in the treatment of low back pain. N Engl J Med 1991; 325:10391040.

252. Bogduk N. Low back pain. Clinical
Anatomy of Lumbar Spine and Sacrum. 4th edition. Churchill Livingstone, New York, 2005, pp 183-216.

253. Carragee EJ. Clinical practice. Persistent low back pain. N Engl J Med 2005; 352:1891-1898.

254. Mooney V. Where is the pain coming from? Spine (Phila Pa 1976)1987; 12:754-759.

255. Spitzer WO, LeBlanc FE, Dupuis M. Scientific approach to the assessment and management of activity-related spinal disorders: A monograph for clinicians. Report of Quebec Task Force on Spinal Disorders. Spine (Phila Pa 1976)1987; 12:S1-59.

256. Thomas Lindsey; Alexander M. Dydyk. Spinal Osteoarthritis. StatPearls [Internet]. https://www.ncbi.nlm.nih. gov/books/NBK55319o/

257. Perolat R, Kastler A, Nicot B, et al. Facet joint syndrome: From diagnosis to interventional management. Insights Imaging 2018; 9:773-789.

258. Bogduk N. International Spinal Injection Society guidelines for the performance of spinal injection procedures. Part 1 : Zygapophyseal joint blocks. Clin J Pain 1997; 13:285-302.

259. Manchikanti L, Falco FJE, Benyamin RM. Neck and cervical radicular pain. In: Manchikanti L, Christo PJ, Trescot AM, Falco FJE (eds). Clinical Aspects of Pain Medicine and Interventional Pain Management: A Comprehensive Review. ASIPP Publishing, Paducah, KY, 2011, pp 35-60.

260. Manchikanti L, Singh V, Datta S. Thoracic and chest wall pain and radicular pain. In: Manchikanti L, Christo PJ, Trescot AM, Falco FJE (eds). Clinical Aspects of Pain Medicine and Interventional Pain Management: A Comprehensive Review. ASIPP Publishing, Paducah, KY, 2011, pp 61-86.

261. Mooney V, Robertson J. The facet syndrome. Clin Orthop 1976; 115:149-156.

262. McCall IW, Park WM, O'Brien JP. Induced pain referral from posterior elements in normal subjects. Spine (Phila Pa 1976)1979; 4:441-446.

263. Marks R. Distribution of pain provoked from lumbar facet joints and related structures during diagnostic spinal infiltration. Pain 1989; 39:37-40.

264. Fukui S, Ohseto K, Shiotani M, Ohno K, Karasawa $H$, Naganuma Y. Distribution of referral pain from the lumbar zygapophyseal joints and dorsal rami. Clin J Pain 1997; 13:303-307. 
265. Hirsch C, Ingelmark BE, Miller M. The anatomical basis for low back pain. Acta Orthop Orthop Scand 1963; 33:1-17.

266. Windsor RE, King FJ, Roman S), et al. Electrical stimulation induced lumbar medial branch referral patterns. Pain Physician 2002; 5:347-353.

267. Pawl RP. Headache, cervical spondylosis, and anterior cervical fusion. Surg Ann 1977; 9:391-498.

268. Fukui S, Ohseto K, Shiotani M, et al. Referred pain distribution of the cervical zygapophyseal joints and cervical dorsal rami. Pain 1996; 68:79-83.

269. Dwyer A, Aprill C, Bogduk N. Cervical zygapophyseal joint pain patterns: A study in normal volunteers. Spine (Phila Pa 1976) 1990; 15:453-457.

270. Windsor RE, Nagula D, Storm S. Electrical stimulation induced cervical medial branch referral patterns. Pain Physician 2003; 6:411-418.

271. Manchikanti L. Facet joint pain and the role of neural blockade in its management. Curr Rev Pain 1999; 3:348-358.

272. Aprill C, Dwyer A, Bogduk N. Cervical zygapophyseal joint pain patterns. II: A clinical evaluation. Spine (Phila Pa 1976) 1990; 15:458-461.

273. Cooper G, Bailey B, Bogduk N. Cervical zygapophysial joint pain maps. Pain Med 2007; 8:344-353.

274. Dreyfuss $P$, Michaelsen M, Fletcher D. Atlanto-occipital and lateral atlantoaxial joint pain patterns. Spine (Phila $\mathrm{Pa}$ 1976) 1994; 19:1125-1131.

275. Fukui S, Ohseto K, Shiotani M. Patterns of pain induced by distending the thoracic zygapophyseal joints. Reg Anesth 1997; 22:332-336.

276. Dreyfuss P, Tibiletti C, Dreyer SJ. Thoracic zygapophyseal joint pain patterns: A study in normal volunteers Spine (Phila Pa 1976) 1994; 19:807-811.

277. Fortin JD, Aprill CN, Ponthieux B, Pier J. Sacroiliac joint: pain referral maps upon applying a new injection/arthrography technique. Part II: Clinical evaluation. Spine (Phila Pa 1976) 1994; 19:1483-1489.

278. Fortin JD, Dwyer AP, West S, Pier J. Sacroiliac joint: pain referral maps upon applying a new injection/arthrography technique. Part I: Asymptomatic volunteers. Spine (Phila Pa 1976) 1994; 19:1475-1482.

279. Manchikanti L, Schultz DM, Falco FJE, Singh V. Lumbar facet joint interventions. In: Manchikanti L, Kaye AD, Falco FJE, Hirsch JA (eds). Essentials of Interventional Techniques in Managing Chronic Spinal Pain. Springer, New York, NY, 2018, pp 349-368.

280. Manchikanti L, Schultz DM, Benyamin RM, Falco FJE. Thoracic facet joint interventions. In: Manchikanti L, Kaye AD, Falco FJE, Hirsch JA (eds). Essentials of Interventional Techniques in Managing Chronic Spinal Pain. Springer, New York, NY, 2018, pp 369-385.

281. Manchikanti L, Schultz DM, Falco FJE, Singh V. Cervical facet joint interventions. In: Manchikanti L, Kaye AD, Falco FJE, Hirsch JA (eds). Essentials of Interventional Techniques in Managing Chronic Spinal Pain. Springer, New York, NY, 2018, pp 387-412.

282. Pang WW, Mok MS, Lin ML, Chang $\mathrm{DP}$, Hwang $\mathrm{MH}$. Application of spinal pain mapping in the diagnosis of low back pain-analysis of 104 cases. Acta Anaesthesiol Sin 1998; 36:71-74.

283. Manchikanti L, Singh V, Pampati V, et al. Evaluation of the relative contributions of various structures in chronic low back pain. Pain Physician 2001; 4:308-316.

284. Schwarzer AC, Aprill C, Derby R, Fortin $J$, Kine G, Bogduk N. Clinical features of patients with pain stemming from the lumbar zygapophyseal joints. Is the lumbar facet syndrome a clinical entity? Spine (Phila Pa 1976) 1994; 10:1132-1137.

285. Schwarzer AC, Aprill CN, Derby R, Fortin J, Kine G, Bogduk N. The false-positive rate of uncontrolled diagnostic blocks of the lumbar zygapophysial joints. Pain 1994; 58:195-200.

286. Schwarzer AC, Wang SC, O'Driscoll D, Harrington T, Bogduk N, Laurent R. The ability of computed tomography to identify a painful zygapophysial joint in patients with chronic low back pain. Spine (Phila Pa 1976) 1995; 20:907-912.

287. Schwarzer AC, Aprill CN, Derby R, Fortin J, Kine G, Bogduk N. The prevalence and clinical features of internal disc disruption in patients with chronic low back pain. Spine (Phila Pa 1976) 1995; 20:1878-1883.

288. Schwarzer AC, Aprill CN, Bogduk M. The sacroiliac joint in chronic low back pain. Spine (Phila Pa 1976) 1995; 20:31-37.

289. Schwarzer AC, Wang S, Bogduk $N$, McNaught PJ, Laurent R. Prevalence and clinical features of lumbar zygapophysial joint pain: A study in an Australian population with chronic low back pain. Ann Rheum Dis 1995; 54:100-106.

290. Schwarzer AC, Aprill CN, Derby R, Fortin J, Kine G, Bogduk N. The relative contributions of the disc and zygapophyseal joint in chronic low back pain. Spine (Phila Pa 1976) 1994; 19:801-806.

291. DePalma MJ, Ketchum JM, Saullo T. What is the source of chronic low back pain and does age play a role? Pain Med 2011; 12:224-233.

292. Bokov A, Perlmutter O, Aleynik A, Rasteryaeva M, Mlyavykh S. The potential impact of various diagnostic strategies in cases of chronic pain syndromes associated with lumbar spine degeneration. J Pain Res 2013; 6:289-296.

293. Bogduk N, Aprill C. On the nature of neck pain, discography and cervical zygapophysial joint blocks. Pain 1993; 54:213-217.

294. Yin W, Bogduk N. The nature of neck pain in a private pain clinic in the United States. Pain Med 2008; 9:196-203.

295. Kirkaldy-Willis WH, Wedge JH, Yong-Hing K, Reilly J. Pathology and pathogenesis of lumbar spondylosis and stenosis. Spine (Phila Pa 1976) 1978; 3:319-328.

296. Kundakci YE, Unver Dogan N, Guler I, Uysal II, Fazliogullari Z, Karabulut AK. Evaluation of the facet joints with magnetic resonance images in the patients with disc degeneration and spondylolisthesis. Surg Radiol Anat 2018; 40:1063-1075.

297. Guo R, Yang X, Zhong $Y$, et al. Correlations between Modic change and degeneration in 3-joint complex of the lower lumbar spine: A retrospective study. Medicine (Baltimore) 2018; 97:e12496.

298. Rade $M$, Määttä $J H$, Freidin $M B$, Airaksinen $\mathrm{O}$, Karppinen J, Williams FMK. Vertebral endplate defect as initiating factor in intervertebral disc degeneration: Strong association between endplate defect and disc degeneration in the general population. Spine (Phila Pa 1976) 2018; 43:412-419.

299. Lv B, Yuan J, Ding H, et al. Relationship between endplate defects, modic change, disc degeneration, and facet joint degeneration in patients with low back pain. Biomed Res Int 2019; 2019:9369853.

300. O'Leary SA, Paschos NK, Link JM, Klineberg EO, Hu JC, Athanasiou KA. Facet Joints of the spine: Structurefunction relationships, problems and treatments, and the potential for regeneration. Annu Rev Biomed Eng 2018; 20:145-170. 
301. Ita ME, Zhang S, Holsgrove TP, Kartha $S$, Winkelstein BA. The physiological basis of cervical facet-mediated persistent pain: Basic science and clinical challenges. J Orthop Sports Phys Ther 2017; 47:450-461.

302. Yong-Hing $\mathrm{K}$, Kirkaldy-Willis $\mathrm{WH}$. The pathophysiology of degenerative disease of the lumbar spine. Orthop Clin North Am 1983; 14:491-504.

303. Szkoda-Poliszuk K, Dak M, Pezowicz C. Finite element analysis of the influence of three-joint spinal complex on the change of the intervertebral disc bulge and height. Int J Numer Method Biomed Eng 2018; 34:e3107.

304. Seichi A, Kimura A, Higashi T, et al. Localization of the medial branches of the cervical dorsal rami during cervical laminoplasty. Spine (Phila Pa 1976) 2012; 37:E1603-E1606.

305. Farrell SF, Osmotherly PG, Cornwall J, Rivett DA. Immunohistochemical investigation of nerve fiber presence and morphology in elderly cervical spine meniscoids. Spine ] 2016; 16:1244-1252.

306. Kirkaldy-Willis W, Farfan H. Instability of the Lumbar Spine. Clin. Orthop. Relat. Res. 1982; 165:110.

307. Farshad-Amacker NA, Hughes A, Herzog RJ, Seifert B, Farshad M. The intervertebral disc, the endplates and the vertebral bone marrow as a unit in the process of degeneration. Eur Radiol 2017; 27:2507-2520.

308. Fujiwara A, Tamai $K$, Yamato $M$, et al. The relationship between facet joint osteoarthritis and disc degeneration of the lumbar spine: An MRI study. Eur Spine J 1999; 8:396-401.

309. Suri P, Miyakoshi A, Hunter DJ, et al. Does lumbar spinal degeneration begin with the anterior structures? A study of the observed epidemiology in a community-based population. BMC Musculoskelet Disord 2011; 12:202.

310. Youssef P, Loukas M, Chapman JR, Oskouian RJ, Tubbs RS. Comprehensive anatomical and immunohistochemical review of the innervation of the human spine and joints with application to an improved understanding of back pain. Childs Nerv Syst 2016; 32:243-251.

311. Zhou L, Schneck CD, Shao Z. The anatomy of dorsal ramus nerves and its implications in lower back pain. Neurosci Med 2012; 3:192-201.

312. Cavanaugh JM, Ozaktay AC, Yamashita T, Avramov A, Getchell TV, King AI Mechanisms of low back pain: A neurophysiologic and neuroanatomic study. Clin Orthop 1997; 335:166-180.

313. Bogduk N, Wilson AS, Tynan W. The human lumbar dorsal rami. J Anat 1982; 134:383-397.

314. Lau P, Mercer S, Govind J, Bogduk N. The surgical anatomy of lumbar medial branch neurotomy (facet denervation). Pain Med 2004; 5:289-298.

315. Ishikawa T, Miyagi M, Ohtori S, et al. Characteristics of sensory DRG neurons innervating the lumbar facet joints in rats. Eur Spine ] 2005; 14:559-564.

316. Suseki K, Takahashi Y, Takahashi K, et al. Innervation of the lumbar facet joints. Origins and functions. Spine (Phila $\mathrm{Pa}$ 1976)1997; 22:477-485.

317. Sameda H, Takahashi Y, Takahashi K, Chiba T, Ohtori S, Moriya H. Primary sensory neurons with dichotomizing axons projecting to the facet joint and the sciatic nerve in rats. Spine (Phila Pa 1976) 2001; 26:11051109.

318. Konnai $Y$, Honda T, Sekiguchi Y, Kikuchi $S$, Sugiura Y. Sensory innervation of the lumbar dura mater passing through the sympathetic trunk in rats. Spine (Phila Pa 1976) 2000; 25:776-782.

319. Masini M, Paiva WS, Araujo AS Jr. Anatomical description of the facet joint innervation and its implication in the treatment of recurrent back pain. J Neurosurg Sci 2005; 49:143-146.

320. Ahmed M, Bjurholm A, Kreicbergs A, Schultzberg M. Sensory and autonomic innervation of the facet joint in the rat lumbar spine. Spine (Phila Pa 1976) 1993; 18:2121-2126.

321. Cavanaugh JM, Lu Y, Chen C, Kallakuri $S$. Pain generation in lumbar and cervical facet joints. J Bone Joint Surg Am 2006; 2:63-67.

322. Kallakuri S, Li Y, Chen C, Cavanaugh JM. Innervation of cervical ventral facet joint capsule: Histological evidence. World J Orthop 2012; 3:10-14.

323. Siegenthaler A, Schliessbach J, Curatolo $M$, Eichenberger $U$. Ultrasound anatomy of the nerves supplying the cervical zygapophyseal joints: An exploratory study. Reg Anesth Pain Med 2011; 36:606-610.

324. Bogduk $N$. The clinical anatomy of the cervical dorsal rami. Spine (Phila Pa 1976) 1982; 7:319-330.

325. Ohtori S, Takahashi K, Chiba T, Yamagata M, Sameda $H$, Moriya $H$. Sensory innervation of the cervical facet joints in rats. Spine (Phila Pa 1976) 2001; 26:147-150.
326. Zhang J, Tsuzuki N, Hirabayashi S, Saiki K, Fujita K. Surgical anatomy of the nerves and muscles in the posterior cervical spine. Spine (Phila Pa 1976) 2003; 1379-1384.

327. Yoganandan N, Knowles SA, Maiman DJ, Pintar FA. Anatomic study of the morphology of human cervical facet joint. Spine (Phila Pa 1976) 2003; 28:2317-2323.

328. Inami $S$, Shiga $T$, Tsujino $A$, Yabuki T, Okado N, Ochiai N. Immunohistochemical demonstration of nerve fibers in the synovial fold of the human cervical facet joint. J Orthop Res 2001; 19:593-596.

329. Chua WH, Bogduk N. The surgical anatomy of thoracic facet denervation. Acta Neurochir 1995; 136:140-144.

330. Piraccini E, Byrne H, Calli M, Maitan, S. High abdominal wall pain: an unusual radiation in thoracic facet joint syndrome. Pain Med 2017; 18:1603-1604.

331. Mitra R, Do H, Alamin T, Cheng I. Facet pain in thoracic compression fractures. Pain Med 2010; 11:1674-1677.

332. Kallakuri S, Singh A, Chen C, Cavanaugh $J M$. Demonstration of substance $P$, calcitonin gene-related peptide, and protein gene product 9.5 containing nerve fibers in human cervical facet joint capsules. Spine (Phila Pa 1976) 2004; 29:1182-1186

333. Chen C, Lu Y, Kallakuri S, Patwardhan A, Cavanaugh JM. Distribution of A-delta and $\mathrm{C}$-fiber receptors in the cervical facet joint capsule and their response to stretch. J Bone Joint Surg Am 2006; 88:1807-1816.

334. Ohtori S, Takahashi K, Moriya H. Calcitonin gene-related peptide immunoreactive DRG neurons innervating the cervical facet joints show phenotypic switch in cervical facet injury in rats. Eur Spine J 2003; 12:211-215.

335. Miyagi M, Ohtori S, Ishikawa T, et al. Upregulation of TNFalpha in DRG satellite cells following lumbar facet joint injury in rats. Eur Spine J 2006; 15:953-958.

336. Ohtori S, Takahashi K, Chiba T, Yamagata $M$, Sameda H, Moriya H. Substance $\mathrm{P}$ and calcitonin gene-related peptide immunoreactive sensory DRG neurons innervating the lumbar facet joints in rats. Auton Neurosci 2000; 86:13-17.

337. Suseki K, Takahashi Y, Takahashi K, Chiba T, Tanaka K, Moriya H. CGRPimmunoreactive nerve fibers projecting to lumbar facet joints through the paravertebral sympathetic trunk in rats. Neurosci Lett 1996; 221:41-44. 
338. Ohtori S, Moriya H, Takahashi K Calcitonin gene-related peptide immunoreactive sensory DRG neurons innervating the cervical facet joints in rats. J Orthop Sci 2002; 7:258-261.

339 Ohtori S, Takahashi K, Chiba T, Yamagata $M$, Sameda $H$, Moriya $H$. Brain-derived neurotrophic factor and vanilloid receptor subtype immunoreactive sensory DRG neurons innervating the lumbar facet joints in rats. Auton Neurosci 2001; 94:132-135.

340. McLain RF, Pickar JG. Mechanoreceptor endings in human thoracic and lumbar facet joints. Spine (Phila Pa 1976) 1998; 23:168-173.

341. McLain RF. Mechanoreceptors ending in human cervical facets joints. Spine (Phila Pa 1976) 1994; 5:495-501.

342. Boszczyk BM, Boszczyk AA, Putz R, Buttner A, Benjamin M, Milz S. An immunohistochemical study of the dorsal capsule of the lumbar and thoracic facet joints. Spine (Phila Pa 1976) 2001; 26:E338-E343.

343. Yamashita T, Cavanaugh JM, Ozaktay AC, Avramov Al, Getchell TV, King Al. Effect of substance $P$ on mechanosensitive units of tissues around and in the lumbar facet joint. J Orthop Res 1993; 11:205-214.

344. Beaman DN, Graziano GP, Glover RA, Wojtys EM, Chang V. Substance P innervation of lumbar spine facet joints. Spine (Phila Pa 1976) 1993; 18:1044-1049.

345. Ohtori S, Takahashi K, Chiba T, Yamagata M, Sameda $H$, Moriya $H$. Phenotypic inflammation switch in rats shown by calcitonin gene-related peptide immunoreactive dorsal root ganglion neurons innervating the lumbar facet joints. Spine (Phila Pa 1976) 2001; 26:1009-1013.

346. Arciszewski MB. Distribution of calcitonin gene-related peptide (CGRP), substance $P(S P)$ and galanin (GAL) immunoreactive nerve fibers in the seminal vesicle and prostate of the male sheep. Ann Anat 2004; 186:83-87.

347. Chen C, Lu Y, Cavanaugh JM, Kallakuri $S$, Patwardhan A. Recording of neural activity from goat cervical facet joint capsule using custom-designed miniature electrodes. Spine (Phila Pa 1976) 2005; 30:1367-1372.

348. Lu Y, Chen C, Kallakuri S, Patwardhan A, Cavanaugh JM. Development of an in vivo method to investigate biomechanical and neurophysiological properties of spine facet joint capsules. Eur Spine J 2005; 14:565-572.
349. Lu Y, Chen C, Kallakuri S, Patwardhan A, Cavanaugh JM. Neurophysiological and biomechanical characterization of goat cervical facet joint capsules. J Orthop Res 2005; 23:779-787.

350. Bucknill AT, Coward K, Plumpton C, et al. Nerve fibers in lumbar spine structures and injured spinal roots express the sensory neuronspecific sodium channels $\mathrm{SNS}_{\mathrm{PN}}$ and $\mathrm{NaN} /$ SNS2. Spine (Phila Pa 1976) 2002; 27:135-140.

351. Igarashi A, Kikuchi S, Konno S, Olmarker K. Inflammatory cytokines released from the facet joint tissue in degenerative lumbar spinal disorders. Spine (Phila Pa 1976) 2004; 29:2091-2095.

352. Ozaktay AC, Cavanaugh JM, Blagoev DC, Getchell TV, King Al. Effects of a carrageenan-induced inflammation in rabbit lumbar facet joint capsule and adjacent tissues. Neurosci Res 1994; 20:355364.

353. Ohtori S, Takahashi K, Moriya H. Inflammatory pain mediated by a phenotypic switch in brain-derived neurotrophic factor-immunoreactive dorsal root ganglion neurons innervating the lumbar facet joints in rats. Neurosci Lett 2002; 323:129-132. 371.

354. lanuzzi A, Khalsa PS. Comparison of human lumbar facet joint capsule strains during simulated high-velocity, lowamplitude spinal manipulation versus physiological motions. Spine J 2005; 5:277-290.

355. Yang KH, King Al. Mechanism of facet load transmission as a hypothesis for low-back pain. Spine (Phila Pa 1976)1984; 9:557-565.

356. Borchgrevink GE, Smevik O, Nordby A, Rinck PA, Stiles TC, Lereim I. MR imaging and radiography of patients with cervical hypertension-flexion injuries after car accidents. Acta Radiol 1995; 36:425-428.

357. Ronnen HR, de Korte PJ, Brink PR, van der Bijl HJ, Tonino AJ, Franke CL. Acute whiplash injury: is there a role for MR imaging?-A prospective study of 100 patients. Radiology 1996; 201:93-96.

358. Moldavsky M, Neumann P, Klocke $N$, Hussain M, Bucklen BS. In vitro analysis of circumferential joint replacement, including bilateral facet joint replacement with lateral lumber disc prosthesis: A parametric investigation of disc sizing. European Spine Journal 2017; 26:785-793.

359. Kras JV, Kartha S, Winkelstein BA. Intra- articular nerve growth factor regulates development, but not maintenance, of injury-induced facet joint pain \& spinal neuronal hypersensitivity. Osteoarthritis Cartilage 2015; 23:1999-2008.

360. Schneider GM, Smith AD, Hooper $A$, et al. Minimizing the source of nociception and its concurrent effect on sensory hypersensitivity: An exploratory study in chronic whiplash patients. BMC Musculoskelet Disord 2010; 11:29.

361. Chua NH, van Suijlekom HA, Vissers KC, Arendt-Nielsen L, Wilder-Smith $\mathrm{OH}$. Differences in sensory processing between chronic cervical zygapophysial joint pain patients with and without cervicogenic headache. Cephalalgia 2011; 31:953-963.

362. Dong L, Odeleye AO, Jordan-Sciutto $\mathrm{KL}$, Winkelstein BA. Painful facet joint injury induces neuronal stress activation in the DRG: Implications for cellular mechanisms of pain. Neurosci Lett 2008; 443:90-94.

363. Quinn KP, Dong L, Golder FJ, Winkelstein BA. Neuronal hyperexcitability in the dorsal horn after painful facet joint injury. Pain 2010; 151:414-421.

364. Lee KE, Davis MB, Winkelstein BA. Capsular ligament involvement in the development of mechanical hyperalgesia after facet joint loading: Behavioral and inflammatory outcomes in a rodent model of pain.] Neurotrauma 2008; 25:1383-1393.

365. Winkelstein BA, Santos DG. An intact facet capsular ligament modulates behavioral sensitivity and spinal glial activation produced by cervical facet joint tension. Spine (Phila Pa 1976) 2008; 33:856-862.

366. Tachihara H, Kikuchi S, Konno $S$, Sekiguchi M. Does facet joint inflammation induce radiculopathy?: An investigation using a rat model of lumbar facet joint inflammation. Spine (Phila Pa 1976) 2007; 32:406-412.

367. Kras JV, Dong L, Winkelstein BA. Increased interleukin-1 $\square$ and prostaglandin E2 expression in the spinal cord at 1 day after painful facet joint injury: Evidence of early spinal inflammation. Spine (Phila Pa 1976) 2014; 39:207-212.

368. Anderst WJ, Donaldson WF 3rd, Lee JY, Kang JD. In vivo cervical facet joint capsule deformation during flexionextension. Spine (Phila Pa 1976) 2014; 39: $\mathrm{E}_{514}-\mathrm{E}_{520}$.

369. Kim JS, Kroin JS, Buvanendran A, et al. Characterization of a new animal 
model for evaluation and treatment of back pain due to lumbar facet joint osteoarthritis. Arthritis Rheum 2011; 63:2966-2973.

370. Javanshir K, Ortega-Santiago R, Mohseni-Bandpei MA, MiangolarraPage JC, Fernández-de-Las-Peñas C. Exploration of somatosensory impairments in subjects with mechanical idiopathic neck pain: A preliminary study. J Manipulative Physiol Ther 2010; 33:493-499.

371. Vasquez E, Bär K, Ebersberger A, Klein $B$, Vanegas $H$, Schaible HG. Spinal prostaglandins are involved in the development but not the maintenance of inflammation-induced spinal hyperexcitability. J Neurosci 2001; 21:9001-9008.

372. Sagar DR, Ashraf S, Xu L, et al. Osteoprotegerin reduces the development of pain behaviour and joint pathology in a model of osteoarthritis. Ann Rheum Dis 2014; 73:1558-1565.

373. Bullock CM, Wookey P, Bennett A, Mobasheri A, Dickerson I, Kelly S. Peripheral calcitonin gene-related peptide receptor activation and mechanical sensitization of the joint in rat models of osteoarthritis pain. Arthritis Rheumatol 2014; 66:2188-2200.

374. Lee H, Park Y, Ahn CW, Park SH, Jung EY, Suh HJ. Deer bone extract suppresses articular cartilage damage induced by monosodium iodoacetate in osteoarthritic rats: An in vivo microcomputed tomography study. J Med Food 2014; 17:701-706.

375. Dong L, Crosby ND, Winkelstein BA. Gabapentin alleviates facet-mediated pain in the rat through reduced neuronal hyperexcitability and astrocytic activation in the spinal cord. J Pain 2013; 14:1564-1572.

376. Dong L, Smith JR, Winkelstein BA. Ketorolac reduces spinal astrocytic activation and PAR 1 expression associated with attenuation of pain after facet joint injury. J Neurotrauma 2013; 30:818-825

377. Kras JV, Tanaka K, Gilliland TM, Winkelstein BA. An anatomical and immunohistochemical characterization of afferents innervating the $\mathrm{C}_{6}-\mathrm{C}_{7}$ facet joint after painful joint loading in the rat. Spine (Phila Pa 1976) 2013; 38:E325-E331.

378. Lee KE, Thinnes JH, Gokhin DS, Winkelstein BA. A novel rodent neck pain model of facet-mediated behavioral hypersensitivity: Implications for persistent pain and whiplash injury. J
Neurosci Methods 2004; 137:151-159.

379. Quinn KP, Winkelstein BA. Detection of altered collagen fiber alignment in the cervical facet capsule after whiplash-like joint retraction. Ann Biomed Eng 2011; 39:2163-2173.

380. Dong L, Winkelstein BA. Simulated whiplash modulates expression of the glutamatergic system in the spinal cord suggesting spinal plasticity is associated with painful dynamic cervical facet loading. J Neurotrauma 2010; 27:163-174.

381. Kras JV, Dong L, Winkelstein BA. The prostaglandin $E_{2}$ receptor, $E P_{2}$, is upregulated in the dorsal root ganglion after painful cervical facet joint injury in the rat. Spine (Phila Pa 1976) 2013; 38:217-222.

382. Dong L, Guarino BB, Jordan-Sciutto KL, Winkelstein BA. Activating transcription factor 4 , a mediator of the integrated stress response, is increased in the dorsal root ganglia following painful facet joint distraction. Neuroscience 2011; 193:377-386.

383. Shultz S, Averell K, Eickelman A, Sanker $H$, Donaldson MB. Diagnostic accuracy of self-report and subjective history in the diagnosis of low back pain with non-specific lower extremity symptoms: A systematic review. Man Ther 2015; 20:18-27.

384. King W, Lau P, Lees R, Bogduk N. The validity of manual examination in assessing patients with neck pain. Spine J 2007; 7:22-26.

385. Petersen $T$, Laslett $M$, Juhl C. Clinical classification in low back pain: Bestevidence diagnostic rules based on systematic reviews. BMC Musculoskelet Disord 2017; 18:188.

386. Kent $P$, Keating JL. Classification in nonspecific low back pain: What methods do primary care clinicians currently use? Spine (Phila Pa 1976) 2005; 30:1433-1440.

387. Manchikanti L, Schultz DM, Falco FJE, Singh V. Cervical facet joint interventions. In: Manchikanti L, Singh $\mathrm{V}$ (eds). Interventional Techniques in Chronic Spinal Pain, ASIPP Publishing, Paducah, KY, 2007, pp 295-320.

388. Navani A, Manchikanti L. Lumbar facet joints and regenerative medicine. In: Manchikanti L, Navani A, Atluri S (eds). Essentials of Regenerative Medicine in Interventional Pain Management. ASIPP Publishing, Paducah, KY, 2019, pp 459-472.

389. Jull G, Moore A. Hands on, hands off? The swings in musculoskeletal physiotherapy practice. Man Ther 2012; 17:199-200.

390. Hancock MJ, Maher CG, Latimer J, et al. Systematic review of tests to identify the disc, SIJ or facet joint as the source of low back pain. Eur Spine J 2007; 16:1539-1550.

391. DePalma MJ. Diagnostic nihilism toward low back pain: What once was accepted, should no longer be. Pain Med 2015; 16:1453-1454.

392. de Andrés Ares J, Gilsanz F. Diagnostic nerve blocks in the management of low back pain secondary to facet joint syndrome. Rev Esp Anestesiol Reanim 2019; 66:213-221.

393. Gómez Vega JC, Acevedo-González JC. Clinical diagnosis scale for pain lumbar of facet origin: systematic review of literature and pilot study. Neurocirugia (Astur) 2019; 30:133-143.

394. Ford JJ, Hahne AJ. Pathoanatomy and classification of low back disorders. Man Ther 2013; 18:165-168.

395. Stuber K, Lerede C, Kristmanson K, Sajko $S$, Bruno P. The diagnostic accuracy of the Kemp's test: A systematic review. J Can Chiropr Assoc 2014; 58:258-267.

396. Juan Carlos Acevedo Gonzalez. Validation of a new clinical sign of lumbar facet syndrome. Coluna/ Columna 2018; 17:303-307.

397. Maas ET, Juch JN, Ostelo RW, et al. Systematic review of patient history and physical examination to diagnose chronic low back pain originating from the facet joints. Eur J Pain 2017; 21:403-414.

398. Fritz JM, George S. The use of a classification approach to identify subgroups of patients with acute low back pain. Interrater reliability and short-term treatment outcomes. Spine (Phila Pa 1976) 2000; 25:106-114.

399. Selby DK, Paris SV. Anatomy of facet joints and its correlation with low back pain. Contemp Orthop 1981; 312: 1097-1103.

400. Schleifer J, Kiefer M, Hagen T. Lumbar facet syndrome. Recommendation for staging before and after intra-articular injection treatment. Radiologe 1995; 35:844-847.

401. Lippitt A. The facet joint and its role in spine pain: Management with facet joint injections. Spine (Phila Pa 1976) 1984; 9:746-750.

402. Revel M, Poiraudeau S, Auleley GR, et al. Capacity of the clinical picture to characterize low back pain relieve 
by facet joint anesthesia. Proposed criteria to identify patients with painful facet joints. Spine (Phila Pa 1976)1998; 23:1972-1977.

403. Helbig T, Lee CK.. The lumbar facet syndrome. Spine (Phila Pa 1976) 1988; 13:61-64.

404. Lewinnek GE, Warfield CA. Facet joint degeneration as a cause of low back pain. Clin Orthop 1986; 213:216-222.

405. North RB, Han M, Zahurak M, Kidd $\mathrm{DH}$. Radiofrequency lumbar facet denervation. Analysis of prognostic factors. Pain 1994; 57:77-83.

406. Jackson RP, Jacobs RR, Montesano PX. Facet joint injection in low back pain. A prospective study. Spine (Phila Pa 1976) 1988; 13:966-971.

407. Bogduk N. Evidence-informed management of chronic back pain with facet injections and radiofrequency neurotomy. Spine J 2008; 8:56-64.

408. Souza T. Differential diagnosis and management for the chiropractor: Protocols and algorithms. 2nd (ed). Gaithersburg: Aspen; 2001.

409. Magee D. Orthopedic Physical Assessment. 5 th (ed). St Louis: Saunders Elsevier; 2008.

410. Schneider G, Jull G, Thomas K, et al. Intrarater and interrater reliability of select clinical tests in patients referred for diagnostic facet joint blocks in the cervical spine. Arch Phys Med Rehabil 2013; 94:1628-1634.

411. Revel ME, Listrat VM, Chevalier XJ, et al. Facet joint block for low back pain: Identifying predictors of a good response. Arch Phys Med Rehabil 1992; 73:824-828.

412. Laslett M, Oberg B, Aprill CN, McDonald B. Zygapophysial joint blocks in chronic low back pain: A test of Revel's model as a screening test. BMC Musculoskeletal Disord 2004; 5:43-48.

413. Laslett M, McDonald B, Aprill CN, Tropp H, Oberg B. Clinical predictors of screening lumbar zygapophyseal joint blocks: Development of clinical prediction rules. Spine ] 2006; 6:370-379.

414. Young S, Aprill C, Laslett M. Correlation of clinical examination characteristics with three sources of chronic low back pain. Spine ] 2003; 3:460-465.

415. Manchikanti L, Pampati V, Fellows B, Baha A. The inability of the clinical picture to characterize pain from facet joints. Pain Physician 2000; 3:158-166.

416. Manchikanti L, Fellows B, Singh V, Pampati V. Correlates of non- physiological behavior in patients with chronic low back pain. Pain Physician 2003; 6:159-166.

417. Waddell G, McCulloch JA, Kummel E et al. Nonorganic physical signs in low back pain. Spine (Phila Pa 1976) 1980; 5:117-125.

418. Waddell G, Main CJ, Morris EW et al. Chronic low back pain, psychologic distress, and illness behavior. Spine (Phila Pa 1976) 1984; 9: 209-213.

419. Mainka T, Lemburg SP, Heyer CM, Altenscheidt J, Nicolas V, Maier C. Association between clinical signs assessed by manual segmental examination and findings of the lumbar facet joints on magnetic resonance scans in subjects with and without current low back pain: A prospective, single-blind study. Pain 2013; 154:1886-1895.

420. DePalma MJ, Ketchum JM, Trussell BS, et al. Does the location of low back pain predict its source? Pm R 2011; 3:33-39.

421. DePalma MJ, Ketchum JM, Saullo TR. Multivariable analyses of the relationships between age, gender, and body mass index and the source of chronic low back pain. Pain Med 2012; 13:498-506.

422. Usunier K, Hynes M, Schuster JM, Cornelio-Jin Suen A, Sadi J, Walton D. Clinical diagnostic tests versus medial branch blocks for adults with persisting cervical zygapophyseal joint pain: A systematic review and meta-analysis. Physiother Can 2018; 70:179-187.

423. Jull G, Bogduk N, Marsland A. The accuracy of manual diagnosis for cervical zygapophysial joint pain syndromes. Med J Aust 1988; 148:233-236.

424. Siegenthaler A, Eichenberger $U$, Schmidlin K, et al. What does local tenderness say about the origin of pain? An investigation of cervical zygapophysial joint pain. Anesth Analg 2010; 110:923-927.

425. Speldewinde G, Bashford G, Davidson I. Diagnostic cervical zygapophyseal joint blocks for chronic cervical pain. Med J Aust 2001; 174:174-176.

426. Schneider GM, Jull G, Thomas K, et al. Derivation of a clinical decision guide in the diagnosis of cervical facet joint pain. Arch Phys Med Rehabil 2014; 95:1695-1701.

427. Jull GA, Söderlund A, Stemper BD, et al. Toward optimal early management after whiplash injury to lessen the rate of transition to chronicity: Discussion paper 5. Spine (Phila Pa 1976) 2011; $36: \mathrm{S}_{335}-\mathrm{S}_{342}$.
428. Bogduk N, Jull G. Manual therapy produces greater relief of neck pain than physiotherapy or general practitioner care. Aust J Physiother 2002; 48:240-241.

429. Pathria M, Sartoris DJ, Resnick D. Osteoarthritis of the facet joints: Accuracy of oblique radiographic measurement. Radiology 1987; 164: 227-230.

430. Weishaupt D, Zanetti M, Boos N, Hodler J. MR imaging and CT in osteoarthritis of the lumbar facet joints. Skeletal Radiol 1999; 28:215-219.

431. Freiermuth $D$, Kretzschmar $M$, Bilecen $S$, et al. Correlation of $99 \mathrm{~m}$ Tc-DPD SPECT/CT scan findings and diagnostic blockades of lumbar medial branches in patients with unspecific low back pain in a randomized-controlled trial. Pain Med 2015; 16:1916-1922.

432. Dolan AL, Ryan PJ, Arden NK, et al. The value of SPECT scans in identifying back pain likely to benefit from the facet joint injection. $\mathrm{Br}$ J Rheumatol 1996; 35:1269-1273.

433. Ackerman WE, Ahmad M. Pain relief with intraarticular or medial branch nerve blocks in patients with positive lumbar facet joint SPECT imaging: A 12week outcome study. South Med J 2008; 101:931-934.

434. Holder LE, Machin JL, Asdourian PL, et al. Planar and high- resolution SPECT bone imaging in the diagnosis of facet syndrome. J Nucl Med 1995; 36:37-44.

435. Jain A, Jain S, Agarwal A, et al. Evaluation of efficacy of bone scan with SPECT/ $C T$ in the management of low back pain: A study supported by differential diagnostic local anesthetic blocks. Clin J Pain 2015; 31:1054-1059.

436. Koh WU, Kim SH, Hwang BY, et al. Value of bone scintigraphy and single photon emission computed tomography (SPECT) in lumbar facet disease and prediction of short- term outcome of ultrasound guided medial branch block with bone SPECT. Korean J Pain 2011; 24:81-86.

437. Pneumaticos SG, Chatziioannou SN, Hipp JA, Moore WH, Esses SI. Low back pain: Prediction of short-term outcome of facet joint injection with bone scintigraphy. Radiology, 2006; 238:693-698.

438. Stojanovic MP, Sethee J, Mohiuddin M, et al. MRI analysis of the lumbar spine: Can it predict response to diagnostic and therapeutic facet procedures? Clin J Pain 2010; 26:110-115.

439. Perez-Roman RJ, Brusko GD, Burks SS, 
Serafini AN, Wang MY. Use of singlephoton emission computed tomography imaging for hypermetabolic facet identification in diagnosis of cervical and axial back pain. World Neurosurg 2020; 20:S1878-S8750

440. Kato S, Demura S, Matsubara H, et al. Utility of bone SPECT/CT to identify the primary cause of pain in elderly patients with degenerative lumbar spine disease. J Orthop Surg Res 2019; 14:185.

441. Curatolo M, Bogduk N. Diagnostic blocks for chronic pain. Scand J Pain 2010; 1:186-192.

442. Bogduk N, Holmes S. Controlled zygapophysial joint blocks: The travesty of cost-effectiveness. Pain Med 2000, 1:25-34.

443. Engel A, MacVicar J, Bogduk N. A philosophical foundation for diagnostic blocks, with criteria for their validation. Pain Med 2014; 15:998-1006.

444. Bogduk N. On diagnostic blocks for lumbar zygapophysial joint pain. F1000 Med Rep 2010; 2:57.

445. Rubinstein SM, van Tulder M. A best-evidence review of diagnostic procedures for neck and low-back pain. Best Pract Res Clin Rheumatol 2008; 22:471-482.

446. Pampati S, Cash KA, Manchikanti L. Accuracy of diagnostic lumbar facet joint nerve blocks: A 2-year follow-up of 152 patients diagnosed with controlled diagnostic blocks. Pain Physician 2009; 12:855-866.

447. Manchikanti L, Singh V, Pampati V. Are diagnostic lumbar medial branch blocks valid? Results of 2-year follow up. Pain Physician 2003; 6:147-153.

448. Manchikanti L, Pampati S, Cash KA. Making sense of the accuracy of diagnostic lumbar facet joint nerve blocks: An assessment of implications of $50 \%$ relief, $80 \%$ relief, single block or controlled diagnostic blocks. Pain Physician 2010; 13:133-143.

449. Dreyfuss P, Schwarzer AC, Lau P, Bogduk N. Specificity of lumbar medial branch and $\mathrm{L}_{5}$ dorsal ramus blocks. Spine (Phila Pa 1976) 1997; 22:895-902.

450. Barnsley L, Bogduk N. Medial branch blocks are specific for the diagnosis of cervical zygapophyseal joint pain. Reg Anesth 1993; 18:343-350.

451. Kaplan M, Dreyfuss P, Halbrook B, Bogduk N. The ability of lumbar medial branch blocks to anesthetize the zygapophysial joint. Spine (Phila Pa 1976)1998; 23:18471852.
452. Manchikanti L, Pampati V, Damron KS, et al. The effect of sedation on diagnostic validity of facet joint nerve blocks: An evaluation to assess similarities in population with involvement in cervical and lumbar regions (ISRCTNo: 76376497). Pain Physician 2006; 9:47-52.

453. Manchikanti L, Pampati V, Damron KS. The role of placebo and nocebo effects of perioperative administration of sedatives and opioids in interventional pain management. 2005; 8:349-355

454. Theodore BR, Olamikan S, Keith RV, Gofeld M. Validation of self-reported pain reduction after diagnostic blockade. Pain Med 2012; 13:1131-1136.

455. Cohen SP, Williams KA, Kurihara C, et al. Multicenter, randomized, comparative cost-effectiveness study comparing $o$, 1 , and 2 diagnostic medial branch (facet joint nerve) block treatment paradigms before lumbar facet radiofrequency denervation. Anesthesiology 2010; 113:395-405.

456. Abd-Elsayed A, Narel E, Loebertman M. Is a One Prognostic Block Sufficient to Proceed with Radiofrequency Ablation? A Single Center Experience. Curr Pain Headache Rep. 2020; 24:23.

457. Holz SC, Sehgal N. What is the correlation between facet joint radiofrequency outcome and response to comparative medial branch blocks? Pain Physician 2016; 19:163-172.

458. Cohen SP, Moon JY, Brummett CM, White RL, Larkin TM. Medial Branch Blocks or Intra-articular injections as a prognostic tool before lumbar facet radiofrequency denervation: A multicenter, case-control study. Reg Anesth Pain Med 2015; 40:376-383.

459. Cohen SP, Strassels SA, Kurihara C, et al. Establishing an optimal "cutoff" threshold for diagnostic lumbar facet blocks: A prospective correlational study. Clin J Pain 2013; 29:382-391.

460. Bossuyt PM, Reitsma JB, Bruns $D E$, et al; Standards for Reporting of Diagnostic Accuracy. Towards complete and accurate reporting of studies of diagnostic accuracy: The STARD Initiative. Ann Intern Med 2003; 138:40-44.

461. Falco FJE, Datta S, Manchikanti L, et al. An updated review of diagnostic utility of cervical facet joint injections. Pain Physician 2012; 15:E807-E838.

462. Atluri $S$, Singh $V$, Datta $S$, Geffert $S$, Sehgal N, Falco FJE. Diagnostic accuracy of thoracic facet joint nerve blocks: An update of the assessment of evidence.
Pain Physician 2012; 15:E483-E496.

463. Falco FJE, Manchikanti L, Datta S, et al. An update of the systematic assessment of the diagnostic accuracy of lumbar facet joint nerve blocks. Pain Physician 2012; 15:E869-E907.

464. Manchikanti L, Falco FJE, Singh V, et al. An update of comprehensive evidencebased guidelines for interventional techniques of chronic spinal pain. Part I: Introduction and general considerations. Pain Physician 2013; 16:S1-S48.

465. Whiting PF, Rutjes AW, Westwood ME, et al. QUADAS-2: a revised tool for the quality assessment of diagnostic accuracy studies. Ann Intern Med 2011; 155:529-536.

466. Lucas NP, Macaskill P, Irwing L, Bogduk $\mathrm{N}$. The development of a quality appraisal tool for studies of diagnostic reliability (QAREL). J Clin Epidemiol 2010; 63:854-861.

467. Lucas N, Macaskill P, Irwig L, et al. The reliability of a quality appraisal tool for studies of diagnostic reliability (QAREL). BMC Med Res Methodol 2013; 13:111.

468. Manchikanti L, Pampati V, Fellows B, Pakanati RR. Prevalence of lumbar facet joint pain in chronic low back pain. Pain Physician 1999; 2:59-64.

469. Manchikanti L, Pampati V, Fellows B, Bakhit CE. The diagnostic validity and therapeutic value of medial branch blocks with or without adjuvants. Curr Rev Pain 2000; 4:337-344.

470. Manchikanti L, Boswell MV, Singh V, Pampati V, Damron KS, Beyer CD. Prevalence of facet joint pain in chronic spinal pain of cervical, thoracic, and lumbar regions. BMC Musculoskelet Disord 2004; 5:15.

471. Manchukonda R, Manchikanti KN, Cash KA, Pampati V, Manchikanti L. Facet joint pain in chronic spinal pain: An evaluation of prevalence and false positive rate of diagnostic blocks. J Spinal Disord Tech 2007; 20:539-545.

472. Manchikanti L, Singh V, Rivera J, Pampati V. Prevalence of cervical facet joint pain in chronic neck pain. Pain Physician 2002; 5:243-249.

473. Barnsley L, Lord S, Bogduk N. Comparative local anaesthetic blocks in the diagnosis of cervical zygapophysial joint pain. Pain 1993; 55:99-106.

474. Cohen SP, Strassels SA, Kurihara C, et al. Randomized study assessing the accuracy of cervical facet joint nerve (medial branch) blocks using different 
injectate volumes. Anesthesiology 2010; 112:144-152.

475. Persson M, Sörensen J, Gerdle B Chronic Whiplash Associated Disorders (WAD): Responses to nerve blocks of cervical zygapophyseal joints. Pain Med 2016; 17:2162-2175.

476. Barnsley L, Lord SM, Wallis BJ, Bogduk $N$. The prevalence of chronic cervical zygapophyseal joint pain after whiplash. Spine (Phila Pa 1976) 1995; 20:20-26.

477. Barnsley L, Lord S, Wallis B, Bogduk N. False-positive rates of cervical zygapophysial joint blocks. Clin J Pain 1993; 9:124-130.

478. Lord SM, Barnsley L, Wallis BJ, Bogduk N. Chronic cervical zygapophysial joint pain with whiplash: A placebocontrolled prevalence study. Spine (Phila Pa 1976) 1996; 21:1737-1744.

479. Lord SM, Barnsley L, Bogduk N. The utility of comparative local anesthetic blocks versus placebo-controlled blocks for the diagnosis of cervical zygapophysial joint pain. Clin J Pain 1995; 11:208-213.

480. Manchikanti L, Singh V, Pampati VS, Beyer CD, Damron KS. Evaluation of the prevalence of facet joint pain in chronic thoracic pain. Pain Physician 2002; 5:354-359.

481. Bogduk N, Marsland A. The cervical zygapophysial joints as a source of neck pain. Spine (Phila Pa 1976) 1988; 13:610-617.

482. Aprill C, Bogduk N. The prevalence of cervical zygapophyseal joint pain. A first approximation. Spine (Phila Pa 1976) 1992; 17:744-747.

483. Manchikanti L, Pampati V, Rivera JJ, Fellows B, Beyer CD, Damron KS. Role of facet joints in chronic low back pain in the elderly: A controlled comparative prevalence study. Pain Practice 2001; 1:332-337.

484. Manchikanti L, Pampati V, Singh V, Beyer C, Damron K, Fellows B. Evaluation of role of facet joints in persistent low back pain in obesity: A controlled, prospective, comparative evaluation. Pain Physician 2001; 4:266-272.

485. Manchikanti L, Hirsch JA, Pampati V. Chronic low back pain of facet (zygapophysial) joint origin: Is there a difference based on involvement of single or multiple spinal regions? Pain Physician 2003; 6:399-405.

486. Manchikanti L, Singh V, Pampati V, Damron K, Beyer C, Barnhill R. Is there correlation of facet joint pain in lumbar and cervical spine? An evaluation of prevalence in combined chronic low back and neck pain. Pain Physician 2002; 5:365-371.

487. Manchikanti L, Boswell MV, Manchukonda R, Cash KA, Giordano J. Influence of prior opioid exposure on diagnostic facet joint nerve blocks. J Opioid Manage 2008; 4:351-360.

488. Manchikanti L, Cash KA, Pampati V, Fellows B. Influence of psychological variables on the diagnosis of facet joint involvement in chronic spinal pain. Pain Physician 2008; 11:145-160.

489. Manchikanti L, Singh V, Fellows $B$, Pampati V. Evaluation of influence of gender, occupational injury, and smoking on chronic low back pain of facet joint origin: A subgroup analysis. Pain Physician 2002; 5:30-35.

490. Manchikanti L, Manchikanti K, Cash KA, Singh V, Giordano J. Age-related prevalence of facet joint involvement in chronic neck and low back pain. Pain Physician 2008; 11:67-75.

491. Manchikanti L, Pampati V, Damron $\mathrm{KS}$, et al. A randomized, prospective, double-blind, placebo-controlled evaluation of the effect of sedation on diagnostic validity of cervical facet joint pain. Pain Physician 2004; 7:301-309.

492. Manchikanti L, Damron KS, Rivera JJ, et al. Evaluation of the effect of sedation as a confounding factor in the diagnostic validity of lumbar facet join pain: A prospective, randomized, double-blind, placebo-controlled evaluation. Pain Physician 2004; 7:411-417.

493. Wasan AD, Jamison RN, Pham L, Tipirneni N, Nedeljkovic SS, Katz JN. Psychopathology predicts the outcome of medial branch blocks with corticosteroid for chronic axial low back or cervical pain: A prospective cohort study. BMC Musculoskelet Disord 2009; 10:22.

494. Manchikanti L, Pampati V, Damron KS, McManus CD, Jackson SD, Barnhill RC, Martin JC. The effect of sedation on diagnostic validity of facet joint nerve blocks: An evaluation to assess similarities in population with involvement in cervical and lumbar regions (ISRCTNo: 76376497). Pain Physician 2006; 9:47-52.

495. Cohen SP, Hameed H, Kurihara C, et al. The effect of sedation on the accuracy and treatment outcomes for diagnostic injections: A randomized, controlled, crossover study. Pain Med 2014; 15:588-602.
496. Kim N, Delport E, Cucuzzella T, Marley J, Pruitt $C$. Is sedation indicated before spinal injections? Spine (Phila Pa 1976) 2007; 32:E748-E752.

497. Cucuzzella TR, Delport EG, Kim N, Marley J, Pruitt C, Delport AG. A survey: Conscious sedation with epidural and zygapophyseal injections: Is it necessary?. Spine ] 2006; 6:364-369.

498. Manchikanti L, Pampati V, Damron K. The role of placebo and nocebo effects of perioperative administration of sedatives and opioids in interventional pain management. Pain Physician 2005; 8:349-355.

499. Manchikanti L, Benyamin RM, Candido KD, Hirsch JA. Cohen et al reach inappropriate conclusions on the effect of sedation on the accuracy and treatment outcomes for diagnostic injections Letter to the Editor RE: Cohen $S P$ et al. The effect of sedation on the accuracy and treatment outcomes for diagnostic injections: A randomized, controlled, crossover study. Pain Med 2014; 15:588-602. Pain Med 2014; 15:1978-1980.

500. Bonica JJ. Local anaesthesia and regional blocks. In: Wall PD, Melzack $\mathrm{R}$ (eds.) Textbook of Pain, 2nd ed. Churchill Livingstone, Edinburgh, 1989, pp 724-743.

501. Bonica JJ, Buckley FP. Regional analgesia with local anesthetics. In: Bonica JJ (ed.) The Management of Pain, Vol. II. Lea and Febiger, Philadelphia, PA, 1990, pp 1883-1966.

502. RA Boas. Nerve blocks in the diagnosis of low back pain, Neurosurg. Clin N Am 1991; 2:807-816.

503. Cousins MJ, Mather LE. Clinical pharmacology of local anaesthetics. Anaesth Intensive Care 1980; 8:257-277.

504. Moore DC, Bridenbaugh LD, Bridenbaugh PO, Tucker GT. Bupivacaine. A review of 2,077 cases. JAMA 1970; 214:713-718.

505. Moore DC, Bridenbaugh LD, Bridenbaugh PO, Tucker GT. Bupivacaine for peripheral nerve block: A comparison with mepivacaine, lidocaine, and tetracaine. Anesthesiology 1970; 32:460-463.

506. Watt MJ, Ross DM, Atkinson RS. A double-blind trial of bupivacaine and lignocaine. Latency and duration in extradural blockade. Anaesthesia 1968; 23:331-337.

507. Rubin AP, Lawson DI. A controlled trial 
of bupivacaine. A comparison with lignocaine. Anaesthesia 1968; 23:327-330.

508. Manchikanti L, Singh V, Falco FJE, Cash KA, Pampati V. Evaluation of lumbar facet joint nerve blocks in managing chronic low back pain: A randomized, double-blind, controlled trial with a 2-year follow-up. Int J Med Sci 2010; 7:124-135.

509. Manchikanti L, Pampati V, Bakhit C, et al. Effectiveness of lumbar facet joint nerve blocks in chronic low back pain: A randomized clinical trial. Pain Physician 2001; 4:101-117.

510. Manchikanti L, Singh V, Falco FJE, Cash KA, Pampati V, Fellows B. The role of thoracic medial branch blocks in managing chronic mid and upper back pain: A randomized, doubleblind, activecontrol trial with a 2-year follow-up. Anesthesiol Res Pract 2012; 2012:585806.

511. Manchikanti L, Manchikanti KN, Manchukonda R, Pampati V, Cash KA. Evaluation of therapeutic thoracic medial branch block effectiveness in chronic thoracic pain: A prospective outcome study with minimum 1-year follow up. Pain Physician 2006; 9:97-105.

512. Manchikanti L, Singh V, Falco FJE, Cash KA, Fellows B. Comparative outcomes of a 2-year follow-up of cervical medial branch blocks in management of chronic neck pain: A randomized, double-blind controlled trial. Pain Physician 2010; 13:437-450.

513. Manchikanti L, Manchikanti K, Damron K, Pampati V. Effectiveness of cervical medial branch blocks in chronic neck pain: A prospective outcome study. Pain Physician 2004; 7:195-201.

514. Manchikanti L, Knezevic NN, Parr A, Kaye AD, Sanapati M, Hirsch JA. Does epidural bupivacaine with or without steroids provide long-term relief? A systematic review and meta-analysis. Curr Pain Headache Rep 2020; 24:26.

515. Shanthanna H, Busse JW, Thabane L, et al. Local anesthetic injections with or without steroid for chronic noncancer pain: A protocol for a systematic review and meta-analysis of randomized controlled trials. Syst Rev 2016; 5:18.

516. Hamaya C, Barr T, Strichartz GR. Multiple inhibitory mechanisms of lidocaine on bradykinin receptor activity in model sensory neurons. Reg Anesth Pain Med 2018; 43:605-612.

517. Derby R, Melnik I, Choi J, Lee JE. Indications for repeat diagnostic medial branch nerve blocks following a failed first medial branch nerve block. Pain Physician 2013; 16:479-488.

518. Derby R, Melnik I, Lee JE, Lee SH. Correlation of lumbar medial branch neurotomy results with diagnostic medial branch block cutoff values to optimize therapeutic outcome. Pain Med 2012; 13:1533-1546.

519. Schneider BJ, Doan L, Maes MK, Martinez KR, Gonzalez Cota A, Bogduk $N$. Systematic review of the effectiveness of lumbar medial branch thermal radiofrequency neurotomy, stratified for diagnostic methods and procedural technique. Pain Med 2020 Feb 10. [Epub ahead of print]

520. Bushnell MC, Ceko M, Low LA. Cognitive and emotional control of pain and its disruption in chronic pain. Nat Rev Neurosci 2013; 14:502-511.

521. Hench P, Boland E. The management of chronic arthritis and other rheumatic diseases among soldiers of the United States army. Ann Rheum Dis 1946; 5:106-114.

522. Barsky AJ, Borus JF. Functional somatic syndromes. Ann Intern 1999; 130:910-921.

523. Wolfe $F$, Brahler $E$, Hinz $A$, et al. Fibromyalgia prevalence, somatic symptom reporting, and the dimensionality of polysymptomatic distress: Results from a survey of the general population. Arthritis Care Res 2013; 65:777-785.

524. Association AP. Diagnostic and Statistical Manual of Mental Disorders - DSM-5. Washington, DC: American Psychiatric Publishing; 2013.

525. Crofford LJ. Psychological aspects of chronic musculoskeletal pain. Best Pract Res Clin Rheumatol 2015; 29:147-155.

526. Furlan AD, Malmivaara A, Chou R, et al; Editorial Board of the Cochrane Back, Neck Group. 2015 Updated Method Guideline for Systematic Reviews in the Cochrane Back and Neck Group. Spine (Phila Pa 1976) 2015; 40:1660-1673.

527. Manchikanti L, Hirsch JA, Cohen SP, et al. Assessment of methodologic quality of randomized trials of interventional techniques: Development of an interventional pain management specific instrument. Pain Physician 2014; 17:E263-E290.

528. Manchikanti L, Hirsch JA, Heavner JE, et al. Development of an interventional pain management specific instrument for methodologic quality assessment of nonrandomized studies of interventional techniques. Pain Physician 2014; 17:E291-E317.

529. Carette S, Marcoux S, Truchon R, et al. A controlled trial of corticosteroid injections into facet joints for chronic low back pain. N Engl J Med 1991; 325:1002-1007.

530. Fuchs S, Erbe T, Fischer HL, Tibesku CO. Intraarticular hyaluronic acid versus glucocorticoid injections for nonradicular pain in the lumbar spine. J Vasc Interv Radiol 2005; 16:1493-1498.

531. Nath S, Nath CA, Pettersson K. Percutaneous lumbar zygapophysial (facet) joint neurotomy using radiofrequency current, in the management of chronic low back pain: A randomized doubleblind trial. Spine (Phila Pa 1976) 2008; 33:1291-1298.

532. van Wijk RM, Geurts JW, Wynne HJ. Radiofrequency denervation of lumbar facet joints in the treatment of chronic low back pain: A randomized, doubleblind, sham lesion-controlled trial. Clin J Pain 2005; 21:335-344.

533. van Kleef $M$, Barendse GAM, Kessels A, Voets HM, Weber WE, de Lange S. Randomized trial of radiofrequency lumbar facet denervation for chronic low back pain. Spine (Phila Pa 1976) 1999; 24:1937-1942.

534. Tekin I, Mirzai H, Ok G, Erbuyun K, Vatansever D. A comparison of conventional and pulsed radiofrequency denervation in the treatment of chronic facet joint pain. Clin J Pain 2007; 23:524-529.

535. Civelek E, Cansever T, Kabatas S, et al. Comparison of effectiveness of facet joint injection and radiofrequency denervation in chronic low back pain. Turk Neurosurg 2012; 22:200-206.

536. Lakemeier S, Lind M, Schultz W, et al. A comparison of intraarticular lumbar facet joint steroid injections and lumbar facet joint radiofrequency denervation in the treatment of low back pain: A randomized, controlled, double-blind trial. Anesth Analg 2013; 117:228-235.

537. Sae-Jung S, Jirarattanaphochai K. Outcomes of lumbar facet syndrome treated with oral diclofenac or methylprednisolone facet injection: A randomized trial. Int Orthop 2016; 40:1091-1098.

538. Do KH, Ahn SH, Cho YW, Chang MC. Comparison of intra-articular lumbar facet joint pulsed radiofrequency and intra-articular lumbar facet joint corticosteroid injection for management 
of lumbar facet joint pain: A randomized controlled trial. Medicine (Baltimore) 2017; 96:e6524.

539. Leggett LE, Soril LJ, Lorenzetti DL, et al. Radiofrequency ablation for chronic low back pain: A systematic review of randomized controlled trials. Pain Res Manag 2014; 19:e146-e153.

540. Poetscher AW, Gentil AF, Lenza M, Ferretti M. Radiofrequency denervation for facet joint low back pain: A systematic review. Spine (Phila Pa 1976) 2014; 39:E842-E849.

541. Roy C, Chatterjee N, Ganguly S, Sengupta R. Efficacy of combined treatment with medial branch radiofrequency neurotomy and steroid block in lumbar facet joint arthropathy. J Vasc Interv Radiol 2012; 23:1659-1664.

542. Paulsen RT, Carreon L, Busch F, Isenberg-Jørgensen A. A pilot cohort study of lumbar facet joint denervation in patients with chronic low-back pain. Dan Med J 2019; 66:A5533.

543. Streitberger $\mathrm{K}$, Müller T, Eichenberger U, Trelle S, Curatolo M. Factors determining the success of radiofrequency denervation in lumbar facet joint pain: A prospective study. Eur Spine J 2011; 20:2160-2165.

544. Dobrogowski J, Wrzosek A, Wordliczek J. Radiofrequency denervation with or without addition of pentoxifylline or methylprednisolone for chronic lumbar zygapophysial joint pain. Pharmacol Rep 2005; 57:475-480.

545. Moon JY, Lee PB, Kim YC, Choi SP, Sim WS. An alternative distal approach for the lumbar medial branch radiofrequency denervation: A prospective randomized comparative study. Anesth Analg 2013; 116:1133-1140.

546. Leclaire R, Fortin L, Lambert R, Bergeron $Y M$, Rossignol M. Radiofrequency facet joint denervation in the treatment of low back pain: A placebocontrolled clinical trial to assess efficacy. Spine (Phila Pa 1976) 2001; 26:1411-1416.

547. Kroll H, Kim D, Danic $M$, Sankey $S$, Gariwala M, Brown M. A randomized, double-blind, prospective study comparing the efficacy of continuous versus pulsed radiofrequency in the treatment of lumbar facet syndrome. J Clin Anesth 2008; 20:534-537.

548. Kennedy DJ, Huynh L, Wong J, et al. Corticosteroid injections into lumbar facet joints: A prospective, randomized, double-blind placebo-controlled trial. Am J Phys Med Rehabil 2018; 97:741-746.

549. Kwak DG, Kwak SG, Lee AY, Chang MC.
Outcome of intra-articular lumbar facet joint corticosteroid injection according to the severity of facet joint arthritis. Exp Ther Med 2019; 18:4132-4136.

550. Kennedy DJ, Fraiser R, Zheng P, et al. Intra-articular steroids vs saline for lumbar z-joint pain: A prospective, randomized, double-blind placebocontrolled trial. Pain Med 2019; 20:246-251.

551. Annaswamy TM, Armstead C, Carlson L, Elkins NJ, Kocak D, Bierner SM. Intra-articular triamcinolone versus hyaluronate injections for low back pain with symptoms suggestive of lumbar zygapophyseal joint arthropathy: A pragmatic, double-blind randomized controlled trial. Am J Phys Med Rehabil 2018; 97:278-284.

552. Lamer TJ, Smith J, Hoelzer BC, Mauck WD, Qu W, Gazelka HM. Safety of lumbar spine radiofrequency procedures in patients who have posterior spinal hardware. Pain Med 2016; 17:1634-1637.

553. Joo YC, Park JY, Kim KH. Comparison of alcohol ablation with repeated thermal radiofrequency ablation in medial branch neurotomy for the treatment of recurrent thoracolumbar facet joint pain. J Anesth 2013; 27:390-395.

554. Li ZZ, Hou SX, Shang WL, Song KR, Wu WW. Evaluation of endoscopic dorsal ramus rhizotomy in managing facetogenic chronic low back pain. Clin Neurol Neurosurg 2014; 126:11-17.

555. Campos WK, Linhares MN, Sarda J, et al. Predictors of pain recurrence after lumbar facet joint injections. Front Neurosci 2019; 13:958.

556. Rambaransingh B, Stanford G, Burnham $R$. The effect of repeated zygapophysial joint radiofrequency neurotomy on pain, disability, and improvement duration. Pain Med 2010; 11:1343-1347.

557. BurnhamR, Holitski S. A prospective outcome study on the effects of facet joint radiofrequency denervation on pain, analgesic intake, disability, satisfaction, cost, and employment. Arch Phys Med Rehabil 2009; 90:201-205.

558. Gofeld M, Jitendra J, Faclier G. Radiofrequency facet denervation of the lumbar zygapophysial joints: 10-year prospective clinical audit. Pain Physician 2007; 10:291-300.

559. Schofferman J, Kine G. Effectiveness of repeated radiofrequency neurotomy for lumbar facet pain. Spine (Phila Pa 1976) 2004; 29:2471-2473.

560. Husted DS, Orton D, Schofferman J, Kine G. Effectiveness of repeated radiofrequency neurotomy for cervical facet joint pain. J Spinal Disord Tech 2008; 21:406-408.

561. Lilius G, Laasonen EM, Myllynen P, Harilainen A, Gronlund G. Lumbar facet joint syndrome. A randomised clinical trial. J Bone Joint Surg $\mathrm{Br}$ 1989; 71:681-684.

562. Ye L, Wen C, Liu H. Ultrasound-guided versus low dose computed tomography scanning guidance for lumbar facet joint injections: Same accuracy and efficiency. BMC Anesthesiol 2018; 18:160.

563. Kang WY, Lee JW, Lee E, Kang Y, Ahn JM, Kang HS. Efficacy and outcome predictors of fluoroscopy-guided facet joint injection for spondylolysis. Skeletal Radiol 2018; 47:1137-1144.

564. Kershen LM, Nacey NC, Patrie JT, Fox MG. Fluoroscopically Guided facet injections: Comparison of intra-articular and periarticular steroid and anesthetic injection on immediate and short-term pain relief. AJNR Am J Neuroradiol 2018; 39:2161-2165.

565. Snidvongs S, Taylor RS, Ahmad A, et al. Facet-joint injections for non-specific low back pain: A feasibility RCT. Health Technol Assess 2017; 21:1-130.

566. Çetin A, YektaD A. Evaluation of the short- and long-term effectiveness of pulsed radiofrequency and conventional radiofrequency performed for medial branch block in patients with lumbar facet joint pain. Pain Res Manag 2018; 2018:7492753.

567. Marks RC, Houston T, Thulbourne T. Facet joint injection and facet nerve block: A randomised comparison in 86 patients with chronic low back pain. Pain 1992; 49:325-328.

568. Gallagher J, Petriccione Di Vadi PL, Wedley JR, et al. Radiofrequency facet joint denervation in the treatment of low back pain: A prospective controlled double-blind study to assess its efficacy. Pain Clinic 1994; 7:193-198.

569. Moussa WM, Khedr W. Percutaneous radiofrequency facet capsule denervation as an alternative target in lumbar facet syndrome. Clin Neurol Neurosurg 2016; 150:96-104.

570. Zhou Q, Zhou F, Wang L, Liu K. An investigation on the effect of improved X-rays-guided radiofrequency thermocoagulation denervation on lumbar facet joint syndrome. Clin Neurol Neurosurg 2016; 148:115-120.

571. Kader D, Radha S, Smith F, et al. Evaluation of perifacet injections and paraspinal muscle rehabilitation 
in treatment of low back pain. A randomised controlled trial. Ortop Traumatol Rehabil 2012; 14:251-259.

572. Yun DH, Kim HS, Yoo SD, et al. Efficacy of ultrasonography-guided injections in patients with facet syndrome of the low lumbar spine. Ann Rehabil Med 2012; 36:66-71.

573. Leon JF, Ortiz JG, Fonseca EO, Martinez CR, Cuellar GO. Radiofrequency neurolysis for lumbar pain using a variation of the original technique. Pain Physician 2016; 19:155-1561.

574. Wen CB, Li YZ, Sun L, et al. A clinical trial of ultrasound-guided facet joint block in the lumbar spine to treat facet joint related low back pain. Sichuan $D a$ Xue Xue Bao Yi Xue Ban 2014; 45:712-716.

575. Lee DG, Ahn SH, Cho YW, Do KH, Kwak SG, Chang MC. Comparison of intraarticular thoracic facet joint steroid injection and thoracic medial branch block for the management of thoracic facet joint pain. Spine (Phila Pa 1976) 2018; 43:76-80.

576. Chang MC. Effect of pulsed radiofrequency treatment on the thoracic medial branch for managing chronic thoracic facet joint pain refractory to medial branch block with local anesthetics. World Neurosurg 2018; 111:e644-e648.

577. Kim D. Bipolar intra-articular radiofrequency thermocoagulation of the thoracic facet joints: A case series of a new technique. Korean J Pain 2014; 27:43-48.

578. Stolker RJ, Vervest AC, Groen GJ. Percutaneous facet denervation in chronic thoracic spinal pain. Acta Neurochir (Wien) 1993; 122:82-90.

579. Lord S, Barnsley L, Wallis B, McDonald G, Bogduk N. Percutaneous radiofrequency neurotomy for chronic cervical zygapophyseal-joint pain. $N$ Engl ] Med 1996; 335:1721-1726.

580. Gungor S, Candan B. The efficacy and safety of cooled-radiofrequency neurotomy in the treatment of chronic thoracic facet (zygapophyseal) joint pain: A retrospective study. Medicine (Baltimore) 2020; 99:e19711.

581. Rohof O, Chen CK. The response to radiofrequency neurotomy of medial branches including a bipolar system for thoracic facet joints. Scand J Pain 2018; 18:747-753.

582. Sapir DA, Gorup JM. Radiofrequency medial branch neurotomy in litigant and non-litigant patients with cervical whiplash. Spine (Phila Pa 1976) 2001;
26:E268-E273.

583. Park KD, Jee $H, N a m H S$, et al. Effect of medial branch block in chronic facet joint pain for osteoporotic compression fracture: One year retrospective study. Ann Rehabil Med 2013; 37:191-201.

584. Mehnert MJ, Freedman MK. Update on the role of z-joint injection and radiofrequency neurotomy for cervicogenic headache. PM $R$ 2013; 5:221-227.

585. Speldewinde GC. Outcomes of percutaneous zygapophysial and sacroiliac joint neurotomy in a community setting. Pain Med 2011; 12:209-218.

586. Barnsley L, Lord SM, Wallis BJ, Bogduk N. Lack of effect of intra-articular corticosteroids for chronic pain in the cervical zygapophyseal joints. $N$ Engl J Med 1994; 330:1047-1050.

587. Park SC, Kim KH. Effect of adding cervical facet joint injections in a multimodal treatment program for long-standing cervical myofascial pain syndrome with referral pain patterns of cervical facet joint syndrome. J Anesth 2012; 26:738-745.

588. McDonald G, Lord S, Bogduk N. Longterm follow-up of patients treated with cervical radiofrequency neurotomy for chronic spinal pain. Neurosurgery 1999; 45:61-67.

589. Barnsley L. Percutaneous radiofrequency neurotomy for chronic neck pain: Outcomes in a series of consecutive patients. Pain Med 2005; 6:282-286.

590. Hahn T, Halatsch ME, Wirtz C, Klessinger $S$. Response to cervical medial branch blocks in patients with cervicogenic vertigo. Pain Physician 2018; 21:285-294.

591. Lee DW, Huston C. Fluoroscopicallyguided cervical zygapophyseal therapeutic joint injections may reduce the need for radiofrequency. Pain Physician 2018; 21:E661-E665.

592. Govind J, King W, Bailey B, Bogduk $N$. Radiofrequency neurotomy for the treatment of third occipital headache. J Neurol Neurosurg Psychiatry 2003; 74:88-93.

593. Lord SM, Barnsley L, Bogduk N. Percutaneous radiofrequency neurotomy in the treatment of cervical zygapophysial joint pain: A caution. Neurosurgery 1995; 35:732-739.

594. Obernauer J, Galiano K, Gruber H, et al. Ultrasound-guided versus computed tomography-controlled facet joint injections in the middle and lower cervical spine: A prospective randomized clinical trial. Med Ultrason 2013; 15:10-15.

595. Slappendel R, Crul BJ, Braak GJ, et al. The efficacy of radiofrequency lesioning of the cervical spinal dorsal root ganglion in a double blinded randomized study: No difference between $40^{\circ} \mathrm{C}$ and $67^{\circ} \mathrm{C}$ treatments. Pain 1997; 73:159-163.

596. Haspeslagh SR, Van Suijlekom HA, Lame IE, Kessels AG, van Kleef $M$, Weber WE. Randomised controlled trial of cervical radiofrequency lesions as a treatment for cervicogenic headache: ISRCTNo7444684. BMC Anesthesiol 2006; 6:1.

597. Wallis B, Lord S, Bogduk N. Resolution of psychological distress of whiplash patients following treatment by radiofrequency neurotomy: $A$ randomized, double-blind, placebocontrolled trial. Pain 1997; 73:15-22.

598. Schaerer JP. Radiofrequency facet rhizotomy in the treatment of chronic neck and low back pain. Int Surg 1978; 63:53-59.

599. MacVicar J, Borowczyk JM, MacVicar AM, Loughnan BM, Bogduk N. Cervical medial branch radiofrequency neurotomy in New Zealand. Pain Med 2012; 13:647-654.

6oo. Lim JW, Cho YW, Lee DG, Chang MC. Comparison of intraarticular pulsed radiofrequency and intraarticular corticosteroid injection for management of cervical facet joint pain. Pain Physician 2017; 20:E961-E967.

6o1. Singh JR, Miccio VF Jr, Modi DJ, Sein MT. The impact of local steroid administration on the incidence of neuritis following lumbar facet radiofrequency neurotomy. Pain Physician 2019; 22:69-74.

602. Bautista A, Dadabayev A, Rosenquist E, Cheng J. Bipolar radiofrequency neurotomy to treat neck and back pain in patients with automatic implantable cardioverter

603. Stolzenberg DS, Pheifer R, Armstrong $J$, et al. Improving fluoroscopic visualization for lower cervical medial branch blocks with a modified swimmer's view: A technical report. Pain Physician 2018; 21:303-308.

604. Smith AD, Jull G, Schneider G, et al. Cervical radiofrequency neurotomy reduces psychological features in individuals with chronic whiplash symptoms. Pain Physician 2014; 17:265-274.

605. Smith AD, Jull G, Schneider G, Frizzell B, Hooper RA, Sterling M. A comparison 
of physical and psychological features of responders and non-responders to cervical facet blocks in chronic whiplash. BMC Musculoskelet Disord 2013; 14:313.

606. Schneider GM, Jull G, Thomas K, Salo $P$. Screening of patients suitable for diagnostic cervical facet joint block - A role for physiotherapists. Man Ther 2012; 17:180-183.

607. Starr JB, Gold LS, McCormick Z, Suri $P$, Friedly J. Repeat procedures and prescription opioid use after lumbar medial branch nerve radiofrequency ablation in commercially insured patients. Spine J 2020; 20:344-351.

608. GIRFT. Getting it right the first time (GIRFT) is an NHS improvement programme delivered in partnership with the Royal National Orthopaedic Hopstial NHS Trust.

https://gettingitrightfirsttime.co.uk/

609. Hutton M. Spinal services. GIRFT programme national specialty report. GIRFT January 2019.

https://www.researchgate.net/ publication/330912858_Spinal_ Services_GIRFT_Programme_National_ Specialty_Report

610. Onafowokan OO, Fine NF, Brooks $F$, Stokes OM, Briggs TW, Hutton M Multiple injections for low back pain: What's the future?. Eur Spine J 2020; 29:564-578.

611. National Institute for Health and Care Excellence. Low back pain and sciatica in over 16s: Assessment and management. Invasive treatments. NICE guideline NG59. Methods, evidence and recommendations. 2016

https://www.nice.org.uk/guidance/ng59/ evidence/full-guideline-invasivetreatments-pdf-2726157998

612. Ellwood S, Shupper P, Kaufman A. A retrospective review of spinal radiofrequency neurotomy procedures in patients with metallic posterior spinal instrumentation - Is it safe?. Pain Physician 2018; 21:E477-E482.

613. Abd-Elsayed A, Fiala K, Nguyen S, VanderWood J. Safety and efficacy of radiofrequency ablation of the medial branch nerves with preexisting spinal hardware. A case series and review of literature. Curr Pain Headache Rep 2019; 23:11.

614. Bogduk N. Diagnostic blocks: A truth serum for malingering. Clin J Pain 2004; 20:409-414.

615. Chotai S, Sielatycki JA, Parker SL. et al. Effect of obesity on cost per quality- adjusted life years gained following anterior cervical discectomy and fusion in elective degenerative pathology. Spine J 2016; 16:1342-1350.

616. Chang RW, Pellisier JM, Hazen GB. A cost-effectiveness analysis of total hip arthroplasty for osteoarthritis of the hip. JAMA 1996; 275:858-865.

617. Nwachukwu BU, Schairer WW, Shifflett $G D$, et al. Cost-utility analyses in spine care: A qualitative and systematic review. Spine (Phila PA 1976) 2015; 40: 31-40.

618. Rampersaud $Y R$, Tso $P$, Walker KR, et al. Comparative outcomes and cost-utility following surgical treatment of focal lumbar spinal stenosis compared with osteoarthritis of the hip or knee: Part 2-estimated lifetime incremental costutility ratios. Spine ] 2014; 14:244-254.

619. Witiw CD, Tetreault LA, Smieliauskas F. et al. Surgery for degenerative cervical myelopathy: A patient-centered quality of life and health economic evaluation. Spine J 2017; 17:15-25.

620. Furlan AD, Yazdi F, Tsertsvadze A. et al. A systematic review and meta-analysis of efficacy, cost-effectiveness, and safety of selected complementary and alternative medicine for neck and low-back pain. Evid Based Complement Alternat Med 2012; 2012:953139.

621. Driessen MT, Lin CW, van Tulder MW. Cost-effectiveness of conservative treatments for neck pain: A systematic review on economic evaluations. Eur Spine ] 2012; 21:1441-1450.

622. Critchlow $S$, Hirst $M$, Akehurst R, et al. A systematic review of cost-effectiveness modeling of pharmaceutical therapies in neuropathic pain: Variation in practice, key challenges, and recommendations for the future. J Med Econ 2017; 20:129-139.

623. Manchikanti L, Helm II S, Singh V, Hirsch JA. Accountable interventional pain management: A collaboration among practitioners, patients, payers, and government. Pain Physician 2013; 16:E635-E670.

624. Kepler CK, Wilkinson SM, Radcliff KE. et al. Cost-utility analysis in spine care: A systematic review. Spine J 2012; 12:676-69o.

625. Indrakanti SS, Weber $\mathrm{MH}$, Takemoto SK. et al. Value-based care in the management of spinal disorders: A systematic review of cost-utility analysis. Clin Orthop Relat Res 2012; 470:1106-1123.

626. Gannon B, Finn DP, O'Gorman D. et al. The cost of chronic pain: An analysis of a regional pain management service in Ireland. Pain Med 2013; 14:1518-1528.

627. Kumar K, Rizvi S. Cost-effectiveness of spinal cord stimulation therapy in management of chronic pain. Pain Med 2013; 14:1631-1649.

628. Kumar K, Rizvi S, Bishop S. et al. Cost impact of intrathecal polyanalgesia. Pain Med 2013; 14:1569-1584.

629. Tosteson AN, Skinner JS, Tosteson TD. et al. The cost effectiveness of surgical versus nonoperative treatment for lumbar disc herniation over two years: Evidence from the Spine Patient Outcomes Research Trial (SPORT). Spine (Phila Pa 1976) 2008; 33:2108-2115.

630. Tosteson AN, Lurie JD, Tosteson TD, et al; SPORT Investigators. Surgical treatment of spinal stenosis with and without degenerative spondylolisthesis: Cost-effectiveness after 2 years. Ann Intern Med 2008; 149:845-853.

631. Leininger B, McDonough C, Evans $R$. et al. Cost-effectiveness of spinal manipulative therapy, supervised exercise, and home exercise for older adults with chronic neck pain. Spine J 2016; 16:1292-1304.

632. Taylor RS, Ryan J, O'Donnell R, Eldabe S, Kumar K, North RB. The costeffectiveness of spinal cord stimulation in the treatment of failed back surgery syndrome. Clin J Pain 2010; 26:463-469.

633. Fritz JM, Kim M, Magel JS, Asche CV. Cost-effectiveness of primary care management with or without early physical therapy for acute low back pain: economic evaluation of a randomized clinical trial. Spine (Phila Pa 1976) 2017; 42:285-290.

634. Fritz JM, Brennan GP, Hunter SJ, Magel JS. Initial management decisions after a new consultation for low back pain: implications of the usage of physical therapy for subsequent health care costs and utilization. Arch Phys Med Rehabil 2013; 94:808-816.

635. Fritz JM, Childs JD, Wainner RS, Flynn TW. Primary care referral of patients with low back pain to physical therapy: Impact on future health care utilization and costs. Spine (Phila Pa 1976) 2012; 37:2114-2121.

636. Whitehurst DG, Lewis $M$, Yao GL, et al. A brief pain management program compared with physical therapy for low back pain: results from an economic analysis alongside a randomized clinical trial. Arthritis Rheum 2007; 57:466-473.

637. Johnson RE, Jones GT, Wiles NJ, et al. 
Active exercise, education, and cognitive behavioral therapy for persistent disabling low back pain: A randomized controlled trial. Spine (Phila Pa 1976) 2007; 32:1578-1585.

638. Rivero-Arias $\mathrm{O}$, Gray A, Frost $\mathrm{H}$, Lamb SE, Stewart-Brown S. Cost-utility analysis of physiotherapy treatment compared with physiotherapy advice in low back pain. Spine (Phila Pa 1976) 2006; 31:1381-1387.

639. Childs JD, Fritz JM, Wu SS, et al. Implications of early and guideline adherent physical therapy for low back pain on utilization and costs. BMC Health Serv Res 2015; 15:150.

640. Manchikanti L, Malla Y, Wargo BW, Cash KA, Pampati V, Fellows B. Complications of fluoroscopically directed facet joint nerve blocks: A prospective evaluation of 7,500 episodes with 43,000 nerve blocks. Pain Physician 2012; 15:E143-E150.

641. Kim BR, Lee JW, Lee E, Kang Y, Ahn JM, Kang HS. Intra-articular facet joint steroid injection-related adverse events encountered during 11,980 procedures. Eur Radiol 2020; 30:1507-1516.

642. Verrills $P$, Mitchell $B$, Vivian $D$, Nowesenitz G, Lovell B, Sinclair C. The incidence of intravascular penetration in medial branch blocks: Cervical, thoracic, and lumbar spines. Spine (Phila Pa 1976) 2008; 33:E174-E177.

643. Lee CJ, Kim YC, Shin JH, et al. Intravascular injection in lumbar medial branch block: A prospective evaluation of 1433 injections. Anesth Analg 2008; 106:1274-1278.

644. Sullivan WJ, Willick SE, Chira-Adisai W, et al. Incidence of intravascular uptake in lumbar spinal injection procedures. Spine (Phila Pa 1976) 2000; 25:481-486.

645. Manchikanti L, Malla Y, Wargo BW, et al. A prospective evaluation of bleeding risk of interventional techniques in chronic pain. Pain Physician 2011; 14:317-329.

646. Manchikanti L, Benyamin RM, Swicegood JR, et al. Assessment of practice patterns of perioperative management of antiplatelet and anticoagulant therapy in interventional pain management. Pain Physician 2012; 15:E955-E968.

647. Magee $M$, Kannangara $S$, Dennien $B$, Lonergan R, Emmett L, Van der Wall $\mathrm{H}$. Paraspinal abscess complicating facet joint injection. Clin Nucl Med 2000; 25:71-73.

648. Berrigan T. Chemical meningism after lumbar facet joint block. Anaesthesia
1992; 47:905-906.

649. Kim SY, Han SH, Jung MW, Hong JH. Generalized infection following facet joint injection -A case report-. Korean ] Anesthesiol 2010 Apr 58:401-404.

650. Manchikanti L, Singh V, Vilims BD, Hansen HC, Schultz DM, Kloth DS. Medial branch neurotomy in management of chronic spinal pain: Systematic review of the evidence. Pain Physician 2002; 5:405-418.

651. Hoelzer BC, Weingarten TN, Hooten WM, Wright RS, Wilson WR, Wilson PR. Paraspinal abscess complicated by endocarditis following a facet joint injection. Eur J Pain 2008; 12:261-265.

652. Park MS, Moon SH, Hahn SB, Lee HM. Paraspinal abscess communicated with epidural abscess after extra-articular facet joint injection. Yonsei Med ] 2007; 48:711-714.

653. Doita M, Nabeshima Y, Nishida K, Fujioka H, Kurosaka M. Septic arthritis of lumbar facet joints without predisposing infection. J Spinal Disord Tech 2007; 20:290-295.

654. Singh K, Samartzis D, Pennington WT, Wise J, An HS. Unusual presentation of a paraspinal mass with involvement of a lumbar facet joint and the epidural space. Orthopedics 2006; 29:265-267.

655. Weingarten TN, Hooten WM, Huntoon MA. Septic facet joint arthritis after a corticosteroid facet injection. Pain Med 2006; 7:52-56.

656. Okada F, Takayama H, Doita M, Harada T, Yoshiya S, Kurosaka M. Lumbar facet joint infection associated with epidural and paraspinal abscess: A case report with review of the literature. J Spinal Disord Tech 2005; 18:458-461.

657. Dizdar O, Alyamaç E, Onal IK, Uzun O. Group B streptococcal facet joint arthritis: Case report. Spine (Phila Pa 1976) 2005; 30:E414-E416.

658. Takeno K, Kobayashi S, Miyazaki T, et al. Lidocaine cytotoxicity to the zygapophysial joints in rabbits: Changes in cell viability and proteoglycan metabolism in vitro. Spine (Phila Pa 1976) 2009; 34:E945-E951.

659. Dayer MJ, Gransden W, Goldsmith DJ. Facet joint osteomyelitis in a patient on long-term hemodialysis. Am J Kidney Dis 2000; 36:1041-1044.

66o. Bouchez B, Arnott G, Delfosse JM. Acute spinal epidural abscess. J Neurol 1985; 231:343-344.

661. Cook NJ, Hanrahan P, Song S. Paraspinal abscess following facet joint injection.
Clin Rheumatol 1999; 18:52-53.

662. Centers for Disease Control and Prevention. Infection control guidance for healthcare professionals about coronavirus (COVID-19). April 24, 2020. https://www.cdc.gov/coronavirus/2019$\mathrm{nCoV} / \mathrm{hcp} /$ infection-control.html

663. Manchikanti L, Helm S, Singh V, et al. An algorithmic approach for clinical management of chronic spinal pain. Pain Physician 2009; 12:E225-E264.

664. Manchikanti L, Boswell MV, Singh $\checkmark$, et al. Comprehensive review of neurophysiologic basis and diagnostic interventions in managing chronic spinal pain. Pain Physician 2009; 12:E71-E120.

665. Manchikanti L, Benyamin RM. Documentation for evaluation and management services. In: Manchikanti L (ed). Essentials of Practice Management: Billing, Coding, and Compliance in Interventional Pain Management. ASIPP Publishing, Paducah, KY, 2012, pp 163-180.

666. Manchikanti L, Singh V, Hirsch JA. Documentation for interventional techniques: In-office, ASC, and HOPD. In: Manchikanti L (ed). Essentials of Practice Management: Billing, Coding, and Compliance in Interventional Pain Management. ASIPP Publishing, Paducah, KY, 2012, pp 181-198.

667. ICD-10-CM: International Classification of Diseases, 11th Revision. Professional Ed. Saunders/Elsevier, St. Louis, 2018.

668. H.R. 2015. Balanced Budget Act of 1997. P.L. 105-33, August 5, 1997.

669. Quinn C. Issues of medical necessity. A medical director's guide to good faith adjudication. Am J Managed Care 1997; 3:883-888.

670. Jacobson PD, Asch S, Glassman PA, Model KE, Hernandez JB. Defining and implementing medical necessity in Washington State and Oregon. Inquiry 1997; 34:143-154.

671. Centers for Medicare and Medicaid Services (CMS) Billing Guide. Medicare Part B. NHIC Corp., March 2009.

672. Garner BA (ed). Black's Law Dictionary. 8th Edition. Thomson West, St. Paul, 2004.

673. American Medical Association. Model Managed Care Contract. Second Edition. 2000. http://www.ama-assn. org/amai/pub/ upload/mm/395/ modelmgdcare.pdf

674. Manchikanti L, Mehmert J. Diagnostic coding systems. In: Manchikanti L (ed). 
Essentials of Practice Management: Billing, Coding, and Compliance in Interventional Pain Management. ASIPP Publishing, Paducah, KY, 2012, pp 211-220.

675. Manchikanti L, Singh V. Procedural coding systems. In: Manchikanti L (ed). Essentials of Practice Management: Billing, Coding, and Compliance in Interventional Pain Management. ASIPP Publishing, Paducah, KY, 2012, pp 221-236.

676. Mehmert J. Payer regulations. In: Manchikanti L (ed). Essentials of Practice Management: Billing, Coding, and Compliance in Interventional Pain Management. ASIPP Publishing, Paducah, KY, 2012, pp 237-250.

677. Myckowiak V, Myckowiak M, Manchikanti L. Medicare audits. In: Manchikanti L (ed). Essentials of Practice Management: Billing, Coding, and Compliance in Interventional Pain Management. ASIPP Publishing, Paducah, KY, 2012, pp 251-260.

678. Zima L, Falco FJE. Medicaid appeals process. In: Manchikanti L (ed). Essentials of Practice Management: Billing, Coding, and Compliance in Interventional Pain Management.
ASIPP Publishing, Paducah, KY, 2012, pp 273-276.

679. Zima L, Falco FJE. Third party payer denials and appeals. In: Manchikanti L (ed). Essentials of Practice Management: Billing, Coding, and Compliance in Interventional Pain Management. ASIPP Publishing, Paducah, KY, 2012, pp 277-284.

680. Farmer D. Coding for interventional procedures. In: Manchikanti L (ed). Essentials of Practice Management: Billing, Coding, and Compliance in Interventional Pain Management. ASIPP Publishing, Paducah, KY, 2012, pp 327-352.

681. Myckowiak V, Myckowiak M, Manchikanti $L$. Fraud and abuse in interventional pain management. In: Manchikanti L (ed). Essentials of Practice Management: Billing, Coding, and Compliance in Interventional Pain Management. ASIPP Publishing, Paducah, KY, 2012, pp 379-388.

682. Myckowiak V. Compliance in interventional pain practices. In: Manchikanti L (ed). Essentials of Practice Management: Billing, Coding, and Compliance in Interventional Pain Management. ASIPP Publishing,
Paducah, KY, 2012, pp 389-398.

683. Balic A. Government audits and investigations. In: Manchikanti L (ed). Essentials of Practice Management: Billing, Coding, and Compliance in Interventional Pain Management. ASIPP Publishing, Paducah, KY, 2012, pp 399-408.

684. Diwan SA, Manchikanti L, Benyamin $R M$, et al. Effectiveness of cervical epidural injections in the management of chronic neck and upper extremity pain. Pain Physician 2012; 15:E405-E434.

685. Benyamin RM, Singh V, Parr AT, Conn A, Diwan S, Abdi S. Systematic review of the effectiveness of cervical epidurals in the management of chronic neck pain. Pain Physician 2009; 12:137-157.

686. Manchikanti L, Cash KA, Pampati V, Malla Y. Fluoroscopic cervical epidural injections in chronic axial or disc-related neck pain without disc herniation, facet joint pain, or radiculitis. J Pain Res 2012; 5:227-236.

687. Manchikanti L, Singh V, Rivera JJ, et al. Effectiveness of caudal epidural injections in discogram positive and negative chronic low back pain. Pain Physician 2002; 5:18-29. 

Appendix Table 1. Quality Appraisal of Diagnostic Reliability (QAREL) checklist.

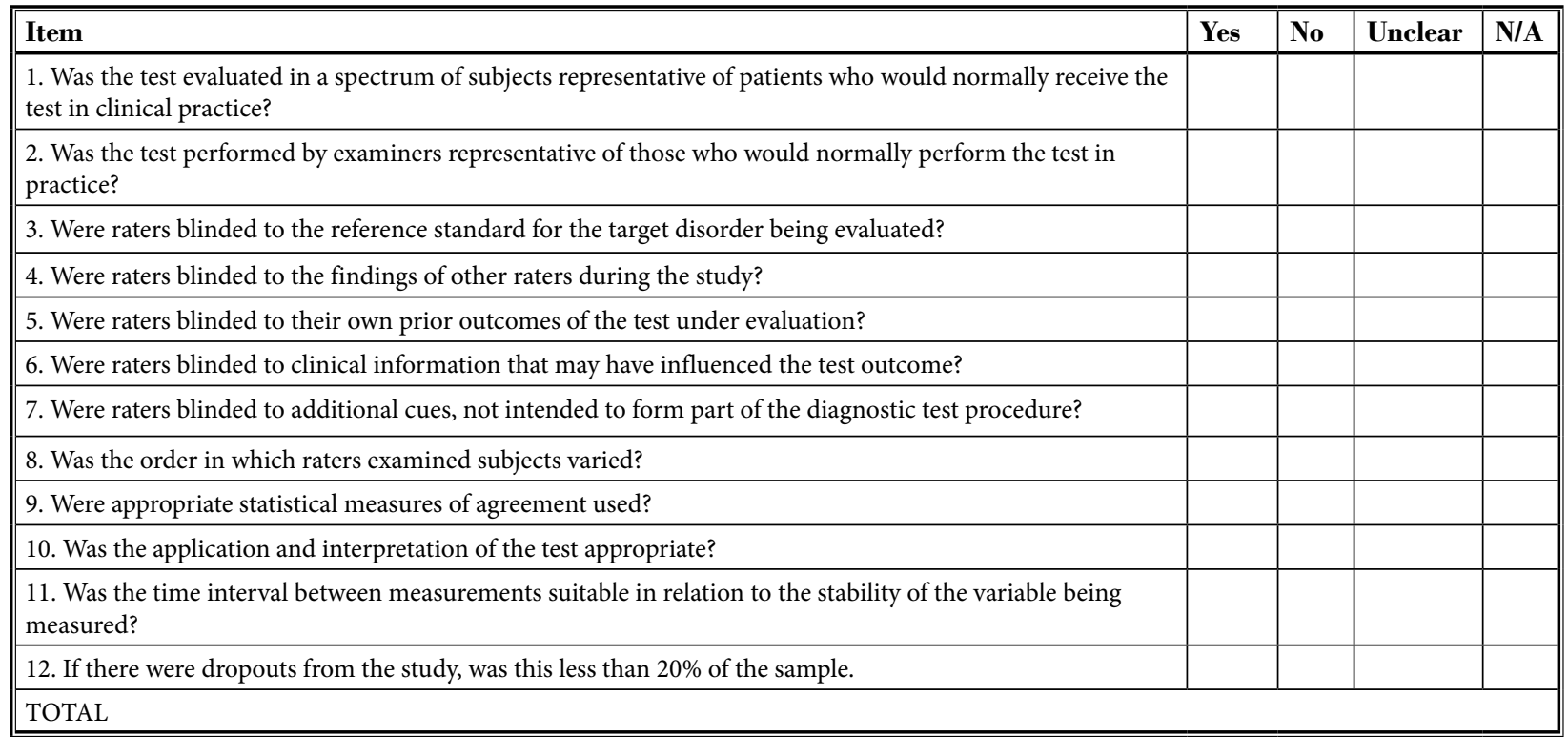

Source: Lucas NP, et al. The development of a quality appraisal tool for studies of diagnostic reliability (QAREL). J Clin Epidemiol 2010; 63:854-861 (466). 
Appendix Table 2. Sources of risk of bias and Cochrane Review rating system.

\begin{tabular}{|c|c|c|c|}
\hline Bias & \multicolumn{2}{|l|}{ Source of Bias } & Possible \\
\hline \multirow[t]{2}{*}{ Selection } & \multirow[t]{2}{*}{$\begin{array}{l}\text { (1) Was the method of } \\
\text { randomization adequate? }\end{array}$} & $\begin{array}{l}\text { A random (unpredictable) assignment sequence. Examples of adequate } \\
\text { methods are coin toss (for studies with } 2 \text { groups), rolling a dice (for studies } \\
\text { with } 2 \text { or more groups), drawing of balls of different colors, drawing of ballots } \\
\text { with the study group labels from a dark bag, computer-generated random } \\
\text { sequence, preordered sealed envelopes, sequentially-ordered vials, telephone } \\
\text { call to a central office, and preordered list of treatment assignments. }\end{array}$ & \multirow[t]{2}{*}{ Yes/No/Unsure } \\
\hline & & $\begin{array}{l}\text { Examples of inadequate methods are: alternation, birth date, social insurance/ } \\
\text { security number, date in which they are invited to participate in the study, and } \\
\text { hospital registration number. }\end{array}$ & \\
\hline Selection & $\begin{array}{l}\text { (2) Was the treatment } \\
\text { allocation concealed? }\end{array}$ & $\begin{array}{l}\text { Assignment generated by an independent person not responsible for } \\
\text { determining the eligibility of the patients. This person has no information } \\
\text { about the persons included in the trial and has no influence on the assignment } \\
\text { sequence or on the decision about eligibility of the patient. }\end{array}$ & Yes/No/Unsure \\
\hline Performance & $\begin{array}{l}\text { (3) Was the patient } \\
\text { blinded to the } \\
\text { intervention? }\end{array}$ & $\begin{array}{l}\text { Index and control groups are indistinguishable for the patients or if the success } \\
\text { of blinding was tested among the patients and it was successful. }\end{array}$ & Yes/No/Unsure \\
\hline Performance & $\begin{array}{l}\text { (4) Was the care } \\
\text { provider blinded to the } \\
\text { intervention? }\end{array}$ & $\begin{array}{l}\text { Index and control groups are indistinguishable for the care providers or if the } \\
\text { success of blinding was tested among the care providers and it was successful. }\end{array}$ & Yes/No/Unsure \\
\hline \multirow[t]{6}{*}{ Detection } & \multirow[t]{6}{*}{$\begin{array}{l}\text { (5) Was the outcome } \\
\text { assessor blinded to the } \\
\text { intervention? }\end{array}$} & $\begin{array}{l}\text { Adequacy of blinding should be assessed for each primary outcome separately. } \\
\text { This item should be scored "yes" if the success of blinding was tested among } \\
\text { the outcome assessors and it was successful or: }\end{array}$ & \multirow[t]{6}{*}{ Yes/No/Unsure } \\
\hline & & $\begin{array}{l}\text { - for patient-reported outcomes in which the patient is the outcome assessor } \\
\text { (e.g., pain, disability): the blinding procedure is adequate for outcome assessors } \\
\text { if participant blinding is scored "yes" }\end{array}$ & \\
\hline & & $\begin{array}{l}\text { - for outcome criteria assessed during scheduled visit and that supposes a } \\
\text { contact between participants and outcome assessors (e.g., clinical examination): } \\
\text { the blinding procedure is adequate if patients are blinded, and the treatment or } \\
\text { adverse effects of the treatment cannot be noticed during clinical examination }\end{array}$ & \\
\hline & & $\begin{array}{l}\text { - for outcome criteria that do not suppose a contact with participants (e.g., } \\
\text { radiography, magnetic resonance imaging): the blinding procedure is adequate } \\
\text { if the treatment or adverse effects of the treatment cannot be noticed when } \\
\text { assessing the main outcome }\end{array}$ & \\
\hline & & $\begin{array}{l}\text { - for outcome criteria that are clinical or therapeutic events that will be } \\
\text { determined by the interaction between patients and care providers (e.g., } \\
\text { cointerventions, hospitalization length, treatment failure), in which the care } \\
\text { provider is the outcome assessor: the blinding procedure is adequate for } \\
\text { outcome assessors if item "4" (caregivers) is scored "yes" }\end{array}$ & \\
\hline & & $\begin{array}{l}\text { - for outcome criteria that are assessed from data of the medical forms: the } \\
\text { blinding procedure is adequate if the treatment or adverse effects of the } \\
\text { treatment cannot be noticed on the extracted data }\end{array}$ & \\
\hline Attrition & $\begin{array}{l}\text { (6) Was the drop-out rate } \\
\text { described and acceptable? }\end{array}$ & $\begin{array}{l}\text { The number of participants who were included in the study but did not } \\
\text { complete the observation period or were not included in the analysis must } \\
\text { be described and reasons given. If the percentage of withdrawals and drop- } \\
\text { outs does not exceed } 20 \% \text { for short-term follow-up and } 30 \% \text { for long-term } \\
\text { follow-up and does not lead to substantial bias a "yes" is scored (N.B. these } \\
\text { percentages are arbitrary, not supported by literature). }\end{array}$ & Yes/No/Unsure \\
\hline Attrition & $\begin{array}{l}\text { (7) Were all randomized } \\
\text { participants analyzed in } \\
\text { the group to which they } \\
\text { were allocated? }\end{array}$ & $\begin{array}{l}\text { All randomized patients are reported/analyzed in the group they were allocated } \\
\text { to by randomization for the most important moments of effect measurement } \\
\text { (minus missing values) irrespective of noncompliance and cointerventions. }\end{array}$ & Yes/No/Unsure \\
\hline
\end{tabular}


Appendix Table 2 cont'. Sources of risk of bias and Cochrane Review rating system.

\begin{tabular}{|c|c|c|c|}
\hline Bias & \multicolumn{2}{|l|}{ Source of Bias } & \multirow{2}{*}{$\begin{array}{l}\text { Possible } \\
\text { Answers } \\
\text { Yes/No/Unsure }\end{array}$} \\
\hline Reporting & $\begin{array}{l}\text { (8) Are reports of the } \\
\text { study free of suggestion } \\
\text { of selective outcome } \\
\text { reporting? }\end{array}$ & $\begin{array}{l}\text { All the results from all prespecified outcomes have been adequately reported } \\
\text { in the published report of the trial. This information is either obtained by } \\
\text { comparing the protocol and the report, or in the absence of the protocol, } \\
\text { assessing that the published report includes enough information to make this } \\
\text { judgment. }\end{array}$ & \\
\hline Selection & $\begin{array}{l}\text { (9) Were the groups } \\
\text { similar at baseline } \\
\text { regarding the most } \\
\text { important prognostic } \\
\text { indicators? }\end{array}$ & $\begin{array}{l}\text { Groups have to be similar at baseline regarding demographic factors, duration } \\
\text { and severity of complaints, percentage of patients with neurological symptoms, } \\
\text { and value of main outcome measure(s). }\end{array}$ & Yes/No/Unsure \\
\hline Performance & $\begin{array}{l}\text { (10) Were } \\
\text { cointerventions avoided } \\
\text { or similar? }\end{array}$ & $\begin{array}{l}\text { If there were no cointerventions or they were similar between the index and } \\
\text { control groups. }\end{array}$ & Yes/No/Unsure \\
\hline Performance & $\begin{array}{l}\text { (11) Was the compliance } \\
\text { acceptable in all groups? }\end{array}$ & $\begin{array}{l}\text { The reviewer determines if the compliance with the interventions is acceptable, } \\
\text { based on the reported intensity, duration, number and frequency of sessions } \\
\text { for both the index intervention and control intervention(s). For example, } \\
\text { physiotherapy treatment is usually administered for several sessions; therefore } \\
\text { it is necessary to assess how many sessions each patient attended. For single- } \\
\text { session interventions (e.g., surgery), this item is irrelevant. }\end{array}$ & Yes/No/Unsure \\
\hline Detection & $\begin{array}{l}\text { (12) Was the timing of } \\
\text { the outcome assessment } \\
\text { similar in all groups? }\end{array}$ & $\begin{array}{l}\text { Timing of outcome assessment should be identical for all intervention groups } \\
\text { and for all primary outcome measures. }\end{array}$ & Yes/No/Unsure \\
\hline \multirow[t]{2}{*}{ Other } & \multirow{2}{*}{$\begin{array}{l}\text { (13) Are other sources of } \\
\text { potential bias unlikely? }\end{array}$} & Other types of biases. For example: & \multirow[t]{2}{*}{ Yes/No/Unsure } \\
\hline & & $\begin{array}{l}\text { - When the outcome measures were not valid. There should be evidence } \\
\text { from a previous or present scientific study that the primary outcome can be } \\
\text { considered valid in the context of the present. } \\
\text { - Industry-sponsored trials. The conflict of interest (COI) statement should } \\
\text { explicitly state that the researchers have had full possession of the trial process } \\
\text { from planning to reporting without funders with potential COI having any } \\
\text { possibility to interfere in the process. If, for example, the statistical analyses } \\
\text { have been done by a funder with a potential COI, usually "unsure" is scored. }\end{array}$ & \\
\hline
\end{tabular}

Source: Furlan AD, et al; Editorial Board of the Cochrane Back, Neck Group. 2015 updated method guideline for systematic reviews in the Cochrane back and neck group. Spine (Phila Pa 1976) 2015; 40:1660-1673 (526). 
Appendix Table 3. Item checklist for assessment of randomized controlled trials of IPM techniques utilizing IPM-QRB.

\begin{tabular}{|c|c|c|}
\hline & & Scoring \\
\hline I. & TRIAL DESIGN AND GUIDANCE REPORTING & \\
\hline \multirow[t]{5}{*}{1.} & CONSORT or SPIRIT & \\
\hline & Trial designed and reported without any guidance & 0 \\
\hline & $\begin{array}{l}\text { Trial designed and reported utilizing minimum criteria other than CONSORT or SPIRIT criteria or trial was } \\
\text { conducted prior to } 2005\end{array}$ & 1 \\
\hline & $\begin{array}{l}\text { Trial implies it was based on CONSORT or SPIRIT without clear description with moderately significant criteria for } \\
\text { randomized trials or the trial was conducted before } 2005\end{array}$ & 2 \\
\hline & $\begin{array}{l}\text { Explicit use of CONSORT or SPIRIT with identification of criteria or trial conducted with high level reporting and } \\
\text { criteria or conducted before } 2005\end{array}$ & 3 \\
\hline II. & DESIGN FACTORS & \\
\hline \multirow[t]{4}{*}{2.} & Type and Design of Trial & \\
\hline & Poorly designed control group (quasi selection, convenient sampling) & 0 \\
\hline & Proper active-control or sham procedure with injection of active agent & 2 \\
\hline & Proper placebo control (no active solutions into active structures) & 3 \\
\hline \multirow[t]{4}{*}{3.} & Setting/Physician & \\
\hline & General setting with no specialty affiliation and general physician & 0 \\
\hline & Specialty of anesthesia/PMR/neurology/radiology/ortho, etc. & 1 \\
\hline & Interventional pain management with interventional pain management physician & 2 \\
\hline \multirow[t]{5}{*}{4.} & Imaging & \\
\hline & Blind procedures & 0 \\
\hline & Ultrasound & 1 \\
\hline & CT & 2 \\
\hline & Fluoro & 3 \\
\hline \multirow[t]{5}{*}{5.} & Sample Size & \\
\hline & Less than 50 participants in the study without appropriate sample size determination & 0 \\
\hline & Sample size calculation with less than 25 patients in each group & 1 \\
\hline & Appropriate sample size calculation with at least 25 patients in each group & 2 \\
\hline & Appropriate sample size calculation with 50 patients in each group & 3 \\
\hline \multirow[t]{3}{*}{6.} & Statistical Methodology & \\
\hline & None or inappropriate & 0 \\
\hline & Appropriate & 1 \\
\hline III. & PATIENT FACTORS & \\
\hline 7. & Inclusiveness of Population & \\
\hline \multirow[t]{4}{*}{ 7a. } & For epidural procedures: & \\
\hline & Poorly identified mixed population & 0 \\
\hline & Clearly identified mixed population & 1 \\
\hline & $\begin{array}{l}\text { Disorders specific trials (i.e. well defined spinal stenosis and disc herniation, disorder specific, disc herniation or } \\
\text { spinal stenosis or post surgery syndrome) }\end{array}$ & 2 \\
\hline \multirow[t]{4}{*}{$7 \mathrm{~b}}$. & For facet or sacroiliac joint interventions: & \\
\hline & No diagnostic blocks & 0 \\
\hline & Selection with single diagnostic blocks & 1 \\
\hline & Selection with placebo or dual diagnostic blocks & 2 \\
\hline \multirow[t]{2}{*}{8.} & Duration of Pain & \\
\hline & Less than 3 months & 0 \\
\hline
\end{tabular}


Appendix Table 3 cont'. Item checklist for assessment of randomized controlled trials of IPM techniques utilizing IPM - QRB.

\begin{tabular}{|c|c|c|}
\hline & & Scoring \\
\hline & 3 to 6 months & 1 \\
\hline & $>6$ months & 2 \\
\hline \multirow[t]{5}{*}{9.} & Previous Treatments & \\
\hline & Conservative management including drug therapy, exercise therapy, physical therapy, etc. & \\
\hline & Were not utilized & 0 \\
\hline & Were utilized sporadically in some patients & 1 \\
\hline & Were utilized in all patients & 2 \\
\hline \multirow[t]{5}{*}{10.} & Duration of Follow-up with Appropriate Interventions & \\
\hline & $\begin{array}{l}\text { Less than } 3 \text { months or } 12 \text { weeks for epidural or facet joint procedures, etc. and } 6 \text { months for intradiscal procedures and } \\
\text { implantables }\end{array}$ & 0 \\
\hline & 3 to 6 months for epidural or facet joint procedures, etc., or 1 year for intradiscal procedures or implantables & 1 \\
\hline & $\begin{array}{l}6 \text { months to } 17 \text { months for epidurals or facet joint procedures, etc., and } 2 \text { years or longer for discal procedures and } \\
\text { implantables }\end{array}$ & 2 \\
\hline & $\begin{array}{l}18 \text { months or longer for epidurals and facet joint procedures, etc., or } 5 \text { years or longer for discal procedures and } \\
\text { implantables }\end{array}$ & 3 \\
\hline IV. & OUTCOMES & \\
\hline \multirow[t]{6}{*}{11.} & Outcomes Assessment Criteria for Significant Improvement & \\
\hline & $\begin{array}{l}\text { No descriptions of outcomes } \\
\text { OR } \\
<20 \% \text { change in pain rating or functional status } \\
\end{array}$ & 0 \\
\hline & $\begin{array}{l}\text { Pain rating with a decrease of } 2 \text { or more points or more than } 20 \% \text { reduction } \\
\text { OR } \\
\text { functional status improvement of more than } 20 \%\end{array}$ & 1 \\
\hline & $\begin{array}{l}\text { Pain rating with decrease of } \geq 2 \text { points } \\
\text { AND } \\
\geq 20 \% \text { change or functional status improvement of } 20 \%\end{array}$ & 2 \\
\hline & $\begin{array}{l}\text { Pain rating with a decrease of } 3 \text { or more points or more than } 50 \% \text { reduction } \\
\text { OR } \\
\text { functional status improvement with a } 50 \% \text { or } 40 \% \text { reduction in disability score }\end{array}$ & 2 \\
\hline & Significant improvement with pain and function $\geq 50 \%$ or 3 points and $40 \%$ reduction in disability scores & 4 \\
\hline \multirow[t]{4}{*}{12.} & Analysis of all Randomized Participants in the Groups & \\
\hline & Not performed & 0 \\
\hline & Performed without intent-to-treat analysis without inclusion of all randomized participants & 1 \\
\hline & All participants included with or without intent-to-treat analysis & 2 \\
\hline \multirow[t]{4}{*}{13.} & Description of Drop Out Rate & \\
\hline & No description of dropouts, despite reporting of incomplete data or $\geq 20 \%$ withdrawal & 0 \\
\hline & Less than $20 \%$ withdrawal in one year in any group & 1 \\
\hline & Less than $30 \%$ withdrawal at 2 years in any group & 2 \\
\hline \multirow[t]{4}{*}{14.} & Similarity of Groups at Baseline for Important Prognostic Indicators & \\
\hline & Groups dissimilar with significant influence on outcomes with or without appropriate randomization and allocation & 0 \\
\hline & Groups dissimilar without influence on outcomes despite appropriate randomization and allocation & 1 \\
\hline & Groups similar with appropriate randomization and allocation & 2 \\
\hline \multirow[t]{3}{*}{15.} & Role of Co-Interventions & \\
\hline & Co-interventions were provided but were not similar in the majority of participants & 0 \\
\hline & No co-interventions or similar co-interventions were provided in the majority of the participants & 1 \\
\hline V. & RANDOMIZATION & \\
\hline 16. & Method of Randomization & \\
\hline
\end{tabular}


Appendix Table 3 cont'. Item checklist for assessment of randomized controlled trials of IPM techniques utilizing IPM - QRB.

\begin{tabular}{|c|c|c|}
\hline & & Scoring \\
\hline & Quasi randomized or poorly randomized or not described & 0 \\
\hline & Adequate randomization (coin toss, drawing of balls of different colors, drawing of ballots) & 1 \\
\hline & $\begin{array}{l}\text { High quality randomization (Computer generated random sequence, pre-ordered sealed envelopes, sequentially } \\
\text { ordered vials, telephone call, pre-ordered list of treatment assignments, etc.) }\end{array}$ & 2 \\
\hline VI. & ALLOCATION CONCEALMENT & \\
\hline \multirow[t]{4}{*}{17.} & Concealed Treatment Allocation & \\
\hline & Poor concealment of allocation (open enrollment) or inadequate description of concealment & 0 \\
\hline & Concealment of allocation with borderline or good description of the process with probability of failure of concealment & 1 \\
\hline & High quality concealment with strict controls (independent assignment without influence on the assignment sequence) & 2 \\
\hline VII. & BLINDING & \\
\hline \multirow[t]{3}{*}{18.} & Patient Blinding & \\
\hline & Patients not blinded & 0 \\
\hline & Patients blinded adequately & 1 \\
\hline \multirow[t]{3}{*}{19.} & Care Provider Blinding & \\
\hline & Care provider not blinded & 0 \\
\hline & Care provider blinded adequately & 1 \\
\hline \multirow[t]{3}{*}{20.} & Outcome Assessor Blinding & \\
\hline & Outcome assessor not blinded or was able to identify the groups & 0 \\
\hline & $\begin{array}{l}\text { Performed by a blinded independent assessor with inability to identify the assignment-based provider intervention } \\
\text { (i.e., subcutaneous injection, intramuscular distant injection, difference in preparation or equipment use, numbness } \\
\text { and weakness, etc.) }\end{array}$ & 1 \\
\hline VIII. & CONFLICTS OF INTEREST & \\
\hline \multirow[t]{7}{*}{21.} & Funding and Sponsorship & \\
\hline & Trial included industry employees & -3 \\
\hline & $\begin{array}{l}\text { Industry employees involved; high levels of funding with remunerations by industry or an organization funded with } \\
\text { conflicts }\end{array}$ & -3 \\
\hline & Industry or organizational funding with reimbursement of expenses with some involvement & 0 \\
\hline & Industry or organization funding of expenses without involvement & 1 \\
\hline & Funding by internal resources only with supporting entity unrelated to industry & 2 \\
\hline & Governmental funding without conflict such as NIH, NHS, AHRQ & 3 \\
\hline \multirow[t]{8}{*}{22.} & Conflicts of Interest & \\
\hline & None disclosed with potential implied conflict & 0 \\
\hline & Marginally disclosed with potential conflict & 1 \\
\hline & Well disclosed with minor conflicts & 2 \\
\hline & Well disclosed with no conflicts & 3 \\
\hline & Hidden conflicts with poor disclosure & -1 \\
\hline & Misleading disclosure with conflicts & -2 \\
\hline & Major impact related to conflicts & -3 \\
\hline \multicolumn{2}{|c|}{ TOTAL } & 48 \\
\hline
\end{tabular}

Source: Manchikanti L, et al. Assessment of methodologic quality of randomized trials of interventional techniques: Development of an interventional pain management specific instrument. Pain Physician 2014; 17:E263-E290 (527). 
Appendix Table 4. IPM checklist for assessment of nonrandomized or observational studies of IPM techniques utilizing IPMQRBNR.

\begin{tabular}{|c|c|c|}
\hline$\overline{\mathrm{I} .}$ & STUDY DESIGN AND GUIDANCE REPORTING & Scoring \\
\hline \multirow[t]{6}{*}{1.} & STROBE or TREND Guidance & \\
\hline & Case Report/Case Series & 0 \\
\hline & Study designed without any guidance & 1 \\
\hline & Study designed with minimal criteria and reporting with or without guidance & 2 \\
\hline & $\begin{array}{l}\text { Study designed with moderately significant criteria or implies it was based on STROBE or TREND without clear } \\
\text { description or the study was conducted before } 2011 \text { or similar criteria utilized with study conducted before } 2011\end{array}$ & 3 \\
\hline & $\begin{array}{l}\text { Designed with high level criteria or explicitly uses STROBE or TREND with identification of criteria or conducted prior } \\
\text { to } 2011\end{array}$ & 4 \\
\hline II. & DESIGN FACTORS & \\
\hline \multirow[t]{6}{*}{2.} & Study Design and Type & \\
\hline & Case report or series (uncontrolled - longitudinal) & 0 \\
\hline & Retrospective cohort or cross-sectional study & 1 \\
\hline & Prospective cohort case-control study & 2 \\
\hline & Prospective case control study & 3 \\
\hline & Prospective, controlled, nonrandomized & 4 \\
\hline \multirow[t]{4}{*}{3.} & Setting/Physician & \\
\hline & General setting with no specialty affiliation and general physician & 0 \\
\hline & Specialty of anesthesia/PMR/neurology, etc. & 1 \\
\hline & Interventional pain management with interventional pain management physician & 2 \\
\hline \multirow[t]{5}{*}{4.} & Imaging & \\
\hline & Blind procedures & 0 \\
\hline & Ultrasound & 1 \\
\hline & $\mathrm{CT}$ & 2 \\
\hline & Fluoro & 3 \\
\hline \multirow[t]{6}{*}{5.} & Sample Size & \\
\hline & Less than 100 participants without appropriate sample size determination & 0 \\
\hline & At least 100 participants in the study without appropriate sample size determination & 1 \\
\hline & Sample size calculation with less than 50 patients in each group & 2 \\
\hline & Appropriate sample size calculation with at least 50 patients in each group & 3 \\
\hline & Appropriate sample size calculation with 100 patients in each group & 4 \\
\hline \multirow[t]{4}{*}{6.} & Statistical Methodology & \\
\hline & None & 0 \\
\hline & Some statistics & 1 \\
\hline & Appropriate & 2 \\
\hline III. & PATIENT FACTORS & \\
\hline 7. & Inclusiveness of Population & \\
\hline \multirow[t]{5}{*}{$7 \mathrm{a}}$. & For epidural procedures: & \\
\hline & Poorly identified mixed population & 1 \\
\hline & Poorly identified mixed population with large sample $(\geq 200)$ & 2 \\
\hline & Clearly identified mixed population & 3 \\
\hline & $\begin{array}{l}\text { Disorders specific trials (i.e. well defined spinal stenosis and disc herniation, disorder specific, disc herniation or spinal } \\
\text { stenosis or post surgery syndrome) }\end{array}$ & 4 \\
\hline $7 \mathrm{~b}$. & For facet or sacroiliac joint interventions: & \\
\hline
\end{tabular}


Appendix Table 4 cont'. IPM checklist for assessment of nonrandomized or observational studies of IPM techniques utilizing IPMQRBNR.

\begin{tabular}{|c|c|c|}
\hline & No specific selection criteria & 1 \\
\hline & No diagnostic blocks based on clinical symptomatology & 2 \\
\hline & Selection with single diagnostic blocks & 3 \\
\hline & Selection with placebo or dual diagnostic blocks & 4 \\
\hline \multirow[t]{4}{*}{8.} & Duration of Pain & \\
\hline & Less than 3 months & 0 \\
\hline & 3 to 6 months & 1 \\
\hline & $>6$ months & 2 \\
\hline \multirow[t]{5}{*}{9.} & Previous Treatments & \\
\hline & Conservative management including drug therapy, exercise therapy, physical therapy, etc. & \\
\hline & Were not utilized & 0 \\
\hline & Were utilized sporadically in some patients & 1 \\
\hline & Were utilized in all patients & 2 \\
\hline \multirow[t]{5}{*}{10.} & Duration of Follow-up with Appropriate Interventions & \\
\hline & $\begin{array}{l}\text { Less than } 3 \text { months or less for epidural or facet joint procedures, etc., and } 6 \text { months for intradiscal procedures and } \\
\text { implantables }\end{array}$ & 1 \\
\hline & 3-6 months for epidural or facet joint procedures, etc., or one year for intradiscal procedures or implantables & 2 \\
\hline & 6-12 months for epidurals or facet joint procedures, etc., and 2 years or longer for discal procedures and implantables & 3 \\
\hline & $\begin{array}{l}18 \text { months or longer for epidurals and facet joint procedures, etc., or } 5 \text { years or longer for discal procedures and } \\
\text { implantables }\end{array}$ & 4 \\
\hline IV. & OUTCOMES & \\
\hline \multirow[t]{6}{*}{11.} & Outcomes Assessment Criteria for Significant Improvement & \\
\hline & $\begin{array}{l}\text { No descriptions of outcomes } \\
\text { OR } \\
<20 \% \text { change in pain rating or functional status }\end{array}$ & 0 \\
\hline & $\begin{array}{l}\text { Pain rating with a decrease of } 2 \text { or more points or more than } 20 \% \text { reduction } \\
\text { OR } \\
\text { functional status improvement of more than } 20 \%\end{array}$ & 1 \\
\hline & $\begin{array}{l}\text { Pain rating with decrease of } \geq 2 \text { points } \\
\text { AND } \\
\geq 20 \% \text { change or functional status improvement of } 20 \%\end{array}$ & 2 \\
\hline & $\begin{array}{l}\text { Pain rating with a decrease of } 3 \text { or more points or more than } 50 \% \text { reduction } \\
\text { OR } \\
\text { functional status improvement with a } 50 \% \text { or } 40 \% \text { reduction in disability score }\end{array}$ & 2 \\
\hline & Significant improvement with pain and function $\geq 50 \%$ or 3 points and $40 \%$ reduction in disability scores & 4 \\
\hline \multirow[t]{4}{*}{12.} & Description of Drop Out Rate & \\
\hline & No description despite reporting of incomplete data or more than $30 \%$ withdrawal & 0 \\
\hline & Less than $30 \%$ withdrawal in one year in any group & 1 \\
\hline & Less than $40 \%$ withdrawal at 2 years in any group & 2 \\
\hline \multirow[t]{4}{*}{13.} & Similarity of Groups at Baseline for Important Prognostic Indicators & \\
\hline & No groups or groups dissimilar with significant influence on outcomes & 0 \\
\hline & Groups dissimilar without significant influence on outcomes & 1 \\
\hline & Groups similar & 2 \\
\hline \multirow[t]{3}{*}{14.} & Role of Co-Interventions & \\
\hline & Dissimilar co-interventions or similar co-interventions in some of the participants & 1 \\
\hline & No co-interventions or similar co-interventions in majority of the participants & 2 \\
\hline
\end{tabular}


Appendix Table 4 cont'. IPM checklist for assessment of nonrandomized or observational studies of IPM techniques utilizing IPMQRBNR.

\begin{tabular}{|l|l|l||}
\hline V. & ASSIGNMENT & \\
\hline 15. & Method of Assignment of Participants & \\
\hline & Case report/case series or selective assignment based on outcomes or retrospective evaluation based on clinical criteria & 1 \\
\hline & Prospective study with inclusion without specific criteria & 2 \\
\hline & Retrospective method with inclusion of all participants or random selection of retrospective data & 3 \\
\hline & $\begin{array}{l}\text { Prospective, well-defined assignment of methodology and inclusion criteria (quasi randomization, matching, } \\
\text { stratification, etc.) }\end{array}$ & 4 \\
\hline VI. & CONFLICTS OF INTEREST & \\
\hline 16. & Funding and Sponsorship & -3 \\
\hline & Trial included industry employees with or without proper disclosure & -3 \\
\hline & $\begin{array}{l}\text { Industry employees involved; high levels of funding with remunerations by industry or an organization funded with } \\
\text { conflicts }\end{array}$ & 0 \\
\hline & Industry or organizational funding with reimbursement of expenses with some involvement or no information available & 0 \\
\hline & Industry or organization funding of expenses without involvement & 1 \\
\hline & Funding by internal resources only & 2 \\
\hline TOTAL MAXIMUM & 38 \\
\hline
\end{tabular}

Source: Manchikanti L, et al. Development of an interventional pain management specific instrument for methodologic quality assessment of nonrandomized studies of interventional techniques. Pain Physician 2014; 17:E291-E317 (528). 